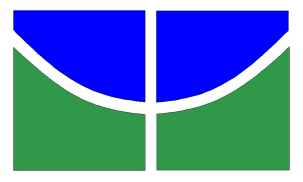

Universidade de Brasília

Instituto de Ciências Exatas

Departamento de Matemática

Programa de Mestrado Profissional em

Matemática em Rede Nacional

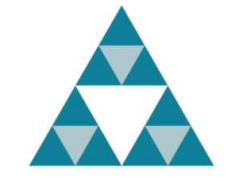

PROFMAT

Colinearidade e Concorrência em Olimpíadas Internacionais de Matemática: uma reflexão voltada para o ensino da Geometria Plana no Brasil

Ronald Alexandre Martins 
Copyright $\odot 2015$ by R. A. Martins

\section{Termo de Autorização para Publicação de Teses e Dissertações Eletrônicas (TDE) na Biblioteca Digital de Teses e Dissertações (BDTD) e na Biblioteca Digital do PROFMAT (BIT)}

Na qualidade de titular dos direitos de autor da presente publicação, autorizo a Universidade de Brasília - UnB, o Instituto Brasileiro de Informação em Ciência e Tecnologia - IBICT e a Sociedade Brasileira de Matemática - SBM a disponibilizar, de forma gratuita, sem ressarcimento dos direitos autorais, de acordo com a Lei no 9610/98, o texto integral desta obra, em meio eletrônico na rede mundial de computadores, para fins de leitura, impressão e/ou download pela Internet, a título de divulgação da produção científica brasileira, a partir desta data.

Brasília, 26 de junho de 2015.

Ronald Alexandre Martins. 
Ronald Alexandre Martins

Colinearidade e Concorrência em Olimpíadas Internacionais de Matemática: uma reflexão voltada para o ensino da Geometria Plana no Brasil

\author{
Dissertação apresentada ao Programa de Mestrado \\ Profissional em Matemática em Rede Nacional como \\ requisito parcial para a obtenção do título de MESTRE \\ em Matemática, pelo Departamento de Matemática da \\ Universidade de Brasília.
}

Orientador: Prof. Dr. Kellcio Oliveira Araújo 
Ficha catalográfica elaborada automaticamente, com os dados fornecidos pelo(a) autor(a)

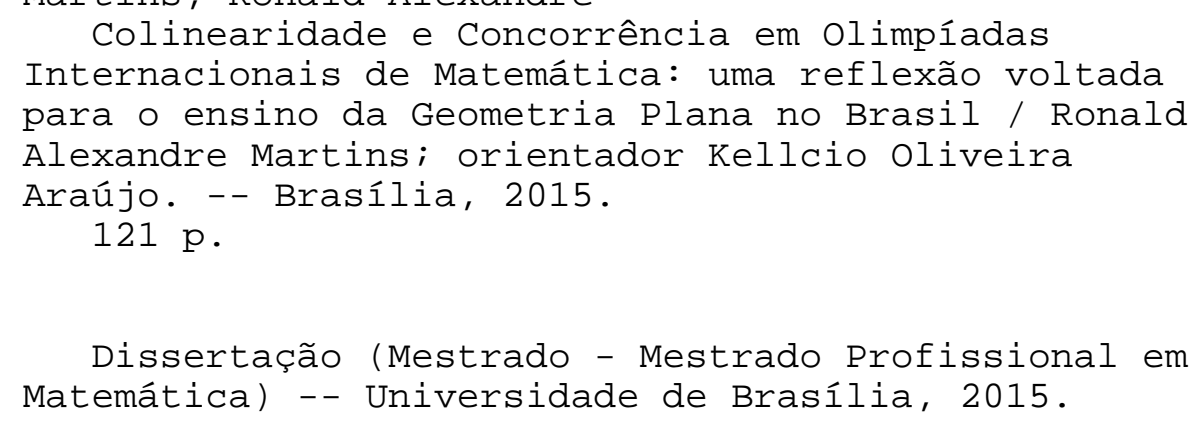

1. Geometria plana. 2. Olimpíadas. 3.

Colinearidade. 4. Concorrência. I. Araújo, Kellcio Oliveira, orient. II. Título. 


$$
\begin{gathered}
\text { Universidade de Brasília } \\
\text { Instituto de Ciências Exatas } \\
\text { Departamento de Matemática }
\end{gathered}
$$

\title{
Colinearidade e Concorrência em Olimpíadas Internacionais de Matemática: uma reflexão voltada para o ensino da Geometria Plana no Brasil
}

\author{
por \\ Ronald Alexandre Martins *
}

Dissertação apresentada ao Programa de Mestrado Profissional em Matemática em Rede Nacional, no Departamento de Matemática da Universidade de Brasília, como requisito parcial para a obtenção do título de

\section{MESTRE}

Brasília, 26 de junho de 2015.

Banca Examinadora:

Prof. Dr. Kellcio Oliveira Araújo - UnB/DF

Presidente

Prof. Dr. Ricardo Ruviaro - UnB/DF

Membro

Prof. Dr. José Eduardo Castilho - FUP/DF

Membro

* O autor foi bolsista da CAPES durante a elaboração desta dissertação. 
Ronald Alexandre Martins é graduado em Engenharia Cartográfica pelo Instituto Militar de Engenharia e atualmente é professor de Matemática do Sistema de Ensino Seleção, do Colégio Militar de Brasília e do Colégio-Curso Pódion. 
Dedico este trabalho às pessoas que sempre me apoiaram, independente das circunstâncias. Somente Deus, eu e elas sabemos quem são. 



\section{Agradecimentos}

A Deus, sempre e por absolutamente TUDO.

À minha querida esposa, Katiuza e aos meus filhos, Manuela, Daniel e Ester, pela compreensão, paciência e consentimento durante o período do curso e de elaboração deste trabalho.

Ao Sistema de Ensino Seleção, que acreditou em mim e me abriu as portas para a arte da docência, ao Colégio Militar de Brasília, onde pude conhecer grandes amigos que me inspiraram na carreira, e ao ColégioCurso Pódion, por me oferecer o desafio de lecionar em turmas compostas por alunos de alto nível intelectual.

Aos meus amigos da Turma 2013 do PROFMAT/UnB, pelo convívio alegre, apoio e palavras de incentivo durante a realização deste sensacional curso: "Vocês são muito bons!".

Ao meu orientador, professor Kellcio, coordenador regional de iniciação científica da OBMEP, cuja humildade me foi um exemplo e cuja orientação foi de grande importância para que esse trabalho pudesse ser realizado.

À Sociedade Brasileira de Matemática (SBM), à CAPES e à Universidade de Brasília (UnB) por, respectivamente, realizar, financiar e executar o projeto PROFMAT, que forneceu a muitos professores, como eu, a chance de alcançar o título de Mestre. 



\section{Nota do autor}

Questões rotuladas como difíceis dentro da Geometria Euclidiana Plana sempre despertaram o meu interesse, desde os tempos de adolescência, época em que era atraído pelas provas de Matemática dos concursos militares, os quais me eram mais conhecidos que as olimpíadas de Matemática. O fascínio era tal que comecei a construir, desde essa época, cadernos com as questões que julgava difíceis ou, pelo menos, interessantes, e que guardo até os dias de hoje como relíquias pessoais.

Lembro-me como ficava maravilhado com problemas geométricos que eram resolvidos por traçados inesperados ou propriedades surpreendentes, difíceis de enxergar em um primeiro momento.

Esse interesse pessoal pelas questões difíceis me levou a prestar o vestibular do Instituto Militar de Engenharia (IME), uma das instituições de ensino superior mais renomadas no Brasil, onde me graduei em Engenharia, mas sempre mantendo viva a paixão pela arte de lecionar Matemática.

Essa paixão inspiradora renovou-se em dois momentos recentes da minha vida como docente: ao assumir em 2013 as aulas da disciplina de Geometria para a turma preparatória IME-ITA, no Colégio-Curso Pódion e, no mesmo ano, ao iniciar as aulas da disciplina MA 13, no mestrado PROFMAT, quando me deparei com listas de exercícios de Geometria raramente trabalhadas no ensino regular de hoje.

Espero que o leitor, ao apreciar este trabalho, possa, assim como eu, sentir o prazer de ser desafiado a buscar mais conhecimento dentro do ensino da Matemática, em especial o da Geometria, buscando melhorar, a cada dia, o ensino básico do nosso país. 



\section{Resumo}

As olimpíadas de Matemática estão cada vez mais ganhando espaço dentro das escolas brasileiras. Esse fato é observado em virtude da crescente participação e interesse dos alunos nas competições nacionais e regionais a cada ano. Isso ocorre porque essas competições, em si, não requerem do aluno, como muitos pensam, memorizações injustas de fórmulas e o conhecimento total da disciplina, mas apenas o conhecimento de alguns conceitos básicos, um raciocínio rápido e certa criatividade. A Geometria sempre esteve presente em todas as olimpíadas de Matemática, apresentando-se como um dos tópicos que os alunos encontram maior dificuldade. Consciente da limitada atenção dada ao ensino da Geometria no Brasil, oferece-se nesse trabalho uma pequena contribuição para ampliar o seu ensino nos bancos escolares, principalmente quanto ao tema Colinearidade e Concorrência, recorrente em diversas olimpíadas, tanto em nível nacional quanto internacional, porém esquecido pelos livros de Matemática atuais. O autor apresenta dados recentes sobre as olimpíadas de Matemática no Brasil e no mundo, e resgata conceitos como os de homotetia, inversão, polaridade, divisão harmônica, circunferência de Apolônio, eixo radical, quadriláteros completos, as retas de Euler, Steiner, Housel, Simson-Wallace, Gauss-Newton, além dos pontos notáveis de Gergonne, Lemoine, Nagel e teoremas como os de Menelaus, Ceva, Arquimedes, Desargues, Pascal, Brianchon, Pappus, Monge, Brahmagupta, Miquel, entre outros.

Palavras-chaves: Geometria plana; olimpíadas; colinearidade; concorrência. 



\section{Abstract}

The Mathematics Olympiads are increasingly gaining ground in Brazilian schools. This fact is observed because of increasing participation and interest of students in national and regional competitions every year. This is because these competitions, in itself, does not require the student, as many think, unjust recollections of formulas and full knowledge of the discipline, but only the knowledge of some basic concepts, a quick thinking and certain creativity. Geometry has always been present in all the math olympiads, presenting itself as one of the topics that students find most difficult. Aware of the limited attention given to the teaching of Geometry in Brazil, this work offers a little contribution to expand its teaching in school benches, especially on the subject Collinearity and Concurrence, recurring in several olympics problems, both at national and international level, but forgotten by current Mathematics books. The author presents recent data about the Mathematics Olympiads in Brazil and worldwide, and rescues the concepts of homothetic transformation, inversion, polarity, harmonic division, circle of Apollonius, radical axis, complete quadrilaterals, lines of Euler, Steiner, Housel, Simson-Wallace, Gauss-Newton, in addition to the notable points of Gergonne, Lemoine, Nagel and theorems such as Menelaus, Ceva, Archimedes, Desargues, Pascal, Brianchon, Pappus, Monge, Brahmagupta, Miquel, among others.

Keywords: Plane geometry; olympiads; collinearity; concurrence. 


\section{Lista de ilustrações}

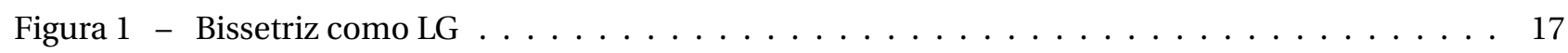

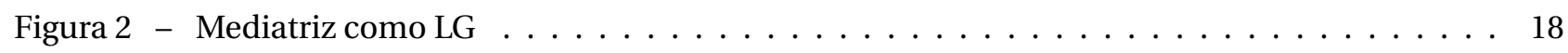

Figura 3 - Tangentes a um círculo traçadas a partir de um ponto exterior. . . . . . . . . . . 19

Figura 4 - Triângulo retângulo inscrito em um semicírculo $\ldots \ldots \ldots \ldots \ldots \ldots \ldots \ldots$

Figura 5 - Perpendicularidade entre as bissetrizes interna e externa de um triângulo . . . . . . . 20

Figura 6 - Ângulo entre duas bissetrizes internas de um triângulo $\ldots \ldots \ldots \ldots \ldots \ldots \ldots 21$

Figura 7 - Ângulo entre duas bissetrizes externas de um triângulo $\ldots \ldots \ldots \ldots \ldots \ldots \ldots 21$

Figura 8 - Ângulo entre bissetriz interna e bissetriz externa relativas a vértices distintos . . . . . . 22

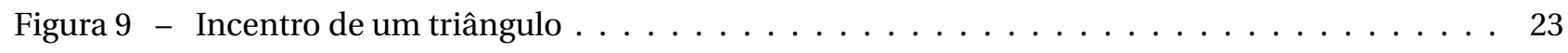

Figura 10 - Circuncentro de um triângulo $\ldots \ldots \ldots \ldots \ldots \ldots \ldots \ldots \ldots \ldots \ldots \ldots \ldots \ldots$

Figura 11 - Exincentro de um triângulo $\ldots \ldots \ldots \ldots \ldots \ldots \ldots \ldots \ldots \ldots \ldots \ldots \ldots \ldots \ldots \ldots \ldots$

Figura 12 - Divisão de um segmento por um ponto $\ldots \ldots \ldots \ldots \ldots \ldots \ldots \ldots \ldots$

Figura 13 - Prova da unicidade na divisão de um segmento por um ponto $\ldots \ldots \ldots \ldots \ldots 25$

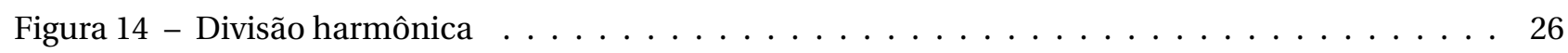

Figura 15 - Configurações para a razão da divisão harmônica $\ldots \ldots \ldots \ldots \ldots \ldots \ldots 26$

Figura 16 - Relação do ponto médio $\ldots \ldots \ldots \ldots \ldots \ldots \ldots \ldots \ldots \ldots \ldots \ldots \ldots \ldots \ldots \ldots \ldots$

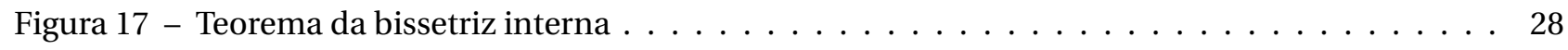

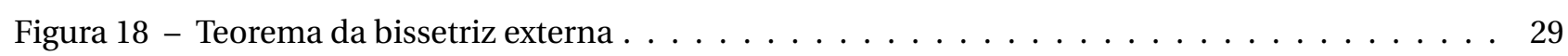

Figura 19 - Recíproca do teorema das bissetrizes $\ldots \ldots \ldots \ldots \ldots \ldots \ldots \ldots \ldots \ldots \ldots$

Figura 20 - Divisão harmônica pelo incentro e exincentro $\ldots \ldots \ldots \ldots \ldots \ldots \ldots \ldots$

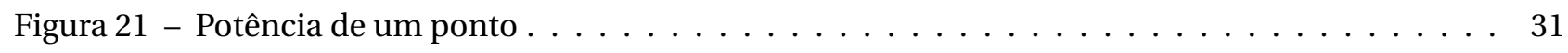

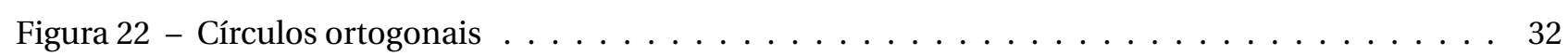

Figura 23 - Círculos ortogonais cortados por uma reta $\ldots \ldots \ldots \ldots \ldots \ldots \ldots \ldots \ldots$

Figura 24 - Circunferência de Apolônio $\ldots \ldots \ldots \ldots \ldots \ldots \ldots \ldots \ldots \ldots \ldots \ldots \ldots \ldots$

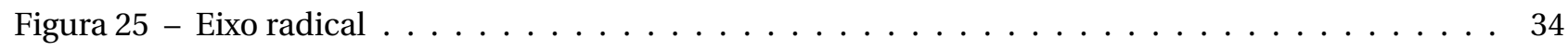

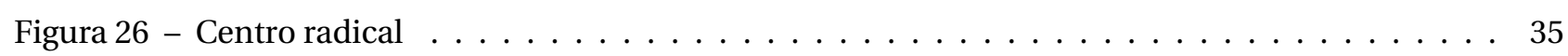

Figura 27 - Colinearidade de pontos $\ldots \ldots \ldots \ldots \ldots \ldots \ldots \ldots \ldots \ldots \ldots \ldots \ldots \ldots \ldots \ldots \ldots$

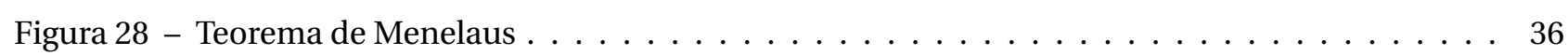

Figura 29 - Demonstração do teorema de Menelaus $\ldots \ldots \ldots \ldots \ldots \ldots \ldots \ldots \ldots \ldots$

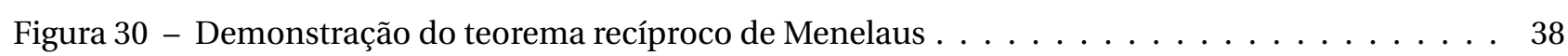


Figura 31 - Prova do lema $\ldots \ldots \ldots \ldots \ldots \ldots \ldots$

Figura 32 - Demonstração do teorema de Menelaus trigonométrico $\ldots \ldots \ldots \ldots$. . . . . . . 39

Figura 33 - Teorema de Ceva . . . . . . . . . . . . . . . . . . . . . . 40

Figura 34 - Demonstração do Teorema Ceva $\ldots \ldots \ldots \ldots \ldots \ldots$. . . . . . . . . 41

Figura 35 - Demonstração do teorema recíproco de Ceva . . . . . . . . . . . . . . . . . . 41

Figura 36 - Colinearidade dos pés das bissetrizes externa e da bissetriz interna . . . . . . . . . 4 43

Figura 37 - Colinearidade dos pés das bissetrizes externas $\ldots \ldots \ldots \ldots \ldots \ldots$. . . . . . 44

Figura 38 - Divisão da mediana pelo baricentro $\ldots \ldots \ldots \ldots \ldots \ldots$

Figura 39 - Concorrência das alturas de um triângulo $\ldots \ldots \ldots \ldots \ldots$. . . . . . . . 45

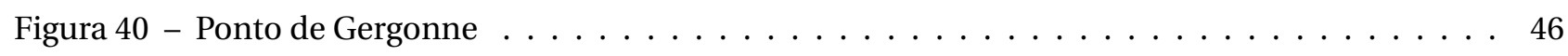

Figura $41-$ Ponto de Nagel $\ldots \ldots \ldots \ldots \ldots \ldots \ldots \ldots \ldots$

Figura $42-$ Cevianas isogonais $\ldots \ldots \ldots \ldots \ldots \ldots \ldots \ldots \ldots$

Figura 43 - Demonstração do ponto de Lemoine $-1^{\mathrm{a}}$ parte $\ldots \ldots \ldots \ldots$. . . . . . . 48

Figura 44 - Demonstração do ponto de Lemoine $-2^{\mathrm{a}}$ parte $\ldots \ldots \ldots \ldots \ldots$. . . . . . . . 49

Figura $45-$ Teorema de Monge $\ldots \ldots \ldots \ldots \ldots \ldots \ldots \ldots \ldots$

Figura 46 - Demonstração do teorema de Monge $\ldots \ldots \ldots \ldots \ldots \ldots$. . . . . . . . 50

Figura 47 - Teorema de Monge-d'Alembert $\ldots \ldots \ldots \ldots \ldots \ldots \ldots \ldots$

Figura 48 - Demonstração do teorema de Monge-d'Alembert $\ldots \ldots \ldots \ldots \ldots \ldots$

Figura $49-$ Reta de Euler $\ldots \ldots \ldots \ldots \ldots \ldots \ldots \ldots \ldots \ldots \ldots$

Figura 50 - Demonstração da Reta de Euler $-1^{\text {a }}$ parte $\ldots \ldots \ldots \ldots \ldots \ldots \ldots$

Figura 51 - Demonstração da Reta de Euler $-2^{\text {a }}$ parte $\ldots \ldots \ldots \ldots \ldots \ldots$. . . . . . . . . 54

Figura 52 - Demonstração da Reta de Housel $-1^{\mathrm{a}}$ parte $\ldots \ldots \ldots \ldots \ldots \ldots \ldots$

Figura 53 - Demonstração da Reta de Housel $-2^{\mathrm{a}}$ parte $\ldots \ldots \ldots \ldots \ldots \ldots$. . . . . . . . 55

Figura 54 - Demonstração da Reta de Housel - $3^{\mathrm{a}}$ parte $\ldots \ldots \ldots \ldots$. . . . . . . . . . . 56

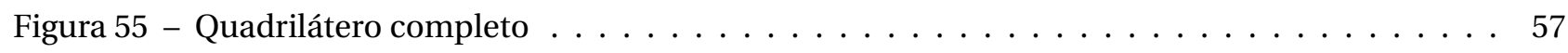

Figura 56 - Demonstração da Reta de Gauss-Newton $\ldots \ldots \ldots \ldots \ldots \ldots$. . . . . . . . 57

Figura 57 - Prova do quadrilátero inscritível $\ldots \ldots \ldots \ldots \ldots \ldots \ldots \ldots$

Figura 58 - Lema $\mathrm{n}^{0} 11$ de Arquimedes $\ldots \ldots \ldots \ldots \ldots$. . . . . . . . . . . . 59

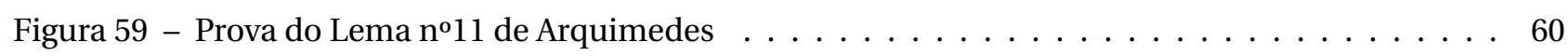

Figura 60 - Demonstração do teorema de Arquimedes $\ldots \ldots \ldots \ldots \ldots \ldots$

Figura 61 - Quadrilátero de diagonais perpendiculares $\ldots \ldots \ldots \ldots \ldots$. . . . . . . . 62

Figura 62 - Demonstração do Teorema de Brahmagupta . . . . . . . . . . . . . . . . . . 62

Figura 63 - Demonstração da Fórmula de Brahmagupta . . . . . . . . . . . . . . . . . 63

Figura 64 - Demonstração do teorema de Simson-Wallace . . . . . . . . . . . . . . . . . . 65

Figura 65 - Demonstração do teorema recíproco de Simson-Wallace . . . . . . . . . . . . . . 66

Figura 66 - Demonstração do teorema de Steiner . . . . . . . . . . . . . . . . . . . 66

Figura 67 - Teorema de Miquel para triângulos $\ldots \ldots \ldots \ldots \ldots \ldots$. . . . . . . . . 67

Figura 68 - Demonstração do teorema de Miquel para triângulos . . . . . . . . . . . . . . 67

Figura 69 - Teorema de Miquel para quadrilátero completo $\ldots \ldots \ldots \ldots \ldots$. . . . . . . 68

Figura 70 - Demonstração do teorema de Miquel para quadrilátero completo $\ldots \ldots \ldots$. . . . . 68

Figura 71 - Homotetia de ponto . . . . . . . . . . . . . . . . . . . . . . . . . 69 
Figura 72 - Homotetia de segmento $\ldots \ldots \ldots \ldots \ldots \ldots \ldots \ldots \ldots$

Figura 73 - Homotetia de ângulo $\ldots \ldots \ldots \ldots \ldots \ldots \ldots \ldots \ldots$

Figura 74 - Homotetia de polígono $\ldots \ldots \ldots \ldots \ldots \ldots \ldots \ldots \ldots \ldots \ldots$

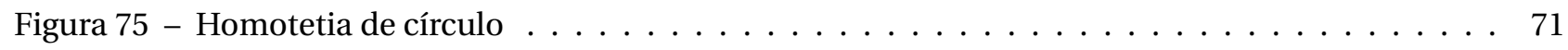

Figura 76 - Centros de homotetia para três círculos $\ldots \ldots \ldots \ldots \ldots \ldots$

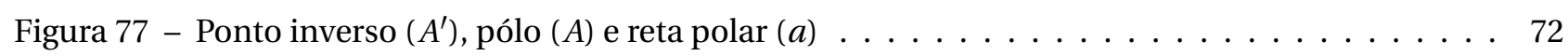

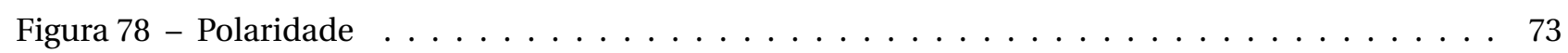

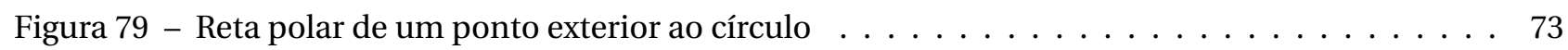

Figura $80-$ Teorema de Desargues $\ldots \ldots \ldots \ldots \ldots \ldots \ldots \ldots \ldots \ldots$

Figura 81 - Teorema recíproco de Desargues $\ldots \ldots \ldots \ldots \ldots \ldots$. . . . . . . . . 76

Figura 82 - Teorema de Pascal $\ldots \ldots \ldots \ldots \ldots \ldots \ldots$. . . . . . . . . . . 77

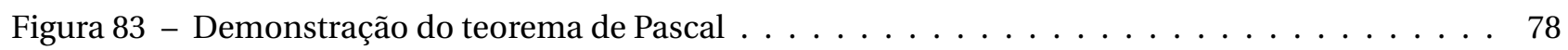

Figura 84 - Teorema de Pappus . . . . . . . . . . . . . . . . . . . . . 79

Figura 85 - Demonstração do teorema de Pappus $\ldots \ldots \ldots \ldots \ldots$. . . . . . . . . . 79

Figura 86 - Demonstração do teorema de Brianchon $\ldots \ldots \ldots \ldots$. . . . . . . . . . . . . . 81

Figura $87-\mathrm{IMO}-2013.1 \ldots \ldots \ldots \ldots \ldots \ldots \ldots \ldots \ldots$

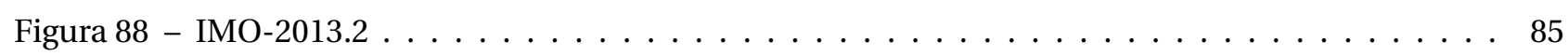

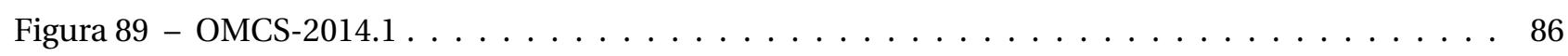

Figura $90-\mathrm{OMCS}-2014.2 \ldots \ldots \ldots \ldots \ldots \ldots \ldots \ldots \ldots \ldots$

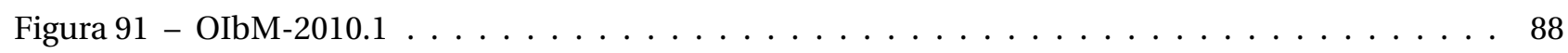

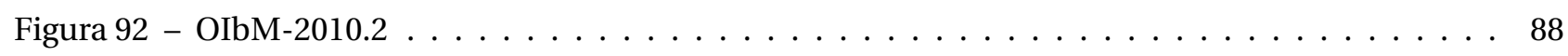

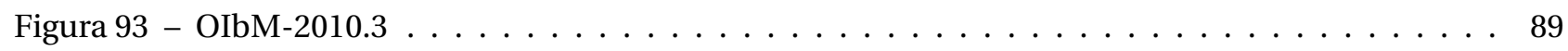

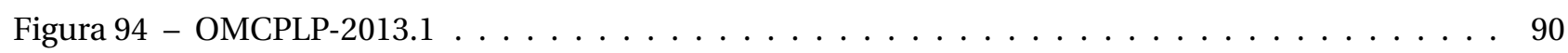

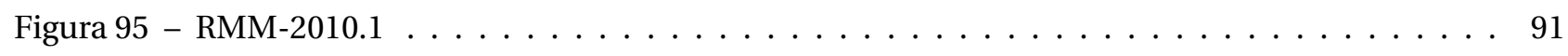

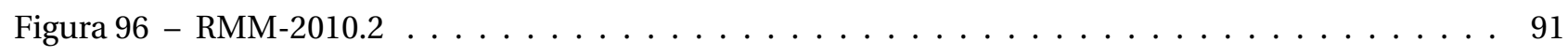

Figura $97-\mathrm{OBM}-2012.1 \ldots \ldots \ldots \ldots \ldots \ldots \ldots \ldots \ldots \ldots \ldots \ldots$

Figura $98-\mathrm{OBM}-2012.2 \ldots \ldots \ldots \ldots \ldots \ldots \ldots \ldots \ldots \ldots$

Figura $99-\mathrm{OBM}-2012.3 \ldots \ldots \ldots \ldots \ldots \ldots \ldots \ldots \ldots \ldots \ldots$

Figura $100-\mathrm{APMO}-2013.1 \ldots \ldots \ldots \ldots \ldots \ldots \ldots \ldots \ldots \ldots$ 


\section{Lista de abreviaturas e siglas}

APMO Asian Pacific Mathematics Olympiad

CAPES Coordenação de Aperfeiçoamento de Pessoal de Nível Superior

CGEE Centro de Gestão e Estudos Estratégicos

CNPq Conselho Nacional de Desenvolvimento Científico e Tecnológico

CT\&E Ciência, Tecnologia e Inovação

ENEM Exame Nacional do Ensino Médio

IIT Indian Institute of Technology

IME Instituto Militar de Engenharia

IMO International Mathematical Olympiad

IMPA Instituto de Matemática Pura e Aplicada

IMU International Mathematical Union

ITA Instituto Tecnológico de Aeronáutica

LG Lugar geométrico

MEC Ministério da Educação e Cultura

MIT Massachusetts Institute of Technology

MMM Movimento da Matemática Moderna

OBM Olimpíada Brasileira de Matemática

OBMEP Olimpíada Brasileira de Matemática das Escolas Públicas

OIbM Olimpíada Iberoamericana de Matemática

OMCPLP Olimpíada de Matemática da Comunidade de Países de Língua Portuguesa 
OMCS Olimpíada de Matemática do Cone Sul

PCN Parâmetros Curriculares Nacionais

PECI Preparação Especial para Competições Internacionais

PIC Programa de Iniciação Científica Junior

PICME Programa de Iniciação Científica - Mestrado

POTI Pólos Olímpicos de Treinamento Intensivo

PROF Programa Oficinas de Formação

PROFMAT Mestrado Profissional em Matemática em Rede Nacional

PUC Pontifícia Universidade Católica

RMM Romanian Master in Mathmatics

SBM Sociedade Brasileira de Matemática

UFF Universidade Federal Fluminense

UFMG Universidade Federal de Minas Gerais

UnB Universidade de Brasília

UNICAMP Universidade de Campinas

UNOCHAPECÓ Universidade Comunitária Regional de Chapecó 
1 Introdução $\ldots \ldots \ldots \ldots \ldots \ldots \ldots \ldots \ldots \ldots \ldots \ldots \ldots \ldots \ldots \ldots \ldots$

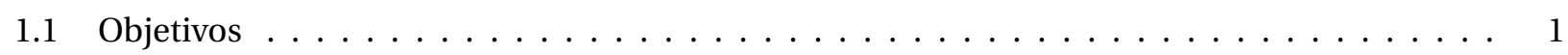

1.2 Motivação e justificativa $\ldots \ldots \ldots \ldots \ldots \ldots \ldots \ldots \ldots \ldots \ldots \ldots \ldots$

1.3 Metodologia e apresentação do trabalho $\ldots \ldots \ldots \ldots \ldots \ldots$

20 ensino da Geometria no Brasil . . . . . . . . . . . . . . . . . 5

3 As competições olímpicas de Matemática e o Brasil . . . . . . . . . . . . . . . 9

$3.1 \quad$ As competições olímpicas e seus reflexos $\ldots \ldots \ldots \ldots \ldots \ldots \ldots \ldots$

3.2 As iniciativas atuais para a promoção da Matemática no país $\ldots \ldots \ldots \ldots \ldots$. . . . 11

3.3 Os resultados observados na pesquisa $\ldots \ldots \ldots \ldots \ldots \ldots \ldots \ldots$

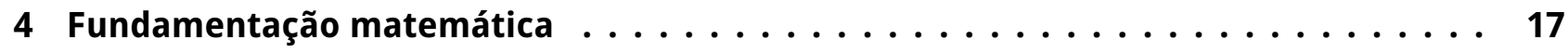

5 Alguns problemas olímpicos . . . . . . . . . . . . . . . . . . 83

5.1 Recomendaçôes $\ldots \ldots \ldots \ldots \ldots \ldots \ldots \ldots \ldots \ldots \ldots \ldots$

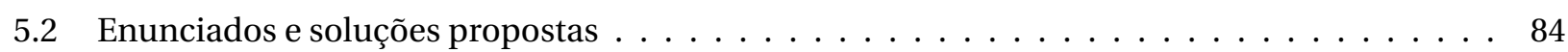

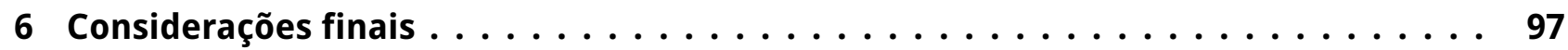

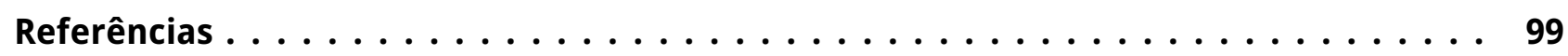

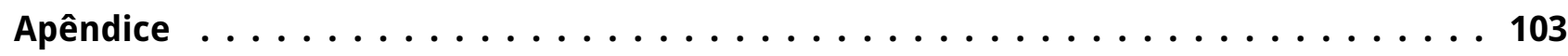





\section{Introdução}

\subsection{Objetivos}

A ideia do mestrado PROFMAT é fornecer um aprimoramento na formação profissional dos professores, com ênfase na busca de um domínio aprofundado e articulado do conteúdo matemático para a atuação como docente na educação básica ${ }^{1}$ das escolas do país.

Com base nesse pensamento e levando em consideração a conjuntura atual de muitos professores e, por conseguinte, as suas diversas dificuldades, este trabalho objetiva tornar o ensino da Geometria Plana mais instigante, resgatando alguns conceitos e teoremas clássicos já esquecidos no Ensino Básico brasileiro, proporcionando subsídios aos docentes e discentes, em especial no tocante ao conteúdo de Concorrência e Colinearidade, cobrado com frequência nas olimpíadas de Matemática no mundo inteiro.

A intenção do autor é de que esse material possa propiciar a todos - professores e alunos - uma outra visão da Geometria Euclidiana Plana e uma reflexão acerca do ponto de vista das questões olímpicas, como forma de melhorar o processo ensino-aprendizagem dessa disciplina e, possivelmente, como elemento motivador para todos aqueles que buscam aprimorar seus conhecimentos visando à preparação para competições de Matemática no âmbito nacional e internacional.

Assim, pode-se resumir como objetivos para este trabalho:

\section{- Objetivo geral:}

$\checkmark$ Apresentar a importância do assunto Colinearidade e Concorrência na preparação de alunos para as competições nacionais e internacionais de Matemática, resgatando conceitos e teoremas clássicos da Geometria Plana, já esquecidos na educação brasileira.

\section{- Objetivos específicos:}

$\checkmark$ Fazer um levantamento quantitativo do assunto nas diversas olimpíadas internacionais de Matemática dos últimos 5 anos (2010-2014);

$\checkmark$ Apresentar e demonstrar os principais tópicos ligados ao assunto Colinearidade e Concor-

1 A educação básica compreende a educação infantil, o ensino fundamental e o ensino médio, e tem por finalidades desenvolver o educando, assegurar-lhe a formação indispensável para o exercício da cidadania e fornecer-lhe meios para progredir no trabalho e em estudos posteriores, contribuindo para a redução das desigualdades sociais (MEC 2013 . 
rência na Geometria Plana;

$\checkmark$ Reunir os problemas sobre Colinearidade e Concorrência cobrados nos últimos anos nas diversas olimpíadas para fins de apoio ao treinamento e preparação de alunos e professores;

$\checkmark$ Selecionar e resolver alguns problemas recentes de olimpíadas de Matemática, nacionais e internacionais, envolvendo Colinearidade e Concorrência;

$\checkmark$ Propor uma reflexão sobre o ensino da Matemática, em especial o da Geometria Plana, na educação básica, no sentido de resgatar conceitos e teoremas abandonados, e, quem sabe, até mesmo repensar a maneira de ensinar a disciplina, com um viés desafiador, também voltado para a preparação olímpica.

\subsection{Motivação e justificativa}

DANTE (1991) afirma que "um dos objetivos do ensino de Matemática é fazer o aluno pensar produtivamente e, para isso, nada melhor que lhe apresentar situações problemas que o envolva, desafie-o e o motive a querer resolvê-las". Entende-se, assim, que um professor que adiciona às suas aulas questões desafiadoras está cumprindo o seu papel de docente de uma forma diferenciada, uma vez que conseguirá despertar nos seus alunos a criatividade para resolver problemas, fazendo-os utilizar, para isso, os mais variados conceitos matemáticos aprendidos ao longo de sua vida.

O que se tem percebido é que o gosto para a resolução de problemas olímpicos aumenta e torna-se mais empolgante à medida que o aluno percebe que, quanto mais problemas resolvidos ele conhecer, maior será o seu banco de estratégias para a resolução dos próximos problemas e, consequentemente, maiores as chances de solucioná-los. Para SARMENTO (2007), resolver um problema de Geometria utilizando diferentes conceitos contribui para despertar no aluno o desejo pela disciplina e o desenvolvimento de habilidades geométricas.

Apesar de a Geometria Euclidiana fazer parte do conteúdo tratado na educação básica, raramente o assunto Colinearidade e Concorrência é ensinado no Ensino Fundamental, no Ensino Médio ou mesmo na maioria dos cursos de graduação em Matemática. Em especial, apenas uma pequena parcela dos estudantes e professores se aprofundam nesse assunto: aqueles que se dedicam às olimpíadas e competições matemáticas.

Dentre as áreas matemáticas exigidas nessas competições, a Geometria é um tópico sempre presente e que é considerado um dos mais difíceis. Analisando as diversas olimpíadas internacionais de Matemática, o autor observou que o assunto Colinearidade e Concorrência tem sido, de certa forma, bastante cobrado, seja diretamente ou indiretamente, nos problemas apresentados. Portanto, é um tema importante a ser estudado e, porque não dizer, resgatado dentro das escolas e nos livros didáticos atuais utilizados no ensino regular do país.

Assim, o presente trabalho se justifica no sentido de mostrar a importância do assunto Colinearidade e Concorrência e suas aplicações na Geometria Plana, em especial, na preparação de jovens para as modernas olimpíadas de Matemática, o que, sem dúvida, traz um diferencial desafiador e motivante para os 
educadores e estudantes brasileiros, fomentando o gosto pela Matemática.

\subsection{Metodologia e apresentação do trabalho}

Com o intuito de atingir os objetivos traçados, o presente trabalho foi desenvolvido mediante a seguinte metodologia:

$\checkmark$ realizar inicialmente uma pesquisa bibliográfica em livros especializados em olimpíadas de Matemática, bem como nos sítios oficiais de cada competição na Internet, fazendo os contatos necessários com os respectivos coordenadores, a fim de coletar o maior número de provas aplicadas nessas competições mundiais nos últimos 5 anos (2010 a 2014);

$\checkmark$ selecionar os problemas de geometria que envolvam diretamente a aplicação dos conceitos de Colinearidade e Concorrência;

$\checkmark$ relacionar conceitos e demonstrar teoremas aplicáveis a uma parte desses problemas, buscando preencher, de forma sequenciada, a lacuna existente nos livros escolares brasileiros sobre o assunto, construindo um instrumental de apoio didático para o ensino voltado à preparação olímpica;

$\checkmark$ apresentar soluções a alguns desses problemas olímpicos utilizando os teoremas estudados, notadamente os cobrados em competições das quais o Brasil participa;

$\checkmark$ elaborar uma coletânea de problemas olímpicos recentes (2010-2014), sobre Colinearidade e Concorrência, visando dar suporte à preparação de alunos e professores; e

$\checkmark$ propor, ao final, o uso de questões olímpicas em sala de aula como desafios no ensino e no aprendizado da Geometria, tanto por parte dos professores quanto dos alunos, bem como a sua introdução nos livros didáticos da educação básica.

Procurou-se, ao longo deste trabalho, apresentar todo o texto, enunciados e demonstrações de uma maneira simplificada e de fácil entendimento, fugindo, às vezes, do formalismo teórico, com fins a possibilitar uma fácil compreensão do tema para professores e alunos da educação básica, construindo assim um instrumental de apoio didático para o ensino voltado à preparação das olimpíadas de Matemática.

As figuras utilizadas para apoiar as demonstrações dos lemas, teoremas e corolários, bem como das soluções dos problemas, foram elaboradas pelo autor com o auxílio do recurso computacional de Matemática dinâmica chamado GeoGebra ${ }^{2}$

No decorrer do texto, o leitor encontrará ainda, em notas de rodapé, um pouco da história e da biografia de alguns dos matemáticos e dos teoremas citados, que o ajudarão a compreender melhor o momento em que estes teoremas surgiram, qual a sua repercussão à época e qual a sua importância atual.

A dissertação ficou dividida em 6 (seis) capítulos, conforme descrição a seguir.

2 Criado por Markus Hohenwarter, o GeoGebra é um programa gratuito multiplataforma de Matemática dinâmica desenvolvido para o ensino e aprendizagem da Matemática do nível básico ao universitário. O programa reúne recursos de geometria, álgebra, tabelas, gráficos, probabilidade, estatística e cálculos simbólicos em um único ambiente BORTOLOSSI; RESENDE; PESCO 2015) 
Neste primeiro capítulo, é feita uma introdução em que são apresentados, dentro do contexto do Programa de Mestrado Profissional em Matemática PROFMAT, os objetivos do trabalho, a motivação e a justificativa do tema desenvolvido, bem como a metodologia empregada pelo autor na sua elaboração.

No segundo capítulo, o autor resgata um pequeno histórico das mudanças sofridas pelo ensino da Matemática no Brasil, notadamente na Geometria, a partir da segunda metade do século XX, quando sérias mudanças no processo ensino-aprendizagem ocorreram no país. O autor sugere então a ideia da utilização da resolução de problemas olímpicos como uma maneira de incrementar esse processo, despertando no aluno da educação básica um interesse maior pela Matemática.

O Capítulo 3 é dedicado à apresentação de algumas características das competições olímpicas matemáticas e seus reflexos positivos no Brasil e no mundo, principalmente para o desenvolvimento das Ciências em geral. O autor cita as várias iniciativas existentes hoje no país, ligadas à preparação de estudantes para uma Matemática desafiadora e emocionante, destacando os resultados recentes alcançados, por exemplo, pela Olimpíada Brasileira de Matemática das Escolas Públicas (OBMEP). Além disso, são apresentados os resultados da pesquisa realizada, justificando a relevância do tema Colinearidade e Concorrência para o trabalho.

No Capítulo 4, o autor apresenta, de forma simples e didática, diversos conceitos e teoremas matemáticos, praticamente ausentes dos livros didáticos atuais, com o intuito de fornecer um embasamento teórico capaz de ajudar os alunos na resolução de muitos problemas olímpicos envolvendo o tema Colinearidade e Concorrência.

O Capítulo 5 contém soluções elaboradas pelo autor para 7 (sete) problemas selecionados sobre Colinearidade e Concorrência, cobrados em olimpíadas recentes, nas quais a participação de estudantes brasileiros é permitida, como forma de aplicar o conteúdo desenvolvido na fundamentação teórica do Capítulo 4.

No Capítulo 6 são apresentadas as considerações finais do autor sobre o trabalho realizado e, por fim, a bibliografia consultada para a sua execução e um Apêndice com os enunciados dos 141 problemas olímpicos encontrados na pesquisa, que poderão auxiliar, em muito, professores e alunos em relação ao tema. 


\title{
O ensino da Geometria no Brasil
}

\author{
Em 27/01/1921, na Conferência “Geometria e Experiência”, realizada \\ na Academia Prussiana de Ciências, Einstein proferiu: "Atribuo \\ especial importância quanto à visão que tenho à Geometria, porque \\ sem ela eu não teria sido capaz de formular a teoria da relatividade". \\ LORENZATO, 1995)
}

A Geometria é considerada um dos principais eixos da Matemática para a formação do cidadão porque está sempre presente no seu cotidiano, nas mais variadas situações, como nas construções, na natureza e nos diversos objetos existentes.

A chamada Geometria Euclidiana foi construída com base nos escritos do matemático grego Euclides. Sua obra "Elementos", escrita por volta do ano 300 a.C., apresenta a Geometria segundo o método dedutivo (ou axiomático), que consiste em iniciar com afirmações chamadas "axiomas" ou "postulados", os quais são aceitos como verdade, sem necessidade de justificativas, e, a partir daí, ir deduzindo, através de demonstrações, outras afirmações decorrentes, desenvolvendo assim o seu conteúdo (GUALBERTO, 2007).

GONÇALVES e LANDO (2012) apresentam um breve passeio pela história da Educação Brasileira, notadamente da Geometria, desde o início do século XX, quando o Brasil ainda era essencialmente um país agrícola. Destacam que, assim como outras disciplinas passaram por reformas ao longo dos anos, a Matemática também sofreu, principalmente durante a década de 1950 e 1960, quando uma transformação, em especial na forma de aprendizagem da Geometria, foi estabelecida: uma abordagem didática nova e restrita, com a substituição das tradicionais demonstrações, simplesmente, pela apresentação de fórmulas capazes de resolver problemas algébricos e que deveriam ser memorizadas pelos discentes.

Ainda hoje é comum encontrar, no cotidiano escolar, listas de exercícios de geometria nas quais o menos importante é o conhecimento geométrico em si. Na maioria das vezes o que há é uma exaustiva repetição de aplicações algébricas de fórmulas, em detrimento de uma análise, por exemplo, das propriedades geométricas, da condição de existência de uma figura, da visualização de particularidades, e, principalmente, da construção de elementos auxiliares, responsáveis por resoluções de alto teor geométrico, pouco cálculo e livres de algebrismo. A homotetia (do grego: homo = "similar" + thetós = "posição"), por exemplo, é um conceito envolvendo transformação geométrica, mostrado no Capítulo 4, que resolve problemas difíceis de uma forma simples, sem o uso de cálculos extensos, mas que sequer é citada na maioria dos livros escolares. 
livros didáticos da educação básica brasileira. A priorização no emprego de fórmulas a serem memorizadas e da mecanização de processos ainda é bastante frequente. Para ele, os problemas de geometria não devem se resumir apenas à descoberta de um valor numérico que atenda à proposta de um enunciado. Antes disso, é preciso conceber a figura, reconhecer suas características, interpretar suas propriedades, enfim, uma sequência de raciocínios que pode até não ser percebida, mas que é certamente necessária.

Para GONÇALVES e LANDO (2012), vários foram os motivos que justificam o caos no atual ensino da Geometria, entre eles: a falta de conhecimentos por parte do professor; a importância exagerada dispensada ao livro didático; a fragmentação da disciplina por assunto ou série, e o chamado Movimento da Matemática Modern:[1] ocorrido na década de 1960. A consequência que se colhe no tempo presente é esta: uma geração que não estudou Geometria não sabe como ensiná-la, ficando presa ao que se escreve nos livros didáticos.

Segundo NEVES (2013), diversas pesquisas sobre o aprendizado de Geometria constatam que essa é uma área que apresenta resultados consideravelmente insatisfatórios, uma vez que é menos explorada do que outras áreas da Matemática, não somente nas séries iniciais da educação básica, como também no Ensino Fundamental - Ciclo II e no Ensino Médio.

O que se percebe nas escolas é que o estudo da Geometria, que deveria ocorrer de forma gradativa durante todo o Ensino Fundamental, sendo aprofundada no Ensino Médio, não acontece. Em muitos casos, os alunos chegam ao Ensino Médio sem ter visto nenhuma parte de Geometria; outras vezes, ela é apresentada de uma forma "simplista", apenas com desenhos e fórmulas que permitem resolver problemas de cálculo.

Segundo pesquisas realizadas por GRILLO (2014), existe uma tendência, em muitas escolas, de se omitir o ensino da Geometria. A disciplina é deixada para o final do período letivo, e qualquer atraso no cronograma das aulas implica na abreviação ou mesmo no cancelamento do seu conteúdo.

LORENZATO (1995) é ainda mais categórico; ele afirma que "a Geometria está ausente ou quase ausente da sala de aula". Vários trabalhos de pesquisadores brasileiros, entre eles PEREZ (1991) e PAVANELLO (1993), confirmam que essa lamentável realidade educacional é um problema antigo no país.

Para LORENZATO (1995), um dos motivos para a omissão do ensino de Geometria "deve-se à exagerada importância que, entre nós, desempenha o livro didático". Vários livros didáticos ainda apresentam a Geometria como um conjunto de definições, propriedades, nomes e fórmulas, deixando-a para as últimas páginas do livro, aumentando assim as chances de não vir a ser estudada por falta de tempo no ano letivo.

NEVES (2013) acrescenta que, infelizmente, o ensino de Matemática hoje é, de modo geral, orientado pelos processos contidos nos livros didáticos, o que inflexibiliza e limita os professores na busca do ensino dinâmico e atraente da Geometria.

Para se ter uma ideia, MACEDO (2014) afirma que, nas últimas décadas, teoremas como o de Menelaus e o de Ceva, que tratam de Colinearidade e Concorrência, foram excluídos dos livros didáticos do Ensino Básico sem qualquer justificativa, o que levou, naturalmente, as escolas a abandonarem os seus estudos. Apesar de as demonstrações de tais teoremas serem de fácil entendimento e, portanto,

1 O Movimento da Matemática Moderna (MMM) foi um movimento internacional do ensino da Matemática que surgiu no final da década de 1950 e início de 1960 e se baseava na excessiva preocupação com as estruturas algébricas, utilização de símbolos da teoria dos conjuntos e topologia no processo ensino-aprendizagem das escolas. 
perfeitamente adequadas ao nível de conhecimento básico, renegá-los aos alunos, principalmente do Ensino Médio, não foi uma ideia salutar, haja vista que tais conceitos podem facilitar as resoluções de diversos problemas propostos em vestibulares concorridos no país, como o do Instituto Militar de Engenharia (IME) e o do Instituto Tecnológico de Aeronáutica (ITA), e nas diversas olimpíadas de Matemática existentes.

Segundo DE FREITAS (2013), com a atual decadência do ensino de Geometria na educação básica brasileira, tem-se aumentado o interesse de pesquisadores, ligados ao ensino da Matemática, em debater o assunto nas escolas e, até mesmo, nas universidades, principalmente pelo fato de ser uma disciplina em que os docentes se sentem menos preparados, seja pelo desconhecimento em si, seja pelo fato de exigir do profissional a capacidade de fazer desenhos, traçar retas, ângulos, círculos e curvas, muitas vezes a mão livre e sem precisão, no quadro-negro, o que não é agradável para quem não dispõe de certos dons artísticos e de organização.

VIEIRA (2013) ratifica esse entendimento:

\footnotetext{
"Atualmente, o interesse dos professores pela Geometria tem aumentado. Existe um consenso coletivo sobre a importância dessa área para a formação acadêmica dos alunos. Entretanto, em vários momentos o estudo da Geometria é renegado ou mesmo deixado apenas para o final do ano letivo no ensino básico. [...] O ensino tradicional da Geometria deixa lacunas no conhecimento, pois esse ensino é dado basicamente em aulas expositivas, baseadas em conceitos e fórmulas."
}

Recentemente, com o crescente desenvolvimento, divulgação e expressivo resultado das olimpíadas de Matemática no Brasil, torna-se necessário que o material didático das escolas caminhe no sentido de se adequar, em parte, aos assuntos cobrados nessas competições. Uma ideia interessante é que o livro didático contenha seções em que se apresentem problemas e soluções comentadas, descrições do que são as competições olímpicas, quais os seus benefícios, a fim de despertar, desde cedo, o interesse dos alunos por esse tipo de desafio.

Segundo VIEIRA (2013), algumas correntes da educação matemática defendem a importância da utilização, em sala de aula, da resolução de problemas, uma vez que exploram um conhecimento mais aprofundado de assuntos diversos, como forma eficaz de ensino no campo da Geometria.

Além disso, SARMENTO (2007) acrescenta que uma das correntes atuais na educação matemática é utilizar a resolução de problemas como metodologia de ensino, para que o aluno se habitue a criar uma linha de pensamento, construir estratégias de resolução e argumentação, relacionar diferentes conhecimentos, e ser persistente na busca de uma solução. E, de fato, a escolha do método para se abordar um problema não só influencia o modo como se aprende, mas determina muitas vezes o que se aprende e a linha de pensamento a ser seguida.

É com base nesse pensamento transformador que, após trazer uma fundamentação teórica da Geometria Plana, o presente trabalho vai apresentar e resolver 7 (sete) problemas olímpicos envolvendo o tema Colinearidade e Concorrência, a título de exemplo, cobrados em recentes competições realizadas por estudantes brasileiros. A finalidade é evidenciar que apesar de questões desse tipo parecerem, a uma primeira vista, muito difíceis, podem ser resolvidos por meio de conceitos simples, ensinados nas salas de aula das escolas da educação básica do país. 
Antes de fazer a fundamentação matemática proposta, o autor aborda, no próximo capítulo, um pequeno histórico das olimpíadas de Matemática no mundo e no Brasil, suas propostas e seus reflexos para o desenvolvimento das Ciências. Além disso, é apresentada uma síntese dos dados quantitativos levantados pelo autor sobre o tema Colinearidade e Concorrência nas olimpíadas internacionais nos últimos 5 anos (2010-2014) 


\title{
As competições olímpicas de Matemática e o Brasil
}

\author{
“A própria História da Matemática mostra que ela foi construída \\ como resposta a perguntas provenientes de diferentes origens e \\ contextos, motivadas por problemas de ordem prática (divisão de \\ terras, cálculo de créditos), por problemas vinculados a outras \\ ciências (Física, Astronomia), bem como por problemas relacionados \\ a investigações internas à própria Matemática”.
}

\subsection{As competições olímpicas e seus reflexos}

Uma das iniciativas mais antigas de estímulo ao aprendizado e gosto pela Matemática está ligada aos desafios que eram propostos visando à resolução de problemas considerados de alta dificuldade.

A história conta que, em tempos mais antigos, matemáticos trocavam cartas entre si, desafiando-se uns aos outros, propondo questões complicadas e, muitas vezes, reunindo-se em praça pública para a realização de torneios em que era preciso resolver, diante dos mais diversos expectadores, equações inéditas e consideradas de difícil solução.

Esse tipo de competição tomou uma forma mais salutar e harmônica em 1894, na Hungria, com a realização da $1^{\text {a }}$ Olimpíada de Matemática, a Eötvös Mathematical Competition, que teve seu nome mudado para Kürschák Mathematical Competition após a Segunda Guerra Mundial. Segundo SUPPA (2007), essa tradicional competição deixou de ser realizada apenas nos anos de 1919, 1920 e 1921 (Primeira Guerra Mundial), 1944, 1945 e 1946 (Segunda Guerra Mundial) e em 1956 (Revolução Húngara).

SUPPA (2007) destaca os nomes de alguns vencedores dessa importante olimpíada: o físico Theodore von Kármán (1881-1963), vencedor em 1897, com 16 anos de idade, cognominado hoje como o "pai da era supersônica"; o também físico Leo Szilard (1898-1964), vencedor em 1916, com 17 anos, que realizou diversos estudos sobre fissão nuclear ao lado de Albert Einstein, e ficou conhecido como um dos pais da bomba atômica; em 1925, outro físico, Edward Teller (1908-2003), com apenas 16 anos de idade, conhecido como "o pai da Bomba H", dividiu o $1^{\circ}$ lugar dessa competição com Laszlo Tisza (1907-2009), professor emérito do Massachusetts Institute of Technology (MIT); em 1937, a vitória ficou com o jovem de 16 anos, John Harsanyi 
(1920-2000), economista que dividiu o Prêmio Nobel de Economia de 1994, com o matemático John Nash (1928-2015), pelos relevantes trabalhos desenvolvidos sobre Teoria dos Jogos.

Ao longo dos anos, as competições de Matemática entre estudantes no mundo vêm se mostrando um forte indicador para medir a qualidade do ensino nas escolas e descobrir novos talentos para as Ciências como um todo. O que começou com a Matemática, hoje se espalhou para outras áreas, como Física, Química, Astronomia, Informática, Robótica, Linguística, Biologia, História, Geografia, etc. Algumas dessas olimpíadas consistem em provas teóricas, outras consistem em fazer programas, experimentos, e até mesmo realizar discursos e debates (BERSCH, 2015).

Para BERSCH (2015), muitos alunos pensam que para participar de uma olimpíada de Matemática é preciso ter todo o conteúdo da matéria vista na escola em sua mente. Mas, na verdade, os problemas olímpicos não exigem essa dose maior de conhecimento por parte do aluno, mas sim um pouco de criatividade e uma capacidade de raciocínio rápido, principalmente nas áreas de Álgebra, Combinatória, Geometria e Teoria dos Números.

Qualquer aluno do ensino médio ou fundamental pode adquirir essas características a partir de um programa de aulas específicas, com professores capacitados; da prática da resolução de problemas olímpicos; e da própria experiência adquirida em participações nessas competições oficiais ou simuladas nas escolas.

Para um aluno da educação básica, participar das olimpíadas de Matemática é uma oportunidade diferenciada de melhorar o seu rendimento escolar, aprofundar-se em um assunto de seu interesse, conhecer alunos e professores de toda parte do país e do mundo, concorrer a uma bolsa de estudos nas melhores instituições de ensino, além de viver momentos de descontração, viagens, diversão e a chance de bem representar o Brasil no exterior.

Várias universidades americanas como Harvard, Yale, Princeton, MIT, e outras como Oxford, Cambridge, Indian Institute of Technology (IIT) e a Universidade de Tókio valorizam e oferecem bolsas a alunos premiados em certas olimpíadas internacionais. Muitos jovens brasileiros, que galgaram medalhas nas olimpíadas científicas, conseguiram bolsas para estudar nas universidades mais bem conceituadas do mundo. Cabe destacar que muitos alunos brasileiros nessas universidades foram considerados destaques entre os demais estudantes de outras nacionalidades.

Motivar jovens a participar de olimpíadas de Matemática é algo que ajuda a desenvolver o pensamento lógico do estudante, fomentando o interesse pela disciplina; o que traz, sem dúvida, reflexos marcantes também para o professor, principalmente pela melhoria do rendimento escolar, mudança de comportamento e empolgação dos alunos durante as aulas.

Ciente da importância dessas competições para o desenvolvimento da Matemática no mundo, em 1959, foi organizada a 1ª Olimpíada Internacional de Matemática, a International Mathematical Olympiad IMO, realizada na Romênia. A partir desse marco, anualmente, uma centena de países apresentam equipes formadas por 6 alunos do Ensino Básico para a competição de Matemática mais importante do planeta. Em 2017, o Brasil terá o privilégio de sediar a 58a IMO (IMO, 2015.

Cabe destacar que vários jovens medalhistas da IMO conquistaram, mais tarde, já na fase adulta, 
prêmios importantes como a Medalha Fields ${ }^{1}$. O professor australiano Terence Tao, por exemplo, ganhador da Medalha Fields em 2006, foi a pessoa mais jovem a receber uma medalha de ouro na IMO, em 1988, com apenas 13 anos de idade. A primeira mulher a receber a Medalha Fields, a iraniana Maryam Mirzakhani, em 2014, foi bicampeã da IMO, recebendo duas medalhas de ouro em 1994 e 1995. O primeiro brasileiro a receber a Medalha Fields, Artur Ávila Cordeiro de Melo, em 2014, também foi medalhista de ouro na IMO em 1995, com 16 anos de idade. Artur foi o primeiro matemático na América Latina a receber essa importante comenda (IMO, 2015).

O Brasil iniciou sua participação na IMO em 1979 e desde então vem obtendo resultados cada vez mais expressivos. Ao todo foram 9 medalhas de ouro, 33 de prata, 68 de bronze e 29 menções honrosas (IMO. 2015), o que habilitou o país a participar da Romanian Master in Mathematics (RMM), nos anos de 2010, 2012 e 2013, competição considerada dificílima, onde só os 15 melhores países classificados na IMO do ano anterior competem entre si (RMM, 2015).

Dentre os brasileiros medalhistas de ouro na IMO, somente dois atingiram o Perfect Score, ou seja, gabaritaram a prova ( $1^{\circ}$ lugar absoluto): os renomados professores de Matemática Nicolau Corção Saldanha (PUC-Rio), em 1981, e Ralph Costa Teixeira (UFF), em 1987, sendo este último o único brasileiro a ganhar duas medalhas de ouro na competição (1986 e 1987).

Os bons resultados alcançados pelos brasileiros na IMO se devem muito ao processo seletivo realizado pela Olimpíada Brasileira de Matemática (OBM). Todos os medalhistas de ouro da IMO já haviam conquistado o ouro na OBM (IMPA, 2015):

$\checkmark$ Nicolau Corção Saldanha: ouro na OBM (1980) e ouro na IMO (1981);

$\checkmark$ Ralph Costa Teixeira: ouro na OBM (1986) e ouro na IMO $(1986,1987)$;

$\checkmark$ Carlos Gustavo Tamm de Araujo Moreira: ouro na OBM $(1988,1989)$ e ouro na IMO (1990);

$\checkmark$ Artur Ávila Cordeiro de Melo: ouro na OBM $(1993,1994,1995)$ e ouro na IMO (1995);

$\checkmark$ Rui Lopes Viana Filho: ouro na OBM $(1996,1998)$ e ouro na IMO (1998);

$\checkmark$ Gabriel Tavares Bujokas: ouro na OBM $(2000,2002,2004,2005)$ e ouro na IMO (2005);

$\checkmark$ Henrique Pondé de Oliveira Pinto: ouro na $\operatorname{OBM}(2003,2004,2005,2006,2007,2008)$ e ouro na IMO (2009); e

$\checkmark$ Rodrigo Sanches Ângelo: ouro na OBM $(2011,2012,2013)$ e ouro na IMO (2012).

\subsection{As iniciativas atuais para a promoção da Matemática no país}

Os resultados apresentados pelos estudantes brasileiros comprovam que a Sociedade Brasileira de Matemática (SBM) e o Instituto de Matemática Pura e Aplicada (IMPA), organizadores da OBM, estão trilhando o caminho certo para descobrir jovens talentos nacionais. A ideia original da OBM de estimular o

1 Prêmio criado pela União Internacional de Matemática (IMU) em 1936, que é concedido a cada 4 anos, durante o Congresso Internacional de Matemática, para até quatro pessoas, com até 40 anos de idade, que tenham feito contribuições relevantes para as ciências matemáticas. A Medalha Fields é oficialmente denominada Medalha Internacional de Descobrimentos Proeminentes em Matemática e é um prêmio muitas vezes visto como a maior honraria que um matemático pode receber (IMU) 2015. 
estudo da Matemática pelos alunos brasileiros e desenvolver e aperfeiçoar a capacitação dos professores tem influenciado, sobremaneira, a melhoria do ensino da Matemática no país.

Ciente dessa realidade, a SBM, em estreita cooperação com o IMPA, elaborou recentemente diversos projetos e programas que visam preparar alunos e professores e estimular o uso de material de nível olímpico como veículo para melhorar o ensino de Matemática no país, além de contribuir para a descoberta de talentos para as Ciências em geral.

Dentre esses projetos e programas, é possível citar (OBMEP, 2015):

$\checkmark$ o Programa de Iniciação Científica Junior (PIC), destinado aos medalhistas da OBMEP, que têm a oportunidade de estudar Matemática em nível olímpico por um ano, em encontros mensais realizados em mais de 180 polos no país, recebendo uma bolsa de estudos do CNPq e material didático (vídeos, banco de questões, etc.);

$\checkmark$ o Programa de Iniciação Científica - Mestrado (PICME) para medalhistas olímpicos que estejam cursando a graduação e desejam realizar estudos avançados, com bolsas do CNPq (IC) e da CAPES (Mestrado);

$\checkmark$ a Preparação Especial para Competições Internacionais (PECI), que desde 2009 tem preparado medalhistas de ouro selecionados para participar de competições internacionais, mediante aulas virtuais e presenciais;

$\checkmark$ os Polos Olímpicos de Treinamento Intensivo (POTI), iniciado em 2012, que conta com diversos polos no Brasil que têm o objetivo de ampliar o acesso dos alunos brasileiros a treinamento para competições matemáticas, por meio da disponibilização de vídeos e outros materiais;

$\checkmark$ o Programa Oficinas de Formação (PROF), iniciado em 2012 e destinado ao aperfeiçoamento dos professores de Matemática das escolas públicas. Tem como objetivo promover a inclusão de atividades extraclasse de resolução de problemas desafiadores, de nível olímpico, nas práticas escolares;

$\checkmark$ o Programa Clubes de Matemática, iniciado em 2013, que conta atualmente com a adesão de cerca de 3.000 alunos em 389 clubes em todo o Brasil, propiciando atividades inovadoras, interessantes e lúdicas, desenvolvidas em um ambiente interativo;

$\checkmark$ o Portal da Matemática, com aplicativos e vídeo-aulas que cobrem todo o currículo da Matemática, do sexto ano do Ensino Fundamental ao terceiro ano do Ensino Médio; e

$\checkmark \quad$ o Programa OBMEP na Escola, que estimula os professores da rede pública do país a desenvolverem projetos e atividades extraclasse nas escolas, contando ainda com um auxílio financeiro (bolsa), fornecida pela CAPES.

Verdadeiramente, o Brasil, pela sua extensão territorial, diversidade de regiões e grande população, é naturalmente um país competitivo. No quesito matemático, esse fato é indiscutível, uma vez que existem, na atualidade, diversas competições, em nível regional e estadual, podendo ser citadas, a título de exemplo:

$\checkmark$ Olimpíada Campinense de Matemática (SP);

$\checkmark$ Olimpíada Capixaba de Matemática (ES); 
$\checkmark$ Olimpíada Cearense de Matemática (CE);

$\checkmark$ Olimpíada de Matemática da UNICAMP (SP);

$\checkmark$ Olimpíada da Matemática do Estado de Goiás (GO);

$\checkmark$ Olimpíada de Matemática de Rio Preto (SP);

$\checkmark$ Olimpíada de Matemática do Estado do Rio de Janeiro (RJ);

$\checkmark$ Olimpíada de Matemática do Estado do Rio Grande do Norte (RN);

$\checkmark$ Olimpíada de Matemática do Grande ABC (SP);

$\checkmark$ Olimpíada Interestadual de Matemática (ES, MG, RJ, SP);

$\checkmark$ Olimpíada Mineira de Matemática (MG);

$\checkmark$ Olimpíada Paraense de Matemática (PA);

$\checkmark$ Olimpíada Paulista de Matemática (SP)

$\checkmark$ Olimpíada Pessoense de Matemática (PB);

$\checkmark$ Olimpíada Regional de Matemática da Grande Porto Alegre (RS);

$\checkmark$ Olimpíada Regional de Matemática da UNOCHAPECÓ (SC);

$\checkmark$ Olimpíada Regional de Matemática de Mato Grosso (MT);

$\checkmark$ Olimpíada Regional de Matemática de Ribeirão Preto (SP);

$\checkmark$ Olimpíada Regional de Matemática de Santa Catarina (SC);

$\checkmark$ Olimpíada Relâmpago da PUC (RJ);

$\checkmark$ Olimpíada São Carlense de Matemática (SP), entre outras.

Em nível nacional, o Brasil possui duas olimpíadas de Matemática, organizadas pela SBM. A principal delas é a Olimpíada Brasileira de Matemática (OBM), iniciada em 1979, aberta a todos os estudantes do Ensino Fundamental, a partir do sexto ano, do Ensino Médio e também do Ensino Universitário, e que é responsável pela seleção do grupo de alunos a representar o Brasil em olimpíadas internacionais. A segunda competição é a Olimpíada Brasileira de Matemática das Escolas Públicas (OBMEP), criada em 2005, exclusiva para alunos do ensino público, cuja repercussão atual tem sido bastante expressiva, uma vez que atingiu a marca de mais de 19 milhões de participantes em 99\% dos municípios brasileiros, fazendo dela a maior olimpíada de Matemática do mundo (DA SILVA, 2013).

Uma das contribuições da OBMEP para o país é que até 2011, a maioria dos alunos medalhistas brasileiros e que representavam o Brasil nas competições internacionais eram estudantes da rede particular de ensino. Poucos eram os que estudavam em escolas públicas, notadamente os alunos dos colégios militares. Com o advento da OBMEP, o Brasil teve em sua equipe de competidores da IMO, no ano de 2013, três participantes de escolas públicas não militares, que receberam 2 medalhas de prata e 1 de bronze, fato

2 A Olimpíada Paulista de Matemática é a mais antiga olimpíada do gênero no país. Sua primeira edição ocorreu em 1977, patrocinada pela Academia Paulista de Ciências (IMPA 2015 . 
bastante motivador para o ensino público no país (OBMEP, 2015).

Por sua dimensão e abrangência nacionais, a OBMEP foi classificada por MARANHÃO (2010) como uma das maiores iniciativas governamentais no processo ensino-aprendizagem de Matemática que foi capaz de melhorar a motivação, o interesse e desempenho dos alunos nas escolas públicas brasileiras.

Em 2011, o Centro de Gestão e Estudos Estratégicos (CGEE) ${ }^{3}$ avaliou os impactos da OBMEP após 5 anos de sua existência no Brasil, apresentando resultados bastante significativos na vida dos alunos, dos professores e das próprias escolas, que fizeram dessa competição uma olimpíada de Matemática mundialmente reconhecida (CGEE, 2011).

O CGEE entrevistou, ao todo, dez mil pessoas, entre alunos, professores, gestores, pais e responsáveis, em diversas partes do país. Dentre as conclusões dessa avaliação, vale destacar que (CGEE, 2011):

$\checkmark \quad$ o material didático distribuído às escolas (banco de questões e apostilas do Programa de Iniciação Científica), tanto para os alunos quanto para os professores, foi considerado importante, não apenas para a preparação olímpica, mas principalmente para o uso em sala de aula, por ser um material inovador, desafiador e que exige o raciocínio lógico dos alunos, fazendo muitos docentes repensarem suas práticas pedagógicas;

$\checkmark$ houve unanimidade sobre o alto nível de dificuldade das provas em relação ao nível de ensino-aprendizagem nas escolas, ficando claramente perceptível a baixa qualidade do ensino público atual;

$\checkmark$ ficou evidente, para os professores, que a olimpíada é um canal para a excelência na educação pública;

$\checkmark$ existem desigualdades entre o ensino das escolas públicas nas diferentes regiões do país, bem como entre as escolas federais, municipais e estaduais, com destaque positivo para os colégios militares; e

$\checkmark$ a valorização e o reconhecimento dos alunos premiados e dos professores participantes despertam o interesse pelo estudo da Matemática e também a melhora do ambiente de aprendizagem oferecido nas escolas.

Os fatores negativos apontados pela pesquisa concentraram-se no alto nível de exigência da prova frente à situação do ensino público na maioria das escolas, principalmente em relação ao conteúdo de Geometria. Entretanto, os diversos segmentos consultados relacionaram positivamente essa dificuldade como geradora de uma consequente e gradual melhoria da qualidade do ensino público (CGEE, 2011).

Por fim, a avaliação feita pelo CGEE serviu para refletir a importância das olimpíadas como um instrumento para o avanço da educação brasileira, pois se observou que (CGEE, 2011):

$\checkmark \quad 59 \%$ dos professores confirmaram que os alunos passaram a estudar mais Matemática após a participação na olimpíada;

3 O Centro de Gestão e Estudos Estratégicos (CGEE) é uma associação civil sem fins lucrativos e de interesse público, qualificada como Organização Social pelo executivo brasileiro, sob a supervisão do Ministério da Ciência e Tecnologia. Constitui-se em instituição de referência para o suporte contínuo de processos de tomada de decisão sobre políticas e programas de ciência, tecnologia e inovação (CT\&I) CGEE 2011]. 
$\checkmark 61 \%$ dos professores informaram que o desempenho dos alunos em Matemática, em sala de aula, melhorou;

$\checkmark \quad 69 \%$ dos alunos disseram que passaram a se interessar mais pela Matemática em decorrência de sua participação na competição;

$\checkmark \quad 74 \%$ dos pais e responsáveis responderam que os filhos passaram a estudar mais Matemática;

$\mathrm{e}$

$\checkmark \quad 78 \%$ dos pais responderam que o interesse dos filhos pela Matemática aumentou.

Além disso, em 2014, um estudo encomendado pelo IMPA à Universidade Federal de Minas Gerais (UFMG) mostrou que os estudantes que frequentam aulas preparatórias para a OBMEP em suas escolas obtêm, em média, 16 pontos a mais na prova de Matemática do Exame Nacional do Ensino Médio (ENEM) (TOKARNIA, 2014).

Diante do exposto, não há dúvidas de que a utilização das olimpíadas nas escolas e no ensino em geral da Matemática constitui um fator de estímulo ao estudo da disciplina entre os alunos; incentiva o aperfeiçoamento dos professores e sua valorização profissional; identifica jovens talentos, motivando-os ao ingresso nas áreas científicas e tecnológicas; e, acima de tudo, contribui para a melhoria da qualidade da educação no Brasil.

Conhecedor dessa realidade, o autor procurou trazer a público, no presente trabalho, a necessidade de se olhar para as competições matemáticas como uma importante alavanca pedagógica no processo de impulsionar o ensino da Matemática no âmbito nacional, escolhendo, em particular, a Geometria Plana, pela sua dificuldade entre os alunos, e o tema Colinearidade e Concorrência, pela sua expressiva incidência em problemas olímpicos a nível mundial.

\subsection{Os resultados observados na pesquisa}

Na pesquisa realizada, foi possível coletar, mediante o contato por email com dezenas de coordenadores de olimpíadas no mundo e por meio da busca nos sítios eletrônicos oficiais da Internet, o total de 283 provas aplicadas entre os anos de 2010 e 2014, contemplando 62 competições, em mais de 50 países, em todos os continentes. A distribuição dessas provas, por ano, é a seguinte: 2010 (58 provas); 2011 (59 provas); 2012 (59 provas); 2013 (56 provas); 2014 (51 provas).

Das 283 provas, 37\%, ou seja, 104 delas, continham pelo menos um problema envolvendo diretamente o tema Colinearidade ou Concorrência. Verificou-se que este percentual de incidência é aproximadamente regular a cada ano: 2010 (34\%); 2011 (41\%); 2012 (34\%); 2013 (46\%); 2014 (27\%) (ver Apêndice).

É importante citar que os problemas que envolviam este tema de uma forma indireta foram descartados pelo autor, bem como as provas encontradas em idiomas originais de difícil tradução (escritas não alfabéticas). Além disso, outras competições deixaram de ser analisadas pelo fato de o país não disponibilizar, por motivos diversos, as suas provas.

Das 104 provas contendo problemas sobre o tema, foi possível extrair 141 questões (73 sobre Coline- 
aridade e 68 sobre Concorrência), apresentadas pelo autor no Apêndice a este trabalho. Desse total, 7 (sete) problemas foram selecionados e resolvidos pelo autor no Capítulo 5. A seleção dessas questões baseou-se na diversidade das técnicas usadas para solucioná-las e na condição de pertencer a uma competição em que a participação de estudantes brasileiros fosse permitida.

No próximo capítulo, denominado "Fundamentação matemática" são apresentados uma série de conceitos matemáticos, muitos deles não presentes nos livros didáticos escolares, que ajudam a dar embasamento teórico aos professores e estudantes na preparação para as competições olímpicas, em especial, envolvendo o tema Colinearidade e Concorrência. Somente após isso, no Capítulo 5, esses conceitos serão aplicados na resolução dos problemas selecionados. 


\section{Fundamentação matemática}

“Todos nós sabemos alguma coisa. Todos nós ignoramos alguma coisa. Por isso, aprendemos sempre."

Paulo Freire

Neste capítulo serão apresentadas algumas definições, proposições, lemas, teoremas e corolários que ajudarão os estudantes na resolução de problemas olímpicos envolvendo o assunto Colinearidade e Concorrência. Para não torná-lo tão extenso, alguns pré-requisitos da Geometria Euclidiana, usuais no Ensino Fundamental ou Médio, deixarão de ser demonstrados propositalmente, uma vez que se considera o leitor conhecedor de tais conceitos, já bastante consolidados no meio matemático.

Definição 4.1 (Bissetriz). A bissetriz de um ângulo é uma semirreta interna com origem em seu vértice, que o divide em dois outros ângulos adjacentes e congruentes.

Proposição 4.1. A bissetriz de um ângulo é o lugar geométrico dos pontos que equidistam dos lados desse ângulo.

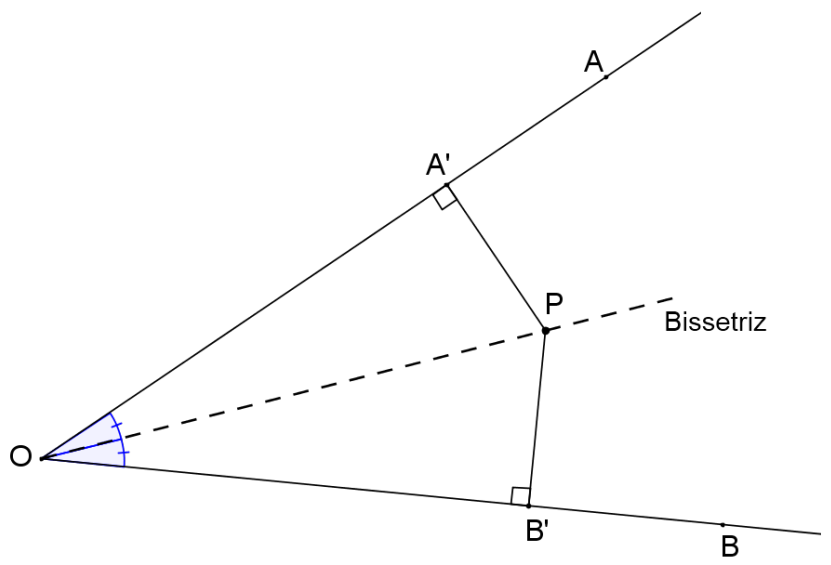

Figura 1 - Bissetriz como LG

Prova. Suponha inicialmente que $P$ pertença à bissetriz do ângulo $\angle A O B$. Sejam $A^{\prime}$ e $B^{\prime}$ os pés das perpendiculares baixadas de $P$ a cada um dos lados do referido ângulo (Figura[1]. Então, tem-se que os triângulos 
$O A^{\prime} P$ e $O B^{\prime} P$ são congruentes, uma vez que $\measuredangle A^{\prime} O P=\measuredangle B^{\prime} O P, \measuredangle O A^{\prime} P=\measuredangle O B^{\prime} P=90^{\circ}$ e $O P$ é lado comum aos triângulos. Portanto, $P A^{\prime}=P B^{\prime}$.

Reciprocamente, seja $P$ um ponto no interior do ângulo $\angle A O B$, tal que $P A^{\prime}=P B^{\prime}$, onde $A^{\prime}$ e $B^{\prime}$ são os pés das perpendiculares baixadas de $P$ aos lados desse ângulo. Então, tem-se que os triângulos retângulos $A^{\prime} O P$ e $B^{\prime} O P$ são congruentes, uma vez que possuem catetos congruentes $P A^{\prime}=P B^{\prime}$ e hipotenusa $O P$ como lado comum. Portanto, $\measuredangle A^{\prime} O P=\measuredangle B^{\prime} O P$ e $P$ pertence à bissetriz do ângulo $\angle A O B$.

Definição 4.2 (Mediatriz). A mediatriz de um segmento é a reta perpendicular a esse segmento e que contém o seu ponto médio.

Proposição 4.2. A mediatriz de um segmento é o lugar geométrico dos pontos que equidistam dos extremos desse segmento.

Prova. Seja $M$ o ponto médio do segmento $A B$ e $m$ a reta mediatriz desse segmento. Se $P$ é um ponto qualquer de $m$, então os triângulos retângulos $P M A$ e $P M B$ são congruentes, com catetos $M A=M B$ e $M P$ comum, logo, $P A=P B$ (Figura2).

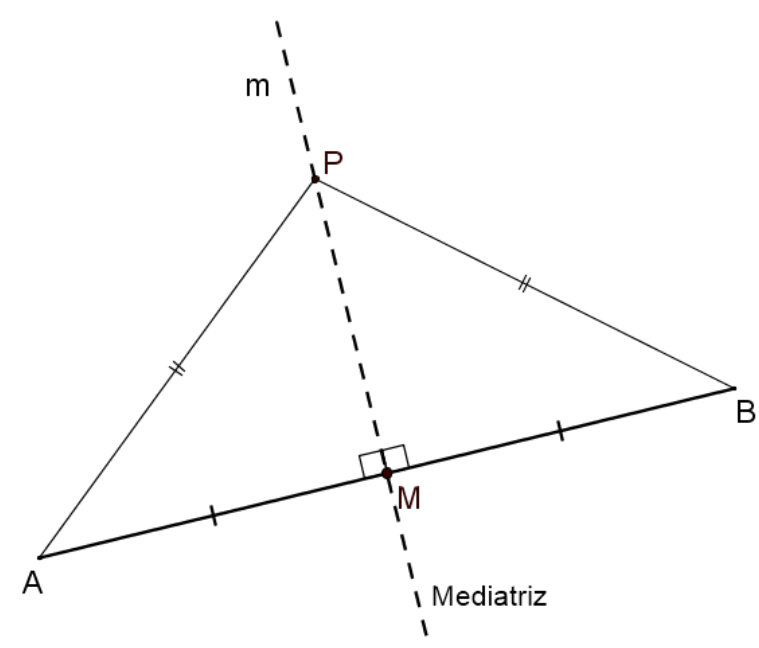

Figura 2 - Mediatriz como LG

Reciprocamente, seja $P$ um ponto no plano tal que $P A=P B$. Então, o triângulo $P A B$ é isósceles de base $A B$. Por este motivo, a altura $P M$, relativa à base $A B$, divide-a ao meio, e, portanto $P M$ é a mediatriz de $A B$.

Proposição 4.3. Sejam $P$ um ponto exterior a um círculo de centro $O$ e raio $r, P A$ e $P B$ as duas tangentes ao círculo traçadas a partir de P (Figura[3). Então,

(i) $P A=P B$;

(ii) $P O$ é bissetriz dos ângulos $\angle A O B$ e $\angle A P B$;

(iii) $P O$ é mediatriz da corda $A B$.

Prova. Como $O A=O B=r, \measuredangle P A O=\measuredangle P B O=90^{\circ}$ e $P O$ é lado (hipotenusa) comum dos triângulos retângulos $P A O$ e $P B O$, então tais triângulos são congruentes, com $P A=P B$. Além disso, nesses triângulos, 


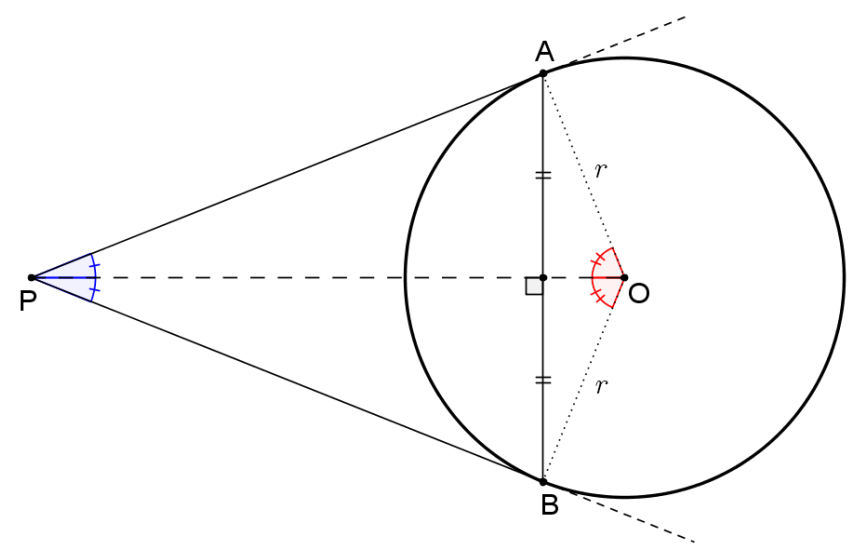

Figura 3 - Tangentes a um círculo traçadas a partir de um ponto exterior

$\measuredangle A P O=\measuredangle B P O$ e $\measuredangle A O P=\measuredangle B O P$ e, portanto, $P O$ é bissetriz dos ângulos $\angle A O B$ e $\angle A P B$. Ademais, uma vez que $P$ e $O$ são equidistantes dos pontos $A$ e $B, P O$ é altura dos triângulos isósceles $A P B$ e $A O B$, dividindo $A B$ ao meio. Assim, $P O$ é mediatriz da corda $A B$, passando por seu ponto médio.

Definição 4.3 (Mediana). A mediana de um triângulo é o segmento que possui uma extremidade em um dos vértices e a outra no ponto médio do lado oposto.

Proposição 4.4. Todo triângulo inscrito em um semicírculo é retângulo, com a hipotenusa sendo o diâmetro e a mediana relativa à hipotenusa tendo comprimento igual ao raio do círculo circunscrito ao triângulo (circuncírculo).

Prova. Sejam $A B C$ um triângulo retângulo em $A$ e $\Gamma$ o seu circuncírculo de raio $r$. Como o ângulo inscrito $\measuredangle B A C=90^{\circ}$, então o arco $\widetilde{B C}$, que não contém $A$, mede $180^{\circ}$, fazendo de $B C$ o diâmetro de $\Gamma$. Se $O$ é o centro do círculo $\Gamma$, então $O$ é médio de $B C$ e $A O$ é o raio de $\Gamma$ e também a mediana do triângulo $A B C$ $(A O=B O=C O=r)($ Figura 4$)$.

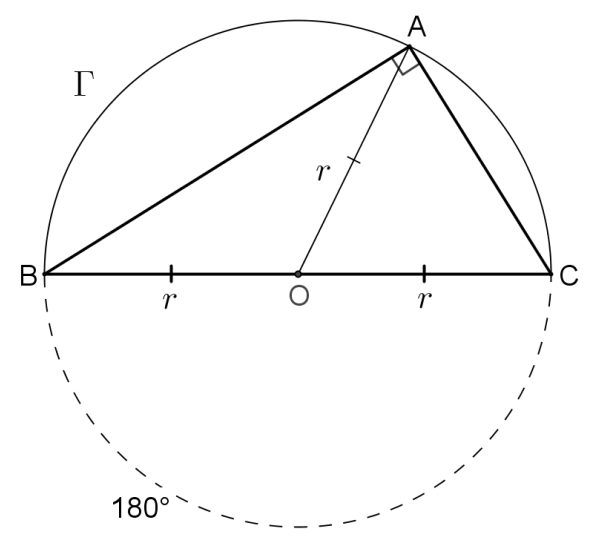

Figura 4 - Triângulo retângulo inscrito em um semicírculo

Nota: O arco $B \widehat{A} C$ é chamado arco-capaz da corda $B C$ (ou do ângulo $\angle A$ ), pois qualquer ponto genérico $A$ deste arco estabelece um ângulo de medida constante $\measuredangle B A C=90^{\circ}$. 
Definição 4.4 (Bissetriz interna). A bissetriz interna de um triângulo é o segmento que possui uma extremidade em um dos vértices e a outra no lado oposto, e que divide o ângulo interno desse vértice em dois ângulos adjacentes e congruentes.

Definição 4.5 (Bissetriz externa). A bissetriz externa de um triângulo é o segmento que possui uma extremidade em um dos vértices e a outra no prolongamento do lado oposto, e que divide o ângulo externo desse vértice em dois ângulos adjacentes e congruentes.

Proposição 4.5. A bissetriz interna e a bissetriz externa relativas a um vértice de um triângulo são perpendiculares entre si.

Prova. Seja $A B C$ um triângulo e sejam $A D$ e $A E$ suas bissetrizes interna e externa, respectivamente. Chamando $\measuredangle B A C=2 \theta$, tem-se $\measuredangle B A D=\measuredangle D A C=\theta$. Além disso, $\measuredangle C A F=180^{\circ}-2 \theta$, donde $\measuredangle C A E=\measuredangle E A F=$ $\frac{180^{\circ}-2 \theta}{2}=90^{\circ}-\theta$ (Figura 5 .

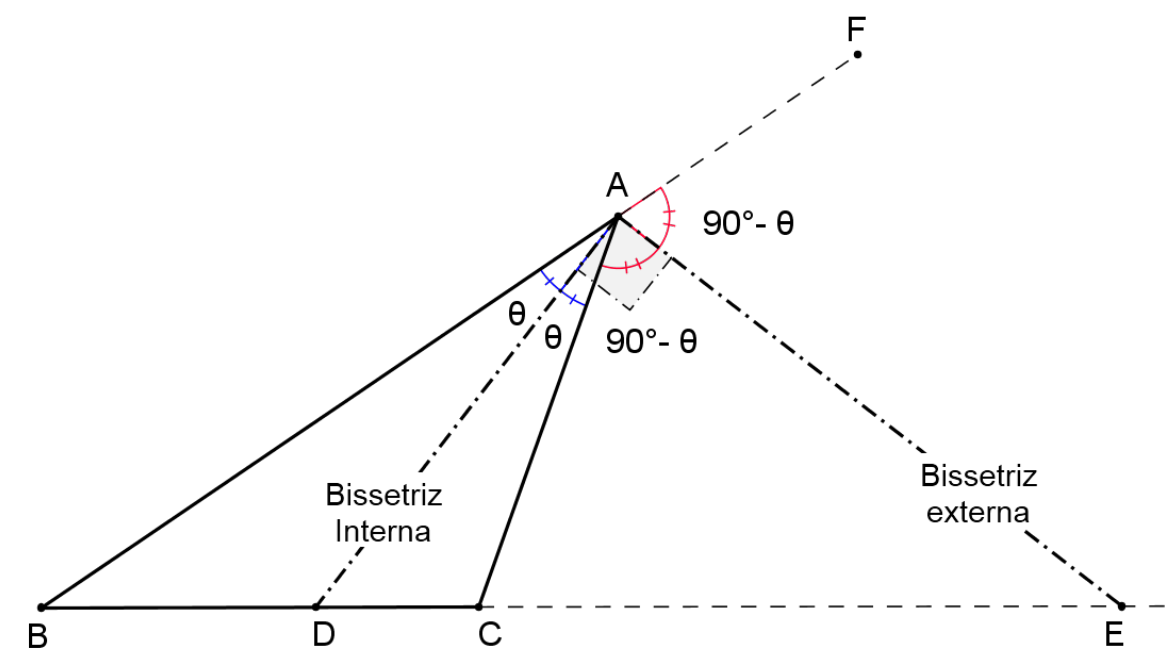

Figura 5 - Perpendicularidade entre as bissetrizes interna e externa de um triângulo

Portanto, $\measuredangle D A E=\measuredangle D A C+\measuredangle C A E=\theta+90^{\circ}-\theta=90^{\circ}$, ou seja, $A D \perp A E$.

Proposição 4.6. O ângulo formado entre duas bissetrizes internas de um triângulo é igual a um reto mais a metade do terceiro ângulo desse triângulo.

Prova. Seja $I$ o ponto de interseção das bissetrizes internas dos ângulos $\angle A B C$ e $\angle A C B$ do triângulo $A B C$ (Figura6).

No triângulo $B I C$, tem-se

$$
\begin{gathered}
\measuredangle B I C=180^{\circ}-\left(\frac{\measuredangle A B C}{2}+\frac{\measuredangle A C B}{2}\right) \\
\measuredangle B I C=\frac{360^{\circ}-(\measuredangle A B C+\measuredangle A C B)}{2} \\
\measuredangle B I C=\frac{360^{\circ}-\left(180^{\circ}-\measuredangle B A C\right)}{2}=\frac{180^{\circ}+\measuredangle B A C}{2} \\
\measuredangle B I C=90^{\circ}+\frac{\measuredangle B A C}{2} .
\end{gathered}
$$




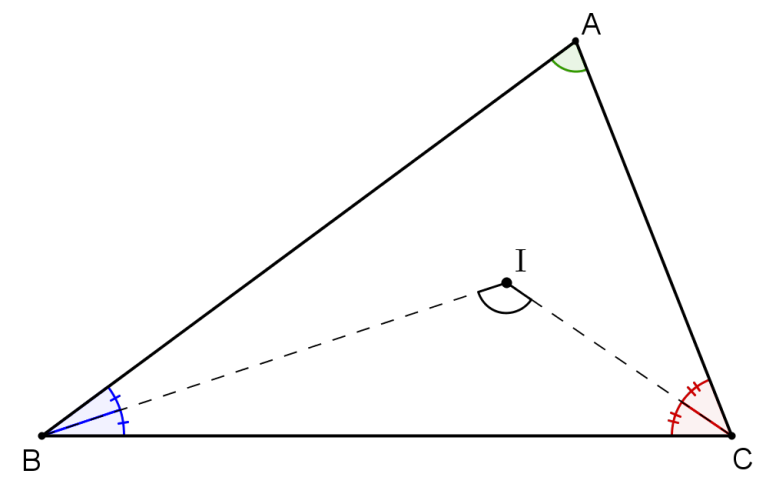

Figura 6 - Ângulo entre duas bissetrizes internas de um triângulo

Proposição 4.7. O ângulo formado entre duas bissetrizes externas de um triângulo é igual a um reto menos a metade do terceiro ângulo desse triângulo.

Prova. Seja $I_{A}$ o ponto de interseção das bissetrizes externas dos ângulos $\angle A B C$ e $\angle A C B$ do triângulo $A B C$ (Figura7).

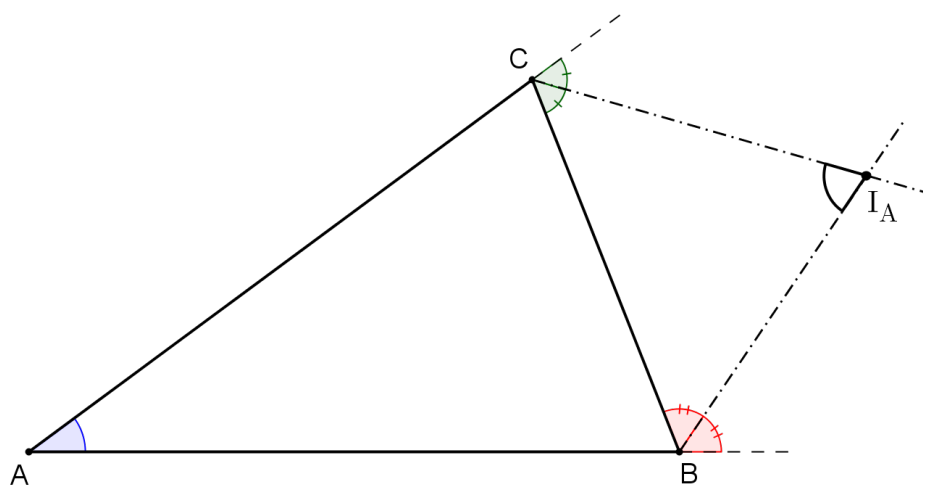

Figura 7 - Ângulo entre duas bissetrizes externas de um triângulo

No triângulo $B I_{A} C$, tem-se $\measuredangle B I_{A} C=180^{\circ}-\left(\measuredangle B C I_{A}+\measuredangle C B I_{A}\right)$.

Mas, $\measuredangle B C I_{A}=\frac{180^{\circ}-\measuredangle A C B}{2}=90^{\circ}-\frac{\measuredangle A C B}{2}$ e $\measuredangle C B I_{A}=\frac{180^{\circ}-\measuredangle A B C}{2}=90^{\circ}-\frac{\measuredangle A B C}{2}$.

Logo,

$$
\begin{gathered}
\measuredangle B I_{A} C=180^{\circ}-\left(90^{\circ}-\frac{\measuredangle A C B}{2}+90^{\circ}-\frac{\measuredangle A B C}{2}\right) \\
\measuredangle B I_{A} C=\frac{\measuredangle A C B+\measuredangle A B C}{2}=\frac{180^{\circ}-\measuredangle B A C}{2} \\
\measuredangle B I_{A} C=90^{\circ}-\frac{\measuredangle B A C}{2} .
\end{gathered}
$$

Proposição 4.8. O ângulo formado entre uma bissetriz interna e uma bissetriz externa, relativas a vértices distintos de um triângulo, é igual à metade do terceiro ângulo desse triângulo. 
Prova. Seja $I_{B}$ o ponto de interseção da bissetriz interna do ângulo $\angle A B C$ com a bissetriz externa do ângulo $\angle A C B$ do triângulo $A B C$ (Figura 8 .

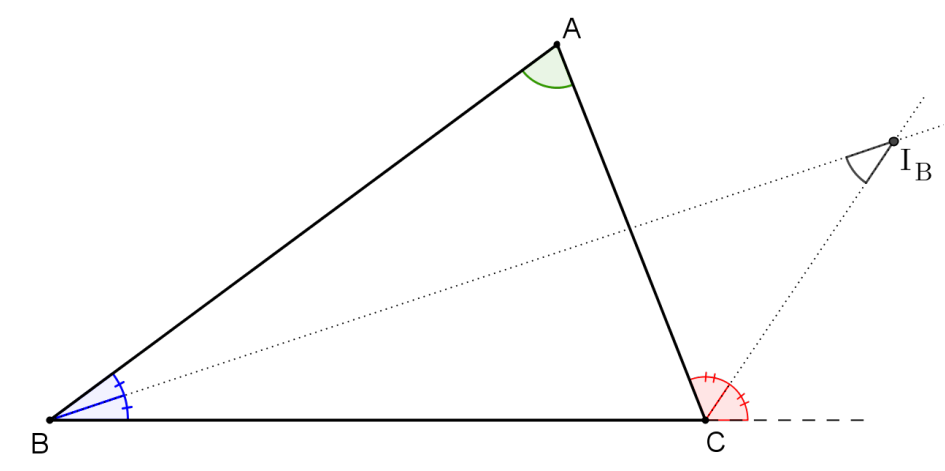

Figura 8 - Ângulo entre bissetriz interna e bissetriz externa relativas a vértices distintos

No triângulo $B I_{B} C$, tem-se

$$
\begin{gathered}
\measuredangle B I_{B} C=180^{\circ}-\left(\frac{\measuredangle A B C}{2}+\measuredangle A C B+\frac{180^{\circ}-\measuredangle A C B}{2}\right) \\
\measuredangle B I_{B} C=90^{\circ}-\frac{\measuredangle A B C}{2}-\frac{\measuredangle A C B}{2} \\
\measuredangle B I_{B} C=90^{\circ}-\left(\frac{\measuredangle A B C+\measuredangle A C B}{2}\right) \\
\measuredangle B I_{B} C=90^{\circ}-\left(\frac{180^{\circ}-\measuredangle B A C}{2}\right) \\
\measuredangle B I_{B} C=\frac{\measuredangle B A C}{2} .
\end{gathered}
$$

Teorema 4.1 (Incentro). As bissetrizes internas de um triângulo são concorrentes em um ponto I, denominado Incentro, que é o centro do círculo inscrito nesse triângulo (incírculo).

Demonstração. Sejam $A D, B E$ e $C F$ as bissetrizes internas do triângulo $A B C$. Seja $I$ o ponto de interseção de $B E$ e $C F$. Assim, tem-se que $I$, por estar sobre $B E$ é equidistante dos lados $A B$ e $B C$, e por estar sobre $C F$ é equidistante dos lados $B C$ e $A C$. Consequentemente, $I$ é equidistante dos lados $A B$ e $A C$, e, desse modo, também está sobre a bissetriz $A D$ (Figura9).

Ademais, se $I$ é equidistante dos lados do triângulo $A B C$, sejam $L, M$ e $N$ os pés das perpendiculares baixadas de $I$ até os lados do triângulo. Dessa forma, existe um círculo (incírculo) com centro em $I$ (incentro), que passa pelos pontos $L, M$ e $N$, cujo raio é dado por $r=I L=I M=I N$ e está inscrito no triângulo $A B C$.

Proposição 4.9. A área de um triângulo é igual ao produto do seu semiperímetro pelo raio do seu incírculo.

Prova. Sejam $p$ o semiperímetro do triângulo $A B C$ e sejam $L, M$ e $N$ os pés das perpendiculares baixadas do seu incentro $I$ até os lados do triângulo (Figura9). Dessa forma, o raio do incírculo de $A B C$ é igual a $r=I L=I M=I N$.

A área de $A B C$ pode ser dada pela soma das áreas dos triângulos $B I C, C I A$ e $A I B$, ou seja, 


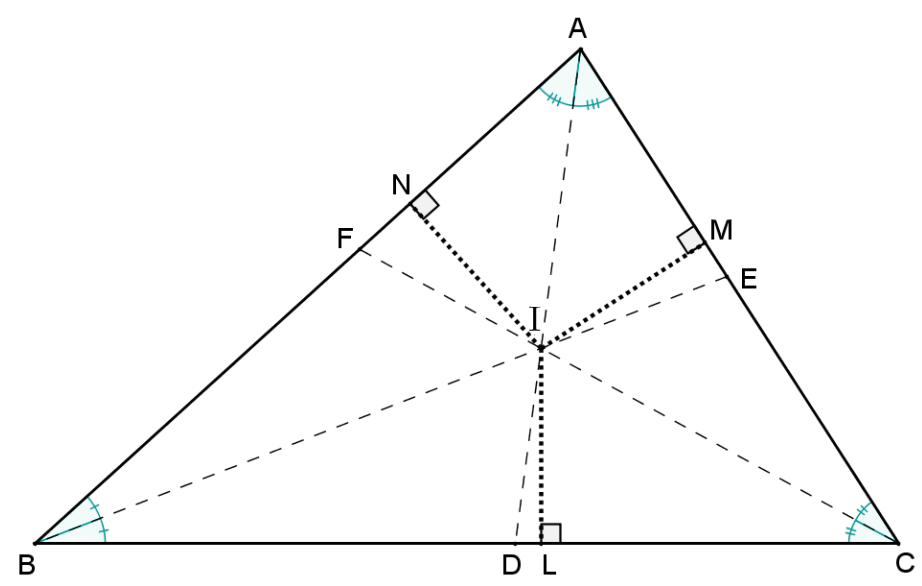

Figura 9 - Incentro de um triângulo

$$
\begin{gathered}
{[A B C]=[B I C]+[C I A]+[A I B]} \\
{[A B C]=\frac{B C \cdot I L}{2}+\frac{A C \cdot I M}{2}+\frac{A B \cdot I N}{2}} \\
{[A B C]=\frac{B C \cdot r}{2}+\frac{A C \cdot r}{2}+\frac{A B \cdot r}{2}} \\
{[A B C]=\left(\frac{B C+A C+A B}{2}\right) \cdot r} \\
{[A B C]=p \cdot r .}
\end{gathered}
$$

Teorema 4.2 (Circuncentro). As três mediatrizes de um triângulo se encontram em um único ponto O, chamado Circuncentro, que é o centro do circuncírculo desse triângulo.

Demonstração. Sejam $u, v$ e $w$, respectivamente, as mediatrizes relativas aos lados $A B, B C$ e $A C$ do triângulo $A B C$, e $L, M$ e $N$ os respectivos pontos médios desses lados (Figura 10 ).

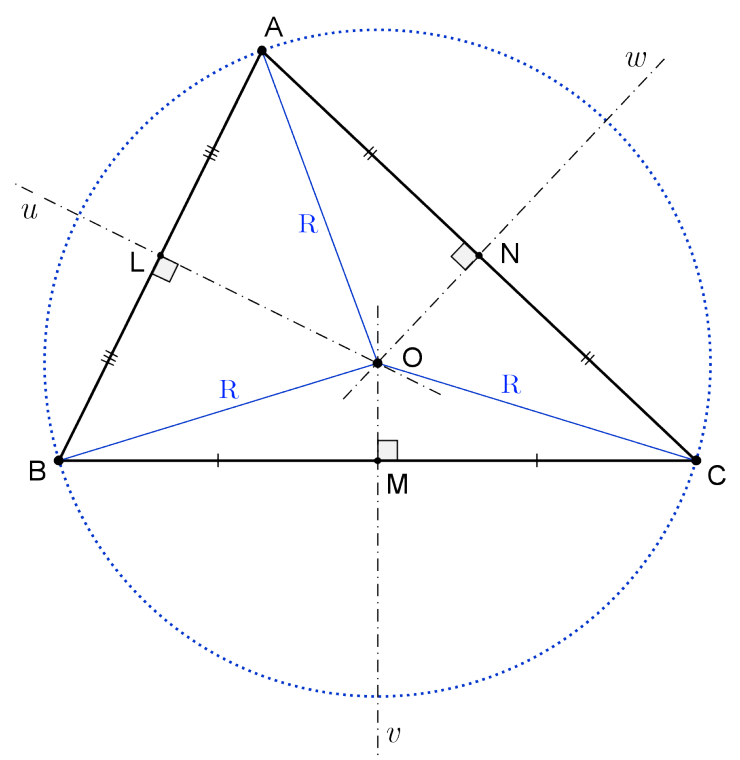

Figura 10 - Circuncentro de um triângulo 
Seja $O$, inicialmente, o ponto de encontro de $u$ e $w$. Como $O$ está sobre essas mediatrizes, tem-se, pela Proposição 4.2 , que

$$
\left\{\begin{array}{l}
O A=O B \\
O A=O C
\end{array} \quad \Rightarrow \quad O A=O B=O C=R\right. \text { (raio). }
$$

Com isso, conclui-se que $O$ é equidistante dos vértices $A, B$ e $C$ e, portanto, $O$ é centro do circuncírculo do triângulo $A B C$, de raio $R$.

Como o raio $R$ do circuncírculo do triângulo $A B C$ corta a corda $B C$ no seu ponto médio $M$, sob um ângulo reto (ver Proposição 4.3 , conclui-se que $O M$ está contido na mediatriz $v$ de $B C$. Assim, as três mediatrizes concorrem no ponto $O$ (Figura 10 .

FEITOSA (2013) demonstra a concorrência das mediatrizes no circuncentro de um triângulo utilizando números complexos.

Definição 4.6 (Exincírculo). O círculo tangente internamente aos prolongamentos dos lados $A B$ e $A C$ e tangente externamente ao terceiro lado $B C$ de um triângulo $A B C$ é chamado círculo exinscrito (ou exincírculo) relativo ao lado BC (ou ao vértice A) do triângulo.

Teorema 4.3 (Exincentro). O centro $I_{A}$ do exincírculo relativo ao lado BC (ou ao vértice A) de um triângulo $A B C$, é chamado Exincentro e é o ponto de interseção das bissetrizes externas dos ângulos $\angle B$ e $\angle C$ e da bissetriz interna do ângulo $\angle A$ do triângulo.

Demonstração. Sejam $b$ e $c$ as bissetrizes externas dos ângulos $\angle B$ e $\angle C$, respectivamente, e $I_{A}$ o ponto de interseção entre elas. Como $I_{A} \in b, I_{A}$ é equidistante dos lados $A B$ e $B C$; e como $I_{A} \in c, I_{A}$ é equidistante de $A C$ e $B C$. Assim, $I_{A}$ é equidistante de $A B$ e $A C$, e, portanto, pertence à bissetriz interna $a$ do ângulo $\angle A$ $\left(I_{A} \in a\right)$ (Figura 11$)$.

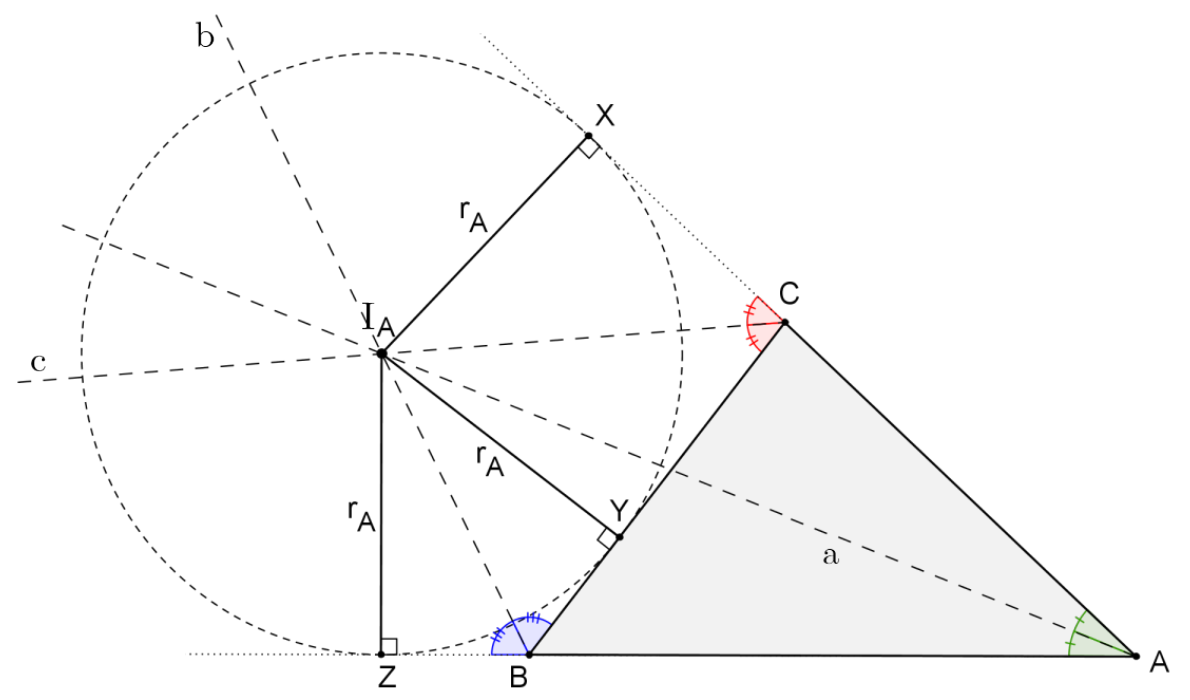

Figura 11 - Exincentro de um triângulo

Sejam $X, Y$ e $Z$ os pés das perpendiculares baixadas de $I_{A}$ a cada um dos lados do triângulo $A B C$ ou seus prolongamentos (Figura 11). Denotando por $r_{A}$ a distância comum entre $I_{A}$ e os lados do triângulo, 
existe um círculo (exincírculo) com centro em $I_{A}$ (exincentro) de raio $r_{A}=I_{A} X=I_{A} Y=I_{A} Z$, tangente ao lado $B C$ e aos prolongamentos dos lados $A B$ e $A C$ (Figura 11 ).

Nota: Todo triângulo admite exatamente três exincírculos.

Definição 4.7 (Divisão de um segmento interiormente). Diz-se que o ponto $M$ divide interiormente um segmento $A B$ na razão $k(k>0)$ quando $M$ é interior ao segmento $\frac{M A}{M B}=k$ (Figura 12 ).

Definição 4.8 (Divisão de um segmento exteriormente). Diz-se que o ponto $N$ divide exteriormente um segmento $A B$ na razão $k(k>0)$ quando $N$ é exterior ao segmento e $\frac{N A}{N B}=k$ (Figura 12 ).

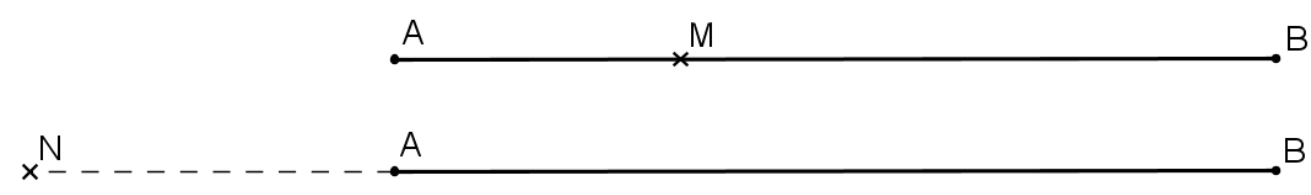

Figura 12 - Divisão de um segmento por um ponto

Nota: Observa-se que para $k=1$, o ponto $N$, exterior ao segmento $A B$, é um ponto no infinito (ponto impróprio).

Proposição 4.10 (Unicidade). Dado um segmento $A B$ e uma razão $k$, existe apenas um ponto $M$ que divide interiormente e apenas um ponto $N$ que divide exteriormente esse segmento nessa razão.

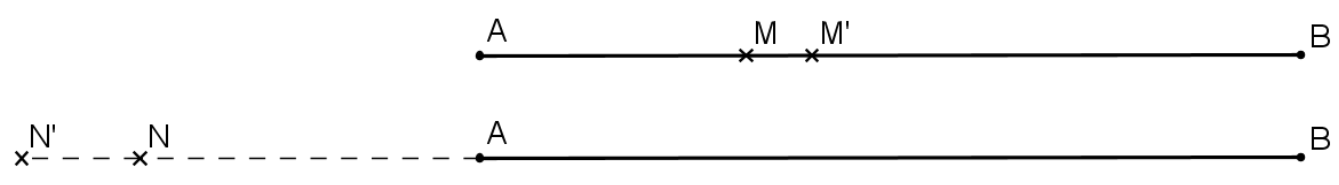

Figura 13 - Prova da unicidade na divisão de um segmento por um ponto

Prova. Considere inicialmente que exista um ponto $M^{\prime}$ que divida $A B$ interiormente na mesma razão $k$ que o ponto $M$, também interior ao segmento (Figura 13 ). Assim, $k=\frac{M A}{M B}=\frac{M^{\prime} A}{M^{\prime} B}$.

Aplicando as propriedades das proporções, tem-se

$$
\begin{aligned}
\frac{M A+M B}{M B} & =\frac{M^{\prime} A+M^{\prime} B}{M^{\prime} B} \\
\frac{A B}{M B} & =\frac{A B}{M^{\prime} B} \\
M B & =M^{\prime} B \\
M & \equiv M^{\prime} .
\end{aligned}
$$

Analogamente, considere que exista um ponto $N^{\prime}$ que divida $A B$ exteriormente na mesma razão $k$ que o ponto $N$, também exterior ao segmento (Figura 13. Assim, $k=\frac{N A}{N B}=\frac{N^{\prime} A}{N^{\prime} B}$.

Aplicando, mais uma vez, as propriedades das proporções, tem-se 


$$
\begin{aligned}
\frac{N B-N A}{N B} & =\frac{N^{\prime} B-N^{\prime} A}{N^{\prime} B} \\
\frac{A B}{N B} & =\frac{A B}{N^{\prime} B} \\
N B & =N^{\prime} B \\
N & \equiv N^{\prime} .
\end{aligned}
$$

Portanto, conclui-se que os pontos $M$ e $N$ são únicos.

Definição 4.9 (Divisão harmônica). Quando um segmento $A B$ está dividido por dois pontos $M$ (interiormente) e $N$ (exteriormente), na mesma razão $k$, diz-se que o segmento está dividido harmonicamente. Os pontos $M$ e $N$ são chamados conjugados harmônicos de $A B$ na razão $k$, e a sequência de pontos $(N, A, M, B)$ forma uma quádrupla harmônica, com $\frac{M A}{M B}=\frac{N A}{N B}=k$ (Figura 14.

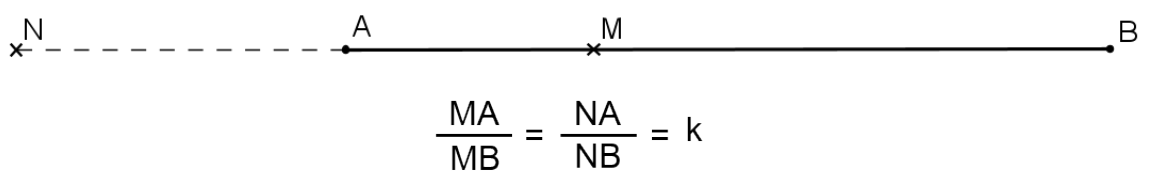

Figura 14 - Divisão harmônica

Nota: As configurações para $k$, razão da divisão harmônica, são mostradas na Figura 15 .

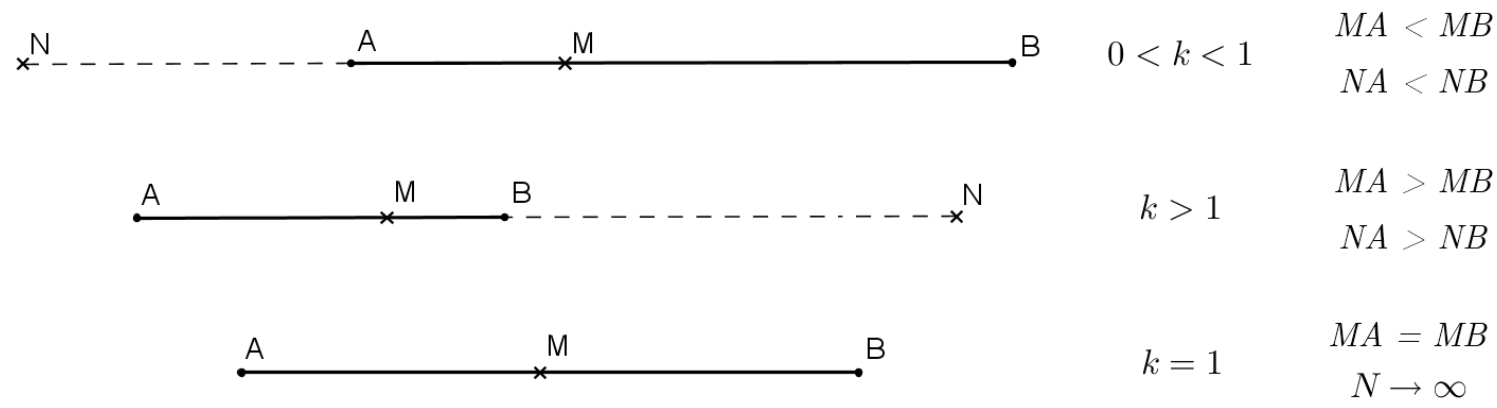

Figura 15 - Configurações para a razão da divisão harmônica

Proposição 4.11. A distância entre dois conjugados harmônicos de um segmento é igual à média harmônica entre as distâncias do ponto divisor exterior a cada um dos extremos do segmento.

Prova. Considere inicialmente o segmento $A B$ dividido harmonicamente pelos pontos $M$ (interior) e $N$ (exterior), na razão $\frac{M A}{M B}=\frac{N A}{N B}=k, \operatorname{com} k>1$ (Figura 15). Assim,

$$
\begin{gathered}
\frac{M A}{M B}=\frac{A B-M B}{M B}=\frac{A B}{M B}-1=\frac{N A-N B}{M B}-1=\frac{N A}{N B} \\
\frac{N A-N B}{M B}=\frac{N A}{N B}+1 \\
M B=\frac{N A-N B}{\frac{N A}{N B}+1}=\frac{N B \cdot(N A-N B)}{N A+N B} .
\end{gathered}
$$


Como $M N=M B+N B$ (Figura[15), então

$$
\begin{gathered}
M N=M B+N B=\frac{N B \cdot(N A-N B)}{N A+N B}+N B \\
M N=\frac{N B \cdot(N A-N B)+N B \cdot(N A+N B)}{N A+N B} \\
M N=\frac{2 \cdot N A \cdot N B}{N A+N B} \quad(\text { razão harmônica entre } N A \text { e } N B) .
\end{gathered}
$$

Analogamente, considerando-se o caso em que $0<k<1$, chega-se ao mesmo resultado ${ }^{1}$ o caso em que $k=1$ é um caso especial, pois o ponto $N$ sendo impróprio, implica que a distância $M N$ é infinita.

Corolário 4.1. Se os pontos $M$ e $N$ dividem harmonicamente o segmento AB, então os pontos $A$ e $B$ também dividem harmonicamente o segmento $M N$.

Prova. De fato, basta permutar, simplesmente, os meios ou os extremos da proporção. Se $\frac{M A}{M B}=\frac{N A}{N B}$, então $\frac{A N}{A M}=\frac{B N}{B M}$.

Novamente, um caso especial ocorre se $M$ é médio de $A B$, donde $k=1$ e $N$ tende ao infinito (impróprio).

Teorema 4.4. Se O é o ponto médio do segmento $A B$, e $M$ e $N$ pontos que o dividem harmonicamente, então $O A \cdot O B=O M \cdot O N$.

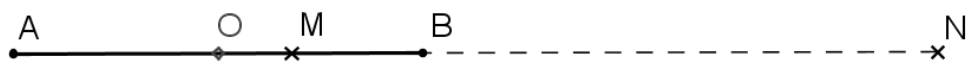

Figura 16 - Relação do ponto médio

Demonstração. Sem perda de generalidade, $\operatorname{com} O, A, B, M$ e $N$ distintos, considere a Figura 16 , em que a razão harmônica é igual a $k>1$. Assim,

$$
\begin{aligned}
\frac{M A}{M B} & =\frac{N A}{N B} \\
\frac{O M+O A}{O B-O M} & =\frac{O N+O A}{O N-O B} \\
(O M+O A)(O N-O B) & =(O N+O A)(O B-O M) \\
O M \cdot O N-O B \cdot O M+O A \cdot O N-O A \cdot O B & =O B \cdot O N-O M \cdot O N+O A \cdot O B-O A \cdot O M .
\end{aligned}
$$

Como $O A=O B$, a equação reduz-se a

$$
\begin{aligned}
O M \cdot O N-O A \cdot O B & =-O M \cdot O N+O A \cdot O B \\
O A \cdot O B & =O M \cdot O N .
\end{aligned}
$$

Analogamente, considerando-se o caso em que $0<k<1$, chega-se ao mesmo resultado.

1 Essa segunda parte da prova será deixada a cargo do leitor. 
Nota: Pela sequência de raciocínio desenvolvida, é fácil observar que a recíproca desse teorema também é válida, ou seja, se $O$ é o ponto médio do segmento $A B$ e $O A \cdot O B=O M \cdot O N$, então $M$ e $N$ são pontos que dividem harmonicamente o segmento $A B{ }^{2}$

Teorema 4.5 (Bissetrizes). As bissetrizes interna e externa de um triângulo dividem o lado oposto em partes proporcionais aos lados adjacentes.

Demonstração. Seja $A D$ a bissetriz interna e $A D^{\prime}$ a bissetriz externa relativas ao ângulo $\angle A$ do triângulo $A B C$.

(i) Bissetriz Interna:

Traçando-se $C E$, paralela a $A D$, tem-se $\measuredangle B E C=\measuredangle B A D=\measuredangle D A C=\measuredangle E C A$ (Figura 17). Assim, o triângulo $E C A$ é isósceles, com $A C=A E$.

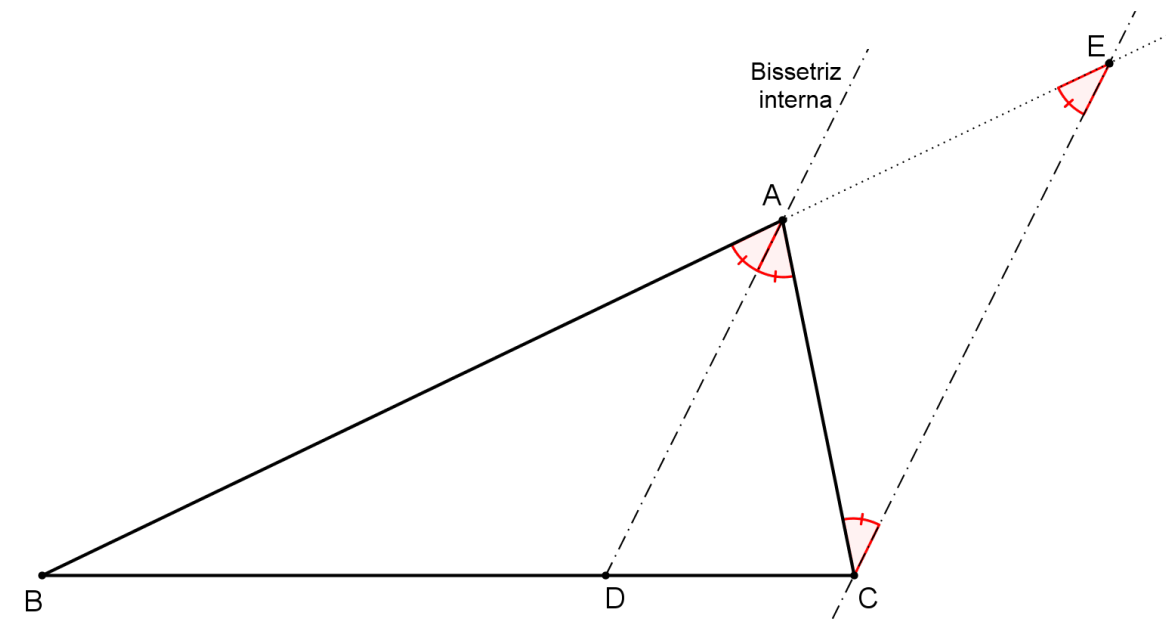

Figura 17 - Teorema da bissetriz interna

Pela Lei de Proporcionalidade de Tales $3^{3} \frac{B A}{B D}=\frac{A E}{D C}$, ou seja, $\frac{A B}{B D}=\frac{A C}{C D}$.

\section{(ii) Bissetriz Externa:}

Traçando-se $C E^{\prime}$, paralela a $A D^{\prime}$, tem-se $\measuredangle C E^{\prime} A=\measuredangle D^{\prime} A E=\measuredangle D^{\prime} A C=\measuredangle E^{\prime} C A$ (Figura 18). Assim, o triângulo $E^{\prime} C A$ é isósceles, com $A C=A E^{\prime}$.

Pela Lei de Proporcionalidade de Tales, $\frac{B A}{B D^{\prime}}=\frac{E^{\prime} A}{C D^{\prime}}$, ou seja, $\frac{A B}{B D^{\prime}}=\frac{A C}{C D^{\prime}}$.

Nota: É importante observar que se o triângulo for isósceles, o teorema da bissetriz externa fica comprometido quando aplicado ao vértice de ângulo desigual, uma vez que essa bissetriz externa será paralela à base do triângulo. No caso de o triângulo ser equilátero, esse fato ocorre para todos os vértices.

Corolário 4.2 (Divisão harmônica pelos pés das bissetrizes). Os pés das bissetrizes interna e externa relativas a um vértice de um triângulo dividem o lado oposto harmonicamente, na mesma razão dos lados adjacentes.

2 A demonstração da recíproca do teorema será deixada a cargo do leitor.

3 Tales de Mileto foi um matemático grego que viveu no Séc. VII a.C. Sua Lei ou Teorema de Proporcionalidade diz que quando duas retas secantes interceptam um feixe de retas paralelas, os segmentos correspondentes determinados são proporcionais. 


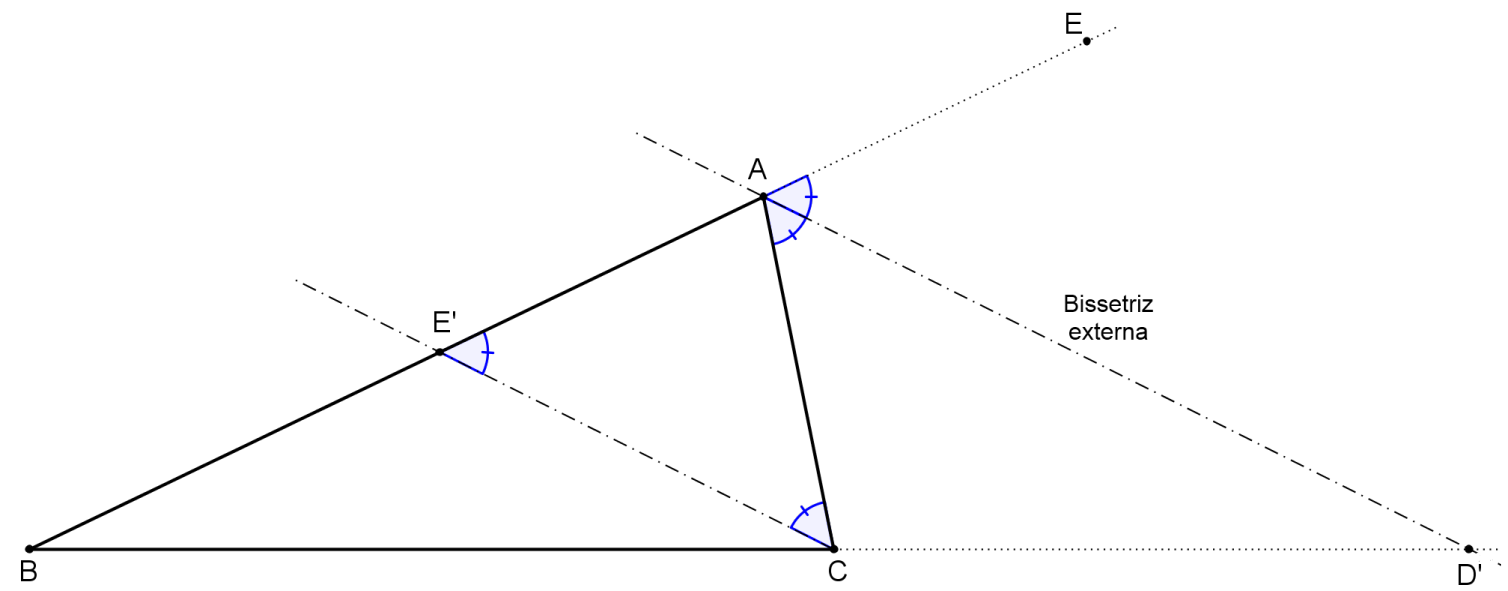

Figura 18 - Teorema da bissetriz externa

Prova. Sejam $k=\frac{A B}{A C}$ a razão dos lados do triângulo escaleno $A B C$ que concorrem no vértice $A$ e $A D$ e $A D^{\prime}$ as suas bissetrizes interna e externa, respectivamente, relativas ao ângulo $\angle A$.

Pelo Teorema 4.5 tem-se que $k=\frac{A B}{A C}=\frac{B D}{D C}$ e, ao mesmo tempo, $k=\frac{A B}{A C}=\frac{B D^{\prime}}{D^{\prime} C}$. Portanto, $k=$ $\frac{D B}{D C}=\frac{D^{\prime} B}{D^{\prime} C}$, o que mostra que os pontos $D$ e $D^{\prime}$ dividem harmonicamente o lado $B C$ do triângulo $A B C$ na razão $k$.

Nota: Observa-se que no caso de o triângulo ser isósceles ou equilátero, o teorema continua válido, com o pé da bissetriz interna sendo o ponto médio da base $(k=1)$ e o pé da bissetriz externa tendendo ao infinito (impróprio), conforme a Figura 15.

Teorema 4.6 (Recíproco das bissetrizes). Sejam $D$ e $D^{\prime}$ pontos sobre a reta que contém o lado $B C$ de um triângulo $A B C$, tais que $D$ é interior e $D^{\prime}$ é exterior a $B C$. Se $\measuredangle D A D^{\prime}=90^{\circ}$ e $\frac{D B}{D C}=\frac{D^{\prime} B}{D^{\prime} C}$ (isto é, $D$ e $D^{\prime}$ dividem harmonicamente $B C$ ), então $A D$ é bissetriz interna e $A D^{\prime}$ é bissetriz externa relativas ao ângulo $\angle A$ do triângulo $A B C$.

Demonstração. Traçando por $D$ uma paralela à reta $A D^{\prime}$, sejam $P$ e $Q$ seus pontos de interseção com os lados $A B$ e $A C$, respectivamente (Figura 19 ).

Com isso, tem-se as seguintes semelhanças de triângulos:

$$
\begin{aligned}
& \triangle P B D \sim \triangle A B D^{\prime} \quad \Rightarrow \quad \frac{D B}{D^{\prime} B}=\frac{P D}{A D^{\prime}} \mathrm{e} \\
& \triangle C D Q \sim \triangle C D^{\prime} A \quad \Rightarrow \quad \frac{C D}{C D^{\prime}}=\frac{D Q}{D^{\prime} A} .
\end{aligned}
$$

Uma vez que, por hipótese, $\frac{D B}{D C}=\frac{D^{\prime} B}{D^{\prime} C}$ ou $\frac{D B}{D^{\prime} B}=\frac{D C}{D^{\prime} C}$, de (1) e (2) decorre que

$$
\begin{aligned}
\frac{P D}{A D^{\prime}} & =\frac{D Q}{D^{\prime} A} \\
P D & =D Q .
\end{aligned}
$$




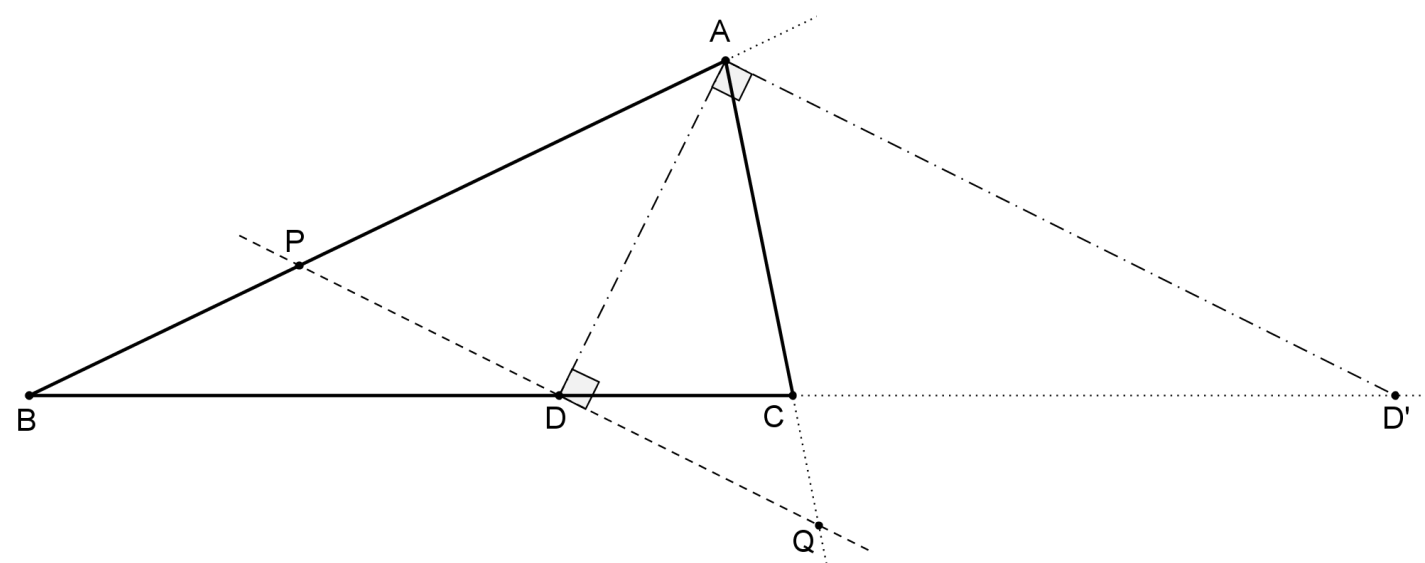

Figura 19 - Recíproca do teorema das bissetrizes

Logo, o ponto $D$ é médio de $P Q$. Como $P Q \| A D^{\prime}$ e $D A \perp A D^{\prime}$, então $A D \perp P Q$ (Figura19).

Assim, $A D$ é mediana e altura do triângulo $P A Q$ que, por sua vez, é isósceles. Desse modo, $A D$ também é bissetriz de $\angle P A Q=\angle B A C$.

Finalmente, se $A D$ é a bissetriz interna do triângulo $A B C$ e, por hipótese, $A D^{\prime} \perp A D\left(\measuredangle D A D^{\prime}=90^{\circ}\right)$, então, pela Proposição $4.5, A D^{\prime}$ é a bissetriz externa do triângulo $A B C$.

Proposição 4.12 (Divisão harmônica pelo Incentro e Exincentro). O incentro e o exincentro relativo a um vértice de um triângulo dividem harmonicamente a bissetriz interna relativa a esse mesmo vértice.

Prova. Sejam $A D$ e $C F$ duas bissetrizes internas do triângulo $A B C$. Sejam ainda $I$ o incentro e $I_{A}$ o exincentro relativo ao vértice $A$ desse triângulo (Figura 20).

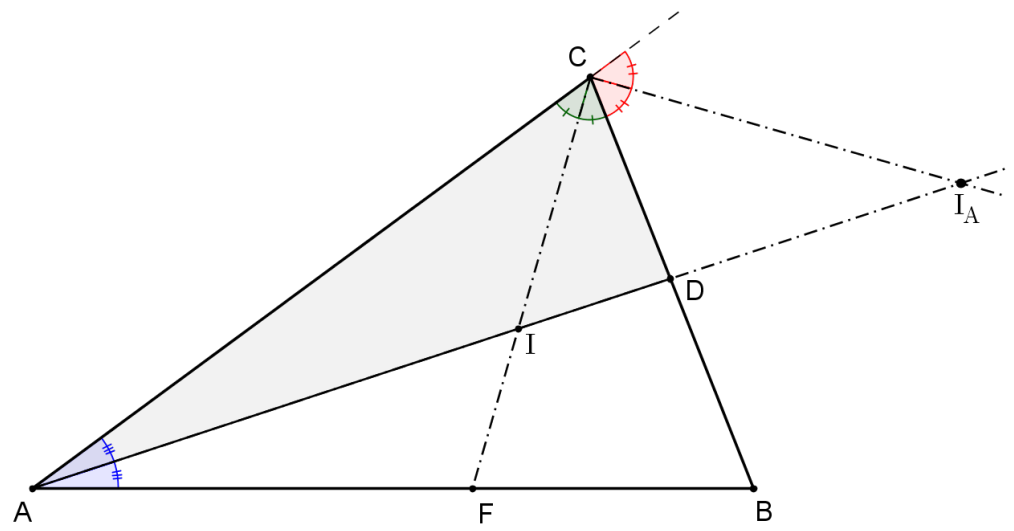

Figura 20 - Divisão harmônica pelo incentro e exincentro

Observando o triângulo $A C D$, tem-se que $C I$ é sua bissetriz interna e $C I_{A}$ é sua bissetriz externa relativas ao vértice $C$ (Figura 20. Portanto, pelo Teorema 4.5 aplicado nesse triângulo, tem-se

$$
\begin{aligned}
& \frac{C A}{I A}=\frac{C D}{I D} \text { ou } \frac{C A}{C D}=\frac{I A}{I D} \\
& \text { e } \\
& \frac{C A}{I_{A} A}=\frac{C D}{I_{A} D} \text { ou } \frac{C A}{C D}=\frac{I_{A} A}{I_{A} D} .
\end{aligned}
$$


De (3) e (4), chega-se à conclusão que $\frac{I A}{I D}=\frac{I_{A} A}{I_{A} D}$, o que mostra que $I$ e $I_{A}$ dividem harmonicamente a bissetriz $A D$ do triângulo $A B C$.

Definição 4.10 (Potência de ponto). A potência de um ponto $P$, em relação a um círculo $\Gamma$, de centro $O$ e raio $r$,édada por $\operatorname{Pot}_{\Gamma}(P)=P O^{2}-r^{2}$.

Observa-se que:

$$
\begin{aligned}
& \checkmark \quad \text { se } P \text { é exterior à } \Gamma, P O>r \text { e } \operatorname{Pot}_{\Gamma}(P)>0 \text { (positiva); } \\
& \checkmark \quad \text { se } P \text { pertence à circunferência de } \Gamma, P O=r \text { e } \operatorname{Pot}_{\Gamma}(P)=0 \text { (nula); e } \\
& \checkmark \quad \text { se } P \text { é interior à } \Gamma, P O<r \text { e } \operatorname{Pot}_{\Gamma}(P)<0 \text { (negativa). }
\end{aligned}
$$

Nota: O centro de um círculo é o ponto de potência mínima: $P O=0$ e $\operatorname{Pot}_{\Gamma}(O)=-r^{2}$.

Proposição 4.13. Sejam $P$ um ponto exterior a um círculo $\Gamma$ de centro $O$ e raio $r$. Por $P$ traçam-se uma tangente PT e uma secante que corta $\Gamma$ nos pontos A e B (Figura 21]. Então, a potência de P em relação ao círculo Г é dada por

$$
P o t_{\Gamma}(P)=P T^{2}=P A \cdot P B
$$

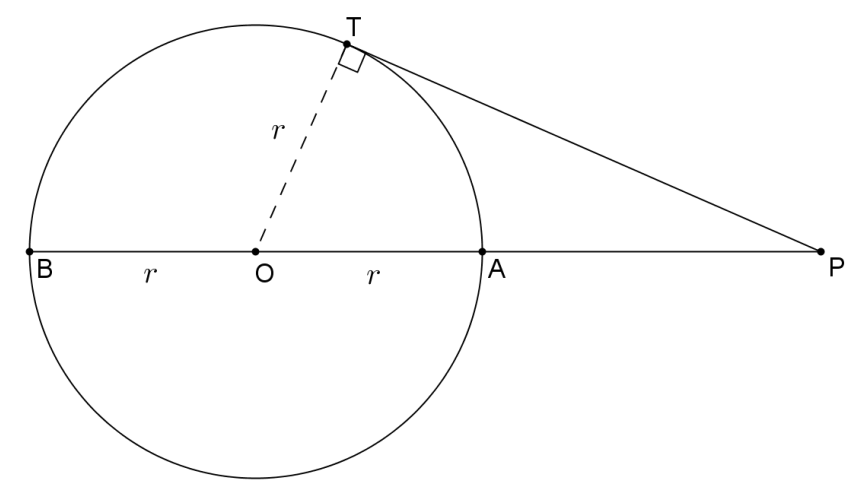

Figura 21 - Potência de um ponto

Prova. Unindo-se o ponto $O$ ao ponto $T$, obtém-se um triângulo retângulo $O T P$, onde, por Pitágoras, tem-se

$$
\begin{gathered}
P O^{2}=P T^{2}+r^{2} \\
P T^{2}=P O^{2}-r^{2}=\operatorname{Pot}_{\Gamma}(P) \\
P T^{2}=(P A+r)^{2}-r^{2}=\operatorname{Pot}_{\Gamma}(P) \\
P T^{2}=P A^{2}+2 r \cdot P A=\operatorname{Pot}_{\Gamma}(P) \\
P T^{2}=P A \cdot(P A+2 r)=\operatorname{Pot}_{\Gamma}(P) \\
P T^{2}=P A \cdot P B=\operatorname{Pot}_{\Gamma}(P) .
\end{gathered}
$$


Proposição 4.14 (Divisão harmônica em círculos ortogonais). Os extremos dos diâmetros de dois círculos ortogonai $4^{4}$, quando alinhados, dividem-se harmonicamente.

Prova. Sejam dois círculos ortogonais, $\lambda_{1}$ e $\lambda_{2}$, de centros $O_{1}$ e $O_{2}$ e diâmetros $A B$ e $M N$, respectivamente, com $T$ sendo uma das suas interseções (Figura 22). A potência do ponto $O_{1}$ de $\lambda_{1}$, em relação ao círculo $\lambda_{2}$, de acordo com a Proposição 4.13 , é dada por

$$
O_{1} M \cdot O_{1} N=O_{1} T^{2}
$$

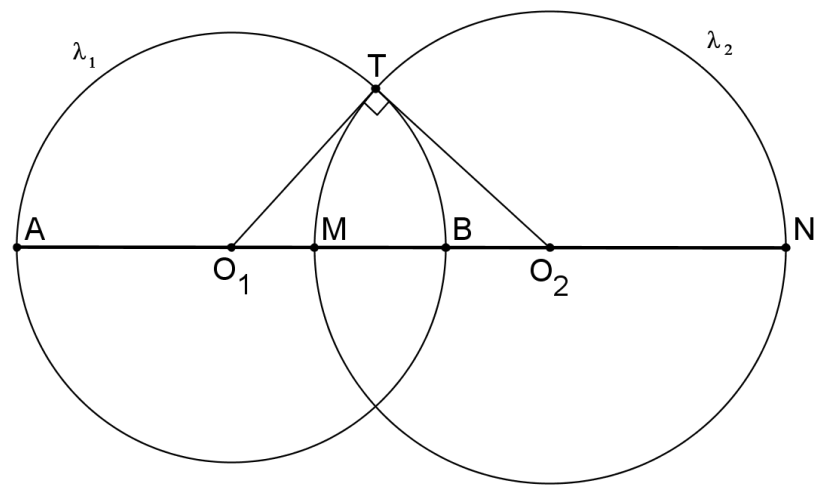

Figura 22 - Círculos ortogonais

Como $O_{1} T=O_{1} A=O_{1} B$, decorre que $O_{1} M \cdot O_{1} N=O_{1} A \cdot O_{1} B$, sendo $O_{1}$ médio de $A B$. Pela recíproca do Teorema 4.4 a sequência de pontos $(A, M, B, N)$ formam uma quádrupla harmônica.

Analogamente, prova-se o mesmo para o ponto $\mathrm{O}_{2}$ de $\lambda_{2}$.

Na realidade, esta Proposição 4.14 pode ser generalizada segundo o teorema a seguir.

Teorema 4.7. Se uma reta corta dois círculos ortogonais passando por um dos centros desses círculos, as interseções desta reta com as circunferências formam uma quádrupla harmônica.

Demonstração. Seja $r$ uma reta que corta dois círculos ortogonais, $\lambda_{1}$ e $\lambda_{2}$, passando pelo centro $O_{1}$ de $\lambda_{1}$, e determinando os pontos $P$ e $Q$ na circunferência de $\lambda_{1}$ e os pontos $R$ e $S$ na circunferência de $\lambda_{2}$ (Figura23).

Se $T$ é um dos pontos de interseção de $\lambda_{1}$ e $\lambda_{2}$, então a potência do ponto $O_{1}$, em relação ao círculo $\lambda_{2}$, é dada por

$$
O_{1} R \cdot O_{1} S=O_{1} T^{2}
$$

Como $O_{1} T=O_{1} P=O_{1} Q$, decorre que $O_{1} R \cdot O_{1} S=O_{1} P \cdot O_{1} Q$, sendo $O_{1}$ médio de $P Q$. Pela recíproca do Teorema 4.4, a sequência de pontos $(P, R, Q, S)$ formam uma quádrupla harmônica.

O mesmo resultado pode ser encontrado se a reta $r$ passasse pelo centro $O_{2}$ de $\lambda_{2}$.

4 Dois círculos são ortogonais quando se cortam de tal modo que as tangentes em cada um dos pontos de interseção são perpendiculares ADAM 1986. MORGADO, WAGNER e JORGE (1990a) complementam dizendo que dois círculos são ortogonais quando a normal de um é a tangente do outro e vice-versa. 


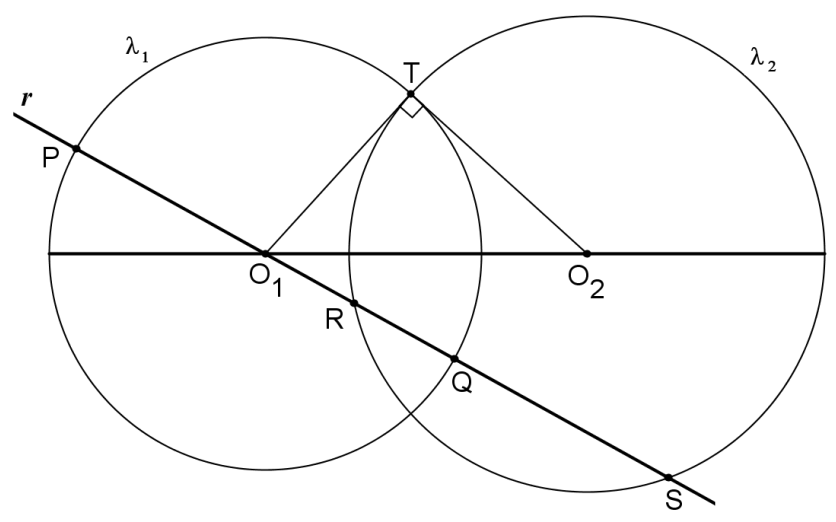

Figura 23 - Círculos ortogonais cortados por uma reta

Teorema 4.8 (Circunferência de Apolônio). Dados dois pontos A e B, o lugar geométrico dos pontos $P$ do plano que possuem razão $\frac{P A}{P B}=k$, sendo $k$ uma constante real positiva diferente de $1(0<k \neq 1)$, é uma circunferência cujo centro está sobre a reta $A B$, chamada circunferência de Apolônid ${ }^{5}$ do segmento $A B$ na razão $k$.

Demonstração. Sejam $M$ e $N$ os conjugados harmônicos do segmento $A B$ na razão $k$, ou seja,

$$
\frac{M A}{M B}=\frac{N A}{N B}=k=\frac{P A}{P B} .
$$

Assim, $M$ e $N$ pertencem ao mesmo LG que $P$.

Observando o triângulo $A P B$ na Figura 24 se $\frac{M A}{M B}=\frac{P A}{P B}$ e $\frac{N A}{N B}=\frac{P A}{P B}$, então, pelo Teorema 4.6 . recíproco das bissetrizes, conclui-se que $P M$ é a sua bissetriz interna e $P N$ é a sua bissetriz externa.

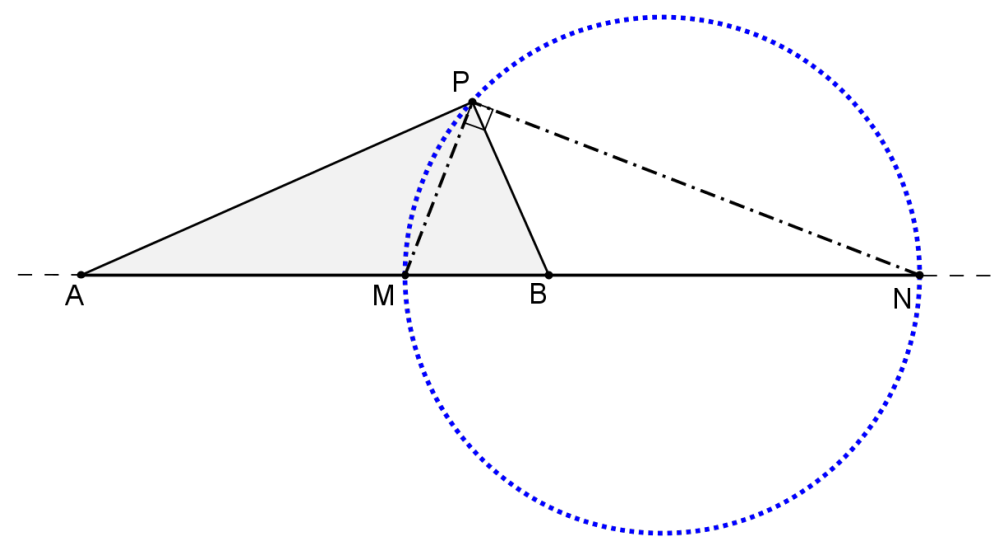

Figura 24 - Circunferência de Apolônio

Como $M$ e $N$ são fixos para o segmento $A B$ na razão $k$ (ver Proposição 4.10 ) e estão sobre a reta suporte de $A B$, com as bissetrizes tais que $P M \perp P N$ (ver Proposição 4.5), então o LG dos pontos $P$ estará sobre o arco-capaz de $90^{\circ}$ do segmento $M N$, ou seja, a circunferência de diâmetro $M N$ (ver Proposição 4.4, com $M$ e $N$ sendo os conjugados harmônicos do segmento $A B$ na razão $k$.

5 Apolônio de Perga foi um matemático grego do Séc. III a.C. que trouxe grandes contribuições à Geometria, notadamente quanto ao estudo das Cônicas (MUNIZ NETO 2013). 
Uma demonstração simples desse teorema, usando Geometria Analítica, pode ser visto em SHINE (2009). Alguns autores chamam também essa circunferência de círculo de Apolônio.

Definição 4.11 (Eixo radical). Dados dois círculos não concêntricos, chama-se eixo radical desses círculos ao lugar geométrico de todos os pontos de igual potência em relação a esses dois círculos.

Proposição 4.15. O eixo radical de dois círculos não concêntricos é uma reta perpendicular ao segmento que une os centros desses círculos.

Prova. Sejam dois círculos, $\Gamma_{A}$ e $\Gamma_{B}$, de centros $A$ e $B$ e raios $r$ e $R$, respectivamente. Sejam ainda $M$ o ponto médio do segmento $A B$ e $P$ um ponto qualquer do plano, com igual potência em relação a $\Gamma_{A}$ e $\Gamma_{B}$, e $H$ a projeção de $P$ sobre $A B$ (Figura 25). Então,

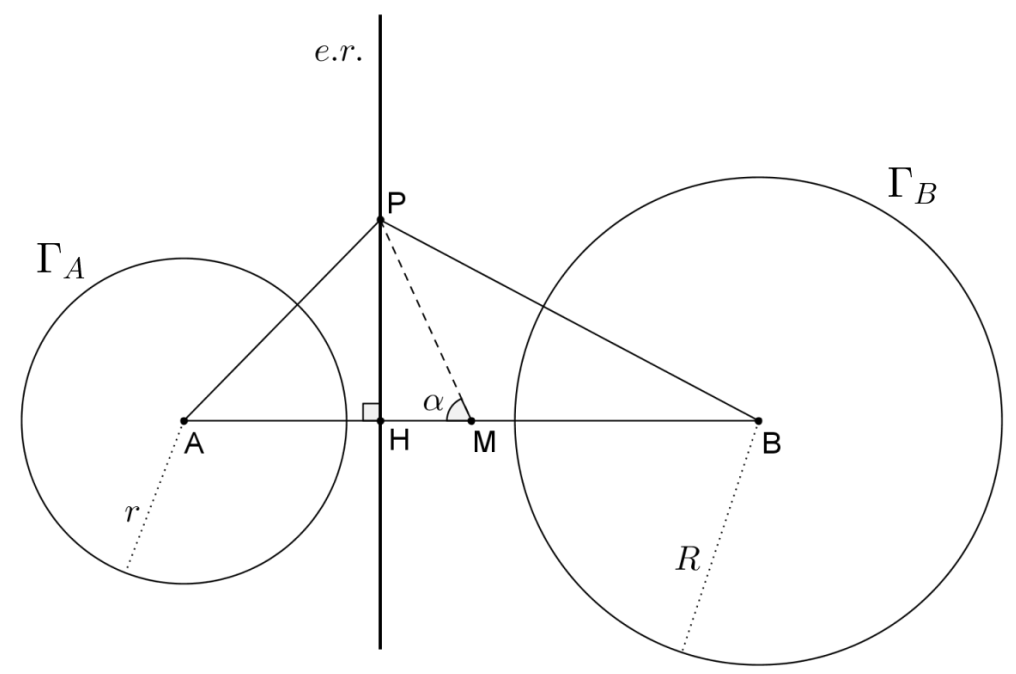

Figura 25 - Eixo radical

$$
\begin{aligned}
& \operatorname{Pot}_{\Gamma_{A}}(P)=\operatorname{Pot}_{\Gamma_{B}}(P) \\
& P A^{2}-r^{2}=P B^{2}-R^{2} \\
& P B^{2}-P A^{2}=R^{2}-r^{2} .
\end{aligned}
$$

Unindo-se $P$ a $M$ e aplicando a lei dos cossenos nos triângulos $P M B$ e $P M A$, tem-se:

$$
\begin{aligned}
\triangle P M B: & P B^{2}=B M^{2}+P M^{2}+2 \cdot B M \cdot P M \cdot \cos \alpha, \mathrm{e} \\
\triangle P M A: & P A^{2}=A M^{2}+P M^{2}-2 \cdot A M \cdot P M \cdot \cos \alpha .
\end{aligned}
$$

Subtraindo-se essas duas equações, uma vez que $A M=B M=\frac{A B}{2}$, obtém-se

$$
P B^{2}-P A^{2}=2 \cdot(B M+A M) \cdot(P M \cdot \cos \alpha)=2 \cdot A B \cdot(P M \cdot \cos \alpha) .
$$

Mas, $P M \cdot \cos \alpha=M H$. Assim, de (5), chega-se a 


$$
\begin{gathered}
P B^{2}-P A^{2}=R^{2}-r^{2}=2 \cdot A B \cdot M H \\
M H=\frac{R^{2}-r^{2}}{2 \cdot A B} .
\end{gathered}
$$

Como o valor de $R^{2}-r^{2}$ é constante e $A B$ é fixo, conclui-se que $M H$ é constante, independente da posição do ponto $P$ ao longo da reta perpendicular que passa pela sua projeção $H$ sobre $A B$. Logo, o lugar geométrico dos pontos $P$ de igual potência em relação aos dois círculos dados é uma reta $P H$ perpendicular ao segmento que une os centros desses círculos.

Teorema 4.9 (Centro radical). Dados três círculos de centros não colineares, os três eixos radicais relativos a cada par de círculos concorrem em um único ponto, chamado Centro Radical, que possui igual potência em relação aos círculos dados.

Demonstração. Sejam três círculos $A, B$ e $C$, de centros não alinhados e os respectivos eixos radicais $e_{A B}$, $e_{A C}$ e $e_{B C}$, entre cada par de círculos (Figura 26).

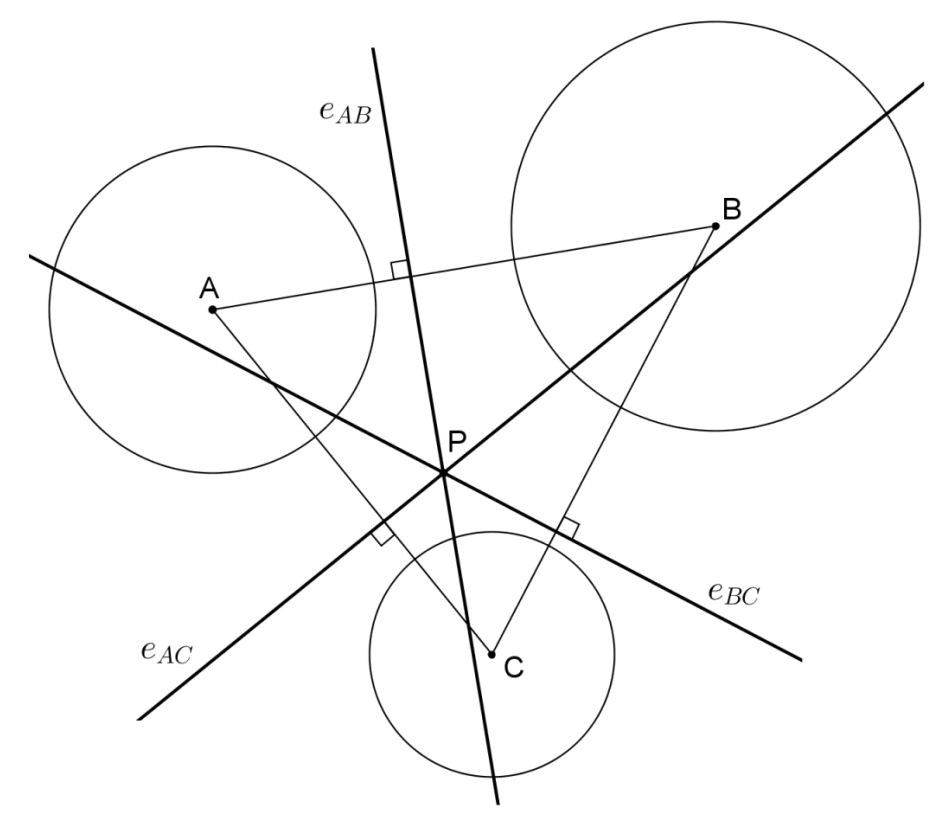

Figura 26 - Centro radical

Seja $P$ o ponto de interseção entre $e_{A B}$ e $e_{A C}$, ou seja, $P$ é único com

$$
\begin{gathered}
P \in e_{A B} \Rightarrow \operatorname{Pot}_{A}(P)=\operatorname{Pot}_{B}(P), \mathrm{e} \\
P \in e_{A C} \Rightarrow \operatorname{Pot}_{A}(P)=\operatorname{Pot}_{C}(P) .
\end{gathered}
$$

Portanto, $\operatorname{Pot}_{B}(P)=\operatorname{Pot}_{C}(P) \Rightarrow P \in e_{B C}$.

Assim, os três eixos radicais $e_{A B}, e_{A C}$ e $e_{B C}$ concorrem no ponto $P$, centro radical dos círculos $A, B$ e $C$, que possui igual potência em relação a esses círculos.

Definição 4.12 (Concorrência de retas). Três ou mais retas são concorrentes quando passam por um mesmo ponto. 
Definição 4.13 (Colinearidade de pontos). Três ou mais pontos são colineares quando pertencem a uma mesma reta.

Nota: Uma forma simples de comprovar a colinearidade de pontos é por meio da soma das medidas dos ângulos existentes entre eles: se a soma dos ângulos adjacentes for igual a 180ª̂ngulo raso), então há colinearidade entre os pontos (Figura27).

Se $\measuredangle A B E+\measuredangle E B D+\measuredangle D B C=180^{\circ}$, então $A, B$ e $C$ são colineares.

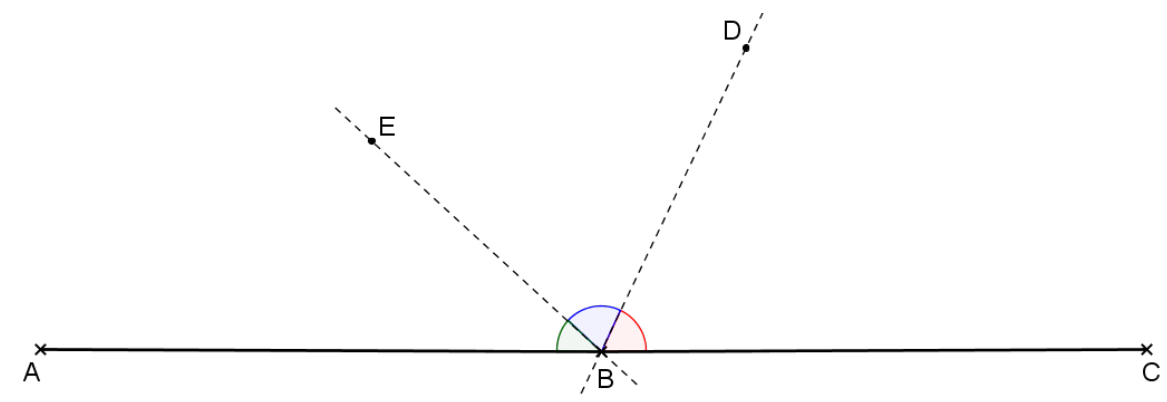

Figura 27 - Colinearidade de pontos

Segundo POSAMENTIER e SALKIND (1996), problemas que tratam de Colinearidade e Concorrência são normalmente complicados, trabalhosos e, consequentemente, impopulares entre os alunos. Entretanto, dois teoremas famosos reduziram essas dificuldades: o primeiro é creditado a Menelaus 6 relacionado à colinearidade de pontos, e o segundo, ao matemático italiano Ceva 7 , relacionado à concorrência de retas.

Para EVES (1972), os teoremas de Menelaus e Ceva são teoremas poderosos que lidam de forma elegante com muitos problemas sobre colinearidade de pontos e concorrência de retas. MUNIZ NETO (2013) dá muita importância a esses dois teoremas clássicos, pois servem de base para demonstrar diversos outros teoremas e resolver uma série de problemas de olimpíadas de Matemática.

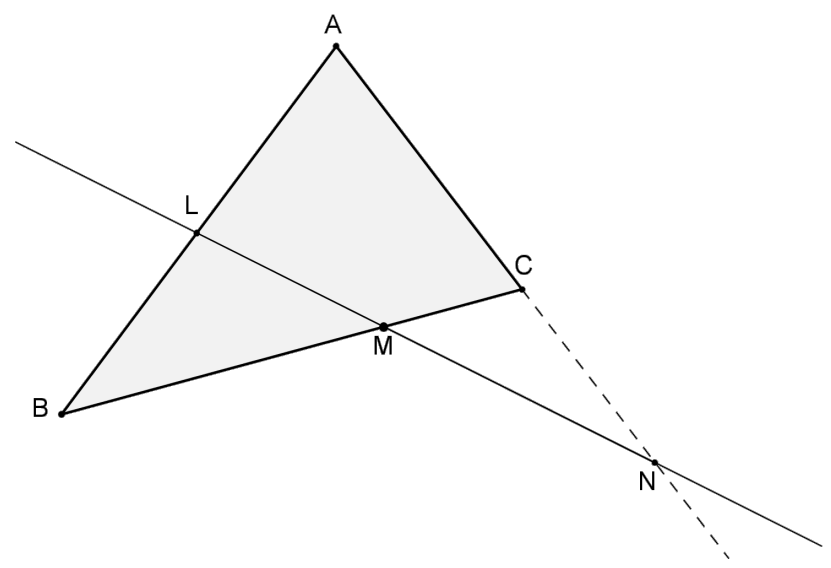

Figura 28 - Teorema de Menelaus

\footnotetext{
6 Menelaus de Alexandria era matemático e astrônomo que viveu no Egito por volta do ano 100 d.C. Escreveu vários tratados de Geometria, Trigonometria e Mecânica, e teve seu teorema de colinearidade de pontos esquecido por 15 séculos, sendo redescoberto só em 1678, por Giovanni Ceva (MACEDO 2014).

7 Giovanni Ceva era matemático e engenheiro italiano do século XVII. Em 1678, na sua obra De lineis rectis, publicou o teorema de Menelaus e o teorema de concorrência de retas que leva seu nome (DE FREITAS 2013).
} 
Teorema 4.10 (Menelaus). Dada uma reta qualquer que corta as retas suportes dos lados de um triângulo $A B C$ nos pontos $L, M$ e $N$, respectivamente, conforme a Figura 28 , então, considerando razões orientada 8 , tem-se que $\frac{A L}{L B} \cdot \frac{B M}{M C} \cdot \frac{C N}{N A}=-1$.

Demonstração. Traçando-se por $A, B$ e $C$ retas paralelas à reta original e prolongando-se o lado $B C$ até o ponto $D$, pertencente à paralela que passa por $A$, conforme a Figura 29, forma-se um feixe de quatro retas paralelas cortadas por três transversais $A B, A N$ e $D B$, donde, pela Lei da Proporcionalidade de Tales, tem-se

$$
\frac{A L}{D M}=\frac{L B}{M B}, \text { que fornece } D M=\frac{A L \cdot M B}{L B}
$$

$\mathrm{e}$

$$
\frac{N C}{M C}=\frac{N A}{M D}, \text { que fornece } M D=\frac{N A \cdot M C}{N C} .
$$

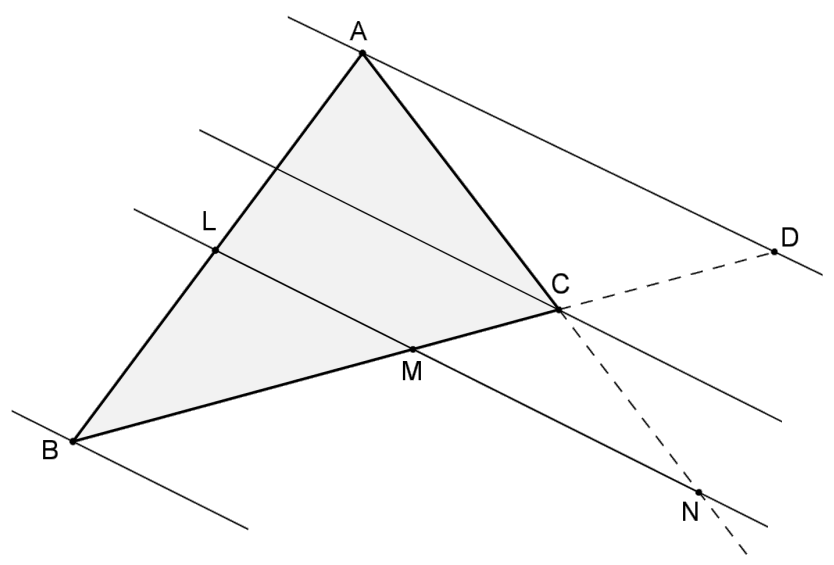

Figura 29 - Demonstração do teorema de Menelaus

De (6) e (7), considerando-se a orientação dos segmentos, obtém-se

$$
\begin{gathered}
\frac{A L \cdot M B}{L B}=-\frac{N A \cdot M C}{N C} \\
\frac{A L}{L B} \cdot \frac{M B}{M C} \cdot \frac{N C}{N A}=-1, \text { ou seja, } \frac{A L}{L B} \cdot \frac{B M}{M C} \cdot \frac{C N}{N A}=-1 .
\end{gathered}
$$

Quando são consideradas as razões orientadas no teorema de Menelaus, isto é, quando as medidas de comprimento utilizadas são algébricas, diz-se que ele está na sua versão completa. Alguns autores como GUALBERTO (2007) e MORGADO, WAGNER e JORGE (1990b), apresentam o teorema utilizando medidas geométricas de comprimento (razões sempre positivas), gerando o produto final das razões igual a 1. Neste caso, diz-se que o teorema está na sua versão básica.

O inconveniente da versão básica é que a recíproca do teorema não é sempre verdadeira. Um contra-exemplo simples ocorre quando os pontos $L, M$ e $N$ são médios dos lados do triângulo $A B C$. Neste

8 Dados três pontos colineares $P, A$ e $B$, em qualquer ordem, a razão orientada $\frac{P A}{P B}$ é positiva se os segmentos $P A$ e $P B$ têm mesmo sentido e, negativa, se tiverem sentidos opostos. 
caso, os pontos não são colineares, mas o produto das razões é igual a 1 (DE FREITAS, 2013). Se o professor ou o aluno têm ciência dessa particularidade e toma o devido cuidado no momento da resolução de um problema, pode aplicar o teorema recíproco de Menelaus na sua versão básica.

Teorema 4.11 (Recíproco de Menelaus). Se $L, M$ e $N$ são, respectivamente, pontos sobre as retas suportes dos lados $A B, B C$ e $A C$ de um triângulo $A B C e \frac{A L}{L B} \cdot \frac{B M}{M C} \cdot \frac{C N}{N A}=-1$, considerando as razões orientadas, então $L$, M e $N$ são colineares.

Demonstração. Supondo que a reta $L M$ corte o lado $A C$ num ponto $N^{\prime}$ (Figura30, pelo teorema de Menelaus (versão completa), $L, M$ e $N^{\prime}$ são colineares, com

$$
\frac{A L}{L B} \cdot \frac{B M}{M C} \cdot \frac{C N^{\prime}}{N^{\prime} A}=-1
$$

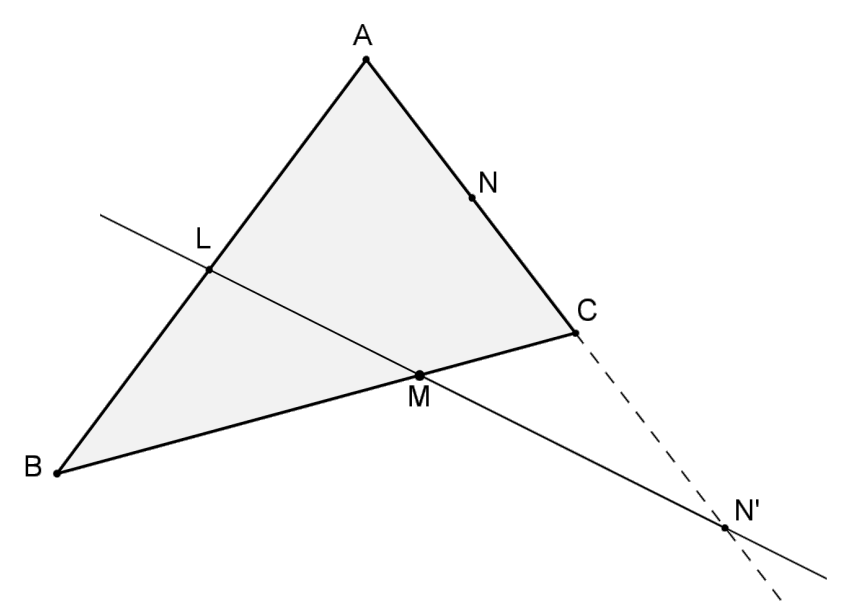

Figura 30 - Demonstração do teorema recíproco de Menelaus são colineares.

Se, por hipótese, $\frac{A L}{L B} \cdot \frac{B M}{M C} \cdot \frac{C N}{N A}=-1$, então $\frac{C N}{N A}=\frac{C N^{\prime}}{N^{\prime} A}$, o que é possível se $N \equiv N^{\prime}$. Logo, $L, M$ e $N$ Nota: Os pontos colineares $L, M$ e $N$ são chamados por EVES (1972) de pontos de Menelaus.

Existem outras formas de demonstrar o teorema de Menelaus. Por exemplo, NEVES (2013) o demonstra utilizando semelhança de triângulos e EVES (1972) por meio do cálculo de áreas.

Teorema 4.12 (Menelaus trigonométrico). Dada uma reta qualquer que corta as retas suportes dos lados $A B, B C$ e CA de um triângulo $A B C$, nos pontos $L, M$ e $N$, respectivamente, conforme a Figura 28, então

$$
\frac{\operatorname{sen} \measuredangle A C L}{\operatorname{sen} \measuredangle L C B} \cdot \frac{\operatorname{sen} \measuredangle B A M}{\operatorname{sen} \measuredangle M A C} \cdot \frac{\operatorname{sen} \measuredangle C B N}{\operatorname{sen} \measuredangle N B A}=-1 .
$$

Demonstração. Para demonstrar este teorema, considere o lema a seguir.

Lema 4.1. Dados um triângulo $A B C$ e a ceviand 9 AD, então $\frac{B D}{D C}=\frac{A B \cdot \operatorname{sen} \measuredangle B A D}{A C \cdot \operatorname{sen} \measuredangle D A C}$.

9 Ceviana é todo segmento que liga um vértice de um triângulo ao seu lado oposto ou ao seu prolongamento. Esse termo foi dado em homenagem ao matemático Giovanni Ceva que publicou este teorema em 1678 (COXETER; GREITZER 1967). 
Prova. Seja $A H$ a altura relativa ao vértice $A$ do triângulo $A B C$ (Figura 31). Então, a área do triângulo $B A D$ pode ser dada por

$$
\begin{gathered}
{[B A D]=\frac{B D \cdot A H}{2}=\frac{A B \cdot A D}{2} \cdot \operatorname{sen} \measuredangle B A D, \text { donde }} \\
B D=\frac{A B \cdot A D}{A H} \cdot \operatorname{sen} \measuredangle B A D .
\end{gathered}
$$

Da mesma forma, a área do triângulo $D A C$ é dada por

$$
\begin{gathered}
{[D A C]=\frac{D C \cdot A H}{2}=\frac{A C \cdot A D}{2} \cdot \operatorname{sen} \measuredangle D A C, \text { donde }} \\
D C=\frac{A C \cdot A D}{A H} \cdot \operatorname{sen} \measuredangle D A C .
\end{gathered}
$$

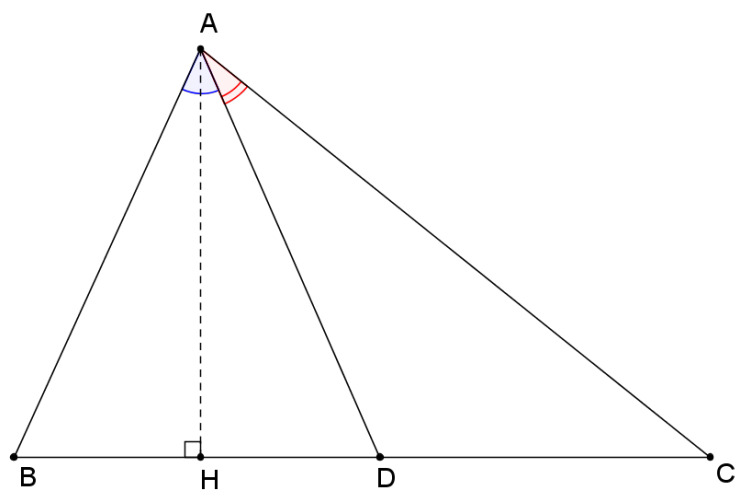

Figura 31 - Prova do lema

Dividindo (8) por (9), tem-se $\frac{B D}{D C}=\frac{A B \cdot \operatorname{sen} \measuredangle B A D}{A C \cdot \operatorname{sen} \measuredangle D A C}$.

Nota: Observe que se os ângulos $\measuredangle B A D$ e $\measuredangle D A C$ forem iguais, ou seja, se $A D$ for bissetriz interna relativa ao vértice $A$, o lema acima gera o teorema da bissetriz interna. Em outras palavras, o teorema da bissetriz interna é um caso particular do Lema 4.1

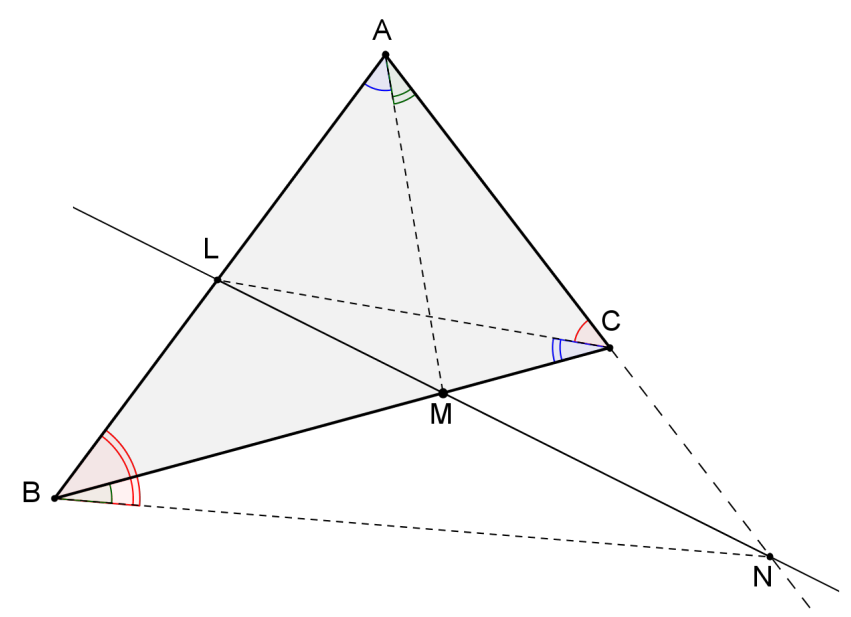

Figura 32 - Demonstração do teorema de Menelaus trigonométrico

Portanto, com base no Lema 4.1 e, observando a Figura 32, pode-se escrever, após traçar as cevianas $A M, B N$ e $C L$, 


$$
\frac{A L}{L B}=\frac{A C \cdot \operatorname{sen} \measuredangle A C L}{C B \cdot \operatorname{sen} \measuredangle L C B}, \quad \frac{B M}{M C}=\frac{B A \cdot \operatorname{sen} \measuredangle B A M}{A C \cdot \operatorname{sen} \measuredangle M A C} \quad \text { e } \quad \frac{C N}{N A}=\frac{C B \cdot \operatorname{sen} \measuredangle C B N}{B A \cdot \operatorname{sen} \measuredangle N B A} .
$$

Multiplicando-se essas três igualdades, obtém-se

$$
\frac{A L}{L B} \cdot \frac{B M}{M C} \cdot \frac{C N}{N A}=\frac{A C \cdot \operatorname{sen} \measuredangle A C L}{C B \cdot \operatorname{sen} \measuredangle L C B} \cdot \frac{B A \cdot \operatorname{sen} \measuredangle B A M}{A C \cdot \operatorname{sen} \measuredangle M A C} \cdot \frac{C B \cdot \operatorname{sen} \measuredangle C B N}{B A \cdot \operatorname{sen} \measuredangle N B A},
$$

como o teorema de Menelaus fornece, para os pontos $L, M$ e $N, \frac{A L}{L B} \cdot \frac{B M}{M C} \cdot \frac{C N}{N A}=-1$, então,

$$
\frac{\operatorname{sen} \measuredangle A C L}{\operatorname{sen} \measuredangle L C B} \cdot \frac{\operatorname{sen} \measuredangle B A M}{\operatorname{sen} \measuredangle M A C} \cdot \frac{\operatorname{sen} \measuredangle C B N}{\operatorname{sen} \measuredangle N B A}=-1 .
$$

Nota: Observe que as razões trigonométricas também são orientadas, ou seja, o sentido em que o ângulo é marcado importa: $\measuredangle N B A=-\measuredangle A B N$. Cabe destacar que a recíproca desse teorema também é válida ${ }^{10}$.

USUI (2014), trabalhando com trigonometria esférica, demonstra uma série de relações interessantes usando o teorema de Menelaus. Já GUALBERTO (2007) prova, pelo Princípio da Indução, o que chama de "Teorema Generalizado de Menelaus", que pode ser aplicado a um polígono de $n>3$ lados, mas cujo recíproco não é sempre verdadeiro.

A vantagem do teorema de Menelaus é provar, de forma simples, a colinearidade entre pontos, tema muitas vezes cobrado em problemas olímpicos.

Teorema 4.13 (Ceva). Se um triângulo $A B C$ possui três cevianas, $A M, B N$ e $C L$, concorrentes num ponto $P$, conforme a Figura 33 então $\frac{A L}{L B} \cdot \frac{B M}{M C} \cdot \frac{C N}{N A}=1$.

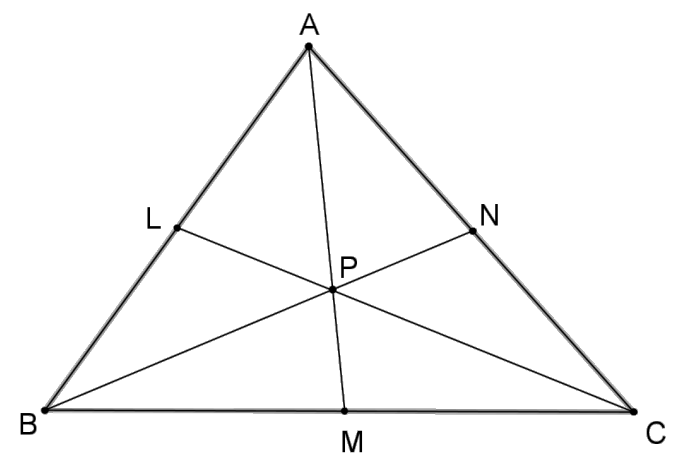

Figura 33 - Teorema de Ceva

Demonstração. Traçando-se por $A$ uma reta paralela ao lado $B C$ e prolongando-se as cevianas $B N$ e $C L$ até encontrar essa reta nos pontos $B^{\prime}$ e $C^{\prime}$, respectivamente, conforme a Figura 34 formam-se os seguintes casos de semelhança de triângulos:

$$
\begin{aligned}
& \triangle C M P \sim \triangle C^{\prime} A P, \text { donde } \frac{M C}{A C^{\prime}}=\frac{P M}{P A} ; \\
& \triangle B M P \sim \triangle B^{\prime} A P, \text { donde } \frac{B M}{B^{\prime} A}=\frac{P M}{P A} ;
\end{aligned}
$$

10 A demonstração da recíproca do teorema será deixada a cargo do leitor. 


$$
\begin{gathered}
\triangle B C N \sim \triangle B^{\prime} A N, \text { donde } \frac{B^{\prime} A}{B C}=\frac{N A}{N C} ; \mathrm{e} \\
\triangle B C L \sim \triangle A C^{\prime} L, \text { donde } \frac{B C}{A C^{\prime}}=\frac{L B}{L A} .
\end{gathered}
$$

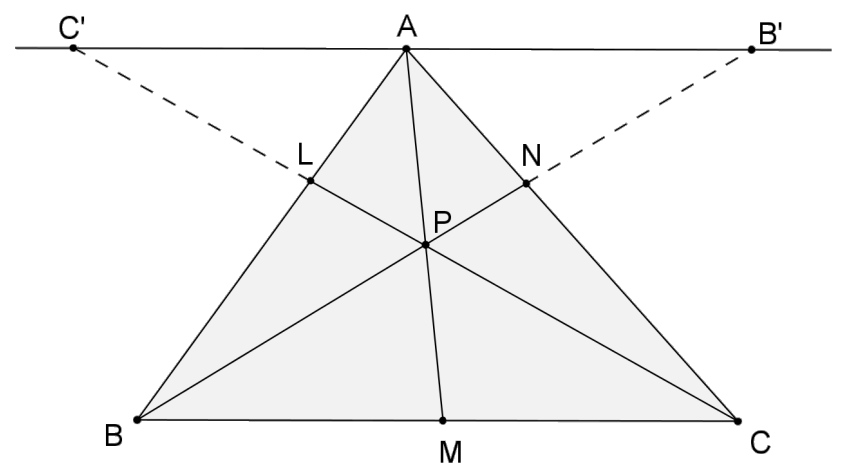

Figura 34 - Demonstração do Teorema Ceva

De (10) e (11), tem-se

$$
\frac{M C}{A C^{\prime}}=\frac{B M}{B^{\prime} A} \text { ou } \frac{B^{\prime} A}{A C^{\prime}}=\frac{B M}{M C}
$$

Multiplicando-se membro a membro as igualdades (12) e (13), tem-se

$$
\frac{B^{\prime} A}{A C^{\prime}}=\frac{N A}{N C} \cdot \frac{L B}{L A}
$$

Por fim, comparando-se (14) e (15), chega-se a

$$
\frac{B M}{M C}=\frac{N A}{N C} \cdot \frac{L B}{L A}, \text { ou seja, } \frac{A L}{L B} \cdot \frac{B M}{M C} \cdot \frac{C N}{N A}=1
$$

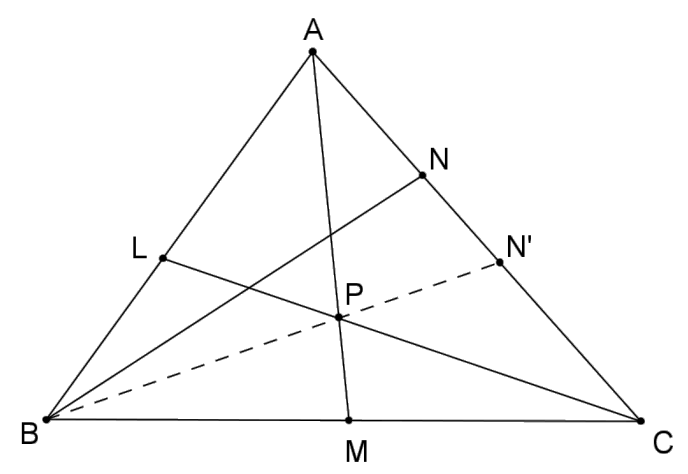

Figura 35 - Demonstração do teorema recíproco de Ceva

Teorema 4.14 (Recíproco de Ceva). Se AM, BN e CL são três cevianas de um triângulo ABC e o produto $\frac{A L}{L B} \cdot \frac{B M}{M C} \cdot \frac{C N}{N A}=1$, então $A M, B N$ e CL são concorrentes num ponto. 
Demonstração. Considere $P$ a interseção de $A M$ e $C L$. Traçando-se a ceviana $B N^{\prime}$ que passa por $P$, conforme a Figura 35 pelo teorema de Ceva, tem-se $\frac{A L}{L B} \cdot \frac{B M}{M C} \cdot \frac{C N^{\prime}}{N^{\prime} A}=1$.

Se, por hipótese, $\frac{A L}{L B} \cdot \frac{B M}{M C} \cdot \frac{C N}{N A}=1$, então $\frac{C N^{\prime}}{N^{\prime} A}=\frac{C N}{N A}$, o que é possível se $N^{\prime} \equiv N$. Logo, $A M, B N$ e $C L$ são concorrentes no ponto $P$.

Outra demonstração do teorema de Ceva, utilizando o conceito de área, pode ser vista em NEVES (2013) e em GUALBERTO (2007).

Teorema 4.15 (Ceva trigonométrico). Se um triângulo $A B C$ possui três cevianas $A M, B N$ e CL, concorrentes num ponto $P$, conforme a Figura 33 , então

$$
\frac{\operatorname{sen} \measuredangle A B N}{\operatorname{sen} \measuredangle N B C} \cdot \frac{\operatorname{sen} \measuredangle B C L}{\operatorname{sen} \measuredangle L C A} \cdot \frac{\operatorname{sen} \measuredangle C A M}{\operatorname{sen} \measuredangle M A B}=1 .
$$

Demonstração. Com base na Figura 33, a aplicação da Lei dos Senos nos triângulos $A C P, A B P$ e $B C P$, produz, respectivamente,

$$
\begin{aligned}
& \triangle A C P: \quad \frac{\operatorname{sen} \measuredangle C A P}{C P}=\frac{\operatorname{sen} \measuredangle P C A}{P A}, \\
& \triangle A B P: \quad \frac{\operatorname{sen} \measuredangle A B P}{A P}=\frac{\operatorname{sen} \measuredangle P A B}{P B}, \\
& \triangle B C P: \quad \frac{\operatorname{sen} \measuredangle B C P}{B P}=\frac{\operatorname{sen} \measuredangle P B C}{P C} .
\end{aligned}
$$

Multiplicando-se essas três igualdades, obtém-se

$$
\begin{aligned}
& \frac{\operatorname{sen} \measuredangle C A P}{C P} \cdot \frac{\operatorname{sen} \measuredangle A B P}{A P} \cdot \frac{\operatorname{sen} \measuredangle B C P}{B P}=\frac{\operatorname{sen} \measuredangle P C A}{P A} \cdot \frac{\operatorname{sen} \measuredangle P A B}{P B} \cdot \frac{\operatorname{sen} \measuredangle P B C}{P C}, \\
& \frac{\operatorname{sen} \measuredangle A B P}{\operatorname{sen} \measuredangle P B C} \cdot \frac{\operatorname{sen} \measuredangle B C P}{\operatorname{sen} \measuredangle P C A} \cdot \frac{\operatorname{sen} \measuredangle C A P}{\operatorname{sen} \measuredangle P A B}=1, \\
& \frac{\operatorname{sen} \measuredangle A B N}{\operatorname{sen} \measuredangle N B C} \cdot \frac{\operatorname{sen} \measuredangle B C L}{\operatorname{sen} \measuredangle L C A} \cdot \frac{\operatorname{sen} \measuredangle C A M}{\operatorname{sen} \measuredangle M A B}=1 .
\end{aligned}
$$

Nota: A recíproca desse teorema também é válida ${ }^{11}$.

EVES (1972) apresenta como exercício para o leitor provar o que chama de "Teorema Generalizado de Ceva", aplicável a um polígono de gênero ímpar $n(n>3)$.

Uma das vantagens do teorema de Ceva é provar, de forma simples, a existência de vários pontos notáveis num triângulo, como o incentro, baricentro, ortocentro, ponto de Gergonne, ponto de Nagel, ponto de Lemoine, etc.

Proposição 4.16. Num triângulo escaleno, os pés das bissetrizes internas de dois ângulos e o pé da bissetriz externa do terceiro ângulo são colineares.

11 A demonstração da recíproca do teorema será deixada a cargo do leitor. 
Prova. Sejam $B N$ e $C L$ as bissetrizes internas e $A M$ a bissetriz externa do triângulo escaleno $A B C$ (Figura 36). Pelo teorema da bissetriz interna (Teorema 4.5(i)), aplicado ao vértice $C$, tem-se

$$
\frac{C A}{A L}=\frac{C B}{L B} \text { ou } \frac{C A}{C B}=\frac{A L}{L B}
$$

Pelo teorema da bissetriz externa (Teorema 4.5(ii)), aplicado ao vértice $A$, tem-se

$$
\frac{A B}{B M}=\frac{A C}{M C} \text { ou } \frac{A B}{A C}=\frac{B M}{M C}
$$

Pelo teorema da bissetriz interna (Teorema $4.5(\mathrm{i})$ ), aplicado ao vértice $B$, tem-se

$$
\frac{B C}{C N}=\frac{B A}{N A} \text { ou } \frac{B C}{B A}=\frac{C N}{N A} .
$$

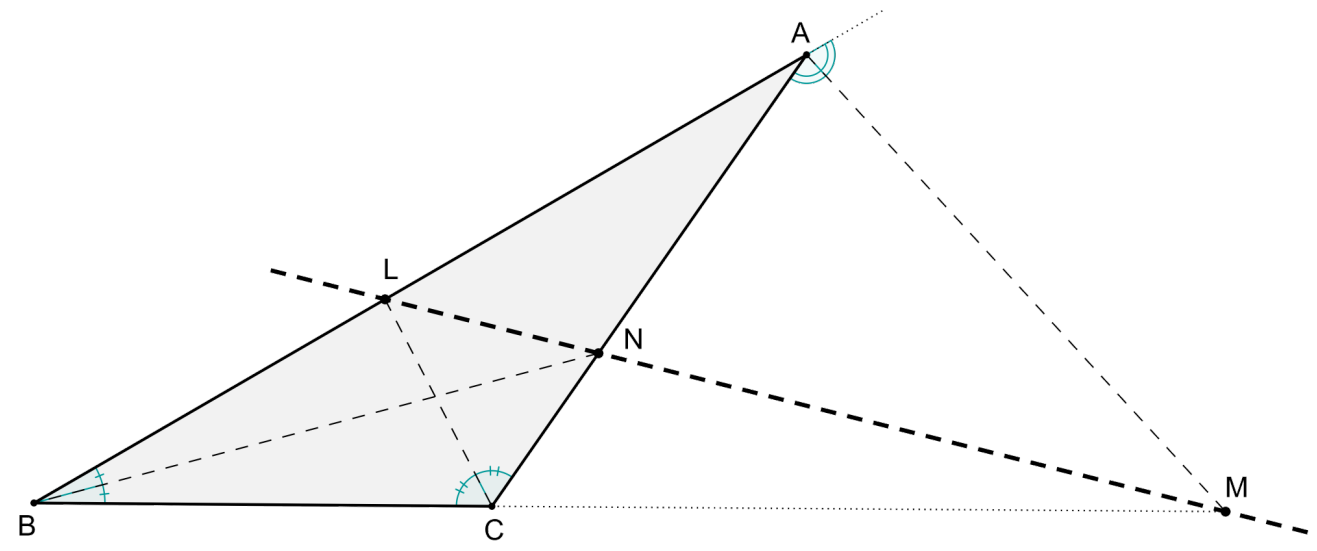

Figura 36 - Colinearidade dos pés das bissetrizes externa e da bissetriz interna

Multiplicando-se, membro a membro, as equações (16), (17) e (18), obtém-se

$$
\begin{gathered}
\frac{C A}{C B} \cdot \frac{A B}{A C} \cdot \frac{B C}{B A}=\frac{A L}{L B} \cdot \frac{B M}{M C} \cdot \frac{C N}{N A} \\
\frac{A L}{L B} \cdot \frac{B M}{M C} \cdot \frac{C N}{N A}=1 .
\end{gathered}
$$

Observa-se, pela Figura 36, que tal equação, ao usar as razões orientadas (versão completa do teorema de Menelaus), resulta -1, e, desse modo, pelo teorema recíproco de Menelaus (Teorema 4.11), aplicado ao triângulo $A B C$, os pontos $L, M$ e $N$ (pés das bissetrizes) são colineares.

Proposição 4.17. Os pés das três bissetrizes externas de um triângulo escaleno são colineares.

Prova. Considere o triângulo escaleno $A B C$ da Figura 37. Sejam $b_{a}, b_{b}$ e $b_{c}$ as bissetrizes externas dos ângulos $\angle A, \angle B$ e $\angle C$, respectivamente, e $A^{\prime}, B^{\prime}$ e $C^{\prime}$, os pontos de encontro dessas bissetrizes com os lados opostos aos respectivos ângulos.

Pelo teorema da bissetriz externa (Teorema 4.5(ii)), aplicado ao triângulo $A B C$, tem-se 


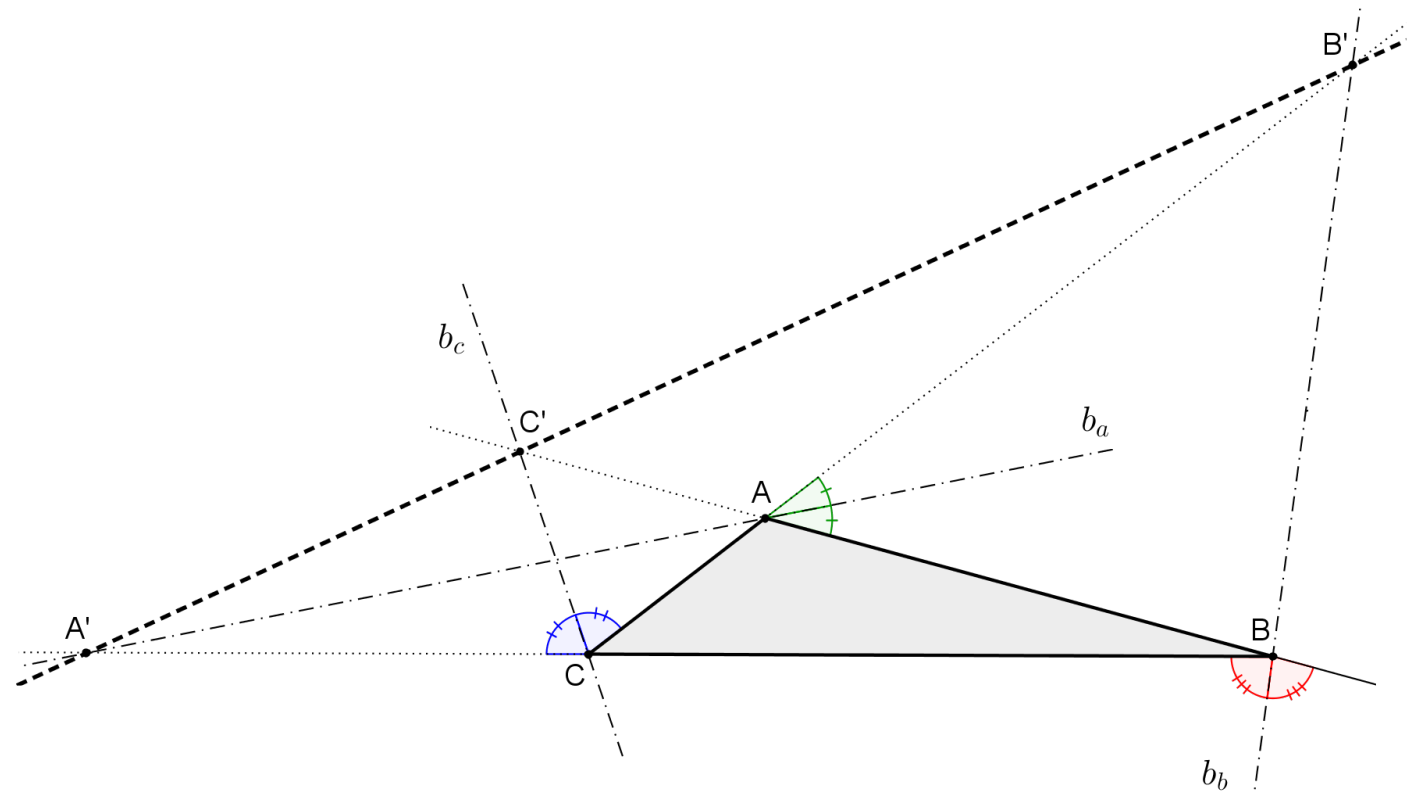

Figura 37 - Colinearidade dos pés das bissetrizes externas

$$
\begin{array}{ll}
\text { - vértice } A: & \frac{A B}{A^{\prime} B}=\frac{A C}{C A^{\prime}} \text { ou } \frac{A B}{A C}=\frac{A^{\prime} B}{C A^{\prime}} ; \\
\text { - vértice } B: & \frac{B A}{B^{\prime} A}=\frac{B C}{B^{\prime} C} \text { ou } \frac{B C}{B A}=\frac{B^{\prime} C}{B^{\prime} A} ; \\
\text { - vértice } C: & \frac{C A}{C^{\prime} A}=\frac{B C}{B C^{\prime}} \text { ou } \frac{C A}{B C}=\frac{C^{\prime} A}{B C^{\prime}} .
\end{array}
$$

Multiplicando-se, membro a membro, essas três igualdades, obtém-se

$$
\begin{gathered}
1=\frac{A^{\prime} B}{C A^{\prime}} \cdot \frac{B^{\prime} C}{B^{\prime} A} \cdot \frac{C^{\prime} A}{B C^{\prime}}, \text { ou } \\
\frac{B A^{\prime}}{A^{\prime} C} \cdot \frac{C B^{\prime}}{B^{\prime} A} \cdot \frac{A C^{\prime}}{C^{\prime} B}=1,
\end{gathered}
$$

que, pelo teorema recíproco de Menelaus (Teorema 4.11, conclui-se que $A^{\prime}, B^{\prime}$ e $C^{\prime}$, pés das bissetrizes externas dos ângulos do triângulo $A B C$, são colineares.

Teorema 4.16 (Baricentro). As três medianas de um triângulo são concorrentes em um ponto G, chamado Baricentro, que as divide na razão $\frac{1}{2}$.

Demonstração. Sejam $A M, B N$ e $C L$ as medianas do triângulo $A B C$. tem-se

Calculando o produto das razões $\frac{A L}{L B}, \frac{B M}{M C} \mathrm{e} \frac{C N}{N A}$, uma vez que $A L=L B, B M=M C$ e $C N=N A$,

$$
\frac{A L}{L B} \cdot \frac{B M}{M C} \cdot \frac{C N}{N A}=1
$$

que, pelo teorema recíproco de Ceva (Teorema 4.14), aplicado ao triângulo $A B C$, conclui-se que as medianas $A M, B N$ e $C L$ são concorrentes em um ponto. Seja $G$ este ponto. 


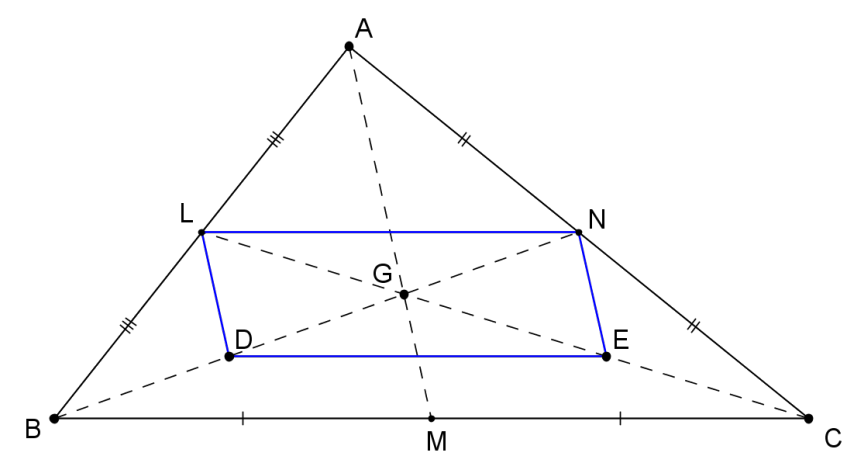

Figura 38 - Divisão da mediana pelo baricentro

Considere agora os pontos $D$, médio de $B G$, e $E$, médio de $C G$. Traçando-se as bases médias $L N$ e $D E$ dos triângulos $A B C$ e $G B C$, respectivamente, tem-se (Figura 38 )

$$
\begin{aligned}
& \triangle A B C: \quad L N \| B C \text { e } L N=\frac{B C}{2}, \\
& \triangle G B C: \quad D E \| B C \text { e } D E=\frac{B C}{2} .
\end{aligned}
$$

Com isso, $L N=D E$ e $L N \| D E$, fazendo com que o quadrilátero $L N D E$ seja um paralelogramo com $G$ sendo o ponto de encontro das suas diagonais. Assim, $N G=G D=D B$ e $L G=G E=E C$. Analogamente, tem-se $A F=F G=G M, \operatorname{com} F$ sendo médio de $A G$.

Portanto, $G$ divide as medianas na razão $\frac{G M}{A G}=\frac{G N}{B G}=\frac{G L}{C G}=\frac{1}{2}$.

FEITOSA (2013) demonstra a concorrência das medianas no baricentro utilizando números complexos.

Teorema 4.17 (Ortocentro). As três alturas de um triângulo são concorrentes em um ponto H, chamado Ortocentro.

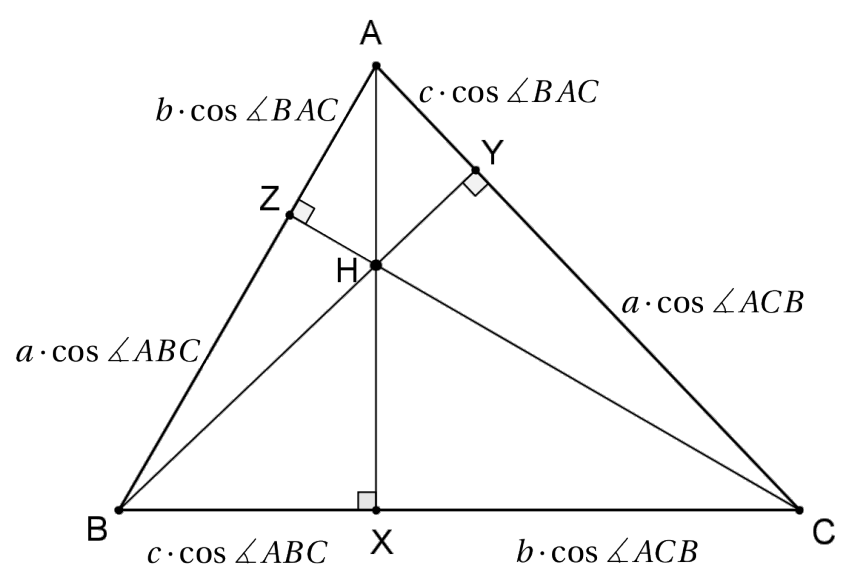

Figura 39 - Concorrência das alturas de um triângulo

Demonstração. Dado um triângulo $A B C$, com lados $B C=a, A C=b$ e $A B=c$, e alturas $A X, B Y$ e $C Z$ (Figura 39), pode-se escrever, com o apoio da Trigonometria, 


$$
\left\{\begin{array}{l}
A Z=b \cdot \cos \measuredangle B A C \\
Z B=a \cdot \cos \measuredangle A B C \\
B X=c \cdot \cos \measuredangle A B C \\
X C=b \cdot \cos \measuredangle A C B \\
C Y=a \cdot \cos \measuredangle A C B \\
Y A=c \cdot \cos \measuredangle B A C
\end{array}\right.
$$

Fazendo o produto das razões $\frac{A Z}{Z B}, \frac{B X}{X C} \mathrm{e} \frac{C Y}{Y A}$ obtém-se, como resultado,

$$
\begin{gathered}
\frac{A Z}{Z B} \cdot \frac{B X}{X C} \cdot \frac{C Y}{Y A}=\frac{b \cdot \cos \measuredangle B A C}{a \cdot \cos \measuredangle A B C} \cdot \frac{c \cdot \cos \measuredangle A B C}{b \cdot \cos \measuredangle A C B} \cdot \frac{a \cdot \cos \measuredangle A C B}{c \cdot \cos \measuredangle B A C}, \text { ou seja, } \\
\frac{A Z}{Z B} \cdot \frac{B X}{X C} \cdot \frac{C Y}{Y A}=1,
\end{gathered}
$$

que, pelo teorema recíproco de Ceva (Teorema 4.14), aplicado ao triângulo $A B C$, conclui-se que as alturas $A X, B Y$ e $C Z$ concorrem em um ponto. Tal ponto $H$ é denominado ortocentro.

Teorema 4.18 (Ponto de Gergonne). Se $X, Y$ e Z são os pontos de contato do incírculo do triângulo ABC com seus lados $A B, A C$ e $B C$, respectivamente, conforme a Figura 40 , então as cevianas $A Z, B Y$ e $C X$ são concorrentes num ponto $G^{\prime}$, chamado Ponto de Gergonne ${ }^{12}$.

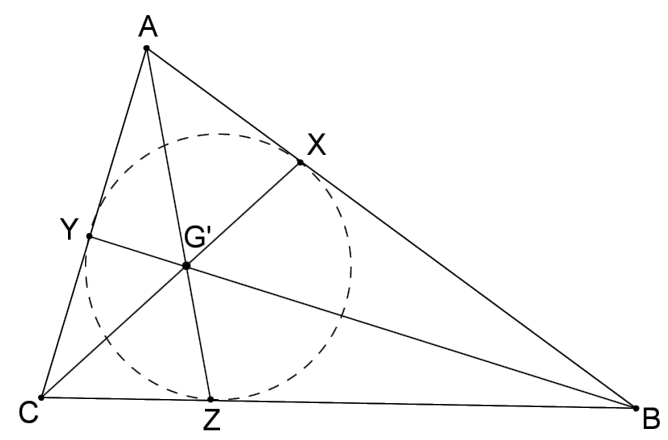

Figura 40 - Ponto de Gergonne

Demonstração. Calculando o produto das razões $\frac{A X}{X B}, \frac{B Z}{Z C} \mathrm{e} \frac{C Y}{Y A}$, uma vez que as tangentes ao incírculo do triângulo $A B C$, traçadas de $A, B$ e $C$, fornecem $A X=A Y, B X=B Z$ e $C Y=C Z$, tem-se

$$
\frac{A X}{X B} \cdot \frac{B Z}{Z C} \cdot \frac{C Y}{Y A}=1
$$

que, pelo teorema recíproco de Ceva (Teorema 4.14), aplicado ao triângulo $A B C$, conclui-se que as cevianas $A Z, B Y$ e $C X$ são concorrentes em um ponto. Tal ponto $G^{\prime}$ é denominado ponto de Gergonne.

12 Joseph-Diez Gergonne (1771-1859) foi um matemático e militar francês, que muito contribuiu para o desenvolvimento da Geometria Projetiva no Séc XIX (MUNIZ NETO 2013). 
Teorema 4.19 (Ponto de Nagel). Se $X, Y$ e $Z$ são os pontos de contato dos exincírculos do triângulo ABC com seus lados $A B, A C$, e $B C$, respectivamente, conforme a Figura 41, então as cevianas $A Z, B Y$ e $C X$ são concorrentes num ponto $N$, chamado Ponto de Nage ${ }^{13}$

Demonstração. Sejam $J, K$ e $L$ os centros dos exincírculos do triângulo $A B C$ de perímetro $2 p$. Os pontos de tangência dessas circunferências com os lados do triângulo são, respectivamente, $Q, X$ e $P$ (exincírculo de centro $J$ ), $U, Y$ e $T$ (exincírculo de centro $K$ ) e $S, Z$ e $R$ (exincírculo de centro $L$ ) (Figura 41 ).

Sejam ainda $B C=a, A C=b$ e $A B=c$ os lados do triângulo $A B C$.

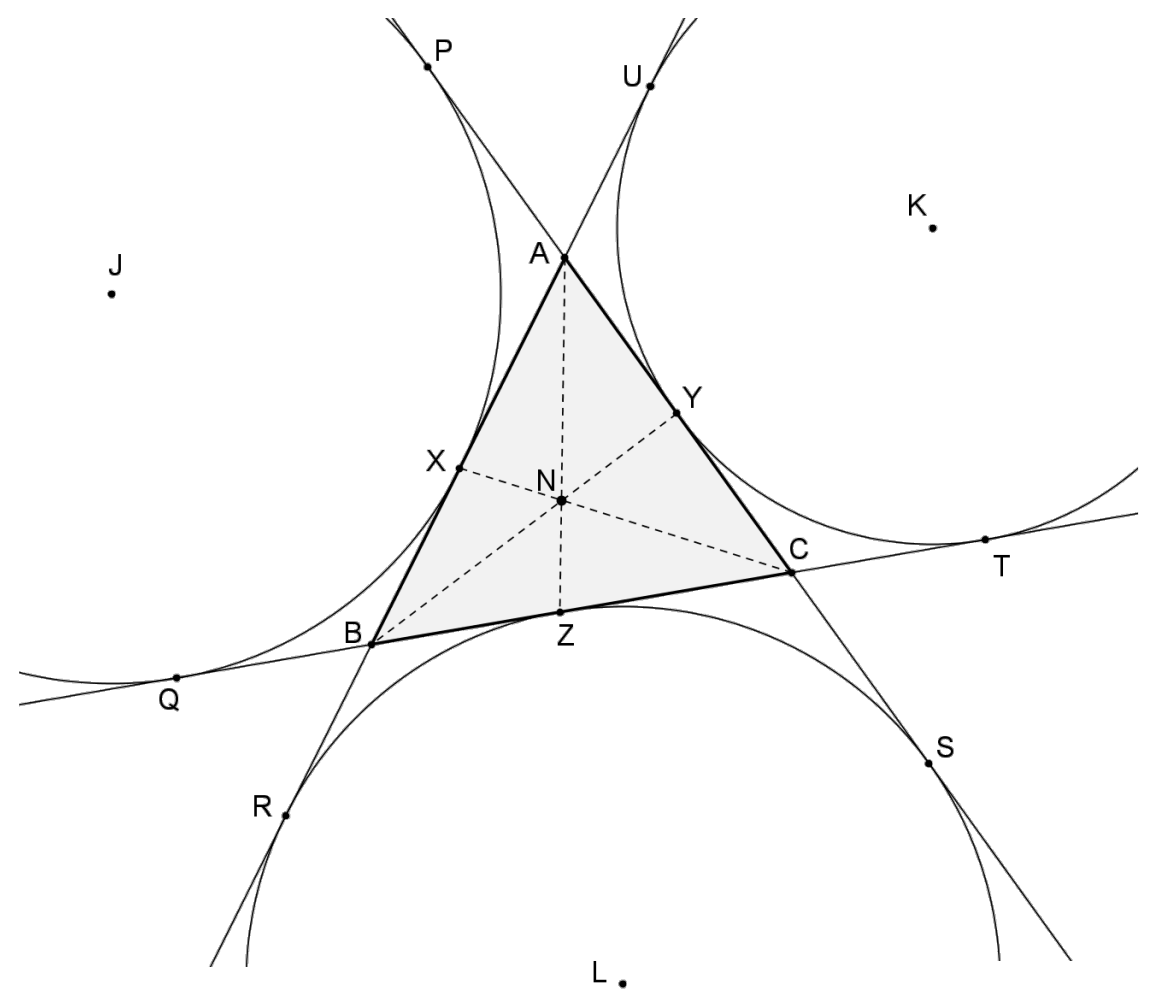

Figura 41 - Ponto de Nagel

Tomando por base o excincírculo de centro $L$, tem-se $A R=A S, B R=B Z$ e $C S=C Z$, o que fornece

$$
\begin{gathered}
A R=A S \\
A B+B R=A C+C S \\
c+B Z=b+C Z .
\end{gathered}
$$

Como $c+B Z+b+C Z=a+b+c=2 p$, decorre que $c+B Z=b+C Z=p$, ou seja,

$$
\begin{aligned}
& B Z=p-c, \\
& C Z=p-b .
\end{aligned}
$$

Analogamente, tomando por base os outros dois exincírculos, chega-se a

13 Christian Heinrich von Nagel (1803-1882) foi um matemático alemão, que desenvolveu diversos trabalhos envolvendo a geometria dos triângulos (MUNIZ NETO 2013. 


$$
\begin{aligned}
& C Y=p-a, \\
& A Y=p-c, \\
& A X=p-b, \\
& B X=p-a .
\end{aligned}
$$
obtém-se

Fazendo o produto das razões $\frac{A X}{X B}, \frac{B Z}{Z C}$ e $\frac{C Y}{Y A}$, a partir dos resultados (19), (20), (21), (22), (23) e (24),

$$
\frac{A X}{X B} \cdot \frac{B Z}{Z C} \cdot \frac{C Y}{Y A}=\frac{p-b}{p-a} \cdot \frac{p-c}{p-b} \cdot \frac{p-a}{p-c}=1,
$$

que, pelo teorema recíproco de Ceva (Teorema 4.14), aplicado ao triângulo $A B C$, conclui-se que as cevianas $A Z, B Y$ e $C X$ concorrem em um ponto. Tal ponto $N$ é denominado ponto de Nagel.

Definição 4.14 (Cevianas isogonais). Se as cevianas $A D$ e $A E$, relativas ao vértice $A$ do triângulo $A B C$, formam ângulos congruentes com os lados $A B$ e AC, respectivamente, então essas cevianas são chamadas Isogonais (Figura 42).

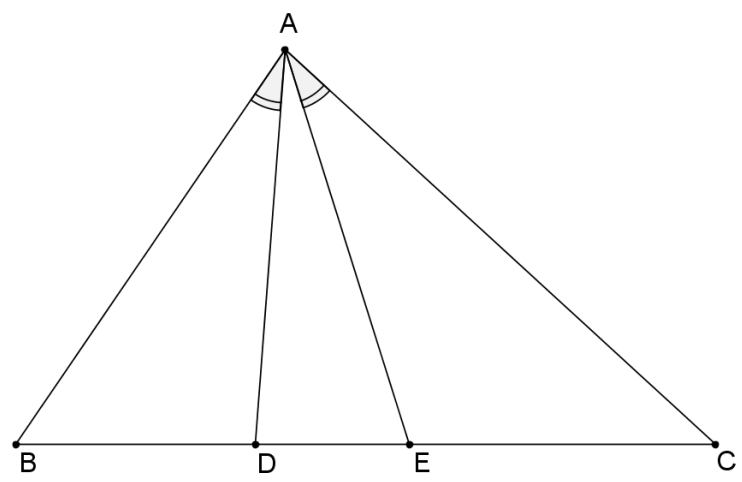

Figura 42 - Cevianas isogonais

Definição 4.15 (Simediana). Chama-se Simediana à isogonal da mediana de um triângulo.

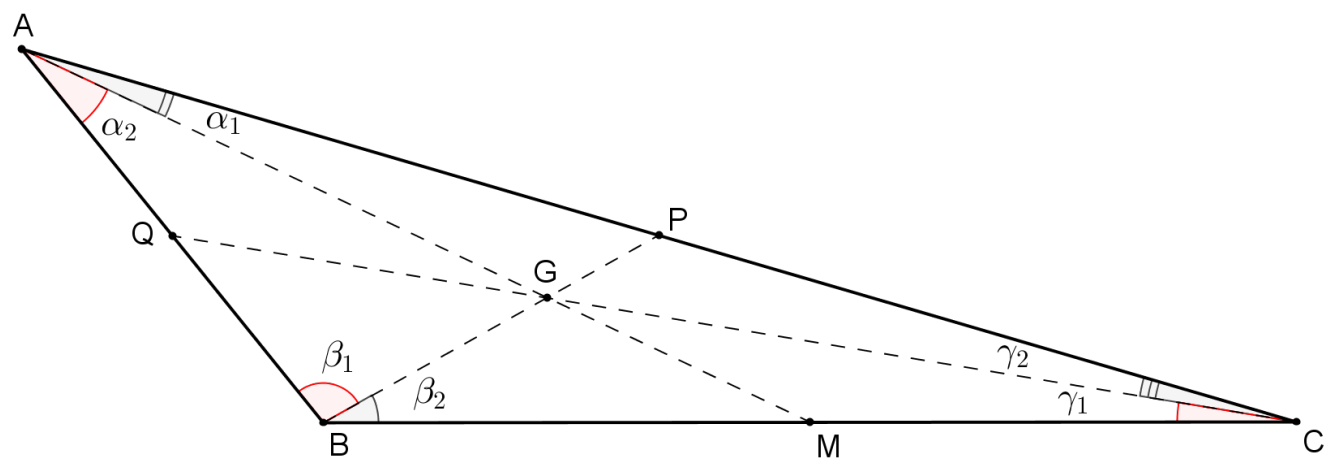

Figura 43 - Demonstração do ponto de Lemoine - $1^{\text {a }}$ parte 
Teorema 4.20 (Ponto de Lemoine). As três simedianas de um triângulo são concorrentes em um ponto K, chamado Ponto Simediano ou Ponto de Lemoine 14

Demonstração. Seja o triângulo $A B C$ com medianas $A M, B P$ e $C Q$, as quais determinam, nos vértices do triângulo, os ângulos $\alpha_{1}, \alpha_{2}, \beta_{1}, \beta_{2}, \gamma_{1}$ e $\gamma_{2}$ (Figura 43 ).

Se pelo Teorema 4.16, essas medianas concorrem no baricentro $G$, então, pelo teorema de Ceva trigonométrico (Teorema 4.15, é possível afirmar que

$$
\frac{\operatorname{sen} \alpha_{1}}{\operatorname{sen} \alpha_{2}} \cdot \frac{\operatorname{sen} \beta_{1}}{\operatorname{sen} \beta_{2}} \cdot \frac{\operatorname{sen} \gamma_{1}}{\operatorname{sen} \gamma_{2}}=1,
$$

onde $\alpha_{1}+\alpha_{2}=\measuredangle B A C, \beta_{1}+\beta_{2}=\measuredangle A B C$ e $\gamma_{1}+\gamma_{2}=\measuredangle B C A$.

Sejam $A M^{\prime}, B P^{\prime}$ e $C Q^{\prime}$ as simedianas do triângulo $A B C$ (Figura 44). Pelo teorema recíproco de Ceva trigonométrico, as simedianas serão concorrentes se

$$
\frac{\operatorname{sen} \alpha_{2}}{\operatorname{sen} \alpha_{1}} \cdot \frac{\operatorname{sen} \beta_{2}}{\operatorname{sen} \beta_{1}} \cdot \frac{\operatorname{sen} \gamma_{2}}{\operatorname{sen} \gamma_{1}}=1
$$

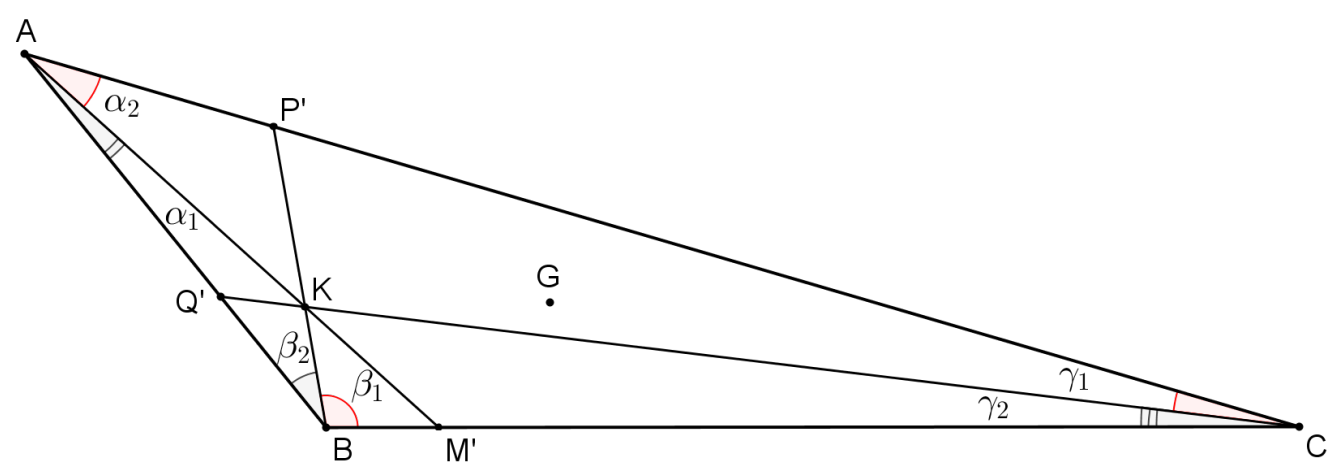

Figura 44 - Demonstração do ponto de Lemoine - $2^{\text {a }}$ parte

Uma vez que as simedianas são isogonais das medianas, os ângulos determinados nos vértices do triângulo $A B C$ são os mesmos $\alpha_{1}, \alpha_{2}, \beta_{1}, \beta_{2}, \gamma_{1}$ e $\gamma_{2}$, mas numa ordem inversa, onde $\alpha_{2}+\alpha_{1}=\measuredangle B A C$, $\beta_{2}+\beta_{1}=\measuredangle A B C$ e $\gamma_{2}+\gamma_{1}=\measuredangle B C A$ (Figura 44). Portanto, a equação (26) é verdadeira, uma vez que é equivalente à equação (25), donde se conclui que as simedianas concorrem em um ponto $K$ (ponto de Lemoine).

Nota: Os pontos $G$ (baricentro) e $K$ (simediano ou de Lemoine) são chamados conjugados isogonais.

MUNIZ NETO (2013) prova a seguinte propriedade do ponto Simediano: a soma dos quadrados das distâncias de um ponto aos lados de um triângulo é mínima se, e somente se, este ponto for o ponto de Lemoine do triângulo.

Teorema 4.21 (Monge $\mathfrak{E}^{15}$ ). Dados três círculos de raios distintos, não situados completamente no interior uns dos outros, então as tangentes comuns externas a cada par de círculos determinam três pontos colineares (Figura 45).

14 Emile Lemoine (1840-1912) foi um engenheiro e matemático francês que contribuiu principalmente com o estudo dos triângulos na Geometria, descobrindo o ponto notável que leva o seu nome em 1873 SMITH 1896.

15 Gaspard Monge (1746-1818) foi um matemático francês considerado o pai da Geometria Descritiva, tendo contribuído muito também na área da Geometria Projetiva. 


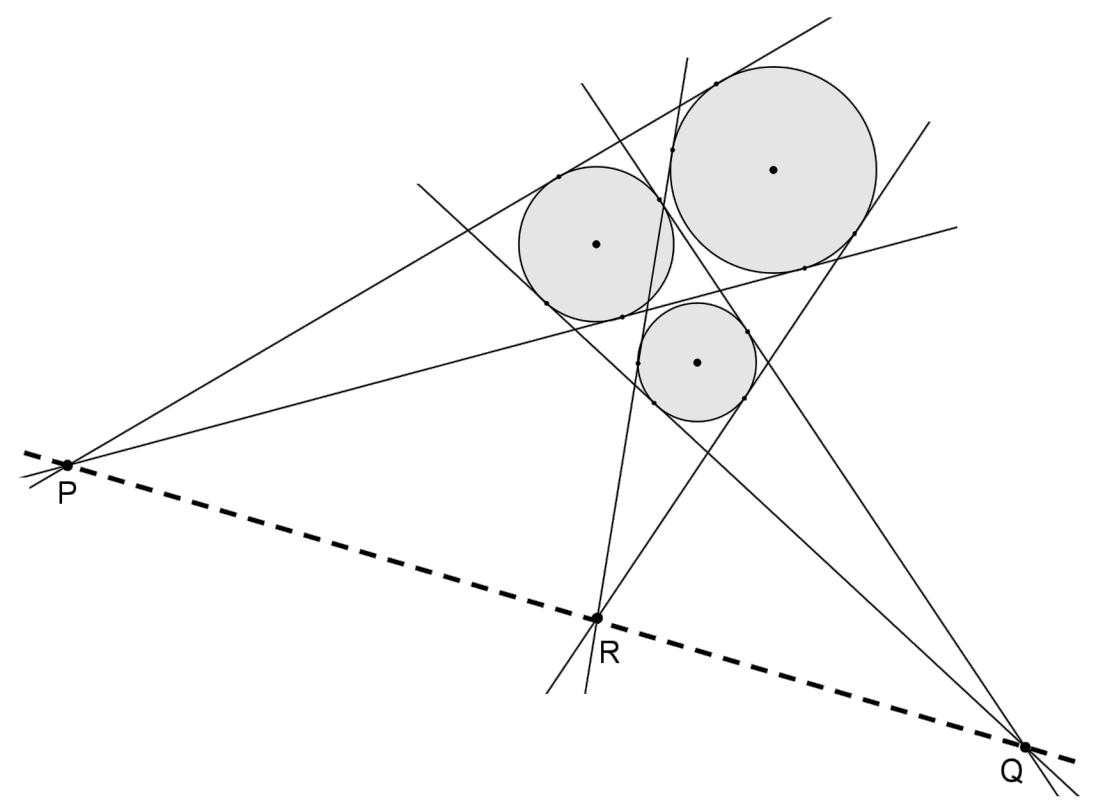

Figura 45 - Teorema de Monge

Demonstração. Denotando por $A, B$ e $C$ os centros dos círculos, então cada terno de pontos $(P, A, C),(R, B, C)$ e $(Q, B, A)$ pertencem a uma reta, que passa por dois centros e pelo ponto exterior de onde partem as tangentes comuns aos círculos (Figura 46).

Sejam $X, Y$ e $Z$ pontos de encontro das tangentes comuns externas que determinam um triângulo $X Y Z$ de lados tangentes aos círculos e que englobam os três círculos dados (Figura 46). Assim, $X A, Y B$ e $Z C$ são bissetrizes internas do triângulo $X Y Z$ que se encontram no seu incentro $I$ (ver Proposição 4.3 .

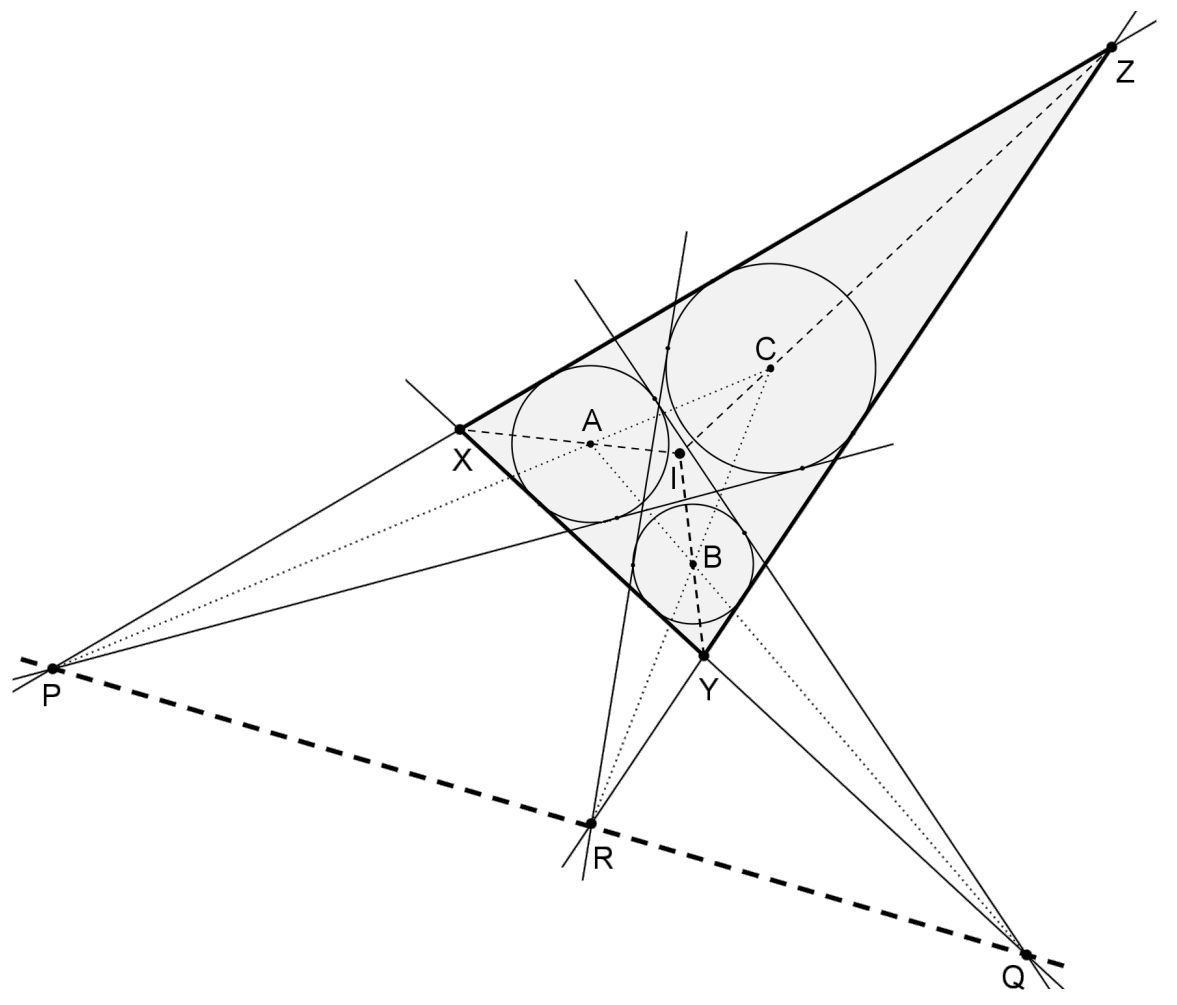

Figura 46 - Demonstração do teorema de Monge

Aplicando o teorema de Menelaus (Teorema 4.10), na sua versão básica, no triângulo $I X Z$, cortado 
pela reta $P C$, tem-se $\frac{Z P}{P X} \cdot \frac{X A}{A I} \cdot \frac{I C}{C Z}=1$, que fornece

$$
\frac{Z P}{P X}=\frac{C Z}{I C} \cdot \frac{A I}{X A}
$$

Analogamente, no triângulo $I X Y$, cortado pela reta $Q A$, tem-se $\frac{I A}{A X} \cdot \frac{X Q}{Q Y} \cdot \frac{Y B}{B I}=1$, que fornece

$$
\frac{X Q}{Q Y}=\frac{B I}{Y B} \cdot \frac{A X}{I A}
$$

De igual modo, no triângulo $I Z Y$, cortado pela reta $R C$, tem-se $\frac{I B}{B Y} \cdot \frac{Y R}{R Z} \cdot \frac{Z C}{C I}=1$, que fornece

$$
\frac{Y R}{R Z}=\frac{C I}{Z C} \cdot \frac{B Y}{I B}
$$

Multiplicando-se as equações (27), (28) e (29), obtém-se

$$
\begin{gathered}
\frac{Z P}{P X} \cdot \frac{X Q}{Q Y} \cdot \frac{Y R}{R Z}=\frac{C Z}{I C} \cdot \frac{A I}{X A} \cdot \frac{B I}{Y B} \cdot \frac{A X}{I A} \cdot \frac{C I}{Z C} \cdot \frac{B Y}{I B} \\
\frac{Z P}{P X} \cdot \frac{X Q}{Q Y} \cdot \frac{Y R}{R Z}=1 .
\end{gathered}
$$

Tal expressão, pelo teorema recíproco de Menelaus (Teorema 4.11), aplicado ao triângulo $X Y Z$, garante que os pontos $P, Q$ e $R$ são colineares.

Nota: O teorema é válido quando a posição relativa entre os três círculos permitir a existência dos três pares de tangentes comuns externas.

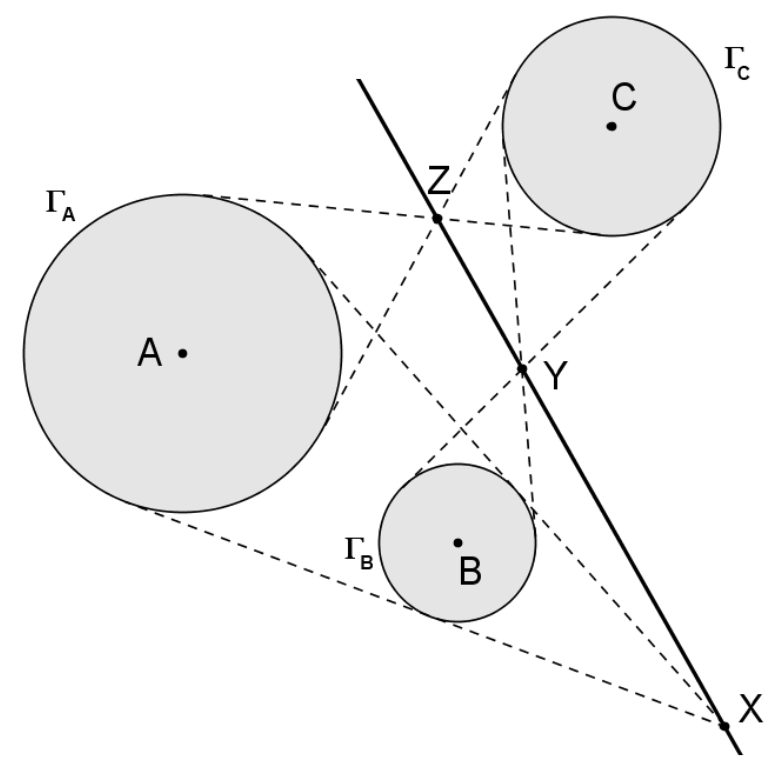

Figura 47 - Teorema de Monge-d'Alembert

Teorema 4.22 (Monge-d'Alembert ${ }^{16}$. Dados três círculos de raios distintos, com pelo menos dois pares deles exteriores entre si, então as tangentes comuns internas de dois pares de círculos e as tangentes comuns externas do par de círculos restante determinam três pontos colineares (Figura 477).

16 Jean Le Rond d'Alembert (1717-1783) foi um matemático e físico francês do séc. XVIII que teve grande destaque nas áreas de Mecânica, Álgebra e Cálculo. 
Demonstração. Sejam $A, B$ e $C$ os centros de três círculos $\Gamma_{A}, \Gamma_{B}$ e $\Gamma_{C}$, de raios $r_{A}, r_{B}$ e $r_{C}$, respectivamente (Figura 47).

Se $Z$ e $Y$ são os pontos de interseção das tangentes comuns internas de $\Gamma_{A}$ e $\Gamma_{C}$ e de $\Gamma_{B}$ e $\Gamma_{C}$, respectivamente, e $X$ é o ponto de interseção das tangentes comuns externas de $\Gamma_{A}$ e $\Gamma_{B}$, então $X, Y$ e $Z$ serão colineares se, aplicando o teorema de Menelaus (Teorema 4.10), na sua versão básica, no triângulo $A B C$ (Figura 48 ), for encontrada a igualdade, ou seja,

$$
\frac{A Z}{Z C} \cdot \frac{C Y}{Y B} \cdot \frac{B X}{X A}=1
$$

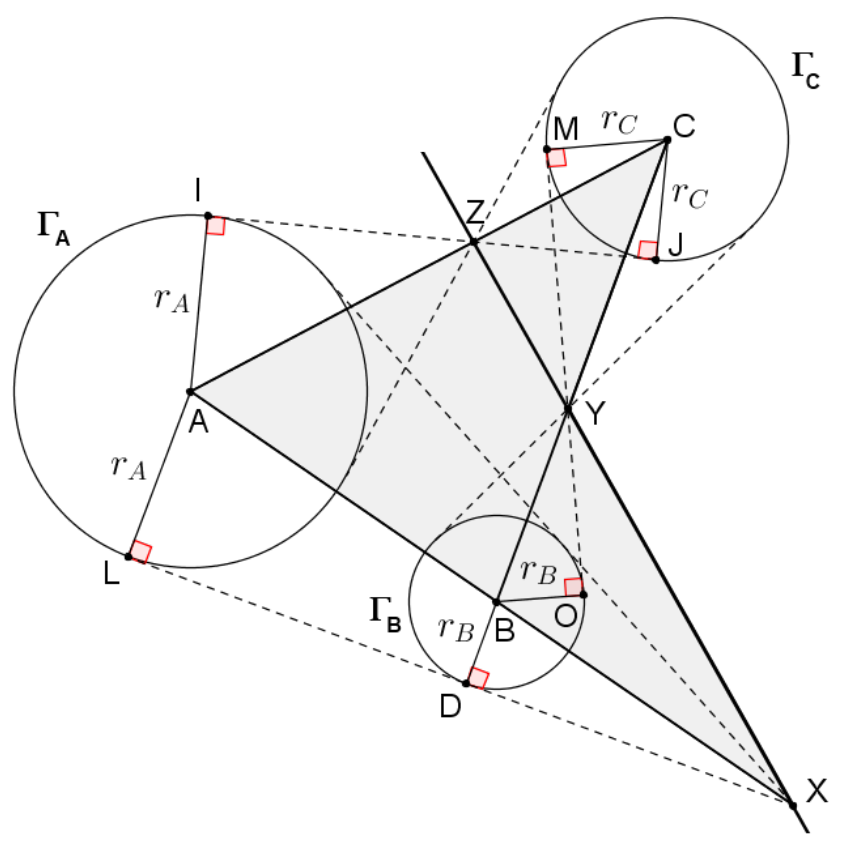

Figura 48 - Demonstração do teorema de Monge-d'Alembert

Considere a Figura 48, onde $A I=A L=r_{A}, B O=B D=r_{B}$ e $C J=C M=r_{C}$. Como os triângulos retângulos $A I Z$ e $C J Z$ são semelhantes, então $\frac{A Z}{Z C}=\frac{r_{A}}{r_{C}}$. Analogamente, os triângulos retângulos $C M Y$ e $B O Y$ são semelhantes, $\operatorname{com} \frac{C Y}{Y B}=\frac{r_{C}}{r_{B}}$; e, os triângulos retângulos $B D X$ e $A L X$ também são semelhantes, $\operatorname{com} \frac{B X}{X A}=\frac{r_{B}}{r_{A}}$.

Desse modo, tem-se, a partir da equação (30), que

$$
\frac{A Z}{Z C} \cdot \frac{C Y}{Y B} \cdot \frac{B X}{X A}=\frac{r_{A}}{r_{C}} \cdot \frac{r_{C}}{r_{B}} \cdot \frac{r_{B}}{r_{A}}=1
$$

o que confirma que os pontos $X, Y$ e $Z$ estão alinhados.

Nota: O teorema é válido quando a posição relativa entre os três círculos permitir a existência de dois pares de tangentes comuns internas e um par de tangentes comuns externas. 
Teorema 4.23 (Reta de Euler). $O$ ortocentro $H$, o circuncentro $O$ e o baricentro $G$ de um triângulo são colineares e pertencem à reta chamada Reta de Euler ${ }^{17}$, com $G$ dividindo o segmento $O H{ }^{18}$ na razão $\frac{O G}{G H}=\frac{1}{2}$ (Figura 49).

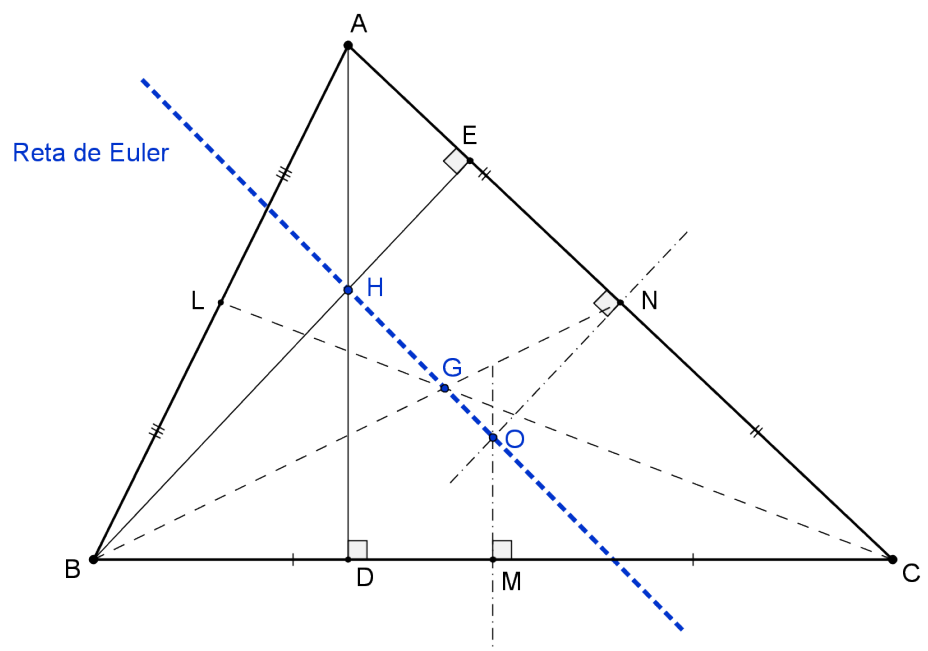

Figura 49 - Reta de Euler

Demonstração. Seja $A B C$ um triângulo cujos pontos médios dos seus lados são os pontos $L, M$ e $N$. Sejam ainda $H$ o seu ortocentro e $O$ o seu circuncentro (Figura 49 ).

Traçando-se o segmento $M N$, obtém-se dois triângulos semelhantes, $A B H$ e $M N O$, com três lados paralelos dois a dois: $A H\|M O, B H\| N O$ e $A B \| M N$ (Figura[50).

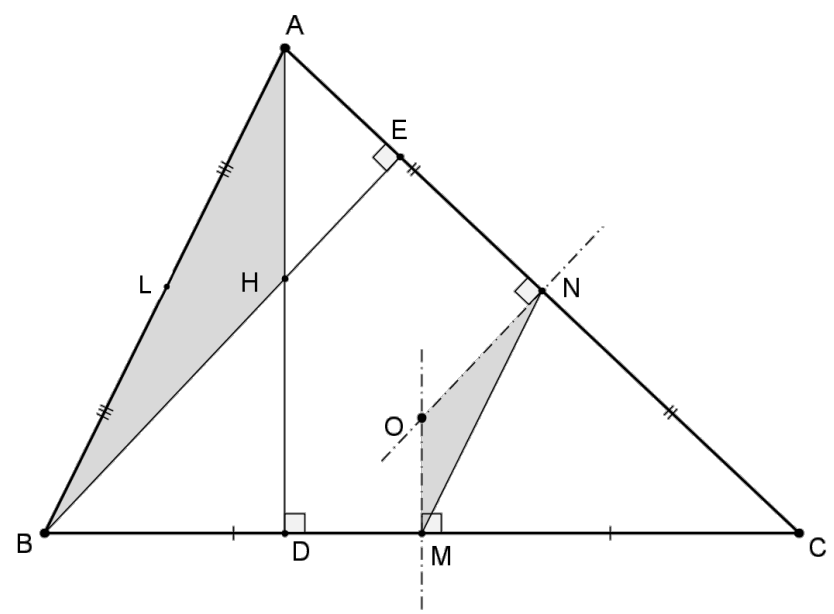

Figura 50 - Demonstração da Reta de Euler - $1^{\text {a }}$ parte

Como $M N$ é base média do triângulo $A B C$, tem-se $\frac{M N}{A B}=\frac{1}{2}$ e, por conseguinte,

$$
\frac{N O}{B H}=\frac{M O}{A H}=\frac{1}{2} .
$$

17 O suiço Leonhard Euler viveu no séc. XVIII e até hoje é considerado o matemático que mais publicou trabalhos relevantes. Suas contribuições variam da Física à Matemática, da Geometria à Combinatória, passando ainda pela Teoria dos Números MUNIZ NETO 2013.

18 MUNIZ NETO (2013) denomina o segmento $O H$ de mediana de Euler do triângulo. 
Considere agora que, ao traçar a mediana $A M$, esta encontre o segmento $H O$ no ponto $T$ (Figura 51), obtendo-se também outros dois triângulos semelhantes, AHT e MOT, com

$$
\frac{M O}{A H}=\frac{O T}{H T}=\frac{T M}{T A} .
$$

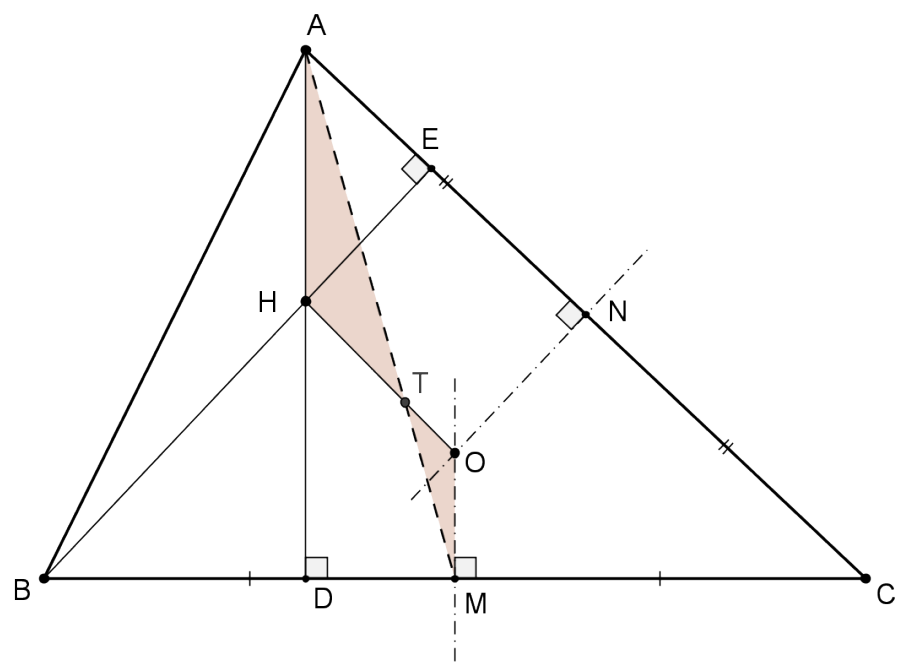

Figura 51 - Demonstração da Reta de Euler - 2a parte

De (31) e (32), tem-se que $\frac{T M}{T A}=\frac{1}{2}$, o que faz de $T$, conforme o Teorema 4.16 , o baricentro $G$ do triângulo $A B C(T \equiv G)$. Logo, o ortocentro $H$, o circuncentro $O$ e o baricentro $G$ são colineares, com $\frac{O G}{G H}=\frac{1}{2}$.

Nota: Observe que em um triângulo equilátero, a reta de Euler não está definida, uma vez que as medianas, as alturas e as mediatrizes são concorrentes num mesmo ponto, com $G \equiv H \equiv O$.

NEVES (2013) demonstra a colinearidade de $G, H$ e $O$ na reta de Euler usando coordenadas cartesianas.

Teorema 4.24 (Reta de Housel). O baricentro $G$, o incentro I e o ponto de Nagel $N$ de um triângulo são colineares e pertencem à reta chamada Reta de Housel, com G dividindo o segmento IN na razão $\frac{I G}{G N}=\frac{1}{2}$.

Demonstração. Sejam os pontos $G$ e $I$, respectivamente, o baricentro e o incentro do triângulo $A B C$, de lados $B C=a, A C=b$ e $A B=c$. Seja $p$ o semiperímetro de $A B C$ e $[A B C]$ a sua área. Sabe-se que, pelo Teorema 4.16, o ponto $G$ divide a mediana $A M$ na razão 1:2, ou seja, se $G M=u$, então $A G=2 u$ (Figura 52).

Ligando-se $I$ a $M$ e prolongando-se o segmento $I G=t$ até um ponto $N$, tal que $G N=2 t$, formam-se dois triângulos semelhantes: $I G M$ e $N G A$ (caso $L A L$ ). Sendo $\measuredangle I M G=\measuredangle N A G$, então $I M \| N A$ (Figura 52).

Deseja-se provar, portanto, que $N$ é o ponto de Nagel do triângulo $A B C$.

Com base no Teorema 4.19 dadas as cevianas $A Z, B Y$ e $C X$ do triângulo $A B C$, concorrentes em $N$, tem-se que $N$ será o ponto de Nagel de $A B C$ se forem verificadas as seguintes igualdades:

$$
\begin{aligned}
& \checkmark \quad \underline{\text { Lado } a}: B Z=p-c, C Z=p-b ; \\
& \checkmark \quad \underline{\text { Lado } b}: A Y=p-c, C Y=p-a ;
\end{aligned}
$$


$\checkmark \quad$ Lado $c: A X=p-b, B X=p-a$.

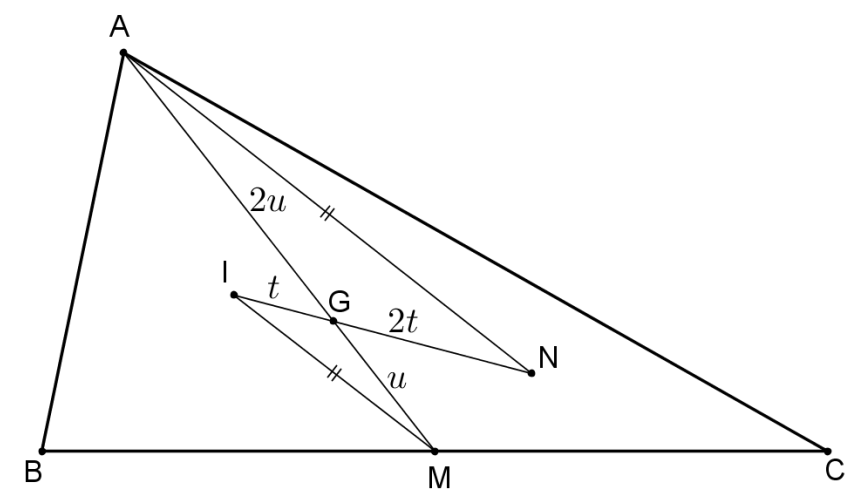

Figura 52 - Demonstração da Reta de Housel - $1^{\text {a }}$ parte

Basta provar essas igualdades para um dos lados - por exemplo, o lado $a$ - que os demais lados são provados analogamente. Dessa forma, prolongando-se $A N$ até encontrar o lado $a \mathrm{em} Z$, deve-se provar que $B Z=p-c$ e que $C Z=p-b$ (Figura 53).

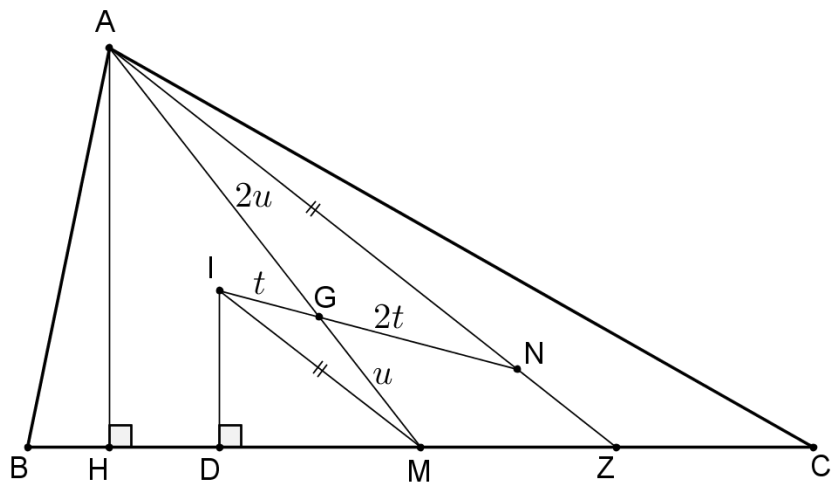

Figura 53 - Demonstração da Reta de Housel - 2a parte

Seja $A H$ a altura relativa ao lado $a$ de $A B C$ e $D$ a projeção ortogonal de $I$ sobre este mesmo lado (Figura[53. Uma vez que $I M \| N A$, tem-se dois triângulos semelhantes: $I D M$ e $A H Z$. Portanto,

$$
\frac{H Z}{D M}=\frac{A H}{I D}
$$

Pelo Teorema 4.1 e pela Proposição 4.9, tem-se que $I D=r$ (raio do incírculo do triângulo $\mathrm{ABC}$ ) e $A H=\frac{2 \cdot[A B C]}{a}=\frac{2 \cdot p r}{a}$. Logo, $\frac{A H}{I D}=\frac{2 p}{a}$ e, de (33), conclui-se que $\frac{H Z}{D M}=\frac{2 p}{a}$, donde

$$
H Z=\frac{2 p}{a} \cdot D M
$$

Com base na Figura 54 onde $A E=A F=y, B D=B F=x$ e $C D=C E=z$, é fácil ver que $x+y+z=p$, ou seja, $B D=x=p-(y+z)=p-b$. Assim,

$$
\begin{gathered}
D M=B M-B D=\frac{a}{2}-(p-b) \\
D M=\frac{a}{2}-\frac{a+b+c}{2}+b
\end{gathered}
$$




$$
D M=\frac{b-c}{2} .
$$

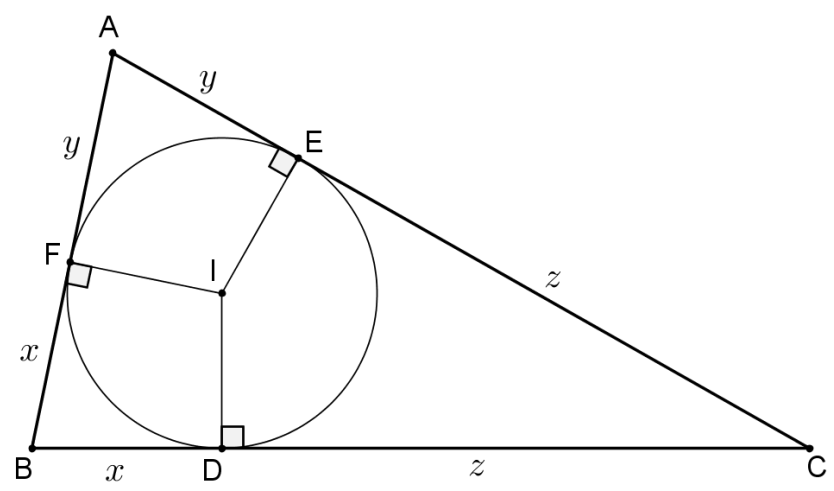

Figura 54 - Demonstração da Reta de Housel - 3ª parte

Substituindo este valor em (34), obtém-se $H Z=\frac{2 p}{a} \cdot \frac{b-c}{2}=\frac{p(b-c)}{a}$.

Ademais, aplicando-se a Lei dos Cossenos no triângulo $A B C$, tem-se que $b^{2}=a^{2}+c^{2}-2 a c \cdot \cos \hat{B}$. Mas, $\operatorname{como} c \cdot \cos \hat{B}=B H$, então $B H=\frac{a^{2}+c^{2}-b^{2}}{2 a}$.

Finalmente,

$$
\begin{gathered}
B Z=B H+H Z \\
B Z=\frac{a^{2}+c^{2}-b^{2}}{2 a}+\frac{p(b-c)}{a} \\
B Z=\frac{a^{2}+c^{2}-b^{2}+(a+b+c)(b-c)}{2 a} \\
B Z=\frac{a^{2}+c^{2}-b^{2}+a b-a c+b^{2}-b c+b c-c^{2}}{2 a} \\
B Z=\frac{a^{2}+a b-a c}{2 a} \\
B Z=\frac{a+b-c}{2} \\
B Z=p-c .
\end{gathered}
$$

E ainda, $C Z=a-B Z=a-(p-c)=a-\frac{a+b+c}{2}+c=\frac{2 a-a-b-c+2 c}{2}=\frac{a+c-b}{2}$, ou seja,

$$
C Z=p-b
$$

Analogamente, prova-se para o lado $b$, que $A Y=p-c$ e $C Y=p-a$; e para o lado $c$, que $A X=p-b$ e $B X=p-a$, o que faz de $N$ o ponto de Nagel do triângulo $A B C, \operatorname{com} \frac{I G}{G N}=\frac{1}{2}$.

Definição 4.16 (Reta de Nagel). A reta que passa pelo incentro I e pelo circuncentro O de um triângulo é chamada Reta de Nagel. 
Definição 4.17 (Reta de Newton). A reta que une os pontos médios das diagonais de um quadrilátero convexo, não paralelogramo, é chamada Reta de Newtor $2^{19}$.

Definição 4.18 (Quadrilátero completo). Sejam quatro retas de um plano em que cada uma intercepta as outras em apenas um ponto, não havendo triplas retas concorrentes. A essa configuração dá-se o nome de Quadrilátero Completo (Figura 55).

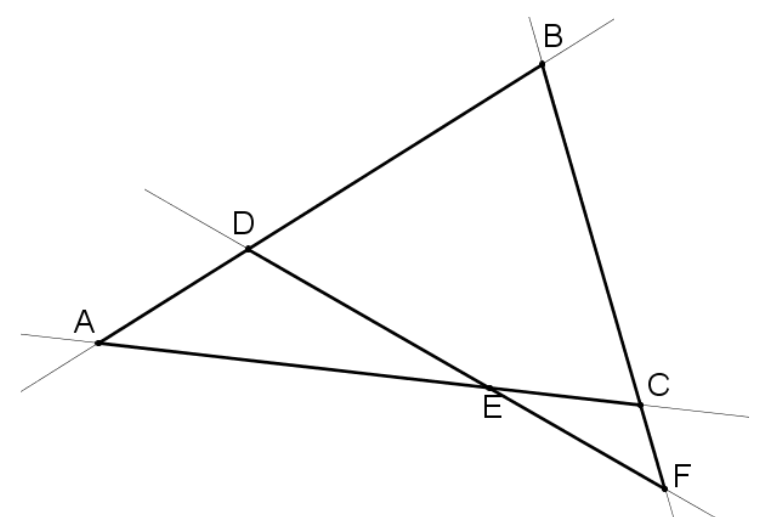

Figura 55 - Quadrilátero completo

Nota: Um quadrilátero completo possui seis pontos de interseção $(A, B, C, D, E, F)$, três diagonais $(A F, B E, C D)$ e forma quatro triângulos ( $A B C, B D F, C E F, D E A)$ (Figura[55).

Teorema 4.25 (Reta de Gauss-Newton). Os pontos médios das diagonais de um quadrilátero completo são colineares e formam a reta de Gauss-Newton ${ }^{20}$.

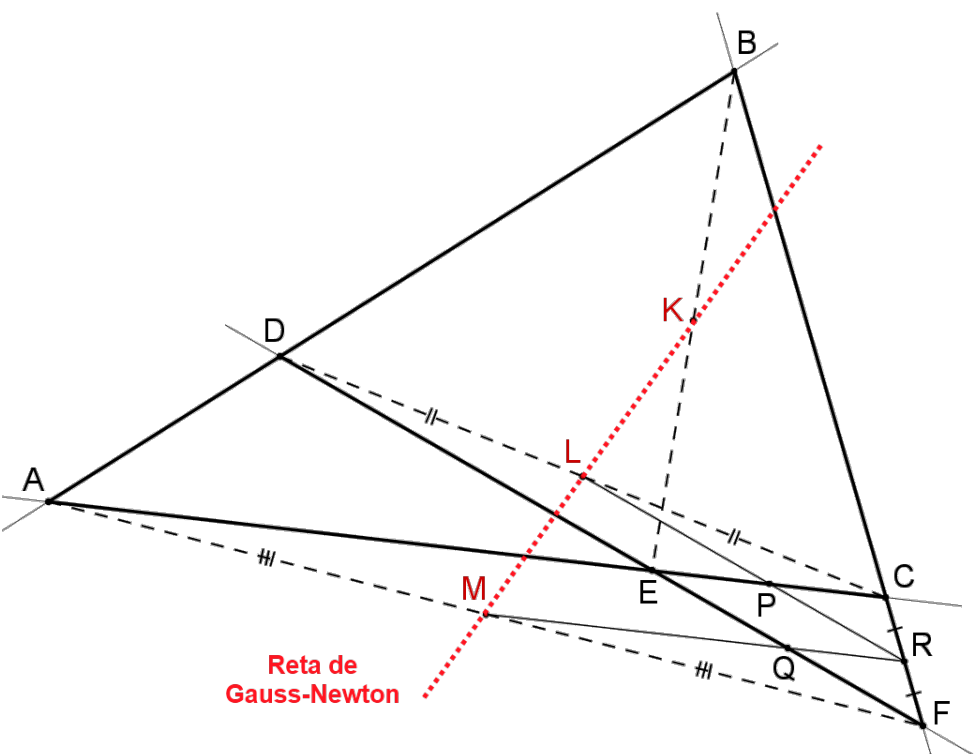

Figura 56 - Demonstração da Reta de Gauss-Newton

19 Isaac Newton (1642-1727) foi um cientista inglês que se destacou em várias áreas do conhecimento, principalmente na Matemática e na Física.

20 Carl Friedrich Gauss (1777-1855) foi um matemático e físico alemão que deixou inúmeras contribuições nas mais diversas Ciências. 
Demonstração. Sejam $K, L$ e $M$, respectivamente, os pontos médios das diagonais $B E, D C$ e $A F$ do quadrilátero completo $A D B C F E$.

Traçando-se por $M$ uma paralela à $A C$, esta encontra $C F$ em $R$ e, como $M$ é médio de $A F$, então $R$ é médio de $C F$ e, portanto, $M R$ é base média do triângulo $A C F$. Analogamente, $L R$ é base média do triângulo $F D C$ e paralela à reta $D F$ (Figura 56 ).

Sejam $P$ o ponto de encontro de $A C$ com $L R$ e $Q$ o ponto de encontro de $D F$ com $M R$.

Pela Lei de Proporcionalidade de Tales no triângulo $A C F$ :

$$
\left.\begin{array}{l}
F M=M A \\
F R=R C
\end{array}\right\} \Rightarrow F Q=Q E(Q \text { é médio de } F E)
$$

Analogamente, no triângulo $F D C$ :

$$
\left.\begin{array}{l}
C L=L D \\
C R=R F
\end{array}\right\} \Rightarrow C P=P E(P \text { é médio de } C E)
$$

Desse modo, a reta $Q P$ ( $Q$ e $P$ médios) encontra $K$ (médio de $B E$ ), formando a base média do triângulo $E B F$.

O teorema de Menelaus (Teorema 4.10 , aplicado no triângulo $C E F$, cortado pela reta $A B$, fornece

$$
\frac{C A}{A E} \cdot \frac{E D}{D F} \cdot \frac{F B}{B C}=1,
$$

que comprova o alinhamento já conhecido dos pontos $A, D$ e $B$.

As bases médias dos triângulos formados determinam as seguintes equações (Figura[56):

$$
\begin{aligned}
& C A=2 \cdot R M(\triangle F C A), \\
& A E=2 \cdot M Q(\triangle F A E), \\
& E D=2 \cdot P L(\triangle C E D), \\
& D F=2 \cdot L R(\triangle C D F), \\
& F B=2 \cdot Q K(\triangle E F B), \\
& B C=2 \cdot K P(\triangle E B C) .
\end{aligned}
$$

Substituindo essas seis equações em (35), obtém-se:

$$
\begin{gathered}
\frac{2 \cdot R M}{2 \cdot M Q} \cdot \frac{2 \cdot P L}{2 \cdot L R} \cdot \frac{2 \cdot Q K}{2 \cdot K P}=1, \text { ou } \\
\frac{Q K}{K P} \cdot \frac{P L}{L R} \cdot \frac{R M}{M Q}=1 .
\end{gathered}
$$

Tal expressão, pelo teorema recíproco de Menelaus (Teorema 4.11), aplicado ao triângulo $Q P R$, garante que os pontos $K, L$ e $M$ são colineares. 
Uma outra forma interessante de demonstrar este teorema é utilizando a Geometria Analítica 21

Proposição 4.18 (Quadrilátero inscritível). Um quadrilátero convexo é inscritível se, e somente se, seus ângulos opostos são suplementares.

Prova. Seja $A B C D$ um quadrilátero inscrito em um círculo. Se $\measuredangle A=\alpha$ e $\measuredangle C=\gamma$, então o $\operatorname{arco} B \widehat{C} D=2 \alpha$ e o $\operatorname{arco} \widehat{D A B}=2 \gamma$. Assim, $2 \alpha+2 \gamma=360^{\circ}$ e $\alpha+\gamma=180^{\circ}$ (suplementares).

Reciprocamente, seja $A B C D$ um quadrilátero com ângulos opostos $\angle D A B$ e $\angle B C D$, tais que $\measuredangle D A B+\measuredangle B C D=180^{\circ}$.

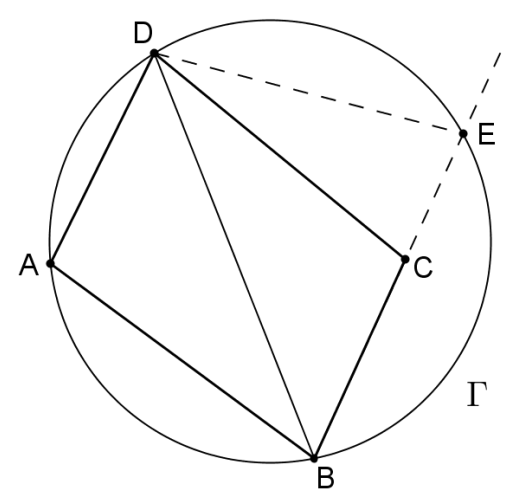

Figura 57 - Prova do quadrilátero inscritível

Considere o circuncírculo $\Gamma$ do triângulo $D A B$. Seja $C$ um ponto (interior ou exterior a $\Gamma$ ), em que $E$ é a interseção de $B C \operatorname{com} \Gamma$ (Figura 57). Desse modo, $\widetilde{D A} B+B \widehat{E} D=360^{\circ}$ e, consequentemente, $\measuredangle D A B+\measuredangle B E D=180^{\circ}$, ou seja, $\measuredangle B E D=\measuredangle B C D$ e $E \equiv C$. Logo, $A B C D$ é inscritível.

Nota: Um quadrilátero inscritível também é chamado de quadrilátero cíclico.

Proposição 4.19 (Lema no11 de Arquimedes ${ }^{22}$ ). Sejam AC e BD duas cordas perpendiculares de um círculo de centro $O$ e raio $r$, que se cruzam no ponto $X$. Se $A X=a, B X=b, C X=c$ e $D X=d$, então $a^{2}+b^{2}+c^{2}+d^{2}=$ $4 r^{2}$ (Figura 58).

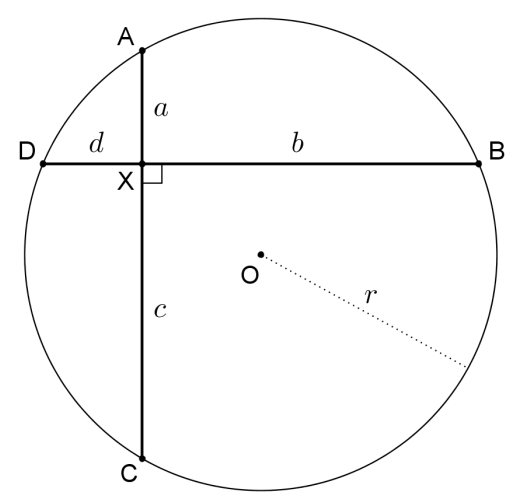

Figura 58 - Lema nº11 de Arquimedes

21 Essa outra forma de demonstrar o teorema será deixada a cargo do leitor.

22 Este lema faz parte da obra Book of Lemmas, manuscrito que chegou à Europa em 1659, no idioma árabe, e cuja autoria é atribuída ao matemático grego Arquimedes. O livro é uma coleção de 15 lemas envolvendo círculos (HEATH 2010 . 
Prova. Traçando-se por $O$ as paralelas $O E \| B D$ e $O F \| C A$, tem-se que $E$ e $F$ são pontos médios de $A C$ e $B D$ (Proposição 4.3), respectivamente (Figura 59). Logo,

$$
\begin{gathered}
B F=\frac{B D}{2}=\frac{b+d}{2}, \mathrm{e} \\
C E=\frac{A C}{2}=\frac{a+c}{2} .
\end{gathered}
$$

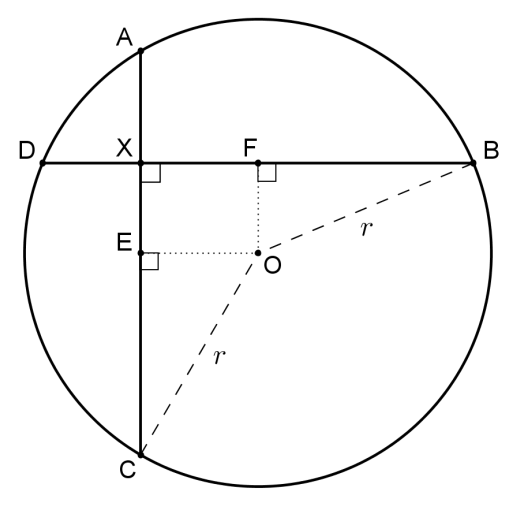

Figura 59 - Prova do Lema no 11 de Arquimedes

Além disso,

$$
\begin{gathered}
O E=B X-B F=b-\frac{b+d}{2}=\frac{b-d}{2}, \mathrm{e} \\
O F=C X-C E=c-\frac{a+c}{2}=\frac{a-c}{2} .
\end{gathered}
$$

Nos triângulos retângulos $O C E$ e $O B F$, tem-se, respectivamente,

$$
\begin{aligned}
& r^{2}=\left(\frac{a+c}{2}\right)^{2}+\left(\frac{b-d}{2}\right)^{2} \mathrm{e} \\
& r^{2}=\left(\frac{b+d}{2}\right)^{2}+\left(\frac{c-a}{2}\right)^{2}
\end{aligned}
$$

Somando-se as equações (36) e (37), obtém-se

$$
\begin{gathered}
2 r^{2}=\left(\frac{a+c}{2}\right)^{2}+\left(\frac{b-d}{2}\right)^{2}+\left(\frac{b+d}{2}\right)^{2}+\left(\frac{c-a}{2}\right)^{2} \\
2 r^{2}=\frac{2 a^{2}+2 c^{2}+2 b^{2}+2 d^{2}}{4} \\
4 r^{2}=a^{2}+b^{2}+c^{2}+d^{2} .
\end{gathered}
$$

Teorema 4.26 (Arquimedes). Seja um quadrilátero inscritível em um círculo de raio $r$, cujas diagonais são perpendiculares entre si. Se $a, b, c$ e d são os lados desse quadrilátero, então $a^{2}+b^{2}+c^{2}+d^{2}=8 r^{2}$.

Demonstração. Seja $A B C D$ um quadrilátero inscritível, com lados $A B=a, B C=b, C D=c$ e $D A=d$, sendo $X$ o ponto de encontro das diagonais $A C$ e $B D$, perpendiculares entre si (Figura 60). 


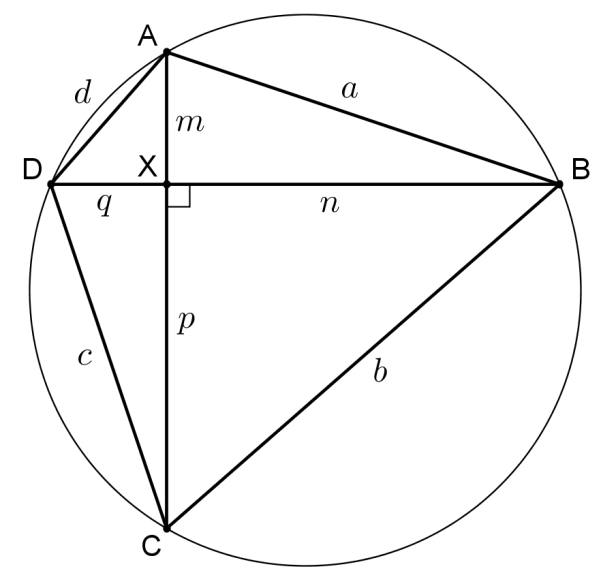

Figura 60 - Demonstração do teorema de Arquimedes

Chamando $A X=m, B X=n, C X=p$ e $D X=q$, tem-se, nos triângulos retângulos $A X B, B X C, C X D$ e $D X A$, que

$$
\begin{aligned}
& m^{2}+n^{2}=a^{2}, \\
& n^{2}+p^{2}=b^{2}, \\
& p^{2}+q^{2}=c^{2}, \\
& q^{2}+n^{2}=d^{2} .
\end{aligned}
$$

Somando-se essas quatro equações, obtém-se

$$
2\left(m^{2}+n^{2}+p^{2}+q^{2}\right)=a^{2}+b^{2}+c^{2}+d^{2} .
$$

Do Lema no 11 de Arquimedes (Proposição 4.19, sabe-se que $4 r^{2}=m^{2}+n^{2}+p^{2}+q^{2}$. Assim,

$$
\begin{gathered}
2\left(4 r^{2}\right)=a^{2}+b^{2}+c^{2}+d^{2} \\
8 r^{2}=a^{2}+b^{2}+c^{2}+d^{2} .
\end{gathered}
$$

Proposição 4.20. Se um quadrilátero qualquer, de lados $a, b, c$ ed, nesta ordem, possui diagonais perpendiculares entre si, então $a^{2}+c^{2}=b^{2}+d^{2}$.

Prova. Seja um quadrilátero com lados $a, b, c$ e $d$, de diagonais perpendiculares, que se cruzam no ponto $X$, conforme Figura 61 .

Chamando $A X=m, B X=n, C X=p$ e $D X=q$, tem-se, nos triângulos retângulos $A X B$ e $C X D$, que

$$
\begin{gathered}
m^{2}+n^{2}=a^{2}, \\
p^{2}+q^{2}=c^{2} .
\end{gathered}
$$

Somando-se essas duas equações, obtém-se 


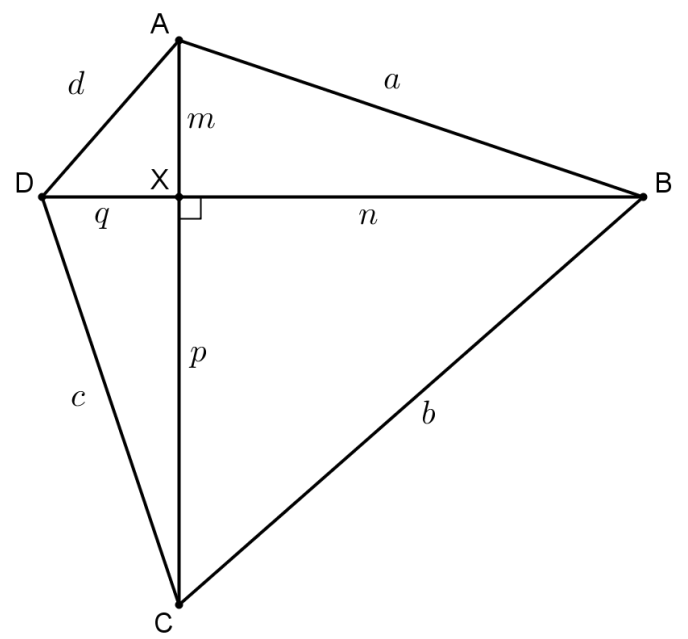

Figura 61 - Quadrilátero de diagonais perpendiculares

$$
m^{2}+n^{2}+p^{2}+q^{2}=a^{2}+c^{2} .
$$

Nos triângulos retângulos $B X C$ e $D X A$, tem-se

$$
\begin{aligned}
& n^{2}+p^{2}=b^{2}, \\
& q^{2}+n^{2}=d^{2} .
\end{aligned}
$$

Somando-se agora essas duas equações, obtém-se

$$
n^{2}+p^{2}+q^{2}+m^{2}=b^{2}+d^{2} .
$$

Finalmente, de (38) e (39), conclui-se que $a^{2}+c^{2}=b^{2}+c^{2}$.

Teorema 4.27 (Brahmagupta). Se um quadrilátero inscritível possui diagonais perpendiculares que se cruzam num ponto $X$, então a perpendicular baixada de X a cada um dos lados do quadrilátero corta o lado oposto no seu ponto médio.

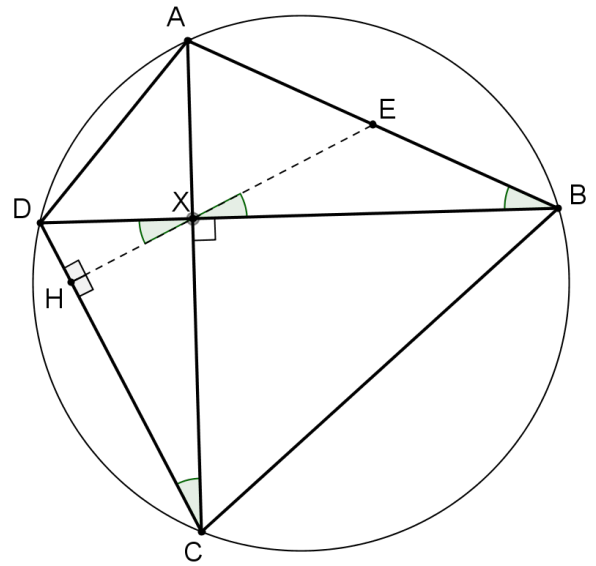

Figura 62 - Demonstração do Teorema de Brahmagupta 
Demonstração. Seja o quadrilátero inscritível $A B C D$, com diagonais perpendiculares que se cruzam no ponto $X$, traçando-se por $X$ uma perpendicular $X H$ ao lado $C D$, esta reta corta o lado oposto $A B$ no ponto $E$. Com isso, considerando os conceitos de ângulos opostos pelo vértice, ângulos inscritos num círculo e semelhança de triângulos $(\triangle D X H \sim \triangle D C X)$, tem-se (Figura 62):

$$
\measuredangle B X E=\measuredangle D X H=\measuredangle D C X=\measuredangle D C A=\measuredangle D B A .
$$

Assim, o triângulo $X E B$ é isósceles, com $X E=B E$. Desse modo, pela Proposição $4.4 X E$ é mediana relativa à hipotenusa do triângulo retângulo $A X B, \operatorname{com} X E=B E=A E$ e, portanto, $E$ é ponto médio de $A B$.

Analogamente, prova-se o mesmo para as outras perpendiculares traçadas por $X$ a cada um dos outros lados do quadrilátero.

Nota: Quando um quadrilátero inscritível possui lados, diagonais e área dados por números inteiros, ele é chamado por SASTRY (2003) de quadrilátero de Brahmagupta.

Proposição 4.21 (Fórmula de Brahmagupta). Se um quadrilátero inscritível de lados $a, b, c$ ed tem semiperímetro $p$, então sua área é dada por $\sqrt{(p-a)(p-b)(p-c)(p-d)}$.

Prova. Seja o quadrilátero inscritível $A B C D$, com $A B=a, B C=b, C D=c, D A=d, B D=x \mathrm{e} \measuredangle B A D=\alpha$, sendo o semiperímetro $p=\frac{a+b+c+d}{2}$ (Figura 63 .

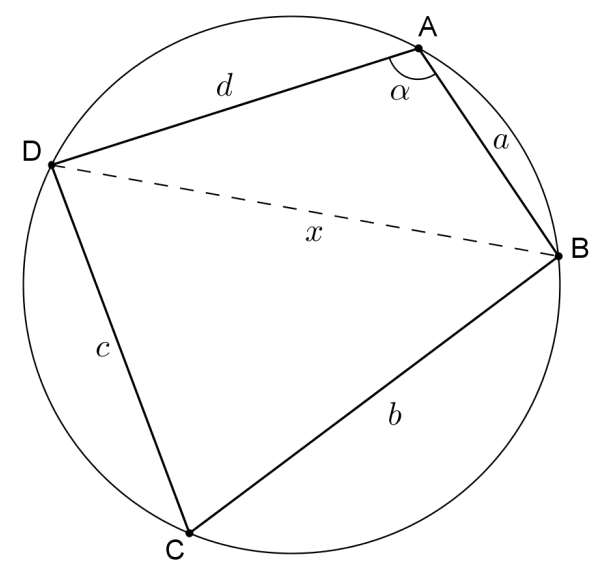

Figura 63 - Demonstração da Fórmula de Brahmagupta

A área do quadrilátero $A B C D$ pode ser dada pela soma das áreas dos triângulos $B A D$ e $B C D$, ou seja,

$$
\begin{gathered}
{[A B C D]=[B A D]+[B C D]=\frac{1}{2} a d \cdot \operatorname{sen} \alpha+\frac{1}{2} b c \cdot \operatorname{sen}\left(180^{\circ}-\alpha\right)} \\
{[A B C D]=\frac{1}{2}(a d+b c) \cdot \operatorname{sen} \alpha} \\
{[A B C D]=\frac{1}{2}(a d+b c) \sqrt{1-\cos ^{2} \alpha} .}
\end{gathered}
$$

Por outro lado, aplicando a Lei dos Cossenos nos triângulos $B A D$ e $B C D$, tem-se 


$$
\begin{gathered}
x^{2}=a^{2}+d^{2}-2 a d \cdot \cos \alpha, \mathrm{e} \\
x^{2}=b^{2}+c^{2}+2 b c \cdot \cos \alpha .
\end{gathered}
$$

Subtraindo-se essas duas equações e isolando os termos, obtém-se

$$
\cos \alpha=\frac{a^{2}+d^{2}-b^{2}-c^{2}}{2 a d+2 b c} .
$$

Substituindo este valor em (40), chega-se a

$$
\begin{gathered}
{[A B C D]=\frac{1}{2}(a d+b c) \sqrt{1-\left(\frac{a^{2}+d^{2}-b^{2}-c^{2}}{2 a d+2 b c}\right)^{2}}} \\
{[A B C D]=\frac{1}{2}(a d+b c) \sqrt{\frac{(2 a d+2 b c)^{2}-\left(a^{2}+d^{2}-b^{2}-c^{2}\right)^{2}}{(2 a d+2 b c)^{2}}}} \\
{[A B C D]=\frac{1}{2}(a d+b c) \sqrt{\frac{\left(2 a d+2 b c+a^{2}+d^{2}-b^{2}-c^{2}\right)\left(2 a d+2 b c-a^{2}-d^{2}+b^{2}+c^{2}\right)}{4(a d+b c)^{2}}}} \\
{[A B C D]=\frac{1}{4} \sqrt{\left[(a+d)^{2}-(b-c)^{2}\right]\left[(b+c)^{2}-(a-d)^{2}\right]}} \\
{[A B C D]=\frac{1}{4} \sqrt{[(a+d+b-c)(a+d-b+c)][(b+c+a-d)(b+c-a+d)]}} \\
{[A B C D]=\frac{1}{4} \sqrt{(2 p-2 c)(2 p-2 b)(2 p-2 d)(2 p-2 a)}} \\
{[A B C D]=\sqrt{16 \cdot(p-a)(p-b)(p-c)(p-d)}}
\end{gathered}
$$

Nota: Observa-se nesta fórmula que se o quadrilátero $A B C D$ degenerar-se em um triângulo, por exemplo, $A B C$, isto é, $D \equiv A$ e $d \rightarrow 0$, a área desse triângulo será dada por meio da simplificação

$$
[A B C]=\sqrt{p(p-a)(p-b)(p-c)},
$$

que corresponde à conhecida fórmula de Heron ${ }^{23}$ para triângulos ${ }^{24}$

Teorema 4.28 (Simson-Wallace ${ }^{25}$. Os pés das perpendiculares traçadas de um ponto da circunferência circunscrita a um triângulo aos lados desse triângulo são colineares e pertencem à reta de Simson-Wallace, relativa a esse ponto.

Demonstração. Seja $P$ um ponto da circunferência circunscrita ao triângulo $A B C$. A partir de $P$ traçam-se perpendiculares a cada um dos lados de $A B C$, cortando $B C$ em $L, A C$ em $M$ e $A B$ em $N$ (Figura 64).

23 Heron, Hero ou Herão de Alexandria foi um matemático e engenheiro grego, do Séc. I, que ficou especialmente conhecido pela fórmula que leva seu nome e se aplica ao cálculo da área de um triângulo (MUNIZ NETO 2013).

24 É importante lembrar que não há inconsistência nessa conclusão, uma vez que todo triângulo é inscritível em uma circunferência.

25 Robert Simson e William Wallace foram dois matemáticos escoceses dos Séc. XVIII e XIX. Apesar de a descoberta da reta ter sido feita por Simson, foi Wallace quem a publicou em 1797 [MUNIZ NETO 2013. 


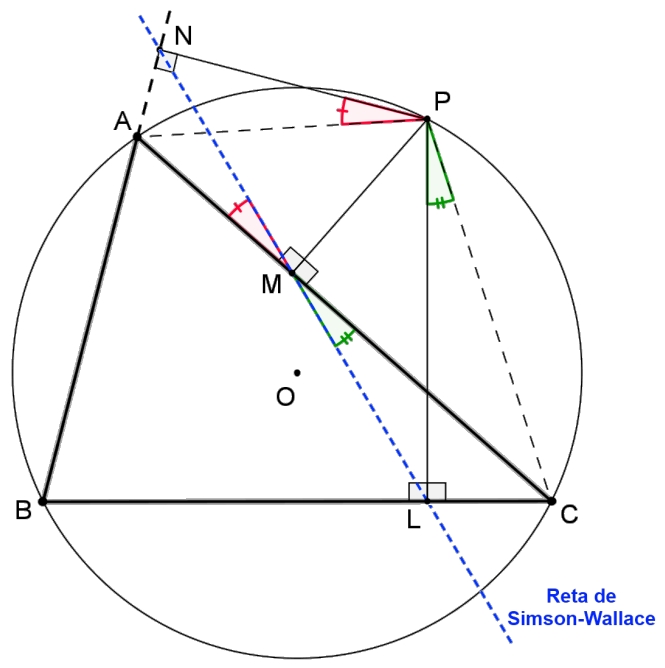

Figura 64 - Demonstração do teorema de Simson-Wallace

Assim, tem-se que os quadriláteros $P N A M$ e $M L C P$ são inscritíveis e, portanto,

$$
\begin{aligned}
& \measuredangle N P A=\measuredangle N M A, \\
& \measuredangle L M C=\measuredangle L P C .
\end{aligned}
$$

Além disso, os quadriláteros $B N P L$ e $B A P C$, sendo também inscritíveis, garantem a igualdade dos ângulos em $P, \measuredangle N P L$ e $\measuredangle A P C$, opostos ao vértice $B$, ou seja,

$$
\begin{gathered}
\measuredangle N P L=\measuredangle A P C \\
\measuredangle N P A+\measuredangle A P L=\measuredangle A P L+\measuredangle L P C \\
\measuredangle N P A=\measuredangle L P C .
\end{gathered}
$$

Uma vez que os pontos $A, M$ e $C$ são colineares, das igualdades (41), (42) e (43) decorre que $\measuredangle N M A=$ $\measuredangle L M C$ (opostos pelo vértice $M$ ), o que mostra que os pontos $L, M$ e $N$ são colineares, pertencendo à reta chamada reta de Simson-Wallace do triângulo $A B C$, relativa a esse ponto $P$.

Teorema 4.29 (Recíproco de Simson-Wallace). Se os pés das perpendiculares de um ponto aos lados de um triângulo são colineares, então este ponto pertence à circunferência circunscrita ao triângulo.

Demonstração. Sejam $L, M$ e $N$ os pés das perpendiculares traçadas do ponto $P$ a cada um dos lados do triângulo $A B C$, tais que pertencem a uma mesma reta $r$.

Assim, o quadrilátero $P N A M$ é inscritível no círculo de diâmetro $P A$, com $\measuredangle N P A=\measuredangle N M A$, e o quadrilátero $M L C P$ é inscritível no círculo de diâmetro $P C$, com $\measuredangle L M C=\measuredangle L P C$. Como $\measuredangle N M A=\measuredangle L M C$ (opostos pelo vértice $M$ ), decorre que $\measuredangle N P A=\measuredangle N M A=\measuredangle L M C=\measuredangle L P C$.

Além disso, observa-se, na Figura 65, que $\measuredangle B A P=90^{\circ}+\theta$ (ângulo externo do triângulo $A N P$ ) e que $\measuredangle B C P=\measuredangle L C P=180^{\circ}-\left(90^{\circ}+\theta\right)=90^{\circ}-\theta$ (triângulo $L C P$ ), ou seja, $\measuredangle B A P$ e $\measuredangle L C P$ são suplementares. 


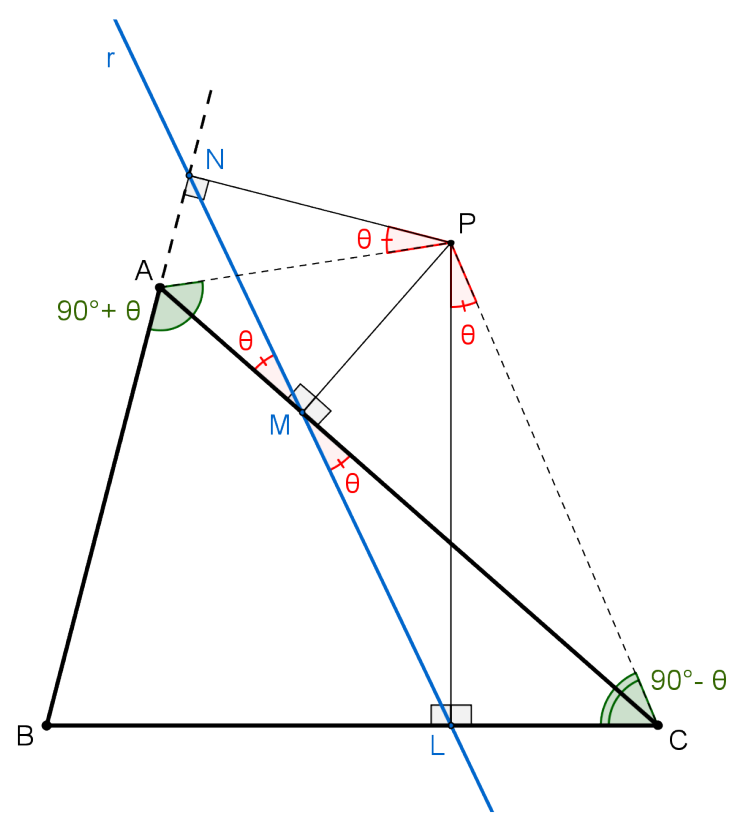

Figura 65 - Demonstração do teorema recíproco de Simson-Wallace

Portanto, o quadrilátero $B A P C$ é inscritível e o ponto $P$ pertence à circunferência circunscrita ao triângulo $A B C$.

FEITOSA (2013) demonstra o teorema de Simson-Wallace e seu recíproco utilizando números complexos.

Teorema 4.30 (Reta de Steiner). Os simétricos de um ponto da circunferência circunscrita a um triângulo em relação aos lados desse triângulo são colineares e pertencem à reta de Steiner que, por sua vez, é paralela à reta de Simson-Wallace, relativa a esse ponto.

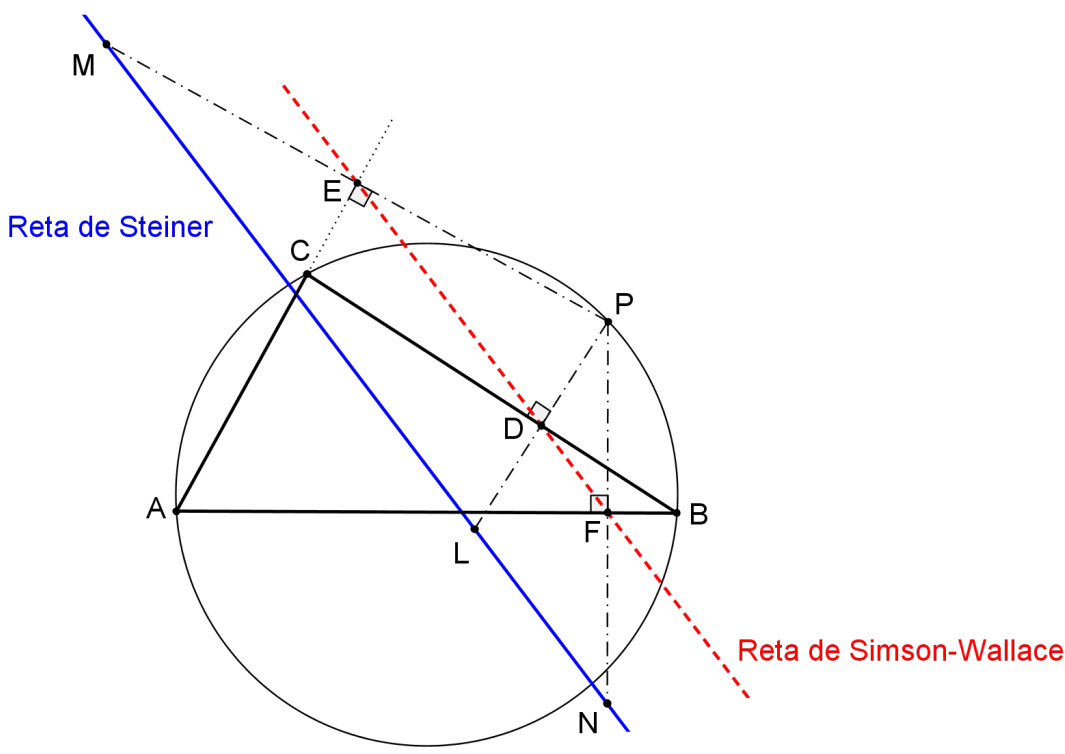

Figura 66 - Demonstração do teorema de Steiner 
Demonstração. Sejam $P$ um ponto da circunferência circunscrita ao triângulo $A B C$ e $L, M$ e $N$ os simétricos de $P$ em relação aos lados $B C, A C$ e $A B$, com $P L \cap B C=\{D\}, P M \cap A C=\{E\}$ e $P N \cap A B=\{F\}$ (Figura 66). Em outras palavras, $D, E$ e $F$ são os pontos médios de $B C, A C$ e $A B$, respectivamente.

Sabe-se, pelo teorema de Simson-Wallace (Teorema 4.28, que os pontos $D, E$ e $F$ - pés das perpendiculares baixadas de $P$ aos lados do triângulo $A B C$ - são colineares e estão sobre a reta de SimsonWallace.

Como $D F \| L N$ (base média do triângulo $P L N$ ) e $E D \| M L$ (base média do triângulo $P M L$ ), então $L$, $M$ e $N$ são colineares e paralelos à reta de Simson-Wallace, relativa ao ponto $P$.

Teorema 4.31 (Miquel para triângulos). Seja $A B C$ um triângulo e $D, E$ e $F$ pontos sobre os lados $B C$, $A C$ e $A B$, respectivamente. Então os circuncírculos $\Gamma_{A}, \Gamma_{B} e \Gamma_{C}$ dos triângulos AFE, BDF e CED, respectivamente, têm um ponto em comum $M$, denominado ponto de Mique 26 , relativo aos pontos D, E e F (Figura 67).

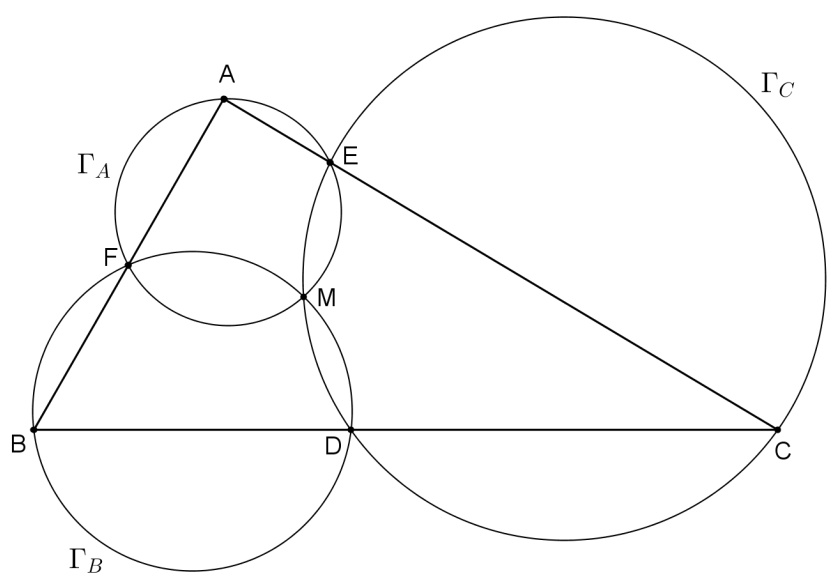

Figura 67 - Teorema de Miquel para triângulos

Demonstração. Seja $M$ o outro ponto comum (além de $D$ ) aos circuncírculos $\Gamma_{B} \mathrm{e} \Gamma_{C}$ dos triângulos $B D F \mathrm{e}$ $C E D$, respectivamente (Figura 67).

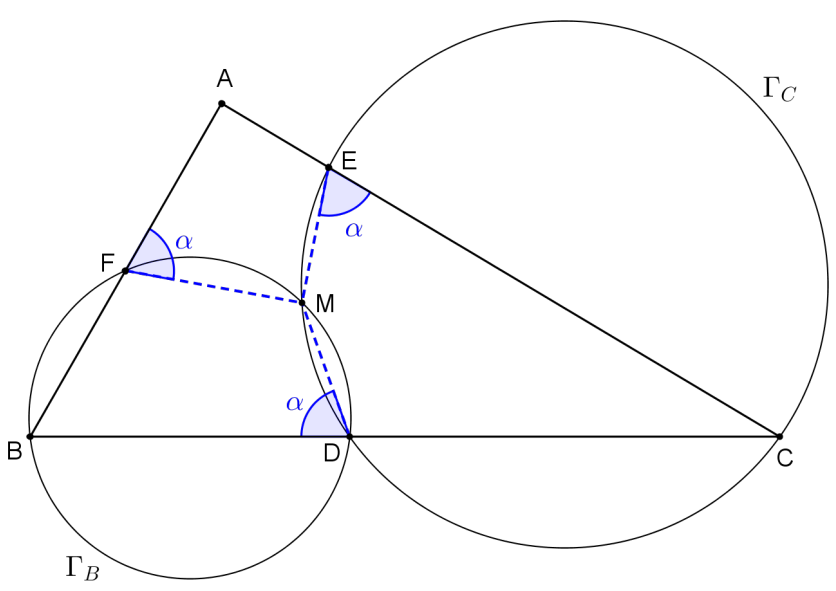

Figura 68 - Demonstração do teorema de Miquel para triângulos

\footnotetext{
26 Auguste Miquel (1816-1851) foi um matemático francês que demonstrou diversos teoremas na Geometria Plana envolvendo círculos e polígonos. Este teorema foi publicado por ele em 1838 (POSAMENTIER e SALKIND 1996).
} 
Se $\measuredangle C E M=\alpha$, então $\measuredangle A E M=180^{\circ}-\alpha$. Além disso, $\measuredangle C D M=180^{\circ}-\alpha$, uma vez que $C E M D$ é inscritível em $\Gamma_{C}$. Por conseguinte, $\measuredangle B D M=\alpha$ e $\measuredangle B F M=180^{\circ}-\alpha$, pois $B D M F$ é inscritível em $\Gamma_{B}$ (Figura 68). Logo, $\measuredangle A F M=\alpha$. E como $A E M=180^{\circ}-\alpha$, o quadrilátero $A F M E$ é inscritível em um círculo $\Gamma_{A}$, com o ponto $M$ pertencendo aos três círculos $\Gamma_{A}, \Gamma_{B}$ e $\Gamma_{C}$. Tal ponto é chamado de ponto de Miquel, relativo aos pontos $D, E$ e $F$.

Teorema 4.32 (Miquel para quadrilátero completo). As circunferências circunscritas aos quatro triângulos formados num quadrilátero completo se encontram em um ponto comum, denominado ponto de Miquel desse quadrilátero (Figura 69).

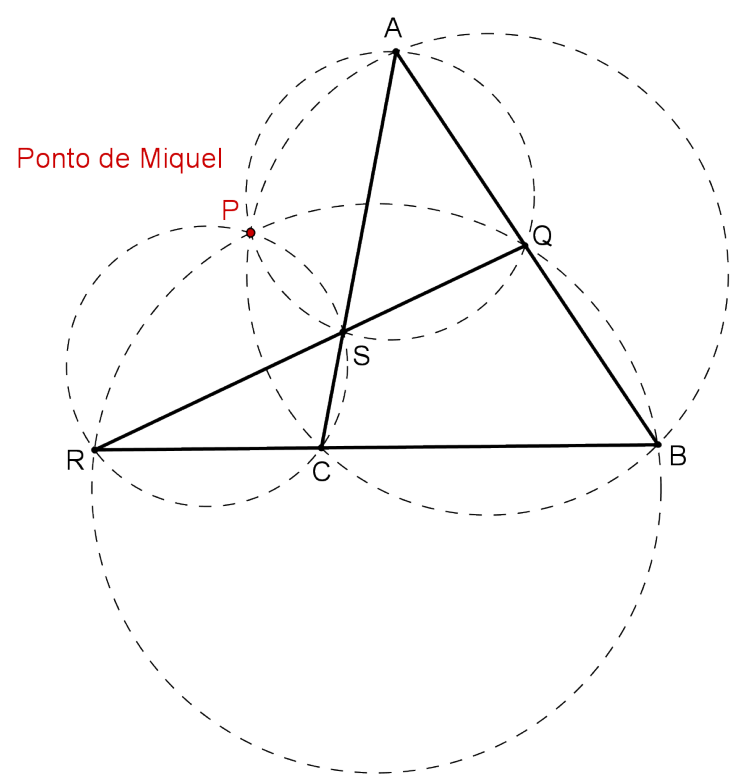

Figura 69 - Teorema de Miquel para quadrilátero completo

Demonstração. Considere o quadrilátero completo AQBCRS (Figura 69). Traçando-se as circunferências circunscritas aos triângulos $A B C$ e $C R S$, tem-se, inicialmente, dois pontos de interseção: $P$ e $C$ (Figura 70).

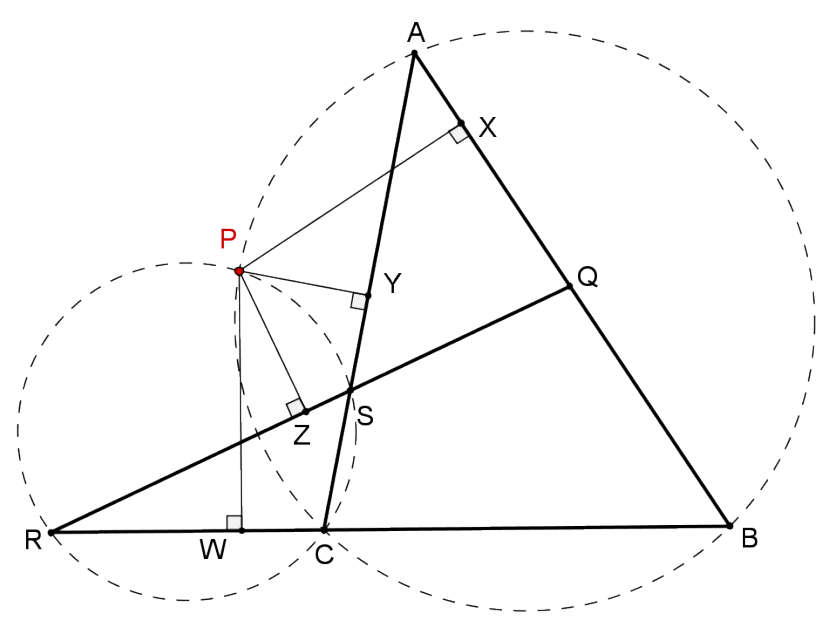

Figura 70 - Demonstração do teorema de Miquel para quadrilátero completo 
Baixando por $P$ as perpendiculares $P W, P X$ e $P Y$, a cada um dos lados $B C, A B$ e $A C$, respectivamente, do triângulo $A B C$, tem-se, pelo teorema de Simson-Wallace (Teorema 4.28), que $W, X$ e $Y$ são colineares.

Analogamente, as perpendiculares baixadas de $P$ ao triângulo $C R S$ determinam que $W, Y$ e $Z$ são colineares.

Portanto, os pontos $W, X, Y$ e $Z$ pertencem à reta de Simson-Wallace, relativa ao ponto $P$.

Uma vez que $P X, P Y$ e $P Z$ são perpendiculares aos segmentos $A Q, A S$ e $Q S$, respectivamente, pelo teorema recíproco de Simson-Wallace (Teorema 4.29), tem-se que $P$ pertence à circunferência circunscrita ao triângulo $A Q S$.

Analogamente, sendo $P X, P W$ e $P Z$ perpendiculares aos segmentos $B Q, R B$ e $R Q$, respectivamente, tem-se que $P$ pertence à circunferência circunscrita ao triângulo $B R Q$.

Desse modo, $P$ é o ponto comum às circunferências circunscritas aos triângulos $A B C, C R S, A Q S$ e $B R Q$ do quadrilátero completo $A Q B C R S$.

DE FREITAS (2013) demonstra o teorema de Miquel para quadrilátero completo utilizando medidas de ângulos nos círculos.

Definição 4.19 (Homotetia). Dado um ponto fixo $O$ e uma constante real $k(k \neq 0)$, chama-se homotetia de centro $O$ e razão $k$ à transformação geométrica que a todo ponto A faz corresponder um ponto-imagem $A^{\prime}$, tal que $\frac{\overrightarrow{O A^{\prime}}}{\overrightarrow{O A}}=k$ ou $\overrightarrow{O A^{\prime}}=k \cdot \overrightarrow{O A}$

O ponto $A^{\prime}$ pertence à reta $O A$ e é chamado ponto homotético de $A$, de razão $k$, em relação a $O$ (centro de homotetia).

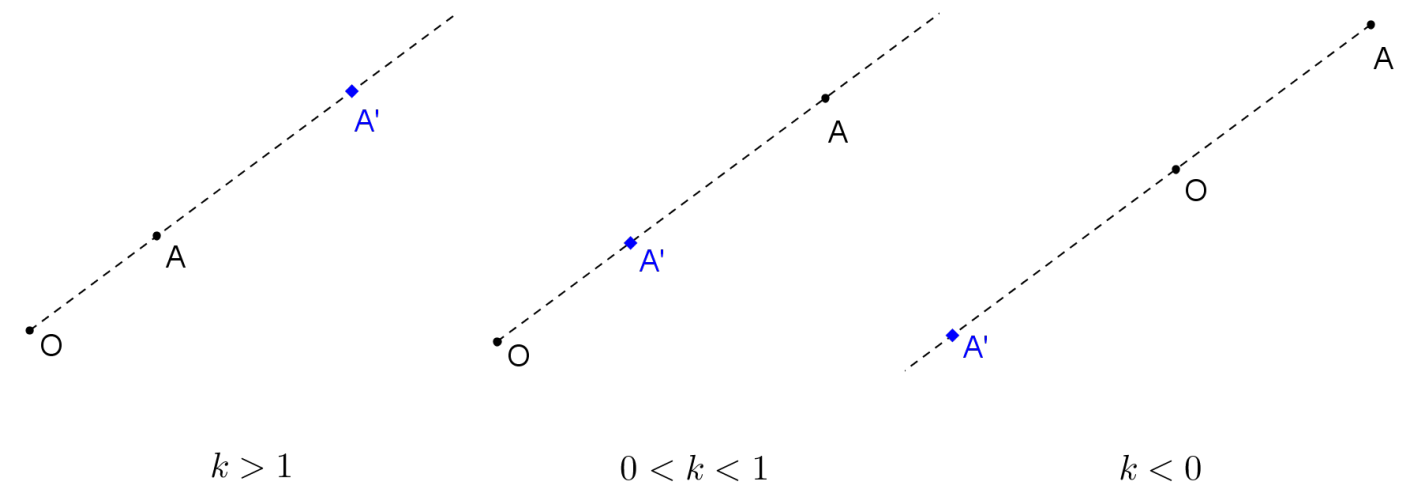

Figura 71 - Homotetia de ponto

Se $k>0$, então $A^{\prime}$ está na semirreta $\overrightarrow{O A}$ (homotetia direta); se $k<0$, então $A^{\prime}$ está na semirreta oposta $\overrightarrow{A O}$ (homotetia inversa); se $0<k<1$, então $A^{\prime}$ está entre $O$ e $A$ (Figura 71 . Ainda, se $k=-1$, a transformação é uma simetria de centro $O$, e se $k=1$ a transformação é uma identidade.

Propriedade 1: A homotetia leva pontos em pontos alinhados com o seu homotético e o centro de homotetia (Figura 71). 
Propriedade 2: A homotetia leva segmentos em segmentos paralelos (Figura 72).

$$
\frac{O A^{\prime}}{O A}=\frac{O B^{\prime}}{O B}=\frac{A^{\prime} B^{\prime}}{A B}=k \quad \text { (Configuração de Tales) }
$$
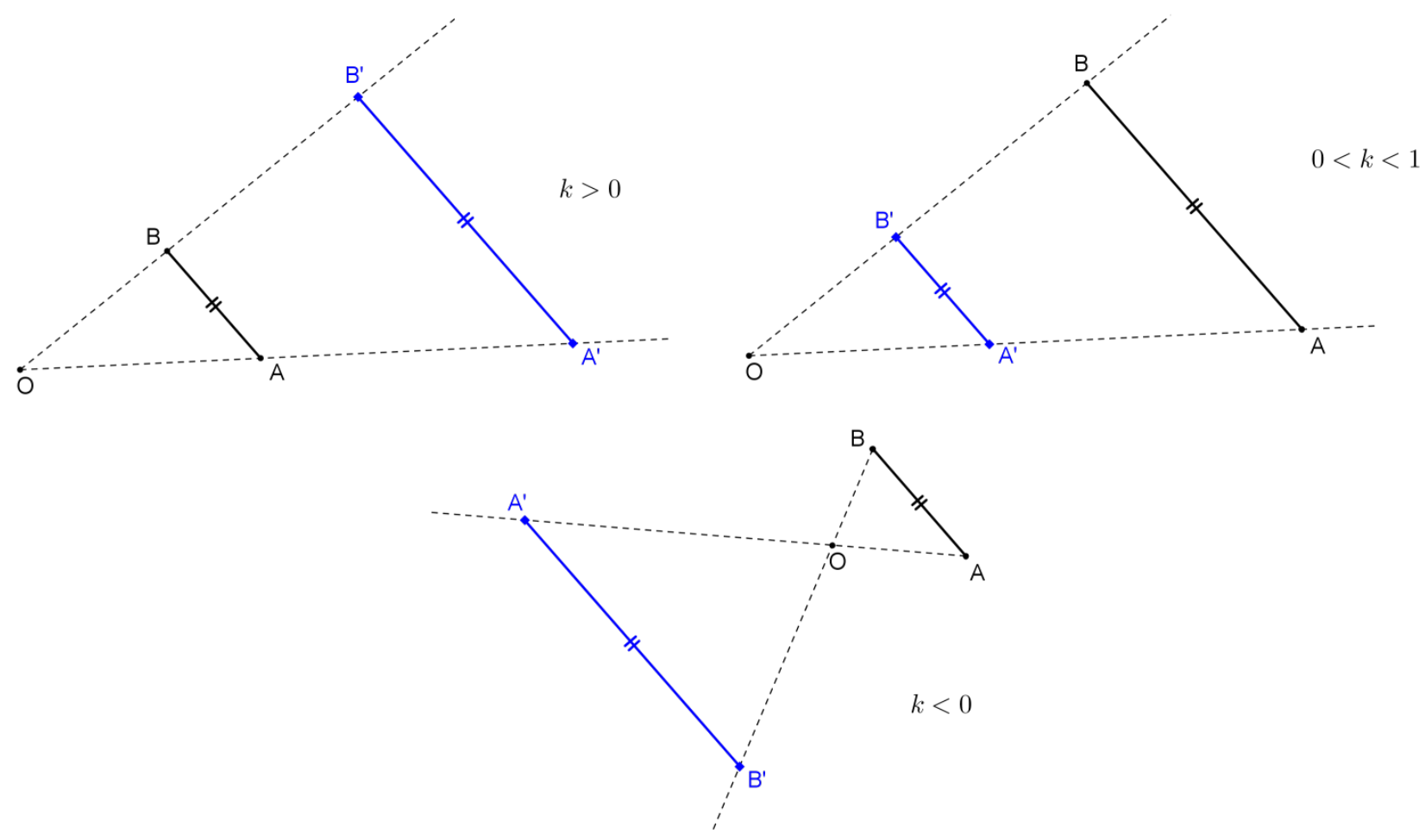

Figura 72 - Homotetia de segmento

Propriedade 3: A homotetia leva ângulos em ângulos congruentes (Figura73).

$$
\frac{O A^{\prime}}{O A}=\frac{O B^{\prime}}{O B}=\frac{O C^{\prime}}{O C}=k
$$

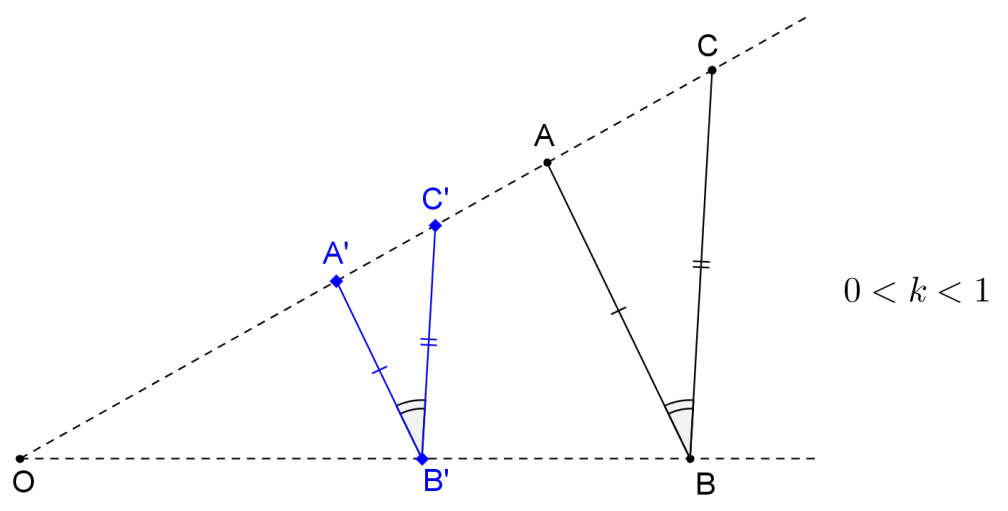

Figura 73 - Homotetia de ângulo

Propriedade 4: A homotetia leva um polígono em outro polígono semelhante (Figura74).

$$
\begin{gathered}
\frac{O A^{\prime}}{O A}=\frac{O B^{\prime}}{O B}=\frac{O C^{\prime}}{O C}=\frac{A^{\prime} B^{\prime}}{A B}=\frac{A^{\prime} C^{\prime}}{A C}=\frac{B^{\prime} C^{\prime}}{B C}=k, \mathrm{e} \\
\frac{\left[A^{\prime} B^{\prime} C^{\prime}\right]}{[A B C]}=k^{2}
\end{gathered}
$$




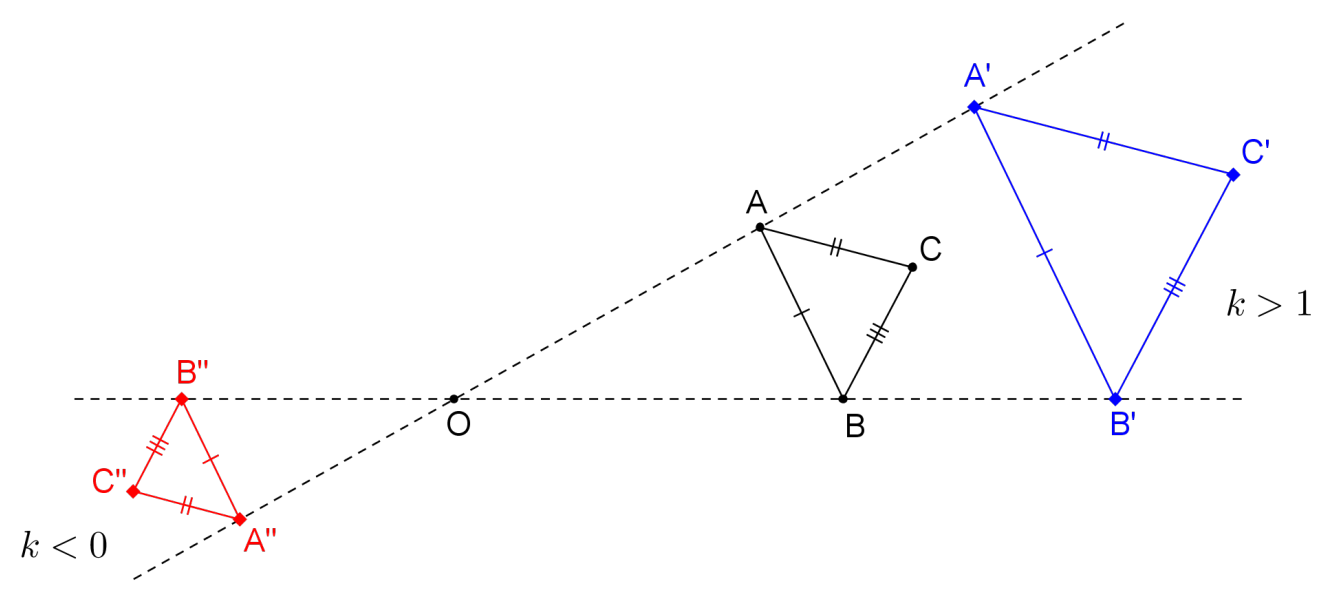

Figura 74 - Homotetia de polígono

Propriedade 5: A homotetia leva círculos em círculos.

Propriedade 6: Dois círculos não concêntricos e de raios distintos são relacionados por meio de duas homotetias: uma direta e outra inversa.

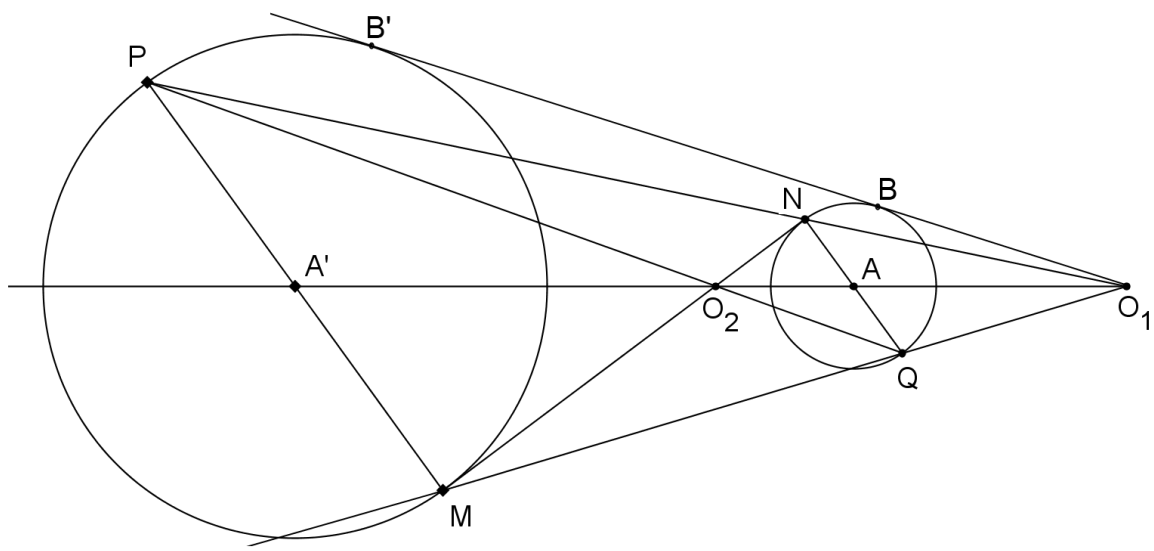

Figura 75 - Homotetia de círculo

Na Figura 75, observa-se, por exemplo:

$\checkmark$ Centro $O_{1}: A$ e $A^{\prime}, N$ e $P, Q$ e $M, B$ e $B^{\prime}$ são homotéticos (homotetia direta);

$\checkmark$ Centro $O_{2}: A$ e $A^{\prime}, N$ e $M, Q$ e $P$ são homotéticos (homotetia inversa);

$\checkmark \quad$ Em ambas as homotetias, tem-se $N Q \| P M$.

Propriedade 7: As tangentes comuns a dois círculos passam pelo centro de homotetia.

$\checkmark \quad$ Centro $O_{1}: O_{1}, B$ e $B^{\prime}$ são colineares;
$\checkmark \quad$ Centro $O_{2}: O_{2}, N$ e $M$ são colineares.

Propriedade 8: Três círculos de raios distintos, exteriores entre si, determinam sempre seis centros de homotetia, que, por sua vez, são colineares três a três (Figura 76 ).

No quadrilátero completo da Figura 76 , as quatro retas que contém, cada uma, três centros de homotetia, são chamadas eixos de homotetia dos três círculos (ADAM, 1986). Observa-se que os centros de homotetias diretas $O_{e 23}, O_{e 13}$ e $O_{e 12}$ são colineares, conforme se demonstrou no teorema de Monge (Teorema 


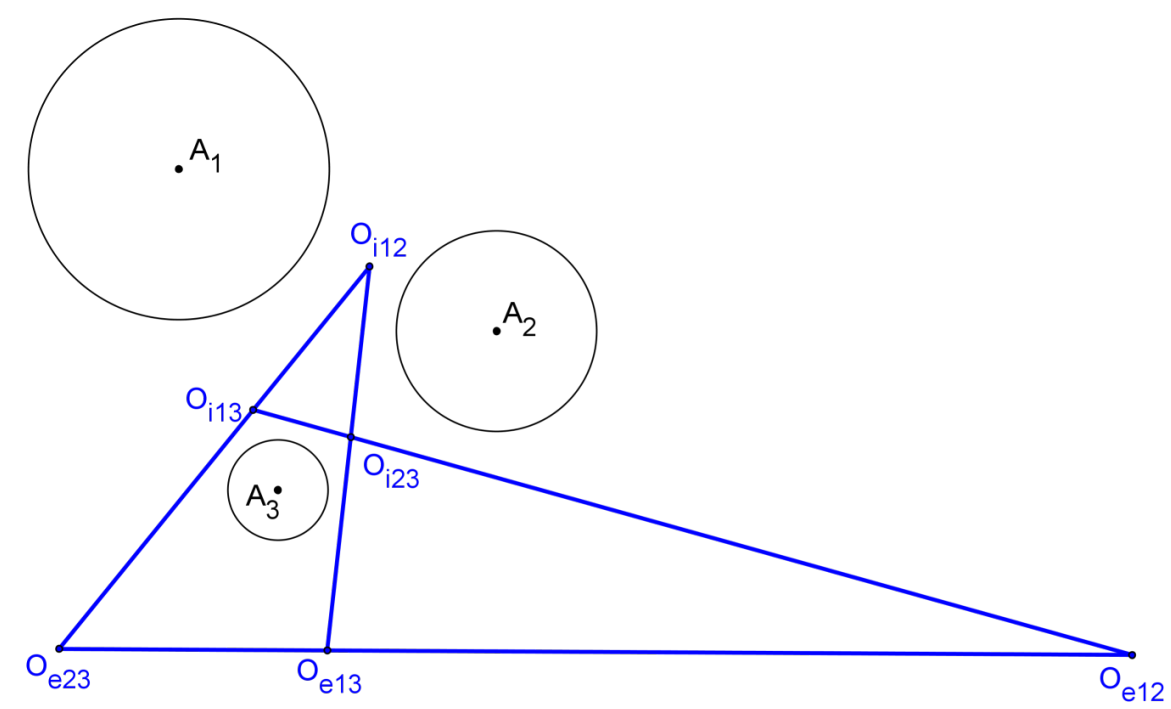

Figura 76 - Centros de homotetia para três círculos

4.21), e cada dois centros de homotetia inversa e um centro de homotetia direta $\left(O_{i 12}, O_{i 13}\right.$ e $O_{e 23} ; O_{i 12}$, $O_{i 23}$ e $O_{e 13} ; O_{i 13}, O_{i 23}$ e $O_{e 12}$ ) são colineares, conforme se demonstrou no teorema de Monge-D'Alembert (Teorema 4.22).

No caso de os três círculos dados terem centros colineares, o quadrilátero completo supracitado seria degenerado numa reta - a reta que une os centros dos círculos - a qual conteria também os seis centros de homotetia.

Definição 4.20 (Inversão). Dado um círculo $\Gamma$ de centro $O$ e raio $k$, chama-se inversão de centro $O$ e raio $k$ à transformação geométrica que a todo ponto A faz corresponder um ponto-imagem $A^{\prime}$, pertencente à semirreta $\overrightarrow{O A}$, tal que $O A \cdot O A^{\prime}=k^{2}$ (Figura 77).

O ponto $A^{\prime}$ é chamado inverso de $A$ em relação ao círculo $\Gamma$. A reta $a$ que passa pelo ponto $A^{\prime}$ e é perpendicular à semirreta $\overrightarrow{O A}$ é chamada reta polar de $A$ em relação ao círculo $\Gamma$, e o ponto $A$ é chamado pólo da reta $a$ em relação ao círculo $\Gamma$.
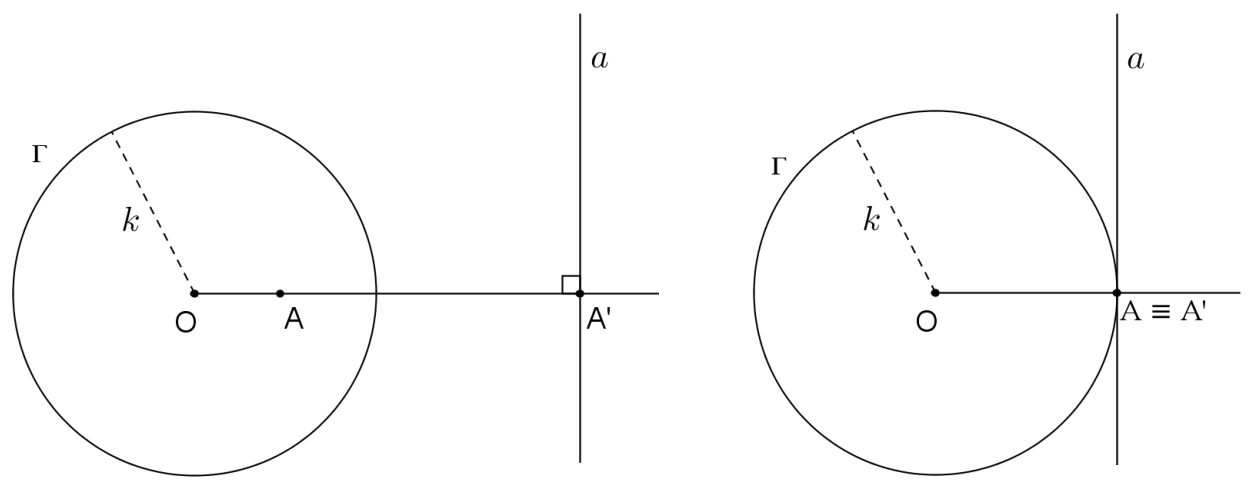

Figura 77 - Ponto inverso $\left(A^{\prime}\right)$, pólo $(A)$ e reta polar $(a)$

Nota: Se um ponto $A$ pertence à circunferência, então o seu inverso $A^{\prime}$ é coincidente, e a sua reta polar é a tangente à circunferência passando por ele (Figura 77). De fato, se $O A=k$ e $O A \cdot O A^{\prime}=k^{2}$, então $O A^{\prime}=k \mathrm{e}$ $A \equiv A^{\prime}$. 
Definição 4.21 (Polaridade). A transformação geométrica que leva um ponto à sua reta polar ou que leva uma reta ao seu pólo é chamada polaridade.

Proposição 4.22. Sejam A e B dois pontos do plano e a e b suas respectivas polares em relação a um círculo $\Gamma$. Se $B \in$ a, então $A \in b$. Neste caso, os pontos $A$ e B são chamados conjugados.

Prova. Sejam $O$ o centro do círculo $\Gamma$, de raio $k$, e $A$ e $B$ pontos cujas polares são $a$ e $b$, respectivamente.

Ligando-se $O$ a $B$, seja $B^{\prime}$ um ponto de $O B$ tal que $A B^{\prime} \perp O B$ (Figura 78 .

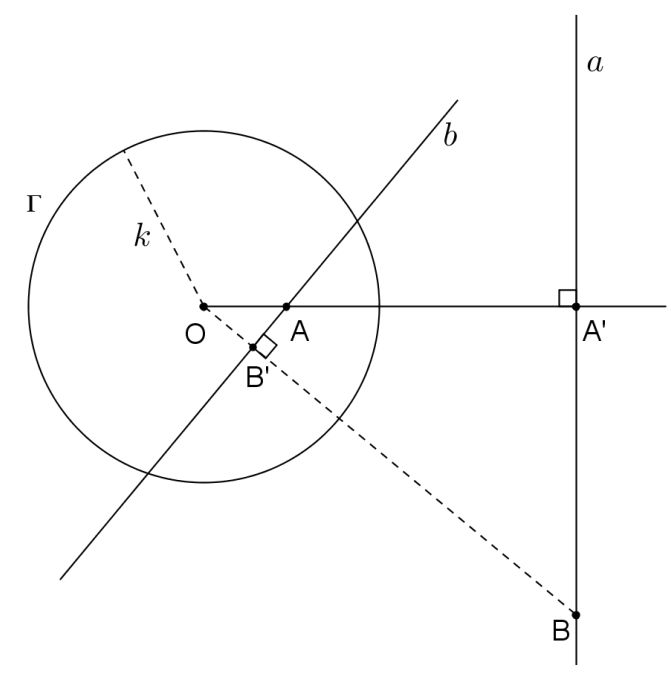

Figura 78 - Polaridade

Neste caso, tem-se que os triângulos $O B^{\prime} A$ e $O A^{\prime} B$ são semelhantes, com

$$
\begin{aligned}
\frac{O A}{O B} & =\frac{O B^{\prime}}{O A^{\prime}}, \\
O A \cdot O A^{\prime} & =O B \cdot O B^{\prime} .
\end{aligned}
$$

Como, por hipótese, $O A \cdot O A^{\prime}=k^{2}$, então $O B \cdot O B^{\prime}=k^{2}$ e, portanto, $B^{\prime}$ é o inverso de $B$ em relação ao círculo $\Gamma$ e a reta $A B^{\prime}=b$ é a sua polar, com $A \in b$.

Proposição 4.23. A polar de um ponto exterior a um círculo passa pelos pontos de contato das tangentes ao círculo traçadas a partir desse ponto exterior.

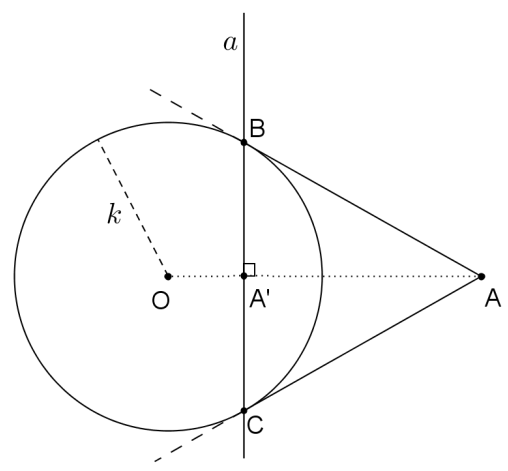

Figura 79 - Reta polar de um ponto exterior ao círculo 
Prova. Com base na Proposição 4.22, se $A$ pertence à reta polar de $B$ então $B$ pertence à reta polar de $A$. Ao mesmo tempo, se $A$ pertence à reta polar de $C$ então $C$ pertence à reta polar de $A$. Logo, $B C$ é a reta polar de $A$ (Figura 79 ).

CASTRO (2000) diz que um ponto e uma reta são incidentes quando o ponto pertence à reta, o que é o mesmo que dizer que a reta passa pelo ponto. Assim, a polaridade (Definição 4.21) é uma transformação que preserva incidências. Além disso, as polaridades não só preservam, mas também dualizam, a relação de incidência (AUFFINGER; VALENTIM, 2003).

Na Geometria Projetiva, quando acontece a troca dos termos ponto por reta, reta por ponto e, consequentemente, de seus adjetivos relacionados, por exemplo, concorrente por colinear, e vice-versa, diz-se que a proposição resultante é a proposição dual da original, evidenciando o chamado "princípio da dualidade" (AUFFINGER; VALENTIM, 2003).

De fato, se a polar de $A$ passa pelo ponto $B$ então a polar de $B$ passa por $A$ (Proposição 4.22). Além disso, se três pólos são colineares, então as respectivas polares são concorrentes (AUFFINGER; VALENTIM. 2003).

Segundo FARIA (2013), o princípio da dualidade traz duas grandes vantagens à Geometria Projetiva:

$\checkmark$ permite a obtenção de resultados, através dos duais de teoremas, proposições, etc., e

$\checkmark$ confere-lhe um poder de síntese, permitindo limitar o número de demonstrações, pois a demonstração de resultados duais fica justificada pelo próprio princípio.

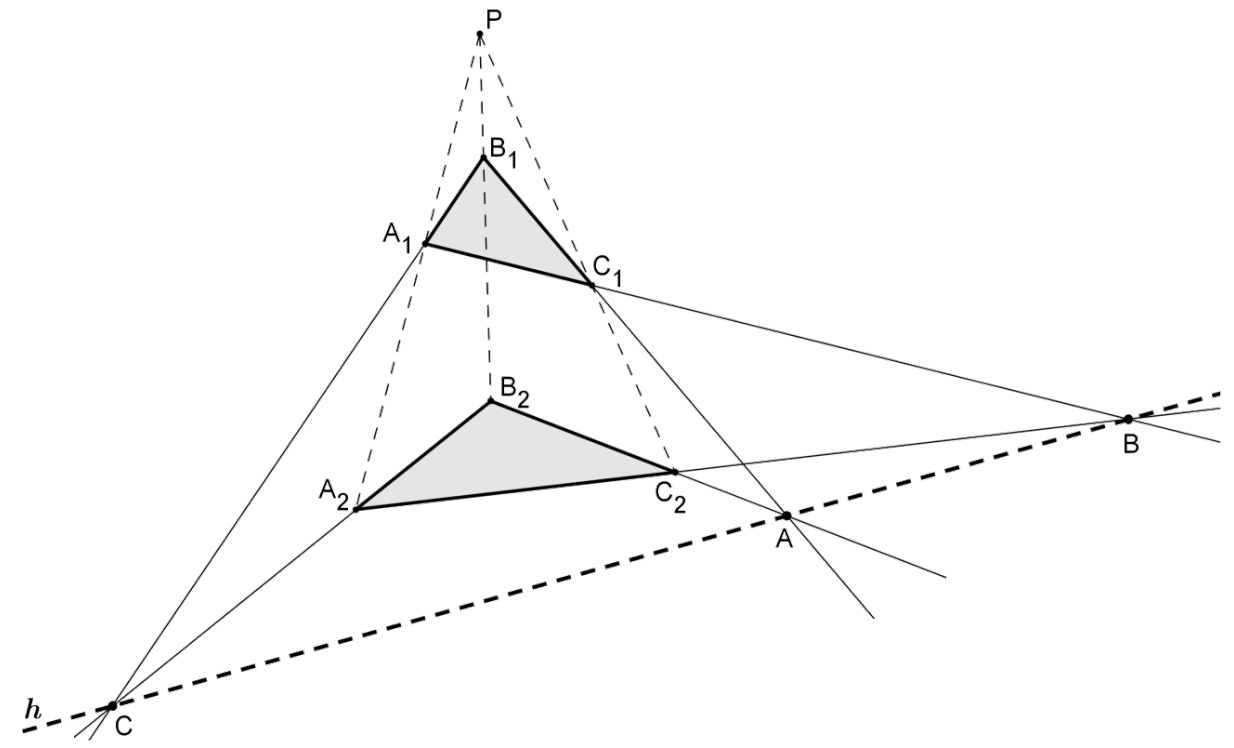

Figura 80 - Teorema de Desargues

Teorema 4.33 (Desargues ${ }^{27}$ ). Se os triângulos $A_{1} B_{1} C_{1}$ e $A_{2} B_{2} C_{2}$ são tais que as retas $A_{1} A_{2}, B_{1} B_{2}$ e $C_{1} C_{2}$ são concorrentes em um ponto $P$ (pólo ou ponto de fuga), conforme a Figura 80, então os lados homólogos desses triângulos $\left(A_{1} B_{1}\right.$ e $A_{2} B_{2}, A_{1} C_{1}$ e $A_{2} C_{2}, B_{1} C_{1}$ e $\left.B_{2} C_{2}\right)$ intersectam-se, respectivamente, em três pontos colineares $C, B$ e A.

27 Gerard Desargues (1591-1661) foi um matemático, arquiteto e engenheiro militar francês, considerado o fundador da Geometria Projetiva. Em pleno século XVII, Desargues utilizava técnicas de perspectiva linear a partir da fixação de um ponto de fuga (MUNIZ NETO 2013). 
Demonstração. Considerando o triângulo $P B_{2} C_{2}$ cortado pela reta $A B_{1}$, pode-se aplicar o teorema de Menelaus (Teorema 4.10 , na sua versão básica, obtendo-se $\frac{P B_{1}}{B_{1} B_{2}} \cdot \frac{B_{2} A}{A C_{2}} \cdot \frac{C_{2} C_{1}}{C_{1} P}=1$, donde

$$
\frac{C_{2} C_{1}}{C_{1} P}=\frac{B_{1} B_{2}}{P B_{1}} \cdot \frac{A C_{2}}{B_{2} A}
$$

Analogamente, no triângulo $P B_{2} A_{2}$, cortado pela reta $C B_{1}$, tem-se, com base no mesmo teorema, que $\frac{P A_{1}}{A_{1} A_{2}} \cdot \frac{A_{2} C}{C B_{2}} \cdot \frac{B_{2} B_{1}}{B_{1} P}=1$, donde

$$
\frac{P A_{1}}{A_{1} A_{2}}=\frac{C B_{2}}{A_{2} C} \cdot \frac{B_{1} P}{B_{2} B_{1}}
$$

Finalmente, no triângulo $P A_{2} C_{2}$, cortado pela reta $B A_{1}$, tem-se

$$
\frac{P A_{1}}{A_{1} A_{2}} \cdot \frac{A_{2} B}{B C_{2}} \cdot \frac{C_{2} C_{1}}{C_{1} P}=1
$$

Substituindo-se nesta equação os resultados (44) e (45), obtém-se

$$
\begin{gathered}
\frac{C B_{2}}{A_{2} C} \cdot \frac{B_{1} P}{B_{2} B_{1}} \cdot \frac{A_{2} B}{B C_{2}} \cdot \frac{B_{1} B_{2}}{P B_{1}} \cdot \frac{A C_{2}}{B_{2} A}=1 \\
\frac{C B_{2}}{A_{2} C} \cdot \frac{A_{2} B}{B C_{2}} \cdot \frac{A C_{2}}{B_{2} A}=1, \text { ou } \\
\frac{A_{2} B}{B C_{2}} \cdot \frac{B_{2} C}{C A_{2}} \cdot \frac{C_{2} A}{A B_{2}}=1 .
\end{gathered}
$$

Tal expressão, pelo teorema recíproco de Menelaus (Teorema 4.11), aplicado ao triângulo $A_{2} B_{2} C_{2}$, garante que os pontos $C, B$ e $A$ são colineares.

Nota: Diz-se que os triângulos $A_{1} B_{1} C_{1}$ e $A_{2} B_{2} C_{2}$ estão em perspectiva a partir da reta $h$ (Figura 80 ), denominada horizonte, ou em perspectiva a partir de $P$, denominado pólo ou ponto de fuga (MUNIZ NETO, 2013).

Historicamente, o teorema de Desargues foi uma peça fundamental na tarefa de organizar a Geometria Projetiva, devido às relações com seus axiomas básicos. ALCARAZ (2012) detalha esse teorema mostrando sua validade na Geometria Plana e na Geometria Espacial.

Segundo ALCARAZ (2012), o valor do teorema de Desargues e a razão por que a sua formulação sobreviveu há séculos, enquanto outros teoremas geométricos igualmente notáveis foram esquecidos, é que ele abriu um horizonte de possibilidades inesperadas no relacionamento da Álgebra e da Geometria, colocando-o em um patamar semelhante ao quinto postulado de Euclides.

Teorema 4.34 (Recíproco de Desargues). Se os triângulos $A_{1} B_{1} C_{1}$ e $A_{2} B_{2} C_{2}$ possuem lados homólogos $\left(A_{1} B_{1}\right.$ e $A_{2} B_{2}, A_{1} C_{1}$ e $A_{2} C_{2}, B_{1} C_{1}$ e $B_{2} C_{2}$ ) que se intersectam, respectivamente, em três pontos $C, B$ e A colineares, conforme a Figura 81, então as retas $A_{1} A_{2}, B_{1} B_{2}$ e $C_{1} C_{2}$ são concorrentes em um ponto $P$ (pólo ou ponto de fuga). 


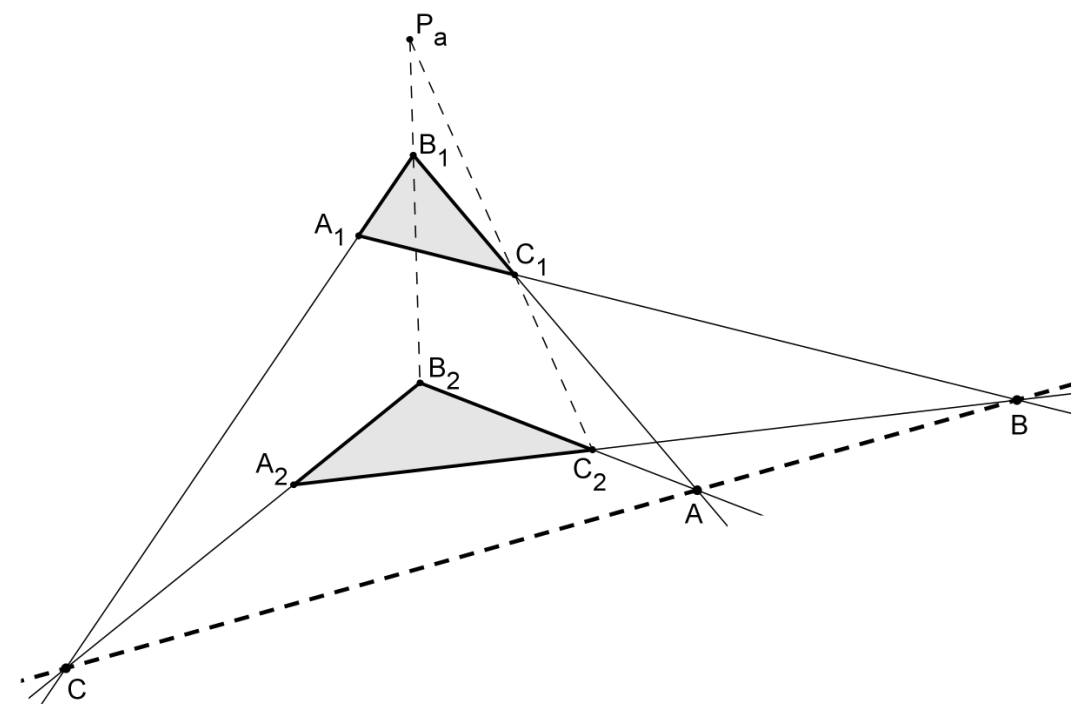

Figura 81 - Teorema recíproco de Desargues

Demonstração. Seja $P_{a}$ o ponto de encontro das retas $B_{1} B_{2}$ e $C_{1} C_{2}$, conforme a Figura 81. Dessa forma, o triângulo $P_{a} B_{2} C_{2}$ é cortado pela reta $C_{1} B_{1}$ e a aplicação do teorema de Menelaus (Teorema 4.10), na sua forma básica, fornece

$$
\begin{gathered}
\frac{P_{a} B_{1}}{B_{1} B_{2}} \cdot \frac{B_{2} A}{A C_{2}} \cdot \frac{C_{2} C_{1}}{C_{1} P_{a}}=1, \text { ou } \\
\frac{P_{a} B_{1}}{C_{1} P_{a}}=\frac{B_{1} B_{2}}{C_{2} C_{1}} \cdot \frac{A C_{2}}{B_{2} A} .
\end{gathered}
$$

Analogamente, sejam $P_{b}$ e $P_{c}$, respectivamente, os pontos de encontro das retas $A_{1} A_{2} \operatorname{com} C_{1} C_{2}$ e $A_{1} A_{2}$ com $B_{1} B_{2}$. Aplicando-se o mesmo teorema para os triângulos $P_{b} A_{2} C_{2}$ e $P_{c} A_{2} B_{2}$, cortados pelas retas $B A_{1}$ e $C B_{1}$, respectivamente, obtém-se

$$
\begin{gathered}
\frac{P_{b} A_{1}}{A_{1} A_{2}} \cdot \frac{A_{2} B}{B C_{2}} \cdot \frac{C_{2} C_{1}}{C_{1} P_{b}}=1, \mathrm{ou} \\
\frac{C_{1} P_{b}}{P_{b} A_{1}}=\frac{C_{2} C_{1}}{A_{1} A_{2}} \cdot \frac{A_{2} B}{B C_{2}}, \mathrm{e} \\
\frac{P_{c} A_{1}}{A_{1} A_{2}} \cdot \frac{A_{2} C}{C B_{2}} \cdot \frac{B_{2} B_{1}}{B_{1} P_{c}}=1, \mathrm{ou} \\
\frac{P_{c} A_{1}}{B_{1} P_{c}}=\frac{A_{1} A_{2}}{B_{2} B_{1}} \cdot \frac{C B_{2}}{A_{2} C} .
\end{gathered}
$$

Multiplicando-se as equações (46), (47) e (48), chega-se a

$$
\begin{gathered}
\frac{P_{a} B_{1}}{C_{1} P_{a}} \cdot \frac{C_{1} P_{b}}{P_{b} A_{1}} \cdot \frac{P_{c} A_{1}}{B_{1} P_{c}}=\frac{B_{1} B_{2}}{C_{2} C_{1}} \cdot \frac{A C_{2}}{B_{2} A} \cdot \frac{C_{2} C_{1}}{A_{1} A_{2}} \cdot \frac{A_{2} B}{B C_{2}} \cdot \frac{A_{1} A_{2}}{B_{2} B_{1}} \cdot \frac{C B_{2}}{A_{2} C} \\
\frac{B_{1} P_{a}}{P_{a} C_{1}} \cdot \frac{C_{1} P_{b}}{P_{b} A_{1}} \cdot \frac{A_{1} P_{c}}{P_{c} B_{1}}=\frac{C_{2} A}{A B_{2}} \cdot \frac{B_{2} C}{C A_{2}} \cdot \frac{A_{2} B}{B C_{2}} .
\end{gathered}
$$

Como os pontos $C$, $A$ e $B$ são colineares, então, pelo teorema de Menelaus (Teorema 4.10), aplicado ao triângulo $A_{2} B_{2} C_{2}$, tem-se $\frac{C_{2} A}{A B_{2}} \cdot \frac{B_{2} C}{C A_{2}} \cdot \frac{A_{2} B}{B C_{2}}=1$. Assim, 


$$
\frac{B_{1} P_{a}}{P_{a} C_{1}} \cdot \frac{C_{1} P_{b}}{P_{b} A_{1}} \cdot \frac{A_{1} P_{c}}{P_{c} B_{1}}=1
$$

que, pelo teorema recíproco de Menelaus (Teorema 4.11), aplicado ao triângulo $A_{1} B_{1} C_{1}$, conclui-se que os pontos $P_{a}, P_{b}$ e $P_{c}$ estão sobre uma mesma reta.

Finalmente, o fato de $P_{a}$ ser colinear com $B_{1} B_{2}$ e $C_{1} C_{2} ; P_{b}$ ser colinear com $A_{1} A_{2}$ e $C_{1} C_{2}$; e $P_{c}$ ser colinear com $A_{1} A_{2}$ e $B_{1} B_{2}$, implica que $P_{a} \equiv P_{b} \equiv P_{c} \equiv P$ (pólo ou ponto de fuga).

O teorema de Desargues e o seu recíproco são válidos também se as retas $A_{1} A_{2}, B_{1} B_{2}$ e $C_{1} C_{2}$ forem paralelas; neste caso, o pólo ou ponto de fuga $P$ é considerado no infinito (MUNIZ NETO, 2013).

Teorema 4.35 (Pascal). Se um hexágono, com nenhum par de lados opostos paralelos, está inscrito em um círculo, então as interseções dos lados opostos determinam três pontos colineares, cuja reta formada recebe o nome de reta de Pasca 28 .

Demonstração. Considere o hexágono $A B C D E F$ inscritível no círculo $\Gamma$, cujos prolongamentos dos lados opostos $C D$ e $F A, A B$ e $D E, B C$ e $E F$ se intersectam, respectivamente, em $L, M$ e $N$ (Figura 82).

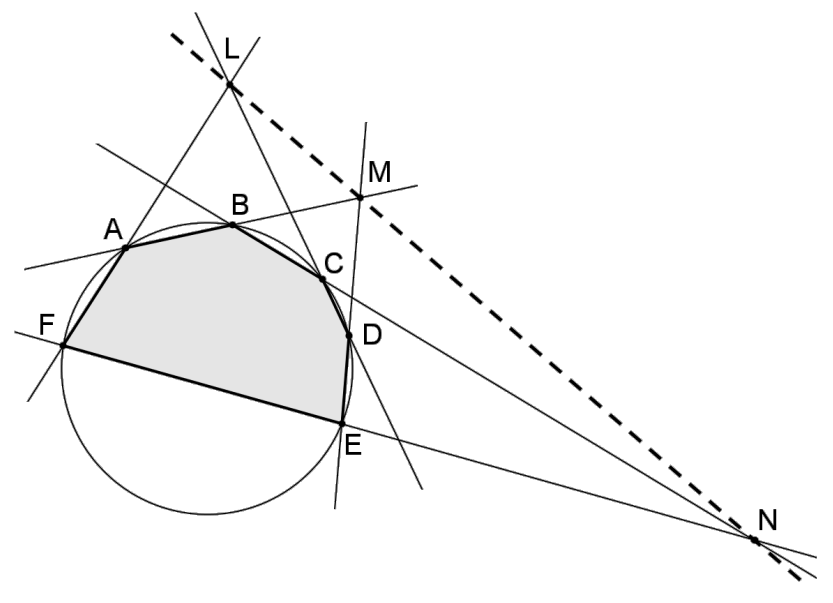

Figura 82 - Teorema de Pascal

Sejam ainda $X, Y$ e $Z$ os pontos de encontro dos prolongamentos dos lados $B C$ e $D E, F A$ e $D E, F A$ e $B C$, respectivamente (Figura 83 .

Tendo por base o triângulo $X Y Z$ e as retas $L D, N F$ e $A M$ que o cortam (Figura 83), pode-se aplicar três vezes o teorema de Menelaus (Teorema 4.10, na sua forma básica, obtendo-se, respectivamente,

$$
\begin{aligned}
& \frac{Y L}{L Z} \cdot \frac{Z C}{C X} \cdot \frac{X D}{D Y}=1, \\
& \frac{Y F}{F Z} \cdot \frac{Z N}{N X} \cdot \frac{X E}{E Y}=1, \\
& \frac{Y A}{A Z} \cdot \frac{Z B}{B X} \cdot \frac{X M}{M Y}=1 .
\end{aligned}
$$

28 Blaise Pascal foi um matemático, físico e filósofo francês do Séc. XVII que inventou a máquina de calcular e tem seu nome associado ao triângulo aritmético formado pelos números binomiais (ANDRADE 2001). O teorema aqui enunciado também é conhecido como o "Teorema do Hexagrama Místico de Pascal" para o círculo. CATALDO (2013) conta que o presente teorema foi apresentado por Blaise Pascal, quando tinha apenas 16 anos de idade, após estudar, em detalhes, o Teorema de Desargues. 


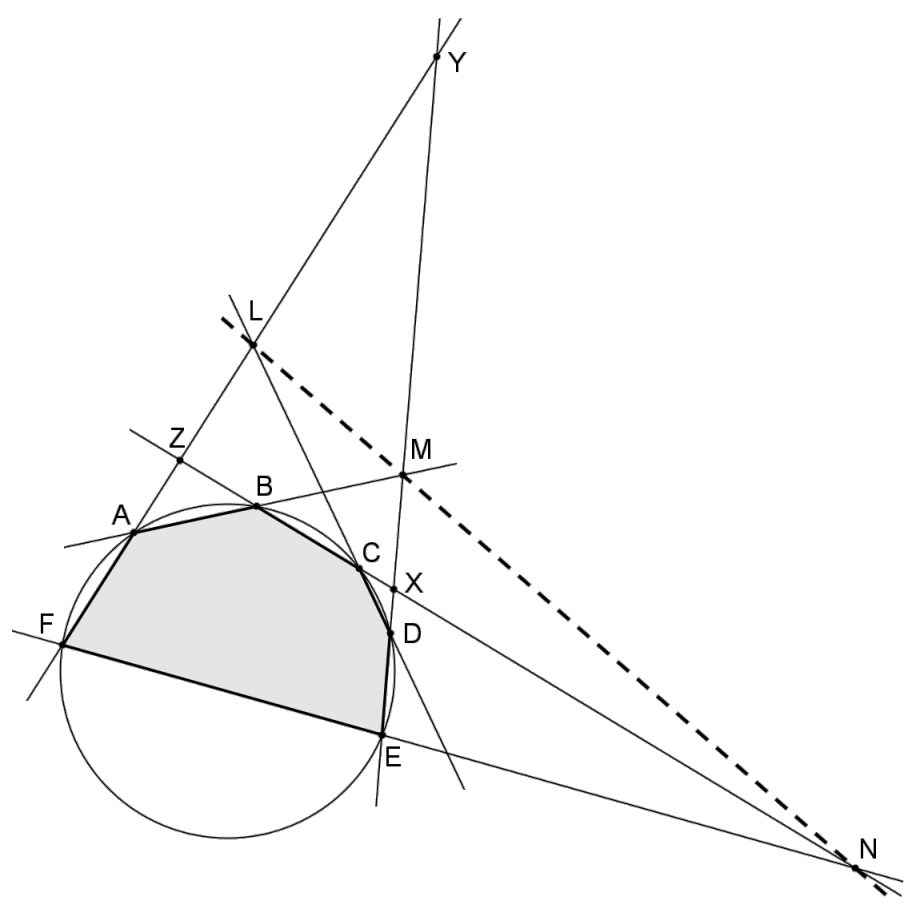

Figura 83 - Demonstração do teorema de Pascal

Multiplicando-se, membro a membro, essas igualdades, obtém-se

$$
\frac{Y L}{L Z} \cdot \frac{Z C}{C X} \cdot \frac{X D}{D Y} \cdot \frac{Y F}{F Z} \cdot \frac{Z N}{N X} \cdot \frac{X E}{E Y} \cdot \frac{Y A}{A Z} \cdot \frac{Z B}{B X} \cdot \frac{X M}{M Y}=1
$$

Considerando as relações de potências dos pontos $X, Y$ e $Z$, relativas ao círculo $\Gamma$,

$$
\begin{aligned}
& X C \cdot X B=X D \cdot X E, \\
& Y A \cdot Y F=Y D \cdot Y E, \\
& Z A \cdot Z F=Z B \cdot Z C,
\end{aligned}
$$

e, substituindo-as em (49), chega-se a $\frac{Y L}{L Z} \cdot \frac{Z N}{N X} \cdot \frac{X M}{M Y}=1$, que, pelo teorema recíproco de Menelaus (Teorema 4.11), aplicado ao triângulo $X Y Z$, garante que os pontos $L, N$ e $M$ são colineares.

Nota: Se o lado $B C$ for paralelo ao lado $D E$, por exemplo, o vértice $X$ do triângulo $X Y Z$ deixa de existir e a demonstração apresentada falha. Porém, neste caso, pode-se escolher um ponto $C^{\prime}$, na circunferência de $\Gamma$, o mais próximo possível de $C$, e considerar o hexágono $A B C^{\prime} D E F$. Assim, uma vez que a linha de Pascal existe para todas as posições de $C^{\prime}$, então vai existir a linha de Pascal também no limite de $C$ (EVES, 1972).

CASTRO (2000) e ANDRADE (2001) comentam que os vértices do hexágono não precisam ser necessariamente distintos, de modo que se fizer coincidir certos pares de vértices, é possível deduzir teoremas análogos ao de Pascal para pentágonos, quadriláteros e até triângulos inscritos num círculo.

Apesar de a demonstração apresentada ser de um hexágono convexo inscrito num círculo, o teorema de Pascal é válido para qualquer hexágono (inclusive os entrecruzados e degenerados), e não apenas inscritos em um círculo, mas também inscritos em cônicas (COXETER; GREITZER, 1967). 
CATALDO (2013) confirma que o teorema independe da cônica dada, destacando, inclusive, o caso das cônicas degeneradas. Por exemplo, o teorema de Pascal permanece válido mesmo quando a elipse se degenera em uma circunferência, conforme demonstrado, ou quando a hipérbole se degenera em duas retas concorrentes e, neste caso, leva o nome de teorema de Pappus.

Uma outra demonstração do Teorema de Pascal, via caminho algébrico, pode ser vista em CATALDO (2013).

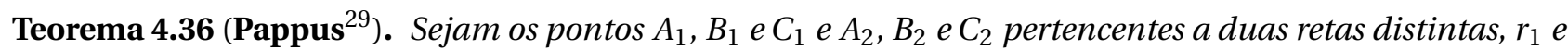
$r_{2}$, respectivamente, conforme a Figura 84 . Se os segmentos $A_{1} B_{2}$ e $A_{2} B_{1}$ intersectam-se em $C, A_{1} C_{2}$ e $A_{2} C_{1}$ intersectam-se em $B$ e $B_{1} C_{2}$ e $B_{2} C_{1}$ intersectam-se em $A$, então os pontos $A, B$ e $C$ são colineares.

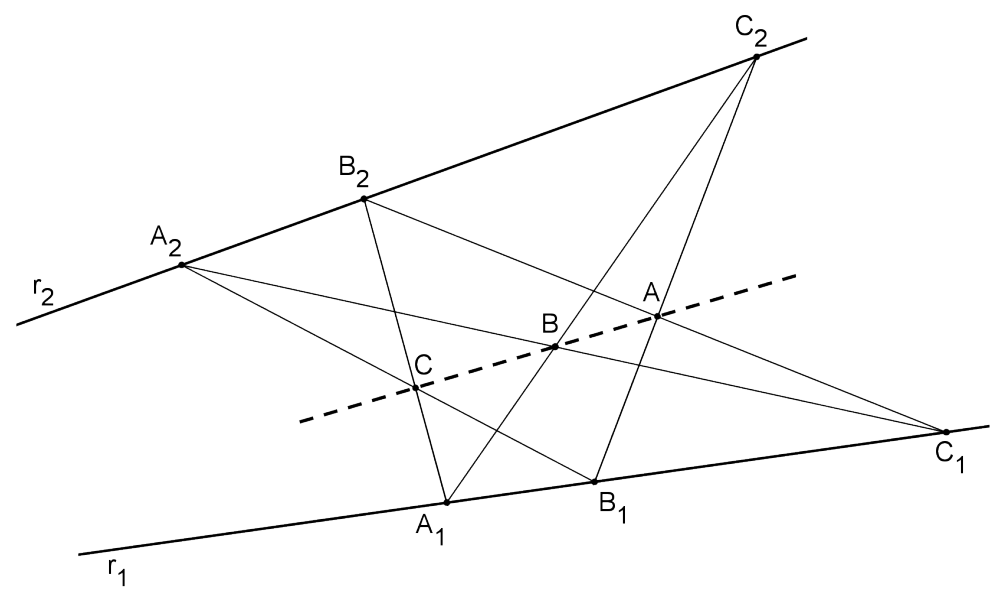

Figura 84 - Teorema de Pappus

Demonstração. Sejam $X, Y$ e $Z$ os pontos de encontro dos segmentos $B_{1} C_{2}$ e $A_{2} C_{1} ; A_{2} C_{1}$ e $A_{1} B_{2} ; A_{1} B_{2}$ e $B_{1} C_{2}$, respectivamente (Figura 85 .

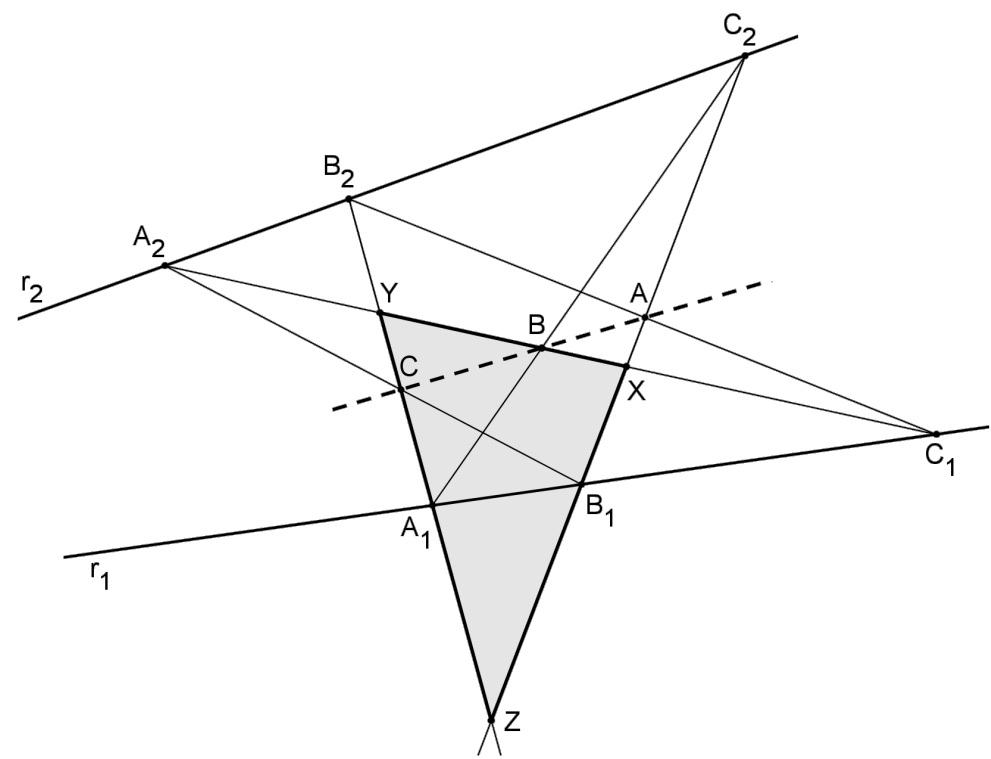

Figura 85 - Demonstração do teorema de Pappus 
Tendo por base o triângulo $X Y Z$ e as retas $A_{1} C_{2}, B_{1} A_{2}$ e $B_{2} C_{1}$ que o cortam (Figura 85), pode-se aplicar três vezes o teorema de Menelaus (Teorema 4.10), obtendo-se, respectivamente,

$$
\begin{aligned}
& \frac{X B}{B Y} \cdot \frac{Y A_{1}}{A_{1} Z} \cdot \frac{Z C_{2}}{C_{2} X}=1, \\
& \frac{X A_{2}}{A_{2} Y} \cdot \frac{Y C}{C Z} \cdot \frac{Z B_{1}}{B_{1} X}=1, \\
& \frac{X C_{1}}{C_{1} Y} \cdot \frac{Y B_{2}}{B_{2} Z} \cdot \frac{Z A}{A X}=1 .
\end{aligned}
$$

Considerando ainda as retas $r_{1}$ e $r_{2}$, que cortam o triângulo $X Y Z$, tem-se, pelo mesmo teorema, que

$$
\begin{aligned}
& \frac{X C_{1}}{C_{1} Y} \cdot \frac{Y A_{1}}{A_{1} Z} \cdot \frac{Z B_{1}}{B_{1} X}=1, \\
& \frac{X A_{2}}{A_{2} Y} \cdot \frac{Y B_{2}}{B_{2} Z} \cdot \frac{Z C_{2}}{C_{2} X}=1 .
\end{aligned}
$$

Multiplicando-se (50), (51) e (52), obtém-se

$$
\frac{X B}{B Y} \cdot \frac{Y A_{1}}{A_{1} Z} \cdot \frac{Z C_{2}}{C_{2} X} \cdot \frac{X A_{2}}{A_{2} Y} \cdot \frac{Y C}{C Z} \cdot \frac{Z B_{1}}{B_{1} X} \cdot \frac{X C_{1}}{C_{1} Y} \cdot \frac{Y B_{2}}{B_{2} Z} \cdot \frac{Z A}{A X}=1,
$$

cuja substituição dos resultados de (53) e (54), garante que

$$
\frac{X B}{B Y} \cdot \frac{Y C}{C Z} \cdot \frac{Z A}{A X}=1,
$$

que, pelo teorema recíproco de Menelaus (Teorema 4.11), aplicado ao triângulo $X Y Z$, permite concluir que os pontos $A, B$ e $C$ são colineares.

Nota: Apesar de a demonstração apresentar os pontos $A, B$ e $C$ de maneira ordenada sobre as retas, o teorema de Pappus é válido para pontos em qualquer ordem. Além disso, as retas $r_{1}$ e $r_{2}$ podem ser paralelas ou concorrentes (MUNIZ NETO, 2013).

O teorema de Pappus serve de base para a Geometria Projetiva moderna e pode ser tratado como um caso particular (ou corolário) do teorema de Pascal, considerando, neste caso, as duas retas como uma cônica degenerada.

CHAVES (2013) apresenta uma demonstração algébrica para este teorema, utilizando, para isso, o teorema de Bézout 30

Teorema 4.37 (Brianchon). Se um hexágono, com nenhum par de lados opostos paralelos, está circunscrito a um círculo, então as suas três diagonais são concorrentes em um ponto chamado Ponto de Brianchon ${ }^{31}$

Demonstração. Seja o hexágono $A B C D E F$ circunscrito a um círculo, com $P, Q, R, S, T$ e $U$ sendo os pontos de tangência dos lados do hexágono com este círculo (Figura[86).

30 Étienne Bézout (1739-1783) foi um matemático francês do séc. XVIII, cujo teorema revela como estimar o número de pontos de interseção de duas curvas planas CHAVES 2013.

31 Charles Julien Brianchon (1783-1864) foi um matemático e químico francês, conhecido por sua demonstração do teorema geométrico que leva seu nome em 1810 CCOXETER; GREITZER 1967. 


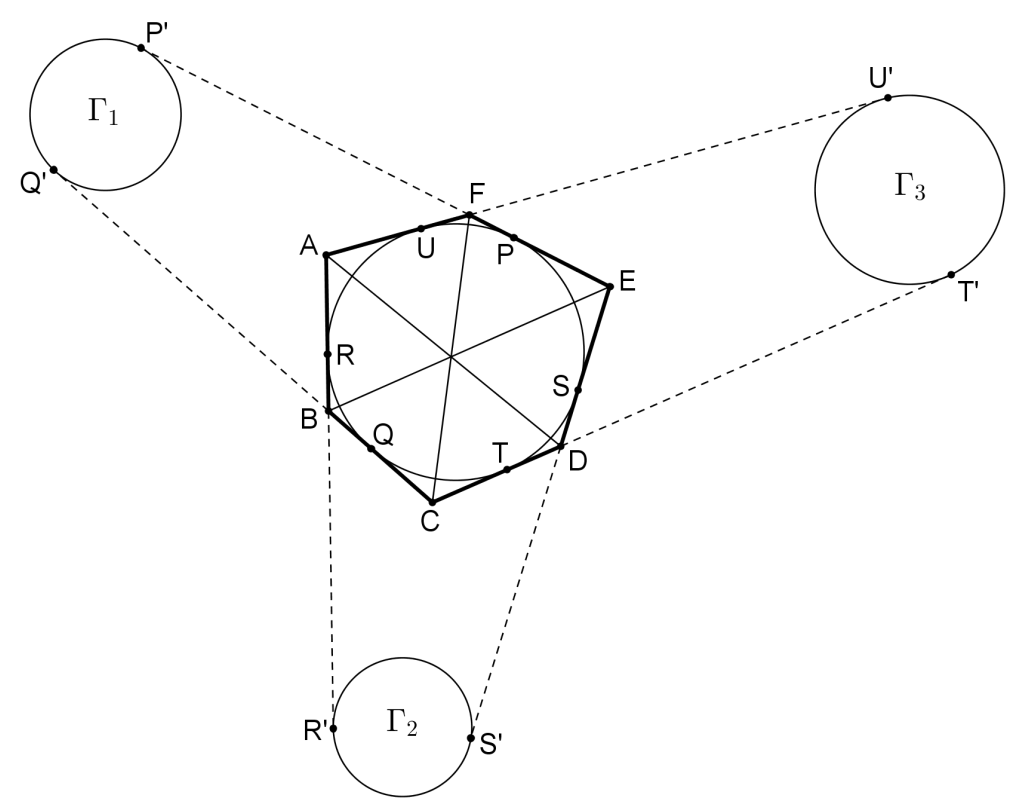

Figura 86 - Demonstração do teorema de Brianchon

Tomem-se, respectivamente, os pontos $P^{\prime}, Q^{\prime}, R^{\prime}, S^{\prime}, T^{\prime}$ e $U^{\prime}$ sobre o prolongamento dos lados $E F, C B, A B, E D, C D$ e $A F$, de um comprimento tal que $P P^{\prime}=Q Q^{\prime}=R R^{\prime}=S S^{\prime}=T T^{\prime}=U U^{\prime}$ permita a construção dos círculos $\Gamma_{1}, \Gamma_{2}$ e $\Gamma_{3}$, tangentes a esses segmentos nesses pontos (Figura 86).

Como $A R=A U$ e $R R^{\prime}=U U^{\prime}$, então $A R^{\prime}=A U^{\prime}$ e, assim, o vértice $A$ tem a mesma potência em relação aos círculos $\Gamma_{2}$ e $\Gamma_{3}$. Analogamente, o mesmo se conclui sobre o vértice $D$ em relação aos mesmos dois círculos. Logo, $A D$ é o eixo radical de $\Gamma_{2}$ e $\Gamma_{3}$ (ver Definição 4.11).

O mesmo raciocínio prova que $F C$ é o eixo radical de $\Gamma_{1}$ e $\Gamma_{3}$ e que $B E$ é o eixo radical de $\Gamma_{1}$ e $\Gamma_{2}$. Portanto, pelo Teorema 4.9 as diagonais $A D, F C$ e $B E$ do hexágono $A B C D E F$ são concorrentes num ponto, que é o centro radical dos três círculos $\Gamma_{1}, \Gamma_{2}$ e $\Gamma_{3}$ criados.

Nota: O hexágono considerado no teorema de Brianchon não precisa ser convexo.

O teorema de Brianchon é o dual do teorema de Pascal na Geometria Projetiva, podendo ser provado facilmente por este princípio. Entretanto, a versão apresentada neste trabalho considera o caso particular da circunferência inscrita, cuja demonstração utilizou apenas conceitos da Geometria Plana.

Finalmente, é importante destacar que as definições, proposições, lemas, teoremas e corolários apresentados pelo autor neste capítulo não esgotam os assuntos necessários à preparação de estudantes para enfrentar uma olimpíada de Matemática, mas servem de embasamento e instrumental para resolver muitos problemas envolvendo o tema Colinearidade e Concorrência, como será visto no capítulo a seguir. 



\section{Alguns problemas olímpicos}

“Um problema matemático é uma situação que demanda a realização de uma sequência de ações ou operações para obter um resultado. Ou seja, a solução não está disponível de início, mas é possível construí-la". \begin{tabular}{|l|l|}
\hline$M E C$ & 1998 \\
\hline
\end{tabular}

\subsection{Recomendações}

Antes de iniciar a apresentação e a resolução de alguns problemas olímpicos, selecionados dentre competições nas quais estudantes brasileiros podem concorrer, é importante deixar registradas algumas recomendações ou dicas, reunidas por POLYA (1996) e CASTRO (2013), para facilitar a resolução desse tipo de questão:

$\checkmark$ Compreender primeiro o enunciado, para depois começar;

$\checkmark$ Planejar uma estratégia para resolução;

$\checkmark$ Procurar semelhanças com outros problemas já conhecidos;

$\checkmark$ Fazer esquemas, diagramas ou desenhos, explorando as simetrias existentes;

$\checkmark$ Supor o problema resolvido e partir do fim para o começo;

$\checkmark$ Usar o método de "redução ao absurdo" pode ser uma alternativa;

$\checkmark$ Experimentar, tentar, errar, mas jamais desanimar;

$\checkmark$ Não teimar excessivamente com uma ideia. Se começar a complicar, pode ser que exista outro caminho, menos árduo;

$\checkmark$ Ter certeza de que, ao final, a solução encontrada está coerente, verificando se não entra em conflito com hipóteses e dados iniciais fornecidos no enunciado.

Na seção 5.2 serão apresentados, a título de exemplo, os enunciados de 7 (sete) problemas olímpicos, cobrados nas competições a seguir discriminadas, aplicados nos últimos 5 anos (2010-2014), bem como as respectivas propostas de solução elaboradas pelo autor, utilizando como base os conceitos explorados no 
Capítulo 4.

$\checkmark$ Olimpíada Internacional de Matemática - IMO: é a competição mais importante, onde participam cerca de 100 países, com equipes formadas por até 6 alunos com até 20 anos de idade, do Ensino Médio. Criada em 1959, sua prova é constituída por um total de 6 problemas, divididos em dois dias consecutivos com duração de 4 horas e meia;

$\checkmark$ Olimpíada de Matemática do Cone Sul - OMCS: é uma olimpíada internacional que existe desde 1989, da qual participam 8 países da América do Sul: Argentina, Bolívia, Brasil, Chile, Equador, Paraguai, Peru e Uruguai; é composta de 2 provas aplicadas em dias consecutivos, contendo cada uma 3 problemas com duração de 4 horas;

$\checkmark$ Olimpíada Iberoamericana de Matemática - OIbM: é uma competição internacional que existe desde 1985, em que participam os países da América Latina, além da Espanha e de Portugal; é composta de 2 provas, aplicadas em dias consecutivos, cada uma com 3 problemas e duração de 4 horas e meia;

$\checkmark$ Olimpíada de Matemática da Comunidade de Países de Língua Portuguesa (Lusofonia) OMCPLP: é uma competição internacional criada em 2011 e destinada a alunos do Ensino Médio, com até 18 anos de idade, dos 8 países de expressão portuguesa: Angola, Brasil, Cabo Verde, Guiné-Bissau, Moçambique, Portugal, São Tomé e Príncipe e Timor-Leste; sua prova é constituída por um total de 6 problemas, divididos em dois dias consecutivos, com duração de 4 horas e meia;

$\checkmark$ Romanian Masters in Mathematics - RMM: é a olimpíada internacional que convoca apenas os 15 melhores países do mundo na IMO realizada no ano anterior; é organizada desde 2007 pela Sociedade Científica Romena de Matemática e sua prova é dividida em dois dias consecutivos, com 3 problemas e duração de 4 horas e meia;

$\checkmark$ Olimpíada Brasileira de Matemática - OBM: é a principal olimpíada de Matemática realizada no Brasil, desde 1979, dividida em várias fases e níveis. Na última fase, a prova é discursiva, realizada em 2 dias, com 3 problemas e duração de 4 horas e meia;

$\checkmark$ Asian Pacific Mathematics Olympiad - APMO: é uma olimpíada internacional, iniciada em 1989, que envolve mais de 30 países da Ásia e do Pacífico, incluindo o Brasil. A prova é composta de 5 problemas com 4 horas de duração.

\subsection{Enunciados e soluções propostas}

Problema 1 (IMO 2013). Seja ABC um triângulo acutângulo com ortocentro $H$ e seja $W$ um ponto do lado $B C$, estritamente entre $B$ e $C$. Os pontos $M$ e $N$ são os pés das alturas traçadas desde $B$ e $C$, respectivamente. Designa-se por $w_{1}$ a circunferência circunscrita ao triângulo $B W N$; seja X o ponto de $w_{1}$ tal que WX é um diâmetro de $w_{1}$. Analogamente, designa-se por $w_{2}$ a circunferência circunscrita ao triângulo CWM; seja $Y$ o ponto de $w_{2}$ tal que WY é um diâmetro de $w_{2}$. Demonstrar que os pontos $X, Y$ e H são colineares.

Uma solução: Seja $Q$ o outro ponto de encontro entre as circunferências $w_{1}$ e $w_{2}$. Uma vez que $W X$ e $W Y$ são diâmetros, no círculo $w_{1}$ tem-se $\measuredangle X Q W=90^{\circ}$ e, no círculo $w_{2}, \measuredangle W Q Y=90^{\circ}$ (Proposição 4.4. Portanto, 
os pontos $X, Q$ e $Y$ são colineares (Figura 87 ).

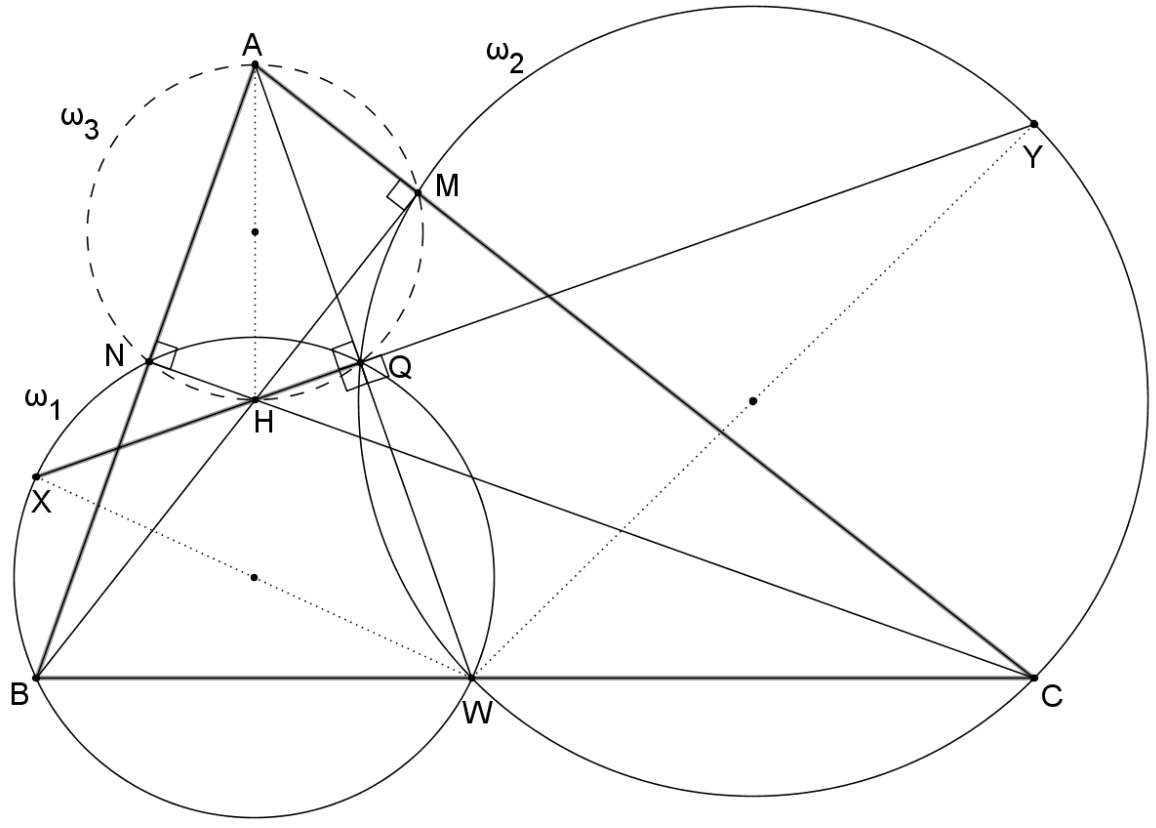

Figura 87 - IMO-2013.1

Como $Q$ é o ponto de Miquel do triângulo $A B C$, em relação aos pontos $W, N$ e $M$, então existe uma circunferência $w_{3}$ que passa por $A, N, M$ e $Q$ (Teorema 4.31). Uma vez que $\measuredangle A N H=\measuredangle A M H=90^{\circ}$, o quadrilátero $A N H M$ é inscritível em $w_{3}$ (Proposição 4.18), sendo $A H$ o seu diâmetro. Assim, $\measuredangle A Q H=90^{\circ} \mathrm{e}$ os pontos $A, N, H, Q$ e $M$ pertencem à circunferência $w_{3}$ (Figura 87).

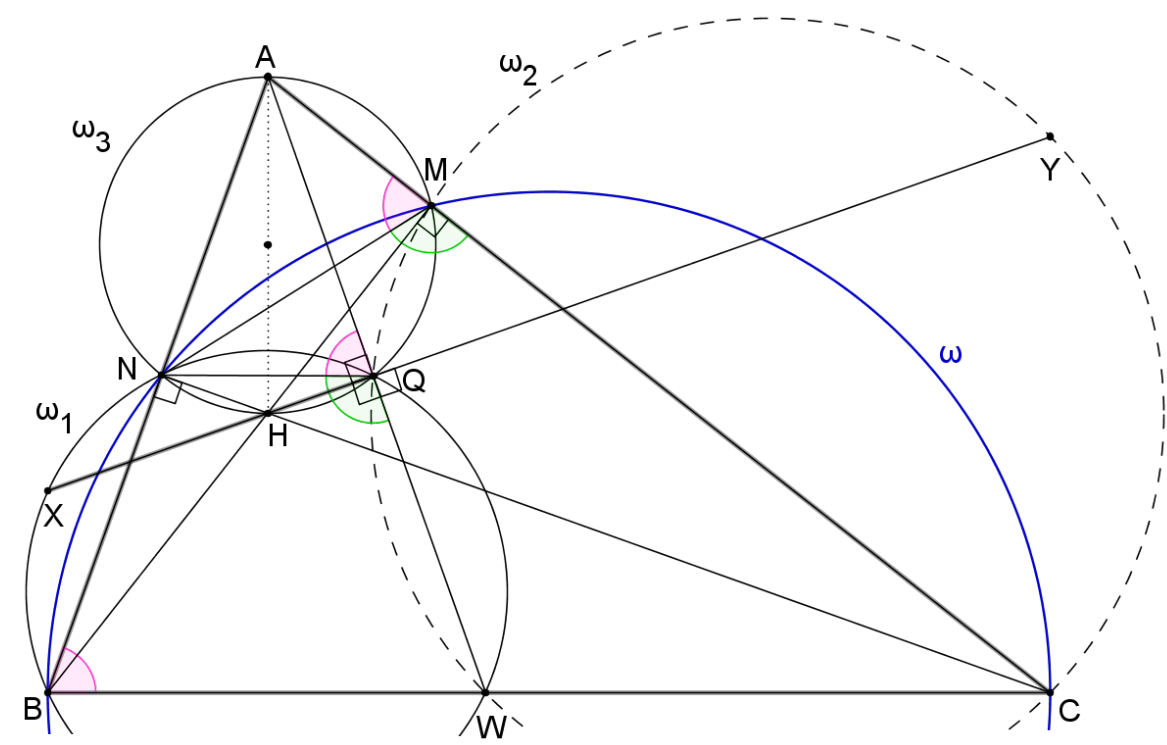

Figura 88 - IMO-2013.2

Além disso, como $\measuredangle B N C=\measuredangle B M C=90^{\circ}$, o quadrilátero $B N M C$ é inscritível numa circunferência $w$ de diâmetro $B C$ (Figura 88 .

No círculo $w_{3}, \measuredangle A Q N=\measuredangle A M N=180^{\circ}-\measuredangle N M C$.

No círculo $w, 180^{\circ}-\measuredangle N M C=\measuredangle N B C=\measuredangle N B W$. 
No círculo $w_{1}, \measuredangle N B W=180^{\circ}-\measuredangle N Q W$.

De (2), (3) e (4), decorre que $\measuredangle A Q N=180^{\circ}-\measuredangle N Q W$, ou seja, $\measuredangle A Q N+\measuredangle N Q W=180^{\circ}$. Assim, os pontos $A$, $Q$ e $W$ são colineares (Figura 88. Dessa forma, se $\measuredangle A Q H=90^{\circ}$ e $\measuredangle X Q W=90^{\circ}$, então os pontos $X$, $H$ e $Q$ também são colineares.

Portanto, das afirmações (1) e (5), conclui-se que os pontos $X, H$, $Q$ e $Y$ são colineares.

Problema 2 (OMCS 2014). Seja ABCD um quadrilátero inscrito em uma circunferência de centro O. Este ponto $O$ está no interior do quadrilátero de modo que os ângulos $\angle B A C$ e $\angle O D A$ são congruentes. As diagonais desse quadrilátero se cortam no ponto E. Por E são traçadas a reta $r$ perpendicular a $B C$ e a reta $s$ perpendicular a $A D$. A reta $r$ intersecta $A D$ em $P$ e a reta s intersecta $B C$ em M. Seja $N$ o ponto médio de EO. Mostre que $M, N$ e $P$ são colineares.

Uma solução: Seja $\Gamma$ o círculo de centro $O$, circunscrito ao quadrilátero $A B C D$, com ângulos tais que $\measuredangle B A C=\measuredangle O D A=\alpha$. Então, $\measuredangle B D C=\measuredangle B A C=\alpha$ (ângulo inscrito em $\Gamma$ ).

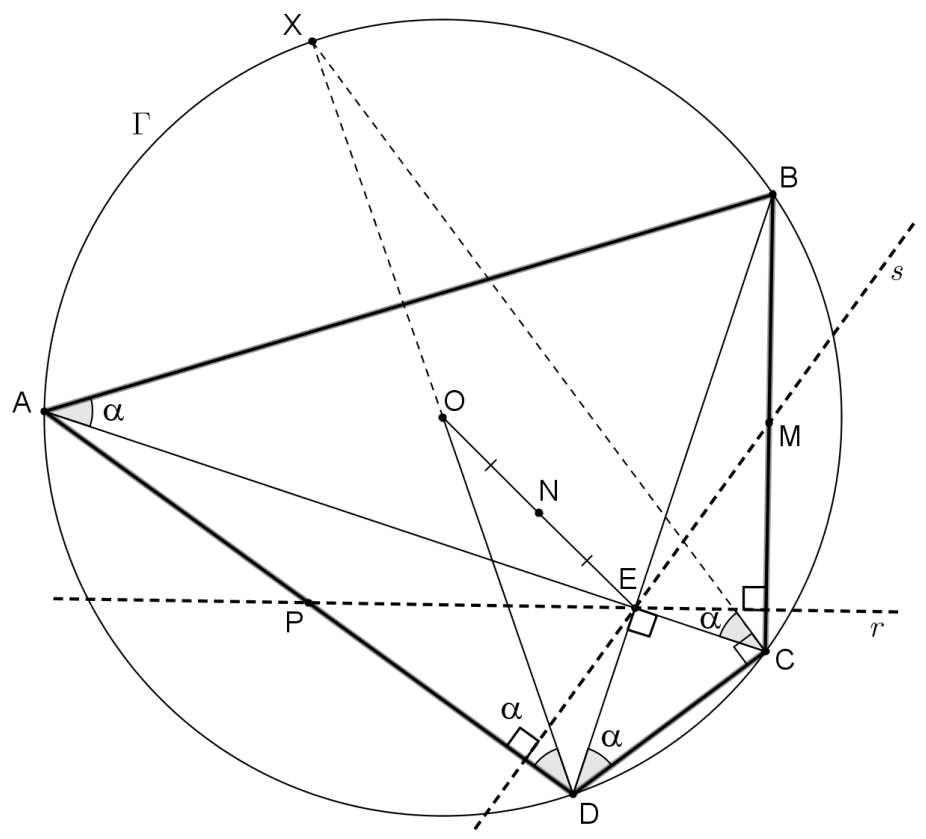

Figura 89 - OMCS-2014.1

Prolongando-se o raio $D O$ determina-se o diâmetro $D X$ em $\Gamma$. Unindo-se o ponto $X$ ao vértice $C$, tem-se $\measuredangle X C A=\measuredangle X D A=\measuredangle O D A=\alpha$ (Figura 89 ).

No triângulo $X C D$, inscrito em $\Gamma$ e retângulo em $C$ (Proposição 4.4 , tem-se $\measuredangle A C D=90^{\circ}-\alpha$ e, consequentemente, $\measuredangle C E D=90^{\circ}$, ou seja, $A C \perp B D$. Assim, $A B C D$ é um quadrilátero inscritível com diagonais perpendiculares entre si (Figura 89 ).

Pelo teorema de Brahmagupta (Teorema 4.27), as retas $r$ e $s$, que se cruzam em $E$, determinam os 
pontos $M$ e $P$ como pontos médios dos lados $B C$ e $A D$, respectivamente (Figura 90). Logo,

$$
\left\{\begin{array}{l}
O M \perp B C \Rightarrow O M \| r \\
O P \perp A D \Rightarrow O P \| s
\end{array}\right.
$$

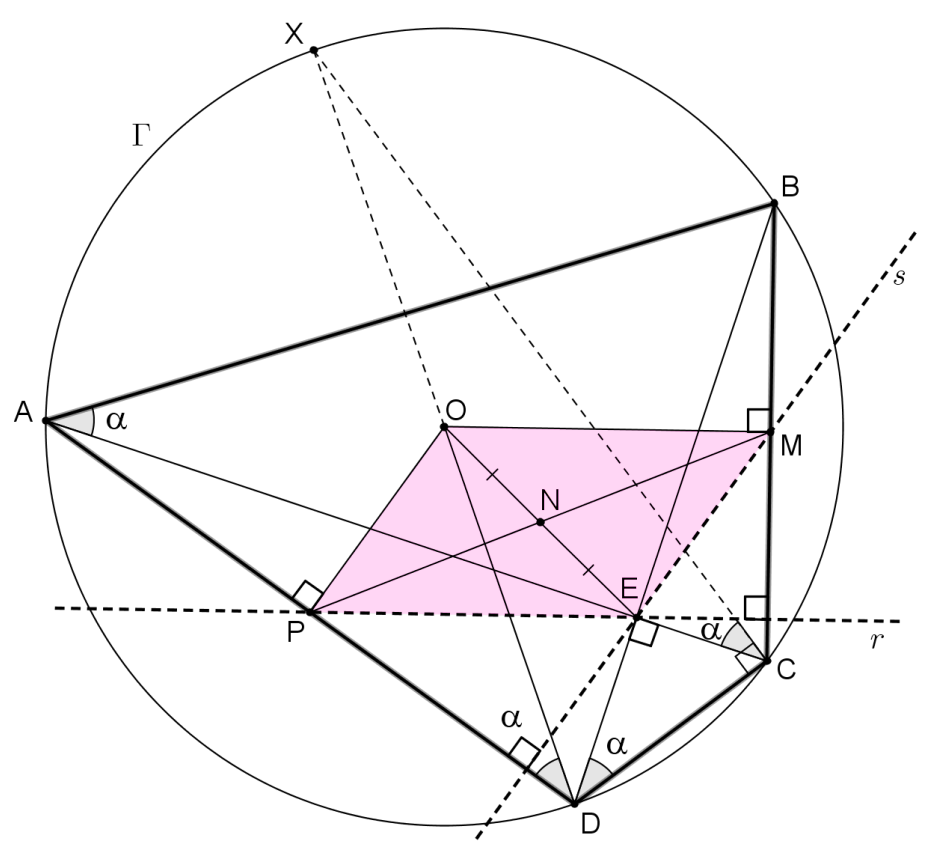

Figura 90 - OMCS-2014.2

Dessa forma, o quadrilátero $P O M E$ é um paralelogramo e, portanto, suas diagonais se cortam ao meio. Se $N$ é ponto médio de $O E$, então a outra diagonal $P M$ corta $O E$ em $N$, o que mostra ser $M, N$ e $P$ colineares, com $N$ sendo também o ponto médio de $M P$.

Problema 3 (OIbM 2010). A circunferência $\Gamma$ inscrita no triângulo escaleno $A B C$ é tangente aos lados $B C$, $C A$ e $A B$ nos pontos $D, E$ e $F$, respectivamente. A reta $E F$ corta a reta $B C$ em $G$. A circunferência de diâmetro GD corta $\Gamma$ em $R(R \neq D)$. Sejam $P$ e $Q(P \neq R, Q \neq R)$ as interseções de $B R$ e CR com $\Gamma$, respectivamente. As retas $B Q$ e $C P$ cortam-se em $X$. A circunferência circunscrita ao triângulo CDE corta o segmento $Q R$ em $M e$ a circunferência circunscrita ao triângulo BDF corta o segmento $P R$ em $N$. Demonstrar que as retas $P M, Q N$ e RX são concorrentes.

Uma solução: Seja $I$ o centro do círculo $\Gamma$. Neste caso, $I$ é o incentro do triângulo $A B C$, com $I D \perp B C, I E \perp A C$ e $I F \perp A B$ (Teorema 4.1). Desse modo, $I$ também é o ponto de interseção dos círculos $\lambda_{b}$ (de diâmetro $I B$ ) e $\lambda_{c}$ (de diâmetro $I C$ ), circunscritos aos triângulos $B D F$ e $C D E$, respectivamente (Figura 91).

Seja $\lambda$ é o círculo que possui diâmetro GD. Assim, em resumo, tem-se (Figura 91):

$\checkmark \quad \Gamma$ : centro $I$ e passa pelos pontos $D, E, F, P, Q, R$;

$\checkmark \quad \lambda$ : diâmetro $G D$ e passa pelos pontos $G, D, R$;

$\checkmark \quad \lambda_{b}$ : diâmetro $B I$ e passa pelos pontos $B, D, I, N, F$; e 


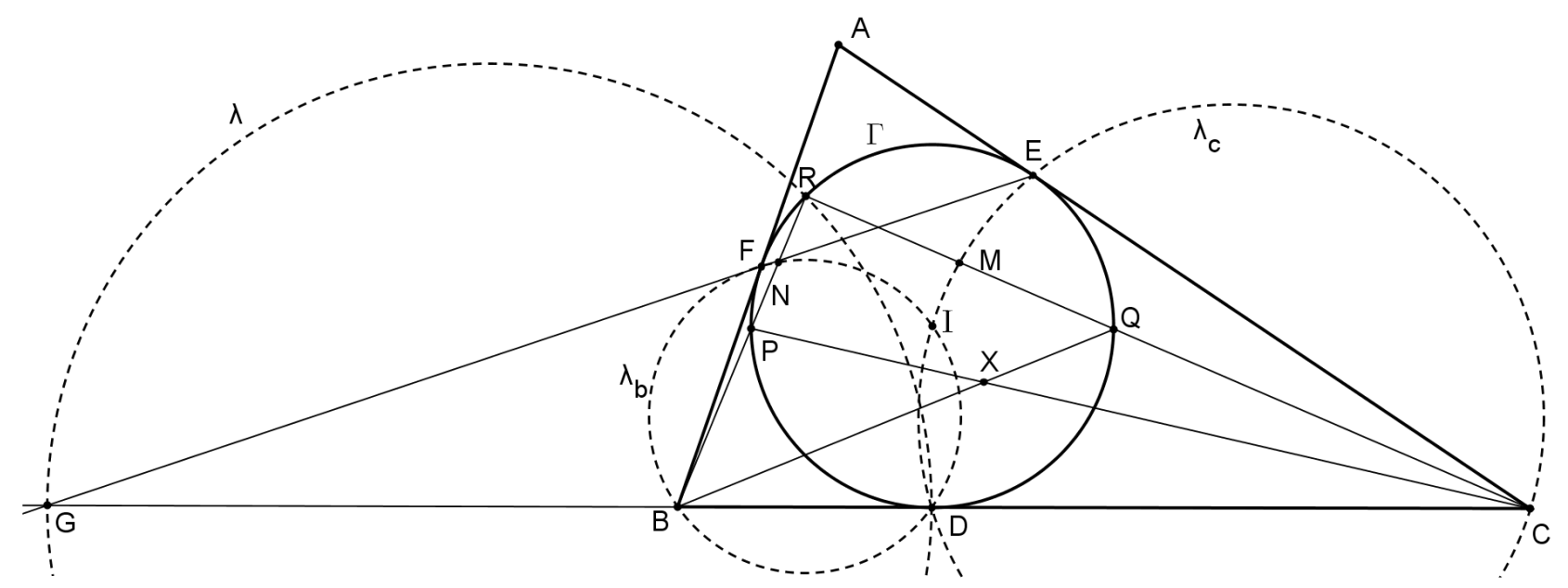

Figura 91 - OIbM-2010.1

$\checkmark \quad \lambda_{c}$ : diâmetro $C I$ e passa pelos pontos $C, D, I, M, E$.

No círculo $\Gamma, I D \perp B C, I E \perp A C$ e $I F \perp A B$.

No círculo $\lambda_{b}, I F \perp F B$ e $I D \perp D B \Rightarrow B I$ é diâmetro $\Rightarrow \measuredangle I N B=90^{\circ}$.

No círculo $\lambda_{c}, I E \perp E C$ e $I D \perp D C \Rightarrow C I$ é diâmetro $\Rightarrow \measuredangle I M C=90^{\circ}$.

Ainda, no círculo $\Gamma$,

$\checkmark$ se $N$ está na corda $P R$ e $I N \perp P R \Rightarrow N$ é médio de $P R$; e

$\checkmark$ se $M$ está na corda $Q R$ e $I M \perp Q R \Rightarrow M$ é médio de $Q R$. Assim, $N M$ é base média do triângulo $R P Q$, e, se $N M \| P Q$, então $N M Q P$ é trapézio (Figura 92).

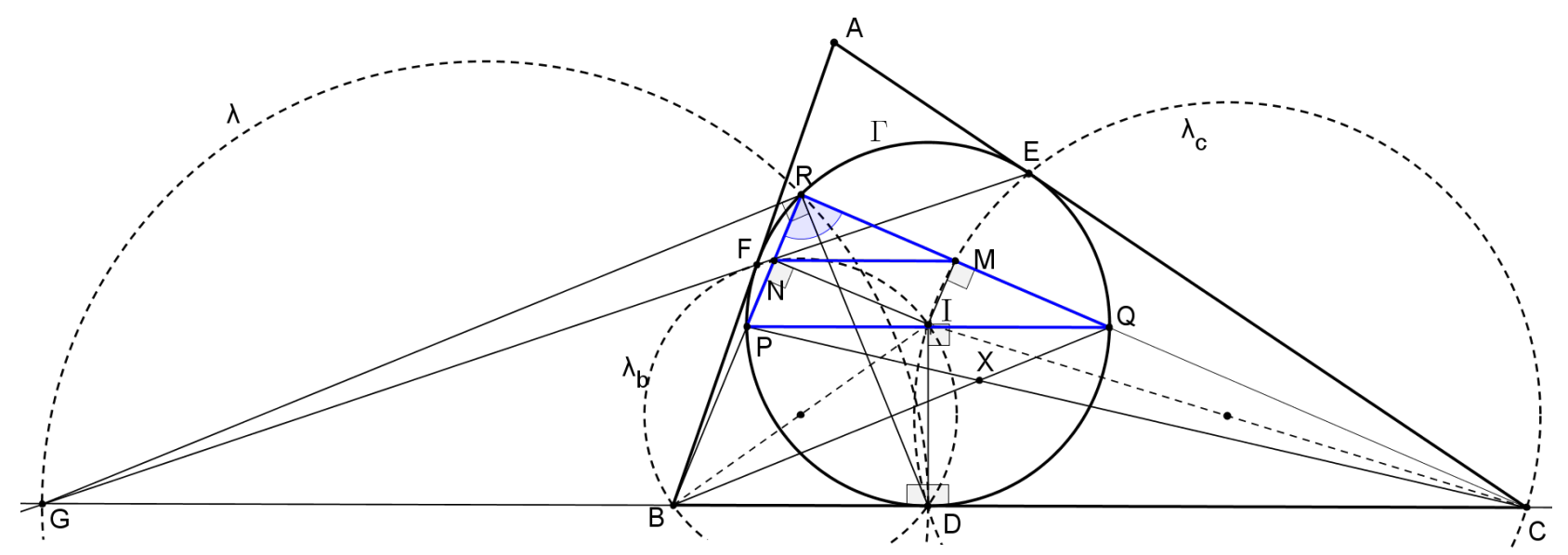

Figura 92 - OIbM-2010.2

Aplicando o teorema de Menelaus (Teorema 4.10), na sua versão básica, no triângulo $A B C$, cortado pela reta $G E$, tem-se

$$
\frac{A E}{E C} \cdot \frac{C G}{G B} \cdot \frac{B F}{F A}=1
$$


Como as tangentes $A E=F A, E C=D C$ e $B F=D B$ (Proposição 4.3), a equação acima reduz-se a

$$
\frac{G B}{G C}=\frac{D B}{D C}=k,
$$

ou seja, $G$ e $D$ dividem $B C$ harmonicamente na razão $k$ (Definição 4.9). Uma vez que, no círculo $\lambda$, $\measuredangle G R D=90^{\circ}$ (Proposição 4.4), tem-se que $R D$ e $R G$ são bissetrizes, interna externa, respectivamente, do triângulo $B R C$ (Teorema 4.6), $\operatorname{com} \lambda$ sendo o seu círculo de Apolônio (Teorema 4.8) na razão $k$ (Figura 92.

Se $R D$ é bissetriz do ângulo $\angle B R C=\angle P R Q$, então $R D$ divide ao meio o arco $P \widehat{D} Q$ de $\Gamma$, ou seja, no círculo $\Gamma, \widehat{P D}=\widehat{D Q}$. Com isso, $I D \perp P Q$. Entretanto, como $I D \perp B C$, então $P Q \| B C$ e $P Q C B$ é trapézio com $X$ sendo o ponto de encontro de suas diagonais (Figura 92 ).

Seja $Y$ o ponto de encontro das diagonais do trapézio $N M Q P$ (Figura93). Observando o triângulo $R B C$ e as paralelas $P Q$ e $N M$ em relação à base $B C$, verifica-se que os triângulos $M P C$ e $N Q B$ estão em perspectiva, com seu ponto de fuga no infinito. Assim, pelo teorema de Desargues (Teorema 4.33), tem-se:

$$
\left.\begin{array}{l}
M P \cap N Q=Y \\
P C \cap Q B=X \\
C M \cap B N=R
\end{array}\right\} \Rightarrow Y, X \text { e } R \text { são colineares. }
$$

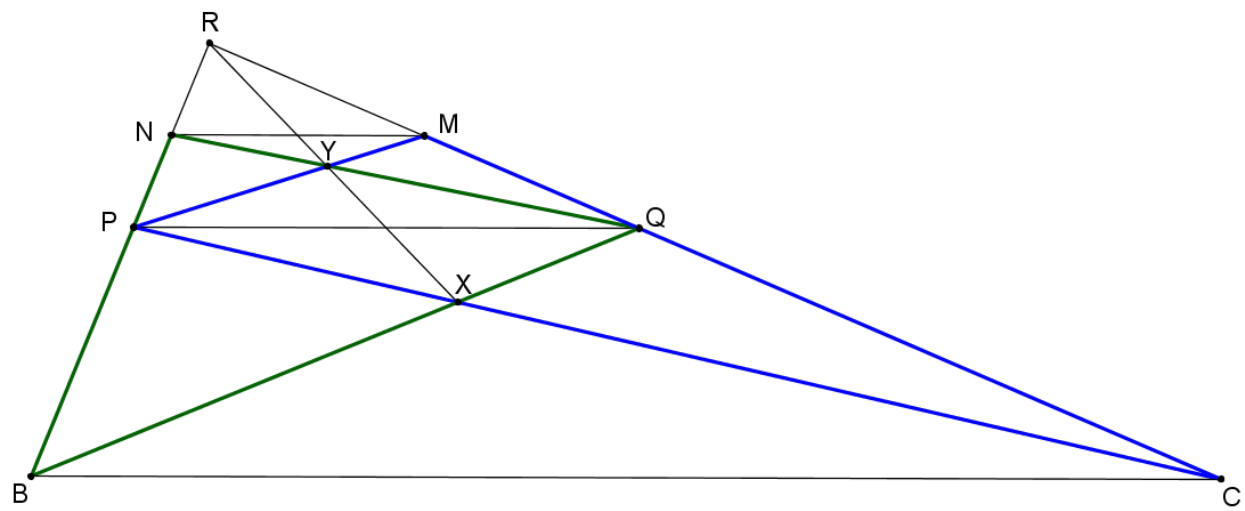

Figura 93 - OIbM-2010.3

Portanto, se $Y, X$ e $R$ são colineares, então as retas $P M, Q N$ e $R X$ concorrem em $Y$.

Problema 4 (OMCPLP 2013). Considere um triângulo ABC. Seja S a circunferência que tangencia internamente os lados $B C, C A$ e $A B$ do triângulo nos pontos $D, E$ e $F$, respectivamente. Externamente ao triângulo constroem-se três circunferências $S_{A}, S_{B}$ e $S_{C}$. A circunferência $S_{A}$ é tangente a $B C$ no ponto L e aos prolongamentos das retas $A B$ e $A C$, nos pontos $M e N$, respectivamente. A circunferência $S_{B}$ é tangente a $A C$ no ponto $E$ e ao prolongamento da reta $B C$ no ponto $P$. A circunferência $S_{C}$ é tangente a $A B$ no ponto $F$ e ao prolongamento da reta $B C$ no ponto $Q$. Prove que as retas $E P, F Q$ e AL são concorrentes em um único ponto sobre $S$.

Uma solução: Inicialmente, é importante notar que $S_{A}$ é um exincírculo do triângulo $A B C$ (Figura 94 . 


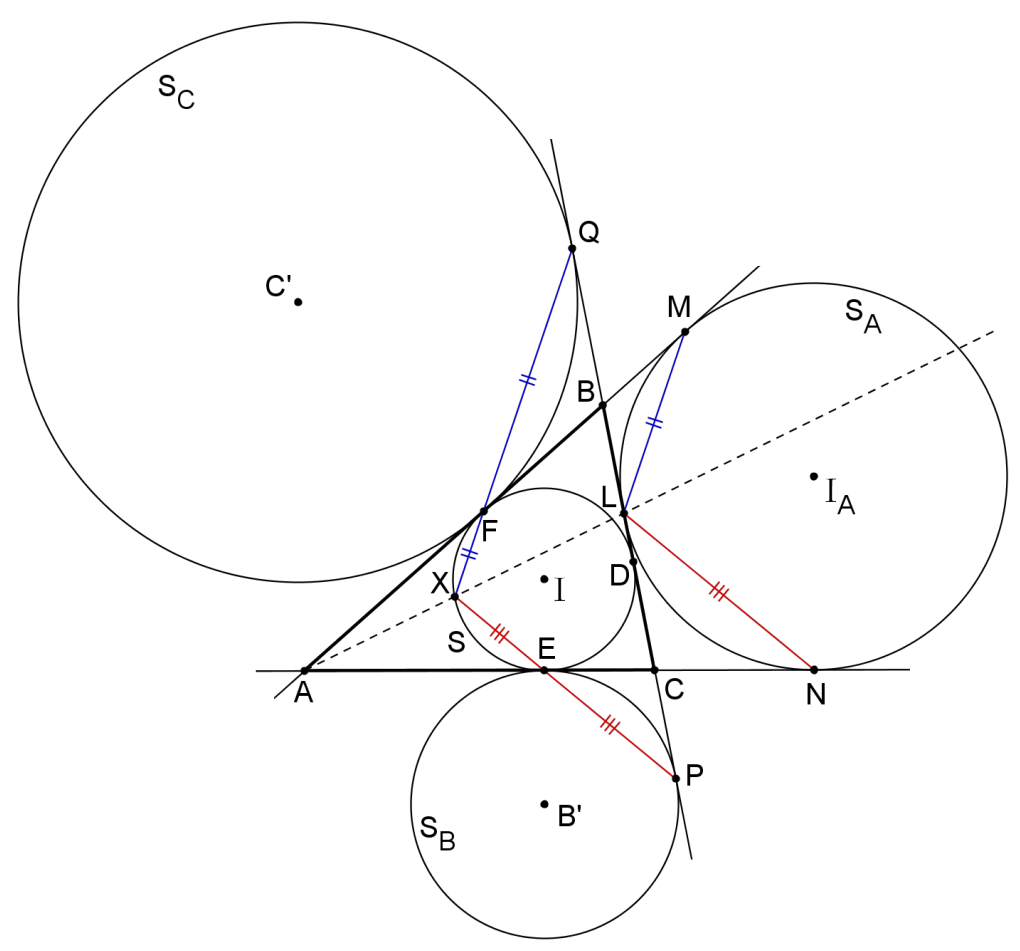

Figura 94 - OMCPLP-2013.1

Seja $X$ um ponto de interseção da reta $A L$ com a circunferência $S$. Uma vez que as retas $A B$ e $A C$ são tangentes comuns ao incírculo $S$ e ao exincírculo $S_{A}$ do triângulo $A B C$, a homotetia direta desses círculos em relação ao vértice $A$ mapeia os pontos $X, F$ e $E$ de $S$ nos pontos $L, M$ e $N$ de $S_{A}$, respectivamente. Portanto, $F X \| M L$ e $E X \| N L$ (Figura 94 ).

Pela homotetia inversa dos círculos $S_{A}$ e $S_{C}$ em relação ao vértice $B$, tem-se que as polares $M L \in S_{A}$ e $Q F \in S_{C}$ são paralelas (Figura 94). Logo,

$$
\left.\begin{array}{l}
F X \| M L \\
M L \| Q F
\end{array}\right\} \Rightarrow X, F \text { e } Q \text { são colineares. }
$$

Analogamente, pela homotetia inversa dos círculos $S_{A}$ e $S_{B}$ em relação ao vértice $C$, tem-se que as polares $N L \in S_{A}$ e $P E \in S_{B}$ são paralelas (Figura 94). Logo,

$$
\left.\begin{array}{l}
E X \| N L \\
N L \| P E
\end{array}\right\} \Rightarrow X, E \text { e } P \text { são colineares. }
$$

Portanto, as retas $E P, F Q$ e $A L$ são concorrentes no ponto $X$, localizado sobre a circunferência $S$.

Problema 5 (RMM 2010). Seja $A_{1} A_{2} A_{3} A_{4}$ um quadrilátero convexo cujos lados opostos não são paralelos. Para cada $i=1,2,3,4$, defina $w_{i}$ como o círculo que toca o quadrilátero externamente e é tangente às retas $A_{i-1} A_{i}, A_{i} A_{i+1}$ e $A_{i+1} A_{i+2}$ (índices são considerados módulo 4, de modo que $A_{0}=A_{4}, A_{5}=A_{1}$ e $A_{6}=A_{2}$ ). Seja 
$T_{i}$ o ponto de tangência de $w_{i}$ com o lado $A_{i} A_{i+1}$. Prove que as retas $A_{1} A_{2}, A_{3} A_{4}$ e $T_{2} T_{4}$ são concorrentes se, $e$ somente se, as retas $A_{2} A_{3}, A_{4} A_{1}$ e $T_{1} T_{3}$ são concorrentes.

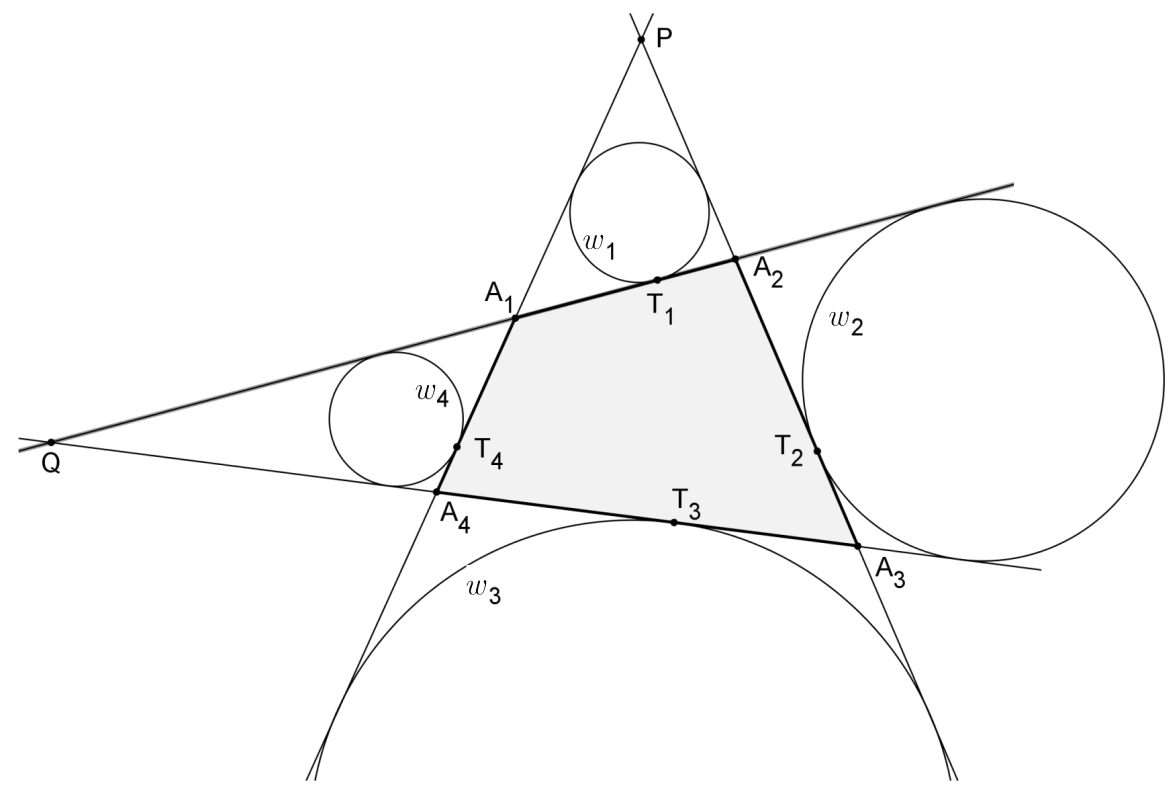

Figura 95 - RMM-2010.1

Uma solução: Uma vez que os lados opostos do quadrilátero $A_{1} A_{2} A_{3} A_{4}$ não são paralelos, considere que as retas $A_{1} A_{2}$ e $A_{3} A_{4}$ se encontrem no ponto $Q$ e as retas $A_{2} A_{3}$ e $A_{4} A_{1}$ se encontrem no ponto $P$ (Figura 95. Nesse caso, para resolver o problema, basta agora provar que os pontos $P, T_{1}$ e $T_{3}$ são colineares se, e somente se, os pontos $Q, T_{4}$ e $T_{2}$ são colineares.

Como existem vários círculos e tangentes comuns (Figura 95), é possível observar algumas homotetias para a resolução do problema.

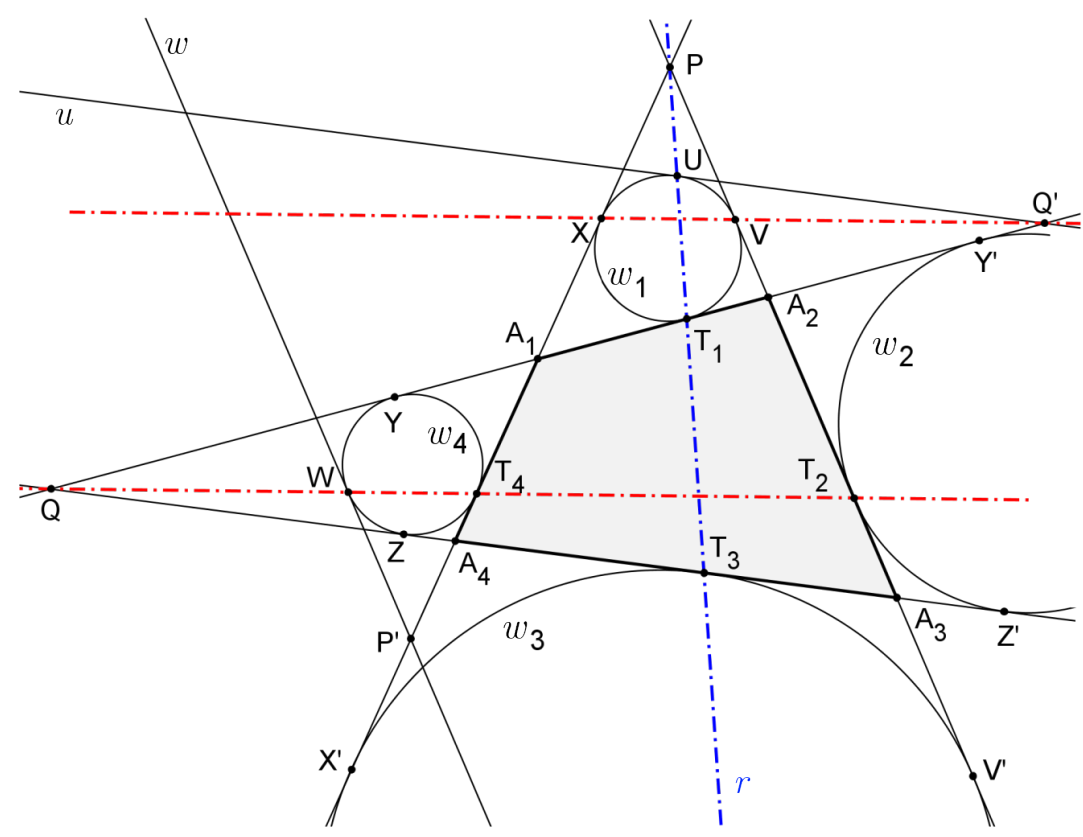

Figura 96 - RMM-2010.2 
Sejam os pontos $V$ e $X$ os pontos de tangência das retas $A_{2} A_{3}$ e $A_{4} A_{1}$ com o círculo $w_{1}$, e $Y$ e $Z$ os pontos de tangência das retas $A_{1} A_{2}$ e $A_{3} A_{4}$ com o círculo $w_{4}$, respectivamente (Figura 96).

Inicialmente, considere, por hipótese, que os pontos $P, T_{1}$ e $T_{3}$ são colineares e estão sobre a reta $r$. Seja $U$ o outro ponto de interseção de $r \operatorname{com} w_{1}$ (Figura96).

Uma vez que as retas $A_{2} A_{3}$ e $A_{4} A_{1}$ são tangentes comuns externas aos círculos $w_{1}$ e $w_{3}$, e que $P, T_{1}$ e $T_{3}$ são colineares, então a homotetia direta com centro em $P$ mapeia o círculo $w_{1}$ em $w_{3}$ e, consequentemente, o ponto $U$ em $T_{3}$. Assim, a reta $u$, tangente a $w_{1}$ em $U$, é paralela à reta $A_{3} A_{4}$, tangente a $w_{3}$ em $T_{3}$ (Figura 96).

As retas $A_{4} A_{1}$ e $A_{2} A_{1}$ são tangentes comuns internas aos círculos $w_{1}$ e $w_{4}$. Desse modo, a homotetia inversa com centro em $A_{1}$ vai relacionar $w_{1}$ e $w_{4}$, bem como as suas polares, $X T_{1}$ e $T_{4} Y$, de modo inverso, ou seja, os pontos $X$ e $T_{1}$ (em $w_{1}$ ) são mapeados em $T_{4}$ e $Y$ (em $w_{4}$ ), respectivamente. Como a reta $A_{3} A_{4}$ tangencia $w_{4}$ em $Z$, a mesma homotetia vai mapear o ponto $Z$ no ponto $U$, dado que a reta $u$ é paralela a $A_{3} A_{4}$ e tangente a $w_{1}$ em $U$. Além disso, o ponto $Q$ será mapeado no ponto $Q^{\prime}$, onde $A_{3} A_{4} \cap A_{2} A_{1}=Q$ e $u \cap A_{2} A_{1}=Q^{\prime}$ (Figura 96).

Considere agora que essa mesma homotetia, centrada em $A_{1}$, mapeie o ponto $V$ de $w_{1}$ em um ponto $W$ de $w_{4}$ (Figura 96). Assim, a reta $w$, tangente a $w_{4}$ em $W$, é paralela à reta $A_{2} A_{3}$, que, por sua vez, é tangente a $w_{1}$ em $V$.

A configuração projetiva de $w_{1}$, com pólo $P$, tangentes $P X$ e $P V$, e os pontos $P, U$ e $T_{1}$ alinhados, garante que, no pólo $Q^{\prime}$, com tangentes $Q^{\prime} U$ e $Q^{\prime} T_{1}$, os pontos $Q^{\prime}, V$ e $X$ estarão também alinhados. Note-se que $X V$ é a polar de $P$ e que $U T_{1}$ é a polar de $Q^{\prime}$. Por conseguinte, a homotetia entre os círculos $w_{1} \mathrm{e} w_{4}$, centrada em $A_{1}$, garante que os pontos homólogos $Q, W$ e $T_{4}$ também estarão alinhados, com $Y Z$ sendo a polar de $Q$ e $W T_{4}$ a polar de $P^{\prime}$ (Proposição 4.22) (Figura 96).

Pela homotetia inversa entre os círculos $w_{1}$ e $w_{2}$, centrada em $A_{2}$, o ponto $V$ (em $w_{1}$ ) é mapeado no ponto $T_{2}\left(\mathrm{em} w_{2}\right)$.

Agora, seja $W^{\prime}$ um ponto em $w_{4}$, homólogo de $T_{2}$ no tocante à homotetia direta com pólo em $Q$, entre $w_{2}$ e $w_{4}$. Assim, $Q, W^{\prime}$ e $T_{2}$ são colineares. Com isso, a reta tangente a $w_{4}$, passando por $W^{\prime}$, é paralela à reta $A_{2} A_{3}$. Entretanto, de (6), tem-se que a reta paralela a $A_{2} A_{3}$ que tangencia $w_{1}$ é a reta $w$, no ponto $W$. Portanto, $W^{\prime} \equiv W$, e $Q, W, T_{4}$ e $T_{2}$ estão alinhados.

A implicação inversa pedida no problema pode ser demonstrada de modo análogo, ou seja, considerandose, inicialmente, $Q, T_{4}$ e $T_{2}$ colineares, chega-se à conclusão que $P, T_{1}$ e $T_{3}$ também são colineares.

Problema 6 (OBM 2012). Dado um triângulo $A B C$, o exincentro relativo ao vértice A é o ponto de interseção das bissetrizes externas dos ângulos $\angle B$ e $\angle C$. Sejam $I_{A}, I_{B}$ e $I_{C}$ os exincentros do triângulo escaleno $A B C$ relativos a $A, B$ e C, respectivamente, e $X, Y$ e $Z$ os pontos médios de $I_{B} I_{C}, I_{C} I_{A}$ e $I_{A} I_{B}$, respectivamente. $O$ incírculo do triângulo $A B C$ toca os lados $B C, C A$ e $A B$ nos pontos $D, E$ e $F$, respectivamente. Prove que as retas $D X, E Y$ e FZ têm um ponto em comum pertencente à reta IO, sendo I e O o incentro e o circuncentro do triângulo $A B C$, respectivamente. 
Uma solução: Sabe-se, pelo Teorema 4.6, que o exincentro relativo a um vértice de um triângulo é o ponto de encontro das bissetrizes externas dos outros dois ângulos, mais a bissetriz interna do ângulo considerado. Desse modo, para o triângulo $A B C$ (Figura 97), cada um dos ternos de pontos $\left(A, I, I_{A}\right),\left(B, I, I_{B}\right)$ e $\left(C, I, I_{C}\right)$ são colineares.

Sejam $2 p$ o perímetro do triângulo $A B C$, $\gamma$ a medida do seu ângulo $\angle C$, e $w$ o seu circuncírculo.

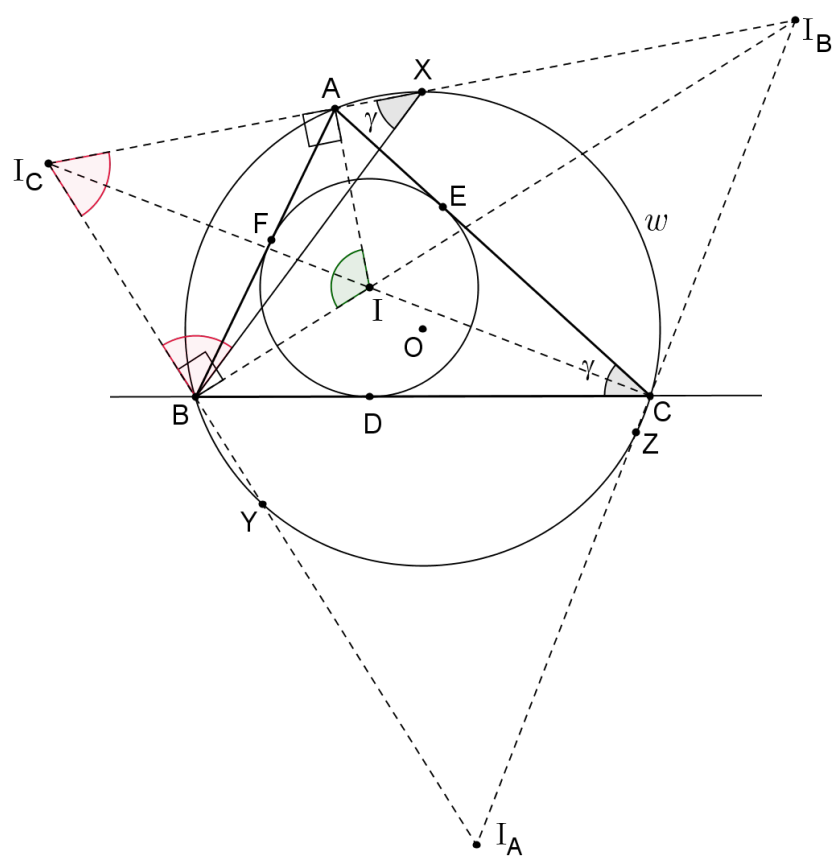

Figura 97 - OBM-2012.1

Uma vez que $B I_{C}$ e $B I_{B}$ são, respectivamente, bissetrizes externa e interna, relativas ao vértice $B$, então $\measuredangle I_{C} B I_{B}=90^{\circ}$ (Proposição 4.5. Como $X$ é médio de $I_{B} I_{C}$, então $B X$ é mediana relativa à hipotenusa do triângulo retângulo $I_{C} B I_{B}$, com $B X=I_{C} X=I_{B} X$ (Proposição 4.4), ou seja, o triângulo $I_{C} X B$ é isósceles (Figura 97).

Se os segmentos $A I$ e $B I$ são bissetrizes internas do triângulo $A B C$, então, $\measuredangle A I B=90^{\circ}+\frac{\gamma}{2}$ (Proposição 4.6. Uma vez que $A I$ e $A I_{C}$, e $B I$ e $B I_{C}$ são as bissetrizes interna e externa, relativas aos vértices $A$ e $B$, respectivamente, ou seja, $A I \perp A I_{C}$ e $B I \perp B I_{C}$ (Proposição 4.5), o quadrilátero $A I B I_{C}$ é inscritível (Proposição 4.18) e $\measuredangle A I_{C} B=90^{\circ}-\frac{\gamma}{2}$ (Figura 97 .

No triângulo isósceles $I_{C} X B$ tem-se $\measuredangle X I_{C} B=\measuredangle X B I_{C}=90^{\circ}-\frac{\gamma}{2}$ e, portanto, $\measuredangle I_{C} X B=\gamma$. Logo, $X$ pertence ao mesmo arco-capaz que o vértice $C$ do triângulo $A B C$, no circuncírculo $w$ (Figura 97).

Sejam $L, M$ e $N$ os pés das perpendiculares baixadas a partir de $I_{C}, X$ e $I_{B}$, respectivamente, até o lado $B C$ do triângulo $A B C$ (Figura 98). Assim, pela Lei de Proporcionalidade de Tales, $M$ é ponto médio de $L N$ e $X M$ é base média do trapézio retângulo $I_{C} I_{B} N L$.

Sejam $L^{\prime}$ e $N^{\prime}$ os pés das perpendiculares baixadas de $I_{C}$ e $I_{B}$ até as retas suportes dos lados $A C$ e $A B$, respectivamente, do triângulo $A B C$ (Figura 98). Uma vez que $L$ e $L^{\prime}$ são os pontos de tangência das tangentes traçadas a partir de $C$ até o exincírculo $\lambda_{C}$, tem-se que $C L=C L^{\prime}$. Além disso, como $B L=B F$ e $A L^{\prime}=A F$, tem-se 


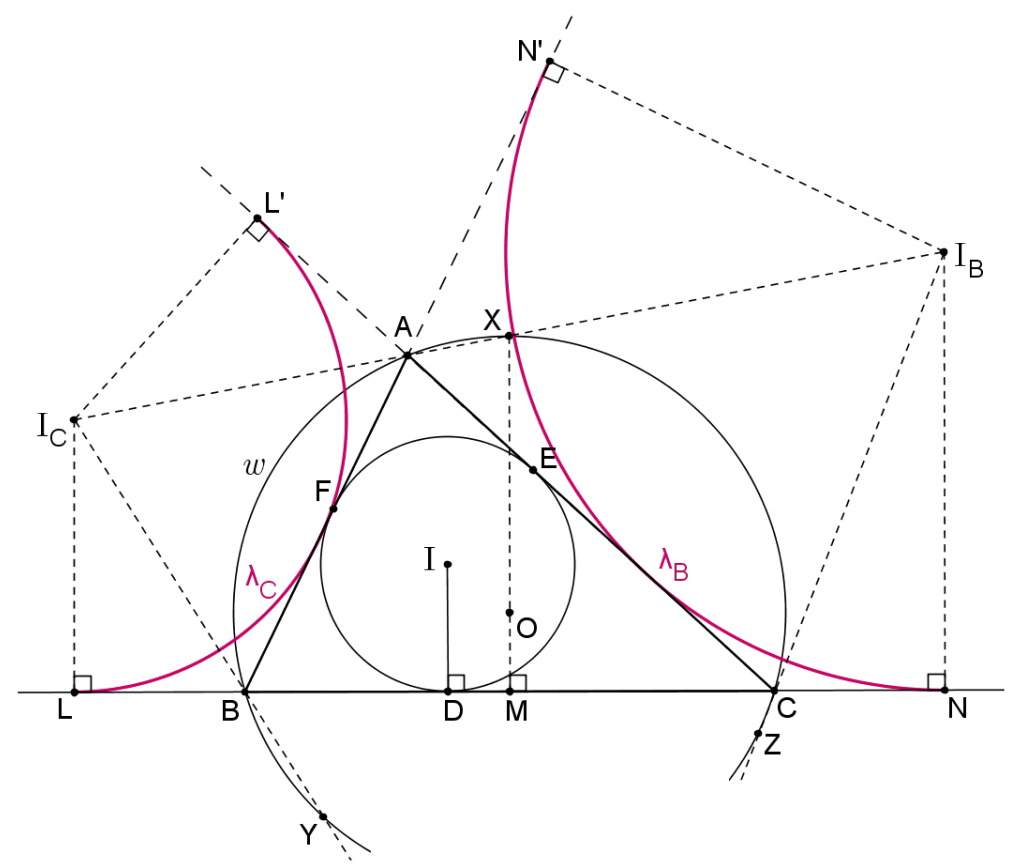

Figura 98 - OBM-2012.2

$$
C L+C L^{\prime}=2 p \Rightarrow 2 \cdot C L=2 p \Rightarrow C L=p .
$$

Analogamente,

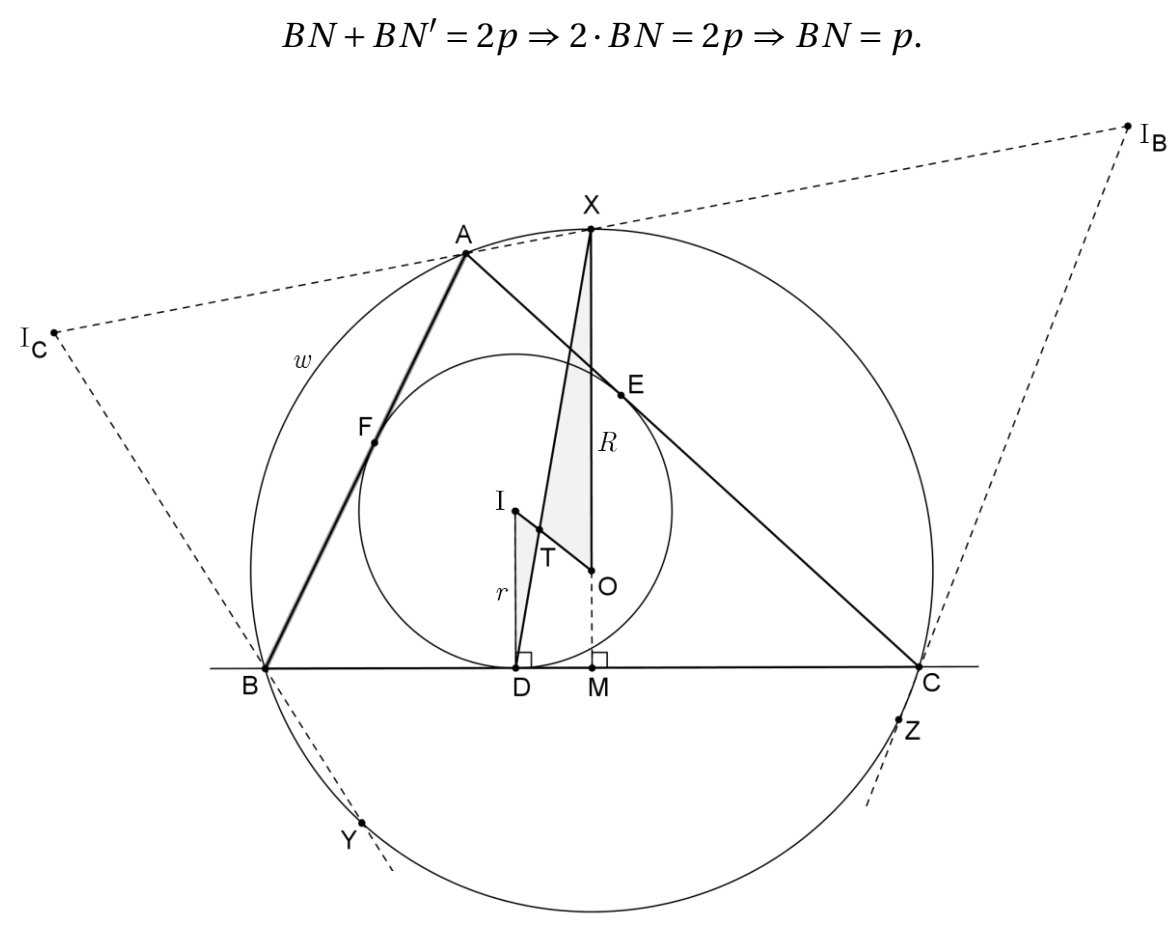

Figura 99 - OBM-2012.3

Se $C L=B N$, então $B L=C N$ e, portanto, $M$, além de médio de $L N$, também é ponto médio da corda $B C$ de $w$. Assim, $X M$ passa pelo centro $O$ de $w$ (Proposição 4.3).

Sejam $r$ e $R$, respectivamente, o valor dos raios do incírculo e do circuncírculo do triângulo $A B C$, ou seja, $I D=r$ e $O X=R$ (Figura 99). 
Seja $T$ o ponto de interseção entre os segmentos $D X$ e $I O$. Os triângulos TID e TOX são homotéticos em relação a $T$ e possuem seus lados paralelos, sendo, portanto, semelhantes entre si (Figura 99), de tal forma que $\frac{T I}{T O}=\frac{I D}{O X}=\frac{r}{R}$.

Analogamente, $I E=r$ e $O Y=R$. Seja $T^{\prime}$ o ponto de interseção entre os segmentos $E Y$ e $I O$. Então, os triângulos $T^{\prime} I E$ e $T^{\prime} O Y$ são homotéticos em relação a $T^{\prime}$ e semelhantes entre si, $\operatorname{com} \frac{T^{\prime} I}{T^{\prime} O}=\frac{I E}{O Y}=\frac{r}{R}$. (8)

As igualdades (7) e (8) confirmam que $T^{\prime} \equiv T$.

Finalmente, procedendo-se da mesma forma para o segmento $F Z$, uma vez que $I F=r$ e $O Z=R$, tem-se que $F Z$ corta $I O$ no mesmo ponto $T$, e, portanto, os segmentos $D X, E Y$ e $F Z$ são concorrentes no ponto $T$, pertencente à reta $I Q^{1}$, tal que $\frac{T I}{T O}=\frac{r}{R}$.

Problema 7 (APMO 2013). Seja ABCD um quadrilátero inscrito no círculo $w$, e seja $P$ um ponto do prolongamento $A C$ tal que os segmentos $P B$ e PD são tangentes a $w$. A reta tangente por $C$ intersecta $P D$ no ponto $Q$ e a reta $A D$ no ponto $R$. Seja $E$ o outro ponto de interseção entre $A Q e w$. Demonstrar que os pontos $B, E, R$ são colineares.

Uma solução: Provar que os pontos $B, E, R$ são colineares é o mesmo que provar que as retas $A D, C Q$ e $B E$ são concorrentes no ponto $R$ (Figura 100 ).

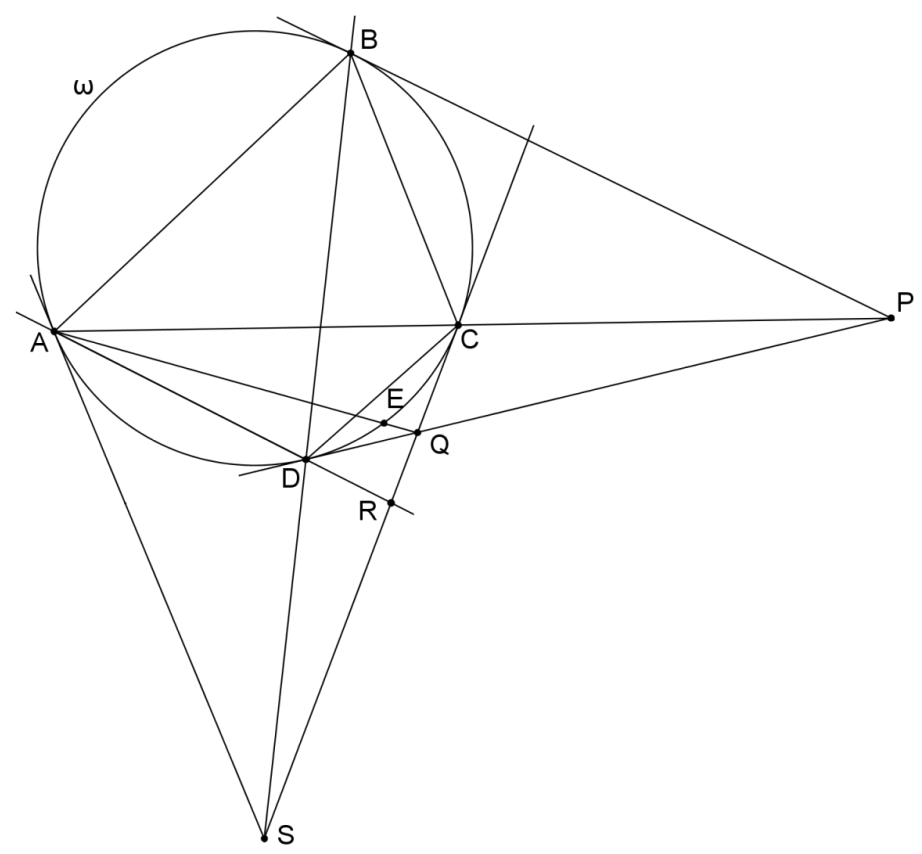

Figura 100 - APMO-2013.1

Sabe-se, pelo enunciado, que $A D \cap C Q=R$.

Por hipótese, considere que a reta $B E$ encontre $A D$ em um ponto $R^{\prime}\left(R^{\prime} \neq R\right)$, ou seja, $A D \cap B E=R^{\prime}$.

$\overline{1}$ Como foi visto na Definição 4.16 IO é chamada reta de Nagel do triângulo $A B C$. 
Seja $S$ o ponto de encontro da reta $C Q$ com a reta tangente a $w$ passando por $A$ (Figura 100 ). Usando os conceitos de homotetia e polaridade no círculo $w$, tem-se que $B D$ é a reta polar do pólo $P$, bem como $A C$ é a reta polar do pólo $S$ (Proposição 4.23). Uma vez que os pontos $P, C$ e $A$ estão alinhados, então os pontos $S, B$ e $D$ também estarão alinhados (Proposição 4.22). Assim, os pontos $C, Q, R$ e $S$ pertencem a uma mesma reta (Figura 100$)$.

Aplicando o teorema de Pascal (Teorema 4.35) para o hexágono degenerado $A A E B D D$, inscrito em $w$, tem-se

$$
\left.\begin{array}{l}
A A \cap B D=S \\
A E \cap D D=Q \\
E B \cap D A=R^{\prime}
\end{array}\right\} \Rightarrow S, Q \text { e } R^{\prime} \text { são colineares. }
$$

Se o ponto $R^{\prime}$ é colinear com $S$ e $Q$, então também pertence à reta $C Q$.

Como $A D \cap B E=R^{\prime}$, mas $R^{\prime} \in C Q$, então $A D \cap C Q=R=R^{\prime}$. E se $R$ e $R^{\prime}$ representam o mesmo ponto $\left(R^{\prime} \equiv R\right.$ ), então, as retas $B E, A D$ e $C Q$ são concorrentes em $R$; em outras palavras, os pontos $B, E, R$ são colineares. 


\section{Considerações finais}

As olimpíadas científicas têm ganhado cada vez mais espaço no ambiente escolar nacional. Nesse contexto, destacam-se as diversas competições de Matemática existentes no país, tanto em nível regional quanto nacional.

À medida que um aluno começa a estudar a Matemática por esse prisma, percebe-se o despertar de um interesse maior pela disciplina, melhorando consideravelmente o rendimento escolar do discente.

Uma vez envolvido nas olimpíadas regionais ou nacionais, o estudante começa a querer atingir patamares mais altos, buscando, inclusive, competir em olimpíadas internacionais representando o Brasil no exterior.

Dentre as áreas da Matemática cobradas nas diversas olimpíadas das quais o Brasil participa, a Geometria é, sem dúvida, a área mais temida pelos estudantes. Isso ocorre porque a Geometria sofreu muitas perdas ao longo dos últimos 50 anos, o que prejudicou seu ensino e aprendizado de uma forma muito evidente nas escolas brasileiras.

Com o intuito de tentar melhorar o ensino da Geometria no país, uma vez que tal assunto é um dos mais cobrados nas olimpíadas de Matemática no mundo, o autor procurou demonstrar neste trabalho a importância de se utilizar problemas olímpicos em sala de aula como um fator motivacional e desafiante para aumentar o interesse do aluno pela Matemática.

Ciente da impossibilidade de abordar toda a Geometria, o autor escolheu o tema Colinearidade e Concorrência, na Geometria Plana, principalmente por ser um tema bastante recorrente nas competições olímpicas e também por ser um tópico inexistente na quase totalidade dos livros didáticos atuais, o que, sem dúvida, prejudica a preparação de alunos e, consequentemente, o seu desempenho nessas competições, cada vez mais presentes no ambiente escolar brasileiro.

O pouco material encontrado nos livros sobre o tema apresenta questões olímpicas da década de 1980 e 1990. O autor então realizou um levantamento extenso de diversas provas, observando os assuntos cobrados nessas olimpíadas internacionais, nos últimos 5 anos (2010-2014), comprovando a importância do tema escolhido na atualidade. A pesquisa possibilitou a construção de um banco de dados com mais de 140 (cento e quarenta) questões recentes, abordando diretamente o tema Colinearidade e Concorrência, que pode servir de base para que professores venham a utilizar esse material didático em suas aulas. Para tanto, são disponibilizados, no Apêndice, os enunciados originais dessas questões, no idioma inglês, para 
composição de possíveis listas de exercícios de treinamento.

Com base no resultado da pesquisa, o autor desenvolveu um ferramental teórico para ajudar professores e estudantes, suprindo uma carência atual nos livros escolares.

Dessa forma, o presente trabalho vem trazer à reflexão dos educadores matemáticos de hoje a necessidade de se resgatar conceitos, já esquecidos no ensino regular, mas considerados importantes do ponto de vista das competições olímpicas, repensando, quem sabe, a maneira de ensinar a Geometria, ou mesmo outras áreas, como a Álgebra, a Combinatória e a Teoria dos Números, temas também bastante cobrados nas competições olímpicas nacionais e internacionais, utilizando esse viés mais desafiador e instigante que a Matemática tem a oferecer. O resultado esperado é somente um: melhorar a qualidade da educação no Brasil. 


\section{Referências}

ADAM, P. P. Curso de Geometria Métrica - Tomo I. 16.ed. Madrid: Euler, 1986.

ALCARAZ, C. T. Que significa "comprender el teorema de Desargues"? Revista Miscelânea Matemática, n.54, abr 2012. Sociedad Matematica Mexicana (México). Tlalpan, 2012. Disponível em: <http://www. miscelaneamatematica.org $>$. Acesso em: 10 fev.2015.

ANDRADE, L. N. A construção de cônicas e o teorema de Pascal. Revista do Professor de Matemática, n.45, jan-abr, p.17. Sociedade Brasileira de Matemática. Rio de Janeiro, 2001.

AUFFINGER, A. C. T. C.; VALENTIM, F. J. S. Introdução à Geometria Projetiva. Dissertação (Mestrado). Universidade Federal do Espírito Santo. Vitória, 2003. Disponível em:<http://www.ime.unicamp.br/ jardim/ ma620/geoproj.pdfs. Acesso em: 20 abr.2015.

BERSCH, T. Olimpíadas científicas. Sítio eletrônico. Disponível em: <http://www.olimpiadascientificas.com> Acesso em: 20 fev.2015.

BORTOLOSSI, H. J.; REZENDE, W. M.; PESCO, D. U. Instituto GeoGebra no Rio de Janeiro. Sítio eletrônico. Universidade Federal Fluminense. Niterói, 2015. Disponível em: <http://www.geogebra.im-uff.mat.br $\rangle$. Acesso em: 22 fev.2015.

CASTRO, F. Z. Uma proposta de sequência didática para treinamento olímpico em Matemática. Dissertação (Mestrado). Universidade Federal do Espírito Santo. Vitória, 2013.

CASTRO, L. G. M. Introdução à Geometria Projetiva. Revista Eureka!, n.8, p.16. Sociedade Brasileira de Matemática. Rio de Janeiro, 2000.

CATALDO, J. C. Teorema do Hexágono de Pascal. Dissertação (Mestrado). Universidade Federal do Estado do Rio de Janeiro. Rio de Janeiro, 2013.

CENTRO DE GESTÃO E ESTUDOS ESTRATÉGICOS. Avaliação do impacto da Olimpíada Brasileira de Matemática nas Escolas Públicas. Série Documentos Técnicos, n. 11, jul. 2011. Brasília, 2011.

CHAVES, J. J. F. Teorema de Pappus. Dissertação (Mestrado). Universidade Federal do Rio de Janeiro. Rio de Janeiro, 2013.

COXETER, H. S. M.; GREITZER, S. L. Geometry revisited. 1. ed. New York: The Mathematical Association of America, 1967.

DANTE, L. R. Didática da resolução de problemas de Matemática. 2.ed. São Paulo: Ática, 1991.

DA SILVA, C. G. Resolução de problemas sobre Geometria para as Olimpíadas Brasileira de Matemática das Escolas Públicas - OBMEP. Dissertação (Mestrado). Universidade Federal do Pará. Belém, 2013. 
DE FREITAS, V. P. Alguns teoremas clássicos da Geometria Sintética e aplicações. Dissertação (Mestrado). Universidade Federal do Amazonas. Manaus, 2013.

EVES, H. A Survey of Geometry. Revised edition. Boston: Allyn and Bacon, 1972.

FARIA, R. M. A. Interpretação geométrica dos problemas clássicos de Desargues, Fagnano e Malfatti. Dissertação (Mestrado). Universidade dos Açores (Portugal). Ponta Delgada, 2013.

FEITOSA, L. F. Aplicações dos números complexos na Geometria Plana. Dissertação (Mestrado). Universidade Federal da Paraíba. João Pessoa, 2013.

GONÇALVES J. S.; LANDO, J. C. O ensino de Geometria em escolas públicas na cidade de Jequié - Bahia. Revista Eventos Pedagógicos, v. 3, n. 3, p. 363, Ago-Dez. Universidade Estadual do Sudoeste da Bahia. Jequié, 2012.

GRILLO, J. D. Atividades e problemas de Geometria Espacial para o Ensino Médio. Dissertação (Mestrado). Universidade Federal de São Carlos. São Carlos, 2014.

GUALBERTO, K. J. Colinearidade e Concorrência na Geometria Euclidiana Plana. Trabalho de Conclusão de Curso. Universidade Federal de Santa Catarina. Florianópolis, 2007.

HEATH, T. L. The works of Archimedes. Edited in modern notation with introductory chapters. New York: Cambridge University Press, 2010.

INSTITUTO DE MATEMÁTICA PURA E APLICADA. Olimpíada Brasileira de Matemática. Sítio eletrônico oficial. Disponível em: <http://www.obm.org.br>. Acesso em: 15 fev.2015.

INTERNATIONAL MATHEMATICAL OLYMPIAD. Sítio eletrônico oficial. Disponível em: <https://www. imo-official.org $>$. Acesso em: 18 fev.2015.

INTERNATIONAL MATHEMATICAL UNION. Sítio eletrônico oficial. Disponível em: <http://www.mathunion. org >. Acesso em: 17 fev.2015.

LORENZATO, S. Porque não ensinar Geometria? Educação Matemática em Revista, n. 4, sem.1. Universidade de Brasília. Brasília, 1995.

MACEDO, D. M. R. Resgatando alguns teoremas clássicos da Geometria Plana. Dissertação (Mestrado). Universidade Federal do Ceará. Juazeiro do Norte, 2014.

MARANHÃO, T. P. A. Avaliação de impacto da Olimpíada Brasileira de Matemática nas Escolas Públicas (OBMEP - 2005/2009). In: Centro de Gestão e Estudos Estratégicos. Série Documentos Técnicos, n. 11, jul 2011, p. 13-41. Brasília, 2011.

MINISTÉRIO DA EDUCAÇÃO. Diretrizes Curriculares Nacionais Gerais da Educação Básica. Secretaria de Educação Básica. Diretoria de Currículos e Educação Integral. Brasília, 2013.

MINISTÉRIO DA EDUCAÇÃO E CULTURA. Parâmetros curriculares nacionais: Matemática. Secretaria de Educação Fundamental. Brasília, 1998.

MORGADO, A. C.; WAGNER, E.; JORGE, M. Geometria I. 5 ed. Rio de Janeiro: Francisco Alves, 1990a.

MORGADO, A. C.; WAGNER, E.; JORGE, M. Geometria II (Métrica Plana). 2 ed. Rio de Janeiro: Francisco Alves, 1990b.

MUNIZ NETO, A. C. Tópicos de Matemática Elementar - Geometria Euclidiana Plana. v. 2. Coleção do Professor de Matemática. Rio de Janeiro: Sociedade Brasileira de Matemática, 2013.

NEVES, E. D. Caracterização e localização dos pontos notáveis do triângulo. Dissertação (Mestrado). Universidade de São Paulo. São Carlos, 2013.

OLIMPÍADA BRASILEIRA DE MATEMÁTICA DAS ESCOLAS PÚBLICAS. Sítio eletrônico oficial. Disponível em: <http://www.obmep.org.br>. Acesso em: 15 fev.2015. 
PAVANELLO, R. M. O abandono do ensino da Geometria no Brasil: causas e consequências. Zetetiké: Revista de Educação Matemática, v. 1, n. 1. Universidade de Campinas. Campinas, 1993. Disponível em: <https: //www.fe.unicamp.br/revistas/ged/zetetike/issue/view/166>. Acesso em: 10 fev.2015.

PEREZ, G. Pressupostos e reflexões teóricas e metodológicas da pesquisa participante no ensino da Geometria para as camadas populares ( $1^{\circ}$ e $2^{\circ}$ graus). Tese (Doutorado). Faculdade de Educação. Universidade de Campinas. Campinas, 1991.

POLYA, G. A arte de resolver problemas: um novo aspecto do método matemático. 2. ed. Rio de Janeiro: Interciência, 1995.

POSAMENTIER, A. S; SALKIND, C. T. Challenging problems in Geometry. 3 ed. New York: Dover Publications, 1996.

ROMANIAN MASTERS OF MATHEMATICS. Sítio eletrônico oficial. Disponível em: $<$ http://rmms.lbi.ro/> Acesso em: 17 fev.2015.

SARMENTO, M. I. Um passeio proveitoso pelos círculos de Apolônio. Dissertação (Mestrado). Universidade do Porto (Portugal). Porto, 2007.

SASTRY, K. R. S. Brahmagupta quadrilaterals: a description. Crux Mathematicorum, v.29, n.1, p.39. Canadian Mathematical Society (Canadá). Ottawa, 2003.

SHINE, C. Y. 21 Aulas de Matemática Olímpica. 1. ed. Coleção Olimpíadas de Matemática. Rio de Janeiro: Sociedade Brasileira de Matemática, 2009.

SILVA, L. S. C. O teorema de Morley. Dissertação (Mestrado). Pontifícia Universidade Católica do Rio de Janeiro. Rio de Janeiro, 2014.

SMITH, D. E. Biography: Emile Michel Hyacinthe Lemoine. The American Mathematical Monthly, v.3, n.2, p.29-33. Mathematical Association of America. Springfield, 1896. Disponível em: <http://poncelet.math. nthu.edu.tw/disk5/js/history/lemoine.pdf>. Acesso em: 20 mar.2015.

SUPPA, E. Eötvös-Kürschák competitions. Mathematical and Physical Society (Hungria). Budapeste, 2007.

TOKARNIA, M. Olimpíada melhora desempenho de estudantes de matemática. Agência Brasil de Notícias, 30 ago.2014. Brasília: Empresa Brasil de Comunicação - EBC, 2014. Disponível em: <http://www.ebc.com. br/educacao/2014/08/olimpiada-melhora-desempenho-de-estudantes-de-matematica $>$. Acesso em: 20 mar.2015.

USUI, T. O globo terrestre e a esfera celeste: uma abordagem interdisciplinar de Matemática, Geografia e Astronomia. Dissertação (Mestrado). Universidade Federal Rural de Pernambuco. Recife, 2014.

VIEIRA, M. A. Construções geométricas e os problemas de Apolônio. Dissertação (Mestrado). Universidade Federal de Goiás. Goiânia, 2013. 



\section{Apêndice}

Na pesquisa realizada para a execução desta dissertação, o autor conseguiu coletar o total de 283 provas olímpicas de Matemática, aplicadas entre os anos de 2010 e 2014, contemplando 62 competições, em mais de 50 países, em todos os continentes.

A distribuição anual dessas provas é a seguinte: 2010 (58 provas); 2011 (59 provas); 2012 (59 provas); 2013 (56 provas); 2014 (51 provas).

Do total de provas encontradas, 104 continham problemas envolvendo o tema Colinearidade e Concorrência de forma direta, sendo possível extrair 141 questões (73 sobre Colinearidade e 68 sobre Concorrência), apresentadas a seguir neste Apêndice, a título de exercícios de treinamento, no idioma inglês e separadas por ano. É apresentada ainda uma tabela-resumo com os dados quantitativos levantados pelo autor na sua pesquisa. 
Asian Pacific Mathematics Olympiad

Austrian Mathematical Olympiad

Balkan Mathematical Olympiad

Baltic Way

Bay Area Mathematical Olympiad

Benelux Mathematical Olympiad

Brazilian Math Olympiad

Brazilian Olympic Revenge

British Mathematical Olympiad

10 Canadian Mathematical Olympiad

11 Chilean Mathematical Olympiad

12 China Girls Math Olympiad

13 China South East Mathematical Olympiad

14 Chinese Mathematical Olympiad

15 Cono Sur Olympiad

16 Czech-Polish-Slovak Match

17 Czech-Slovak Mathematical Olympiad

18 Estonian Mathematical Olympiad

19 European Girls Mathematical Olympiad

20 European Mathematical Cup

21 Geometrical Olympiad in Honour of I.F.Sharygin

22 German Federal Mathematical Competition

23 Gillis Mathematical Olympiad in Israel

24 Greece National Olympiad

25 Harvard-MIT Mathematics Tournament

26 Hong Kong Mathematical Olympiad

27 Iberoamerican Mathematical Olympiad

28 Indian National Mathematical Olympiad

29 Indian Regional Mathematical Olympiad

30 Indonesia National Science Olympiad

31 International Mathematical Olympiad

32 International Mathematics Tournament of the Towns

33 International Tuymaada Olympiad

34 International Zhautykov Olympiad

35 Iranian Mathematical Olympiad

36 Irish Mathematical Olympiad

37 Italian Mathematical Olympiad

38 Junior Balkan Mathematical Olympiad

39 Kazakhstan Mathematical Olympiad

40 Korean Mathematical Olympiad

41 Kürschák/Eötvös Math Competition

42 Kyrgyzstan Mathematical Olympiad

43 Lusophone Mathematical Olympiad (CPLP)

44 Macedonia Mathematical Olympiad

45 Mathematical Olympiad of Centroamerica and the Caribbean

46 Mediterranean Mathematical Olympiad

47 Mexican Mathematical Olympiad

48 Middle European Mathematical Olympiad

49 Montenegro National Math Olympiad

50 National Mathematical Olympiad of Singapore

51 Polish Mathematical Olympiad

52 Romanian District Olympiad

53 Romanian Masters in Mathematics

54 Romanian Stars of Mathematics

55 Russian Mathematical Olympiad

56 Serbia National Math Olympiad

57 Singapore Mathematical Olympiad

58 Swiss Mathematical Olympiad

59 Turkish Mathematical Olympiad

60 United States of America Mathematical Olympiad

61 Uzbekistan National Olympiad

62 Vietnamese Math Olympiad

Total de Problemas

Legenda:

Prova não encontrada ou inexistente

in

\begin{tabular}{|c|c|c|c|c|c|c|}
\hline 1 & & & 1 & & 2 & 0 \\
2
\end{tabular}

2010




\section{COLETÂNEA 2014}

Exercício 1 (Brazilian Math Olympiad 2014). Let $A B C$ be a triangle with incenter I and incircle $\omega$. Circle $\omega_{A}$ is externally tangent to $\omega$ and tangent to sides $A B$ and $A C$ at $A_{1}$ and $A_{2}$, respectively. Let $r_{A}$ be the line $A_{1} A_{2}$. Define $r_{B}$ and $r_{C}$ in a similar fashion. Lines $r_{A}, r_{B}$ and $r_{C}$ determine a triangle $X Y Z$. Prove that the incenter of $X Y Z$, the circumcenter of $X Y Z$ and I are collinear.

Exercício 2 (British Mathematical Olympiad 2014). Let $A B C$ be a triangle and $P$ be a point in its interior. Let $A P$ meet the circumcircle of $A B C$ again at $A^{\prime}$. The points $B^{\prime}$ and $C^{\prime}$ are similarly defined. Let $O_{A}$ be the circumcentre of $B C P$. The circumcentres $O_{B}$ and $O_{C}$ are similarly defined. Let $O_{A}{ }^{\prime}$ be the circumcentre of $B^{\prime} C^{\prime} P^{\prime}$. The circumcentres $O_{B}{ }^{\prime}$ and $O_{C}{ }^{\prime}$ are similarly defined. Prove that the lines $O_{A} O_{A}{ }^{\prime}, O_{B} O_{B}{ }^{\prime}$ and $O_{C} O_{C}{ }^{\prime}$ are concurrent.

Exercício 3 (Cono Sur Olympiad 2014). Let $A B C D$ be an inscribed quadrilateral in a circumference with center $O$ such that it lies inside $A B C D$ and $\measuredangle B A C=\measuredangle O D A$. Let $E$ be the intersection of $A C$ with $B D$. Lines $r$ and $s$ are drawn through $E$ such that $r$ is perpendicular to $B C$, and $s$ is perpendicular to $A D$. Let $P$ be the intersection of $r$ with $A D$, and $M$ the intersection of s with BC. Let $N$ be the midpoint of EO. Prove that $M, N$, and $P$ lie on a line.

Exercício 4 (European Girls Mathematical Olympiad 2014). Let $D$ and $E$ be points in the interiors of sides $A B$ and $A C$, respectively, of a triangle $A B C$, such that $D B=B C=C E$. Let the lines $C D$ and $B E$ meet at $F$. Prove that the incentre I of triangle $A B C$, the orthocentre $H$ of triangle DEF and the midpoint $M$ of the arc $\widehat{B A C}$ of the circumcircle of triangle $A B C$ are collinear.

Exercício 5 (Geometrical Olympiad in Honour of I. F. Sharygin 2014). Let ABC be an isosceles triangle with base $A B$. Line l touches its circumcircle at point $B$. Let $C D$ be a perpendicular from $C$ to $l$, and $A E, B F$ be the altitudes of $A B C$. Prove that $D, E, F$ are collinear.

Exercício 6 (Geometrical Olympiad in Honour of I. F. Sharygin 2014). Given a triangle $A B C$ and an arbitrary point $D$. The lines passing through $D$ and perpendicular to segments $D A, D B, D C$ meet lines $B C, A C$, $A B$ at points $A_{1}, B_{1}, C_{1}$, respectively. Prove that the midpoints of segments $A A_{1}, B B_{1}, C C_{1}$ are collinear.

Exercício 7 (Geometrical Olympiad in Honour of I. F. Sharygin 2014). Let I be the incenter of a circumscribed quadrilateral $A B C D$. The tangents to circle AIC at points $A, C$ meet at point $X$. The tangents to circle $B I D$ at points $B, D$ meet at point $Y$. Prove that $X, I, Y$ are collinear.

Exercício 8 (Geometrical Olympiad in Honour of I. F. Sharygin 2014). Two circles $w_{1}$ and $w_{2}$ touch externally at point $P$. Let $A$ be a point of $w_{2}$ not lying on the line through the centers of the circles, and $A B, A C$ be the tangents to $w_{1}$. Lines BP, CP meet $w_{2}$ for the second time at points $E$ and $F$. Prove that line EF, the tangent to $w_{2}$ at point $A$ and the common tangent at $P$ concur.

Exercício 9 (Geometrical Olympiad in Honour of I. F. Sharygin 2014). A quadrilateral KLMN is given. A circle with center $O$ meets its side $K L$ at points $A$ and $A_{1}$, side $L M$ at points $B$ and $B_{1}$, etc. Prove that if the circumcircles of triangles KDA, LAB, MBC and NCD concur at point $P$, then

a) the circumcircles of triangles $K D_{1} A_{1}, L A_{1} B_{1}, M B_{1} C_{1}$ and $N C_{1} D_{1}$ also concur at some point $Q$;

b) point O lies on the perpendicular bisector to $P Q$. 
Exercício 10 (Indian Regional Mathematical Olympiad 2014). Let $D, E$ and $F$ be the points of contact of the incircle of an acute-angled triangle $A B C$ with $B C, C A$ and $A B$ respectively. Let $I_{1}, I_{2}$ and $I_{3}$ be the incentres of the triangles $A F E, B D F$ and $C E D$, respectively. Prove that the lines $I_{1} D, I_{2} E$ and $I_{3} F$ are concurrent.

Exercício 11 (International Tuymaada Olympiad 2014). A parallelogram $A B C D$ is given. The excircle of triangle $A B C$ touches the sides $A B$ at $L$ and the extension of $B C$ at $K$. The line $D K$ meets the diagonal $A C$ at point $X$; the line $B X$ meets the median $C C_{1}$ of triangle $A B C$ at $Y$. Prove that the line $Y L$, median $B B_{1}$ of triangle $A B C$ and its bisector $C C^{\prime}$ have a common point.

Exercício 12 (International Tuymaada Olympiad 2014). The points $K$ and $L$ on the side $B C$ of a triangle $A B C$ are such that $\measuredangle B A K=\measuredangle C A L=90^{\circ}$. Prove that the midpoint of the altitude drawn from $A$, the midpoint of $K L$ and the circumcentre of $A B C$ are collinear.

Exercício 13 (Kürschák/Eötvös Math Competition 2014). We are given an acute triangle $A B C$, and inside it a point $P$, which is not on any of the heights $A A_{1}, B B_{1}, C C_{1}$. The rays $A P, B P$ and $C P$ intersect the circumcircle of $A B C$ at points $A_{2}, B_{2}$ and $C_{2}$. Prove that the circles $A A_{1} A_{2}, B B_{1} B_{2}$ and $C C_{1} C_{2}$ are concurrent.

Exercício 14 (Mediterranean Mathematical Olympiad 2014). In triangle $A B C$ let $A^{\prime}, B^{\prime}, C^{\prime}$ respectively be the midpoints of the sides $B C, C A, A B$. Furthermore let $L, M, N$ be the projections of the orthocenter on the three sides $B C, C A, A B$, and let $k$ denote the nine-point circle. The lines $A A^{\prime}, B B^{\prime}, C C^{\prime}$ intersect $k$ in the points $D, E, F$. The tangent lines on $k$ in $D, E, F$ intersect the lines $M N, L N, L M$ in the points $P, Q, R$. Prove that $P$, $Q$ and $R$ are collinear.

Exercício 15 (Mexican Mathematical Olympiad 2014). Let $\Gamma_{1}$ be a circle and $P$ a point outside of $\Gamma_{1}$. The tangents from $P$ to $\Gamma_{1}$ touch the circle at $A$ and $B$. Let $M$ be the midpoint of $P A$ and let $\Gamma_{2}$ the circle through $P$, $A$ and $B$. Line $B M$ cuts $\Gamma_{2}$ at $C$, line $C A$ cuts $\Gamma_{1}$ at D, segment $D B$ cuts $\Gamma_{2}$ at $E$ and line $P E$ cuts $\Gamma_{1}$ at $F$, with $E$ in segment $P F$. Prove that the lines $A F, B P$, and $C E$ are concurrent.

Exercício 16 (Serbia National Math Olympiad 2014). On sides $B C$ and $A C$ of triangle $A B C$ given are $D$ and $E$, respectively. Let $F(F \neq C$ ) be a point of intersection of circumcircle of triangle CED and line that is parallel to $A B$ and passing through $C$. Let $G$ be a point of intersection of line $F D$ and side $A B$, and let $H$ be on line $A B$ such that $\measuredangle H D A=\measuredangle G E B$, with $A$ between $H$ and $B$. If $D G=E H$, prove that point of intersection of $A D$ and $B E$ lie on angle bisector of $\angle A C B$.

Exercício 17 (Singapore Mathematical Olympiad 2014). In the triangle $A B C$, the excircle opposite to the vertex $A$ with centre I touches the side BC at D (The circle also touches the sides of $A B, A C$ extended). Let $M$ be the midpoint of $B C$ and $N$ the midpoint of $A D$. Prove that $I, M, N$ are collinear.

Exercício 18 (United States of America Junior Mathematical Olympiad 2014). Let ABC be a triangle with incenter $I$, incircle $\gamma$ and circumcircle $\Gamma$. Let $M, N, P$ be the midpoints of sides $B C, C A, A B$ and let $E, F$ be the tangency points of $\gamma$ with $C A$ and $A B$, respectively. Let $U, V$ be the intersections of line EF with line $M N$ and line $M P$, respectively, and let $X$ be the midpoint of arc $B \bar{A} C$ of $\Gamma$.

a) Prove that I lies on ray $C V$.

b) Prove that line XI bisects $U V$. 
Exercício 19 (Vietnamese Math Olympiad 2014). Given a circle $(O)$ and two fixed points $B, C$ on $(O)$, and an arbitrary point $A$ on $(O)$ such that the triangle $A B C$ is acute. $M$ lies on ray $A B, N$ lies on ray $A C$ such that $M A=M C$ and $N A=N B$. Let $P$ be the intersection of circles $(A M N)$ and $(A B C)$, with $P \neq A$. If $M N$ intersects $B C$ at $Q$, prove that $A, P$ and $Q$ are collinear.

\section{COLETÂNEA 2013}

Exercício 20 (Asian Pacific Mathematics Olympiad 2013). Let $A B C D$ be a quadrilateral inscribed in a circle $\omega$, and let $P$ be a point on the extension of $A C$ such that $P B$ and $P D$ are tangent to $\omega$. The tangent at $C$ intersects $P D$ at $Q$ and the line $A D$ at $R$. Let $E$ be the second point of intersection between $A Q$ and $\omega$. Prove that $B, E, R$ are collinear.

Exercício 21 (Brazilian Olimpic Revenge 2013). Let $A B C$ be an acute triangle. $K$ and $L$ are the intersections of the height from B with the circle of diameter AC, with $K$ closer to B than L. Analogously, $X$ and $Y$ are the intersections of the height from $C$ with the circle of diameter $A B$, with $X$ closer to $C$ than $Y$. Prove that the intersection of $X L$ and $K Y$ lies on $B C$.

Exercício 22 (British Mathematical Olympiad 2013). Two circles $S$ and $T$ touch at $X$. They have a common tangent which meets $S$ at $A$ and $T$ at $B$. The points $A$ and $B$ are different. Let $A P$ be a diameter of $S$. Prove that $B, X$ and $P$ lie on a straight line.

Exercício 23 (China Girls Math Olympiad 2013). As shown in the figure below, $A B C D$ is a trapezoid, $A B \|$ $C D$. The sides $D A, A B, B C$ are tangent to circle $O_{1}$, and $A B$ touches $O_{1}$ at $P$. The sides $B C, C D, D A$ are tangent to circle $\mathrm{O}_{2}$, and $C D$ touches $\mathrm{O}_{2}$ at $Q$. Prove that the lines $A C, B D, P Q$ meet at the same point.

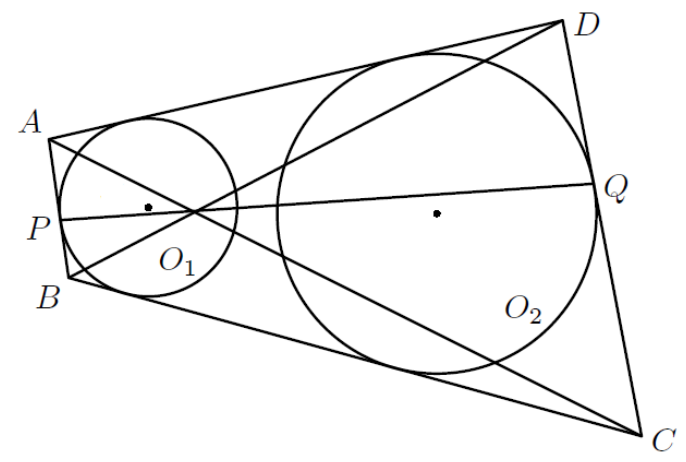

Exercício 24 (Estonian Mathematical Olympiad 2013). A convex quadrilateral $A B C D$ where $\measuredangle D A B+$ $\measuredangle A B C<180^{\circ}$ is given on a plane. Let $E$ be a point different from the vertices of the quadrilateral on the line interval $A B$ such that the circumcircles of triangles $A E D$ and $B E C$ intersect inside the quadrilateral $A B C D$ at point $F$. Point $G$ is defined so that $\measuredangle D C G=\measuredangle D A B, \measuredangle C D G=\measuredangle A B C$ and triangle $C D G$ is located outside quadrilateral $A B C D$. Prove that the points $E, F$ and $G$ are collinear.

Exercício 25 (European Mathematical Cup 2013). Given a triangle ABC let D, E, F be orthogonal projections from $A, B, C$ to the opposite sides respectively. Let $X, Y, Z$ denote midpoints of $A D, B E, C F$ respectively. Prove that perpendiculars from $D$ to $Y Z$, from $E$ to $X Z$ and from $F$ to $X Y$ are concurrent. 
Exercício 26 (Geometrical Olympiad in Honour of I. F. Sharygin 2013). Let $X$ be a point inside triangle $A B C$ such that $X A \cdot B C=X B \cdot A C=X C \cdot A B$. Let $I_{1}, I_{2}, I_{3}$ be the incenters of triangles $X B C, X C A, X A B$. Prove that $A I_{1}, B I_{2}, C I_{3}$ are concurrent.

Exercício 27 (Geometrical Olympiad in Honour of I. F. Sharygin 2013). Let ABC be a right-angled triangle, with $\measuredangle B=90^{\circ}$. The excircle inscribed into the angle $\angle A$ touches the extensions of the sides $A B, A C$ at points $A_{1}, A_{2}$ respectively; points $C_{1}, C_{2}$ are defined similarly. Prove that the perpendiculars from $A, B, C$ to $C_{1} C_{2}$, $A_{1} C_{1}, A_{1} A_{2}$ respectively, concur.

Exercício 28 (Geometrical Olympiad in Honour of I. F. Sharygin 2013). The incircle of triangle ABC touches the side $A B$ at point $C^{\prime}$; the incircle of triangle $A C C^{\prime}$ touches the sides $A B$ and $A C$ at points $C_{1}, B_{1}$; the incircle of triangle $B C C^{\prime}$ touches the sides $A B$ and $B C$ at points $C_{2}, A_{2}$. Prove that the lines $B_{1} C_{1}, A_{2} C_{2}$, and $C C^{\prime}$ concur.

Exercício 29 (Geometrical Olympiad in Honour of I. F. Sharygin 2013). Let $A_{1}$ and $C_{1}$ be the tangency points of the incircle of triangle $A B C$ with $B C$ and $A B$ respectively, $A^{\prime}$ and $C^{\prime}$ be the tangency points of the excircle inscribed into the angle $\angle B$ with the extensions of $B C$ and $A B$ respectively. Prove that the orthocenter $H$ of triangle $A B C$ lies on $A_{1} C_{1}$ if and only if the lines $A^{\prime} C_{1}$ and $B A$ are orthogonal.

Exercício 30 (Geometrical Olympiad in Honour of I. F. Sharygin 2013). Solve the propositions below:

a) The incircle of a triangle $A B C$ touches $A C$ and $A B$ at points $B_{0}$ and $C_{0}$ respectively. The bisectors of angles $\angle B$ and $\angle C$ meet the perpendicular bisector to the bisector $A L$ in points $Q$ and $P$ respectively. Prove that the lines $P C_{0}, Q B_{0}$, and $B C$ concur.

b) Let $A L$ be the bisector of a triangle $A B C$. Points $O_{1}$ and $O_{2}$ are the circumcenters of triangles $A B L$ and $A C L$ respectively. Points $B_{1}$ and $C_{1}$ are the projections of $C$ and $B$ to the bisectors of angles $\angle B$ and $\angle C$ respectively. Prove that the lines $O_{1} C_{1}, O_{1} B_{1}$, and $B C$ concur.

c) Prove that two points obtained in pp. a) and b) coincide.

Exercício 31 (German Federal Mathematical Competition 2013). Let $A B C D E F$ be a convex hexagon whose vertices lie on a circle. Suppose that $A B \cdot C D \cdot E F=B C \cdot D E \cdot F A$. Show that the diagonals $A D, B E$ and $C F$ are concurrent.

Exercício 32 (Gillis Mathematical Olympiad 2013). $A B C D E F$ is a convex hexagon. Inside the hexagon there is a point $K$, such that $A B C K$ and $D E F K$ are both parallelograms. Show that the lines connecting $A, B, C$ to the midpoints of $C E, D F, A E$ respectively concur.

Exercício 33 (Harvard-MIT Mathematics Tournament 2013). Let points $A$ and $B$ be on circle $\omega$ centered at $O$. Suppose that $\omega_{A}$ and $\omega_{B}$ are circles not containing $O$ which are internally tangent to $\omega$ at $A$ and $B$, respectively. Let $\omega_{A}$ and $\omega_{B}$ intersect at $C$ and $D$ such that $D$ is inside triangle $A B C$. Suppose that line $B C$ meets $\omega$ again at $E$ and let line $E A$ intersect $\omega_{A}$ at $F$. If $F C \perp C D$, prove that $O, C, D$ are collinear.

Exercício 34 (Hong Kong Mathematical Olympiad 2013). Let $A B C$ be a triangle with $C A>B C>A B$. Let $O$ and $H$ be the circumcentre and orthocentre of triangle $A B C$ respectively. Denote by $D$ and $E$ the midpoints of the arcs $\widehat{A B}$ and $\widehat{A C}$ of the circumcircle of triangle $A B C$ not containing the opposite vertices. Let $D^{\prime}$ be the 
reflection of $D$ about $A B$ and $E^{\prime}$ the reflection of $E$ about $A C$. Prove that $O, H, D^{\prime}, E^{\prime}$ are concyclic if and only if $A, D^{\prime}, E^{\prime}$ are collinear.

Exercício 35 (Indonesia National Science Olympiad 2013). Let $A B C$ be an acute triangle and $\omega$ be its circumcircle. The bisector of $\angle B A C$ intersects $\omega$ at [another point] $M$. Let $P$ be a point on AM and inside triangle $A B C$. Lines passing $P$ that are parallel to $A B$ and $A C$ intersects $B C$ on $E$ and $F$ respectively. Lines $M E, M F$ intersects $\omega$ at points $K, L$ respectively. Prove that $A M, B L, C K$ are concurrent.

Exercício 36 (International Mathematical Olympiad 2013). Let $A B C$ be an acute triangle with orthocenter $H$, and let $W$ be a point on the side $B C$, lying strictly between $B$ and $C$. The points $M$ and $N$ are the feet of the altitudes from $B$ and $C$, respectively. Denote by $\omega_{1}$ is the circumcircle of triangle $B W N$, and let $X$ be the point on $\omega_{1}$ such that $W X$ is a diameter of $\omega_{1}$. Analogously, denote by $\omega_{2}$ the circumcircle of triangle $C W M$, and let $Y$ be the point such that $W Y$ is a diameter of $\omega_{2}$. Prove that $X, Y$ and $H$ are collinear.

Exercício 37 (International Zhautykov Olympiad 2013). Given a trapezoid $A B C D(A D \| B C)$ with $\measuredangle A B C>$ $90^{\circ}$. Point $M$ is chosen on the lateral side $A B$. Let $O_{1}$ and $O_{2}$ be the circumcenters of the triangles $M A D$ and $M B C$, respectively. The circumcircles of the triangles $M O_{1} D$ and $M O_{2} C$ meet again at the point $N$. Prove that the line $O_{1} O_{2}$ passes through the point $N$.

Exercício 38 (Iranian Mathematical Olympiad 2013). Suppose line $\ell$ and four points $A, B, C, D$ lies on $\ell$. Suppose that circles $\omega_{1}$ and $\omega_{2}$ passes through $A$ and $B$, and that circles $\omega_{1}^{\prime}$ and $\omega_{2}^{\prime}$ passes through $C$ and $D$. If $\omega_{1} \perp \omega_{1}^{\prime}$ and $\omega_{2} \perp \omega_{2}^{\prime}$ then prove that lines $O_{1} O_{2}^{\prime}, O_{2} O_{1}^{\prime}$ and $\ell$ are concurrent where $O_{1}, O_{2}, O_{1}^{\prime}$ and $O_{2}^{\prime}$ are center of $\omega_{1}, \omega_{2}, \omega_{1}^{\prime}$ and $\omega_{2}^{\prime}$, respectively.

Exercício 39 (Iranian Mathematical Olympiad 2013). Let $A B C$ be triangle with circumcircle (O). Let $A O$ cut (O) again at $A^{\prime}$. Perpendicular bisector of $O A^{\prime}$ cut $B C$ at $P_{A}$. The points $P_{B}$ and $P_{C}$ are defined similarly. Prove that:

a) points $P_{A}, P_{B}$ and $P_{C}$ are collinear;

b) the distance of $O$ from this line is equal to $\frac{R}{2}$, where $R$ is the radius of the circumcircle $(O)$.

Exercício 40 (Irish Mathematical Olympiad 2013). $A, B$ and $C$ are points on the circumference of a circle with centre $O$. Tangents are drawn to the circumcircles of triangles $O A B$ and $O A C$ at $P$ and $Q$ respectively, where $P$ and $Q$ are diametrically opposite $O$. The two tangents intersect at $K$. The line $C A$ meets the circumcircle of triangle $O A B$ at $A$ and $X$. Prove that $X$ lies on the line $K O$.

Exercício 41 (Italian Mathematical Olympiad 2013). $A B C$ is an isosceles triangle with $A B=A C$ and the angle $\measuredangle B A C<60^{\circ}$. Let $D$ be a point on $A C$ such that $\measuredangle D B C=\measuredangle B A C$. E is the intersection between the perpendicular bisector of $B D$ and the line parallel to $B C$ passing through $A . F$ is a point on the line AC such that $F A=2 \cdot A C$ ( $A$ is between $F$ and $C$ ). Show that:

a) EB and AC are parallel;

b) the perpendicular from $F$ to $A B$, the perpendicular from $E$ to $A C$ and $B D$ are concurrent.

Exercício 42 (Junior Balkan Mathematical Olympiad 2013). Let ABC be an acute-angled triangle with $A B<A C$ and let $O$ be the centre of its circumcircle $\omega$. Let $D$ be a point on the line segment $B C$ such that 
$\measuredangle B A D=\measuredangle C A O$. Let $E$ be the second point of intersection of $\omega$ and the line $A D$. If $M, N$ and $P$ are the midpoints of the line segments $B E, O D$ and $A C$, respectively, show that the points $M, N$ and $P$ are collinear.

Exercício 43 (Kazakhstan Mathematical Olympiad 2013). Given triangle ABC with incenter I. Let $P, Q$ be point on circumcircle such that $\measuredangle A P I=\measuredangle C P I$ and $\measuredangle B Q I=\measuredangle C Q I$.Prove that $B P, A Q$ and $O I$ are concurrent.

Exercício 44 (Korean Mathematical Olympiad 2013). Let $O$ be circumcenter of triangle $A B C$. For a point $P$ on segmet $B C$, the circle passing through $P, B$ and tangent to line $A B$ and the circle passing through $P, C$ and tangent to line $A C$ meet at point $Q(\neq P)$. Let $D, E$ be foot of perpendicular from $Q$ to $A B, A C(D \neq B, E \neq C)$. Two lines $D E$ and $B C$ meet at point $R$. Prove that $O, P, Q$ are collinear if and only if $A, R, Q$ are collinear.

Exercício 45 (Lusophone Mathematical Olympiad - CPLP 2013). Consider a triangle ABC. Let $S$ be a circumference in the interior of the triangle that is tangent to the sides $B C, C A, A B$ at the points $D, E, F$ respectively. In the exterior of the triangle we draw three circumferences $S_{A}, S_{B}, S_{C}$. The circumference $S_{A}$ is tangent to $B C$ at $L$ and to the prolongation of the lines $A B, A C$ at the points $M, N$ respectively. The circumference $S_{B}$ is tangent to $A C$ at $E$ and to the prolongation of the line $B C$ at $P$. The circumference $S_{C}$ is tangent to $A B$ at $F$ and to the prolongation of the line BC at $Q$. Show that the lines $E P, F Q$ and $A L$ meet at a point of the circumference $S$.

Exercício 46 (Macedonia Mathematical Olympiad 2013). An arbitrary triangle $A B C$ is given. There are two lines, $p$ and $q$, that are not parallel to each other and they are not perpendicular to the sides of the triangle. The perpendicular lines through points $A, B$ and $C$ to line $p$ we denote with $p_{a}, p_{b}, p_{c}$ and the perpendicular lines to line $q$ we denote with $q_{a}, q_{b}, q_{c}$. Let the intersection points of the lines $p_{a}, q_{a}, p_{b}, q_{b}, p_{c}$ and $q_{c}$ with $q_{b}, p_{b}, q_{c}, p_{c}, q_{a}$ and $p_{a}$ are $K, L, P, Q, N$ and $M$. Prove that $K L, M N$ and $P Q$ intersect in one point.

Exercício 47 (Mathematical Olympiad of Centroamerica and the Caribbean 2013). Let $A B C D$ be a convex quadrilateral and let $M$ be the midpoint of side $A B$. The circle passing through $D$ and tangent to $A B$ at $A$ intersects the segment DM at E. The circle passing through $C$ and tangent to $A B$ at $B$ intersects the segment $C M$ at $F$. Suppose that the lines $A F$ and BE intersect at a point which belongs to the perpendicular bisector of side $A B$. Prove that $A, E$, and $C$ are collinear if and only if $B, F$, and $D$ are collinear.

Exercício 48 (Romanian District Olympiad 2013). Given triangle $A B C$ and the points $D, E \in(B C), F, G \in$ $(C A), H, I \in(A B)$ so that $B D=C E, C F=A G$ and $A H=B I$. Note with $M, N, P$ the midpoints of $[G H],[D I]$ and $[E F]$ and with $M^{\prime}$ the intersection of the segments $A M$ and $B C$.

a) Prove that $\frac{B M^{\prime}}{C M^{\prime}}=\frac{A G}{A H} \cdot \frac{A B}{A C}$.

b) Prove that the segments $A M, B N$ and $C P$ are concurrent.

Exercício 49 (Swiss Mathematical Olympiad 2013). Let $A B C D$ be a circumscribed quadrilateral with $B C>$ $B A$. The point $P$ lies on the segment $B C$ so that $B P=B A$. Show that the bisector of $\angle B C D$, the perpendicular to $B C$ through $P$ and the perpendicular to $B D$ through $A$ intersect at a point.

Exercício 50 (Turkish Mathematical Olympiad 2013). Let $A B C$ be a triangle such that $A C>A B$. A circle tangent to the sides $A B$ and $A C$ at $D$ and $E$, respectively, intersects the circumcircle of $A B C$ at $K$ and $L$. Let $X$ and $Y$ be points on the sides $A B$ and $A C$, respectively, satisfying 


$$
\frac{A X}{A B}=\frac{C E}{B D+C E} \quad \text { and } \quad \frac{A Y}{A C}=\frac{B D}{B D+C E} .
$$

Show that the lines $X Y, B C$ and $K L$ are concurrent.

\section{COLETÂNEA 2012}

Exercício 51 (Bay Area Mathematical Olympiad 2012). Given a segment $A B$ in the plane, choose on it a point $M$ different from $A$ and $B$. Two equilateral triangles $A M C$ and $B M D$ in the plane are constructed on the same side of segment $A B$. The circumcircles of the two triangles intersect in point $M$ and another point $N$. Prove that

a) lines $A D$ and $B C$ pass through point $N$;

b) no matter where one chooses the point $M$ along segment $A B$, all lines $M N$ will pass through some fixed point $K$ in the plane.

Exercício 52 (Brazilian Math Olympiad 2012). Let $A B C$ be a triangle, $M$ the midpoint of the side AC, and $N$ the midpoint of the side $A B$. Let $r$ and $s$ be the reflections of $B M$ and $C N$ on the line $B C$, respectively. Let $D$ and $E$ be the intersection of $r$ and $s$ with the line $M N$, respectively. $X$ and $Y$ are the points of intersection between the circuncircles triangles $B D M$ and $C E N$ respectively, $Z$ is the intersection of $B E$ and $C D$, and $W$ is the intersection between $r$ and s. Prove that $X Y, W Z$ and $B C$ are concurrent.

Exercício 53 (Brazilian Math Olympiad 2012). Let $I_{A}, I_{B}, I_{C}$ the ex-centers of non-isosceles triangle ABC relative to the sides $B C, A C, A B$, respectively, and $X, Y$ and $Z$ the midpoints of $I_{B} I_{C}, I_{C} I_{A}$ and $I_{A} I_{B}$, respectively. Let $D, E, F$ be the tangency points of incircle of $A B C$ in the sides $B C, A C, A B$, respectively. Prove that $D X, E Y$, $F Z$ meets a common point in the line IO, with I and $O$ being the incenter and circumcenter of the triangle $A B C$.

Exercício 54 (Canadian Mathematical Olympiad 2012). Let $A B C D$ be a convex quadrilateral and let $P$ be the point of intersection of $A C$ and $B D$. Suppose that $A C+A D=B C+B D$. Prove that the internal angle bisectors of $\angle A C B, \angle A D B$ and $\angle A P B$ meet at a common point.

Exercício 55 (Chinese Mathematical Olympiad 2012). In an acute-angled triangle $A B C, A B>A C . M, N$ are distinct points on side $B C$ such that $\measuredangle B A M=\measuredangle C A N$. Let $O_{1}$ and $O_{2}$ be the circumcentres of triangles $A B C$ and $A M N$, respectively. Prove that $O_{1}, O_{2}$ and $A$ are collinear.

Exercício 56 (European Girls Mathematical Olympiad 2012). Let $A B C$ be an acute-angled triangle with circumcircle $\Gamma$ and orthocentre $H$. Let $K$ be a point of $\Gamma$ on the other side of $B C$ from A. Let $L$ be the reflection of $K$ in the line $A B$, and let $M$ be the reflection of $K$ in the line $B C$. Let $E$ be the second point of intersection of $\Gamma$ with the circumcircle of triangle BLM. Show that the lines $K H, E M$ and BC are concurrent.

Exercício 57 (Geometrical Olympiad in Honour of I. F. Sharygin 2012). Three parallel lines passing through the vertices $A, B$ and $C$ of triangle $A B C$ meet its circumcircle again at points $A_{1}, B_{1}$ and $C_{1}$ respectively. Points $A_{2}, B_{2}$ and $C_{2}$ are the reflections of points $A_{1}, B_{1}$ and $C_{1}$ in $B C, C A$ and $A B$ respectively. Prove that the lines $A A_{2}, B B_{2}$ and $C C_{2}$ are concurrent. 
Exercício 58 (Geometrical Olympiad in Honour of I. F. Sharygin 2012). Consider a triangle ABC. The tangent line to its circumcircle at point $C$ meets line $A B$ at point $D$. The tangent lines to the circumcircle of triangle ACD at points $A$ and $C$ meet at point K. Prove that line DK bisects segment $B C$.

Exercício 59 (Geometrical Olympiad in Honour of I. F. Sharygin 2012). A point $M$ lies on the side BC of square $A B C D$. Let $X, Y$ and $Z$ be the incenters of triangles $A B M, C M D$ and $A M D$ respectively. Let $H_{x}, H_{y}$ and $H_{z}$ be the orthocenters of triangles $A X B, C Y D$ and $A Z D$ respectively. Prove that $H_{x}, H_{y}$ and $H_{z}$ are collinear.

Exercício 60 (Geometrical Olympiad in Honour of I. F. Sharygin 2012). Let BM be the median of rightangled triangle $A B C\left(\measuredangle B=90^{\circ}\right)$. The incircle of triangle $A B M$ touches sides $A B, A M$ in points $A_{1}, A_{2} ;$ points $C_{1}, C_{2}$ are defined similarly. Prove that lines $A_{1} A_{2}$ and $C_{1} C_{2}$ meet on the bisector of angle $\angle A B C$.

Exercício 61 (Geometrical Olympiad in Honour of I. F. Sharygin 2012). Given triangle $A B C$ and point $P$. Points $A^{\prime}, B^{\prime}, C^{\prime}$ are the projections of $P$ to $B C, C A, A B$. A line passing through $P$ and parallel to $A B$ meets the circumcircle of triangle $P A^{\prime} B^{\prime}$ for the second time in point $C_{1}$. Points $A_{1}$ and $B_{1}$ are defined similarly. Prove that

a) lines $A A_{1}, B B_{1}, C C_{1}$ concur;

b) triangles $A B C$ and $A_{1} B_{1} C_{1}$ are similar.

Exercício 62 (Geometrical Olympiad in Honour of I. F. Sharygin 2012). Given triangle ABC. Consider lines $l$ with the next property: the reflections of $l$ in the sidelines of the triangle concur. Prove that all these lines have a common point.

Exercício 63 (Geometrical Olympiad in Honour of I. F. Sharygin 2012). Point D lies on side AB of triangle $A B C$. Let $\omega_{1}$ and $\Omega_{1}, \omega_{2}$ and $\Omega_{2}$ be the incircles and the excircles (touching segment $A B$ ) of triangles $A C D$ and $B C D$ respectively. Prove that the common external tangents to $\omega_{1}$ and $\omega_{2}, \Omega_{1}$ and $\Omega_{2}$ meet on $A B$.

Exercício 64 (Geometrical Olympiad in Honour of I. F. Sharygin 2012). A circle $\omega$ with center I is inscribed into a segment of the disk, formed by an arc and a chord $A B$. Point $M$ is the midpoint of this arc $\widehat{A B}$, and point $N$ is the midpoint of the complementary arc. The tangents from $N$ touch $\omega$ in points $C$ and $D$. The opposite sidelines $A C$ and $B D$ of quadrilateral $A B C D$ meet in point $X$, and the diagonals of $A B C D$ meet in point $Y$. Prove that points $X, Y, I$ and $M$ are collinear.

Exercício 65 (Greece National Olympiad 2012). Let an acute-angled triangle $A B C$ with $A B<A C<B C$, inscribed in circle $c(O, R)$. The angle bisector $A D$ meets $c(O, R)$ at $K$. The circle $c_{1}\left(O_{1}, R_{1}\right)$ (which passes from $A, D$ and has its center $O_{1}$ on $O A$ ) meets $A B$ at $E$ and $A C$ at $Z$. If $M, N$ are the midpoints of $Z C$ and $B E$ respectively, prove that:

a) the lines $Z E, D M, K C$ are concurrent at one point $T$.

b) the lines $Z E, D N, K B$ are concurrent at one point $X$.

c) $O K$ is the perpendicular bisector of $T X$.

Exercício 66 (Indonesia National Science Olympiad 2012). Given a triangle $A B C$, let the bisector of $\angle B A C$ meets the side $B C$ and circumcircle of triangle $A B C$ at $D$ and $E$, respectively. Let $M$ and $N$ be the midpoints 
of $B D$ and $C E$, respectively. Circumcircle of triangle $A B D$ meets $A N$ at $Q$. Circle passing through $A$ that is tangent to $B C$ at $D$ meets line $A M$ and side $A C$ respectively at $P$ and $R$. Show that the four points $B, P, Q$ and $R$ lie on the same line.

Exercício 67 (International Tuymaada Olympiad 2012). Quadrilateral ABCD is both cyclic and circumscribed. Its incircle touches its sides $A B$ and $C D$ at points $X$ and $Y$, respectively. The perpendiculars to $A B$ and $C D$ drawn at $A$ and $D$, respectively, meet at point $U$; those drawn at $X$ and $Y$ meet at point $V$, and finally, those drawn at $B$ and $C$ meet at point $W$. Prove that points $U, V$ and $W$ are collinear.

Exercício 68 (Korean Mathematical Olympiad 2012). Let $w$ be the incircle of triangle $A B C$. Segments $B C$, $C A$ meet with $w$ at points $D, E$, respectively. A line passing through $B$ and parallel to DE meets $w$ at $F$ and $G$ ( $F$ is nearer to $B$ than $G$ ). Line $C G$ meets $w$ at $H(\neq G)$. A line passing through $G$ and parallel to $E H$ meets with line $A C$ at $I$. Line IF meets with circle $w$ at $J(\neq F)$. Lines $C J$ and $E G$ meets at $K$. Let $\ell$ be the line passing through $K$ and parallel to JD. Prove that $\ell, I F, E D$ meet at one point.

Exercício 69 (Macedonia Mathematical Olympiad 2012). A fixed circle $k$ and collinear points $E, F$ and $G$ are given such that the points $E$ and $G$ lie outside the circle $k$ and $F$ lies inside the circle $k$. Prove that, if $A B C D$ is an arbitrary quadrilateral inscribed in the circle $k$, such that the points $E, F$ and $G$ lie on lines $A B, A D$ and $D C$, respectively, then the side $B C$ passes through a fixed point collinear with $E, F$ and $G$, independent of the quadrilateral $A B C D$.

Exercício 70 (Middle European Mathematical Olympiad 2012). Let $K$ be the midpoint of the side $A B$ of $a$ given triangle $A B C$. Let $L$ and $M$ be points on the sides $A C$ and $B C$, respectively, such that $\measuredangle C L K=\measuredangle K M C$. Prove that the perpendiculars to the sides $A B, A C$ and $B C$ passing through $K, L$ and $M$, respectively, are concurrent.

Exercício 71 (National Mathematical Olympiad of Singapore 2012). The incircle with centre I of the triangle $A B C$ touches the sides $B C, C A$ and $A B$ at $D, E, F$ respectively. The line $I D$ intersects the segment $E F$ at $K$. Proof that $A, K, M$ are collinear, where $M$ is the midpoint of $B C$.

Exercício 72 (Polish Mathematical Olympiad 2012). Let $A B C$ be a triangle with $\measuredangle A=60^{\circ}$ and $A B \neq A C$. If $I$ is the incenter and $O$ is the circumcenter of $A B C$, prove that perpendicular bisector of $A I$, line $O I$ and line $B C$ have a common point.

Exercício 73 (Romanian Masters in Mathematics 2012). Let $A B C$ be a triangle. Let I and $O$ be the incentre and circumcentre of $A B C$ respectively. Let $\omega_{A}$ be the circle through $B$ and $C$ which is tangent to the incircle of the triangle $A B C$; the circles $\omega_{B}$ and $\omega_{C}$ are defined similarly. The circles $\omega_{B}$ and $\omega_{C}$ meet at a point $A^{\prime}$ distinct from $A$; the points $B^{\prime}$ and $C^{\prime}$ are defined similarly. Prove that the lines $A A^{\prime}, B B^{\prime}$ and $C C^{\prime}$ are concurrent at a point on the line IO.

Exercício 74 (Russian Mathematical Olympiad 2012). The point $E$ is the midpoint of the segment connecting the orthocentre of the scalene triangle $A B C$ and the point $A$. The incircle of triangle $A B C$ is tangent to $A B$ and $A C$ at points $C^{\prime}$ and $B^{\prime}$ respectively. Prove that point $F$, the point symmetric to point $E$ with respect to line $B^{\prime} C^{\prime}$, lies on the line that passes through both the circumcentre and the incentre of triangle $A B C$. 
Exercício 75 (Turkish Mathematical Olympiad 2012). Let $B$ and $D$ be points on segments $A E$ and $A F$ respectively. Excircles of triangles $A B F$ and $A D E$ touching sides $B F$ and $D E$ is the same, and its center is $I . B F$ and $D E$ intersects at $C$. Let $P_{1}, P_{2}, P_{3}, P_{4}, Q_{1}, Q_{2}, Q_{3}, Q_{4}$ be the circumcenters of triangles IAB, IBC, ICD, IDA, IAE, IEC, ICF, IFA respectively.

a) Show that points $P_{1}, P_{2}, P_{3}, P_{4}$ are concylic and points $Q_{1}, Q_{2}, Q_{3}, Q_{4}$ are concylic, and denote centers of theese circles as $O_{1}$ and $O_{2}$, respectively.

b) Prove that $O_{1}, O_{2}$ and I are collinear.

Exercício 76 (United States of America Mathematical Olympiad 2012). Let $P$ be a point in the plane of triangle $A B C$, and $\gamma$ a line passing through $P$. Let $A^{\prime}, B^{\prime}, C^{\prime}$ be the points where the reflections of lines $P A, P B$, $P C$ with respect to $\gamma$ intersect lines $B C, A C, A B$ respectively. Prove that $A^{\prime}, B^{\prime}, C^{\prime}$ are collinear.

Exercício 77 (Uzbekistan National Olympiad 2012). Given points $A, B, C$ and $D$ lie a circle, and $A C \cap B D=K$. $I_{1}, I_{2}, I_{3}, I_{4}$ are the incenters of $A B K, B C K, C D K, D K A$, respectively. $M_{1}, M_{2}, M_{3}, M_{4}$ are midpoints of arcs $\widehat{A B}, \widehat{B C}, \widetilde{C A}, \widetilde{D A}$ respectively. Prove that $M_{1} I_{1}, M_{2} I_{2}, M_{3} I_{3}, M_{4} I_{4}$ are concurrent.

Exercício 78 (Vietnamese Math Olympiad 2012). Let $A B C D$ be a cyclic quadrilateral with circumcentre $O$, and the pair of opposite sides not parallel with each other. Let $M=A B \cap C D$ and $N=A D \cap B C$. Denote by $P$, $Q, S, T$ the intersection of the internal angle bisectors of $\angle M A N$ and $\angle M B N, \angle M B N$ and $\angle M C N, \angle M D N$ and $\angle M A N, \angle M C N$ and $\angle M D N$ respectively. Suppose that the four points $P, Q, S, T$ are distinct.

a) Show that the four points $P, Q, S, T$ are concyclic. Find the centre of this circle, and denote it as $I$.

b) Let $E=A C \cap B D$. Prove that $E, O, I$ are collinear.

\section{COLETÂNEA 2011}

Exercício 79 (Austrian Mathematical Olympiad 2011). Two circles $k_{1}$ and $k_{2}$ with radii $r_{1}$ and $r_{2}$ touch each outside at point $Q$. The other endpoints of the diameters through $Q$ are $P$ on $k_{1}$ and $R$ on $k_{2}$. We choose two points $A$ and $B$, one on each of the arcs $\widetilde{P Q}$ of $k_{1}$ (PBQA is a convex quadrangle). Further, let $C$ be the second point of intersection of the line $A Q$ with $k_{2}$ and let $D$ be the second point of intersection of the line $B Q$ with $k_{2}$. The lines $P B$ and $R C$ intersect in $U$ and the lines $P A$ and $R D$ intersect in $V$. Show that there is a point $Z$ that lies on all of these lines $U V$.

Exercício 80 (British Mathematical Olympiad 2011). Let $A B C$ be a triangle with $\angle C A B$ a right-angle. The point $L$ lies on the side $B C$ between $B$ and $C$. The circle $A B L$ meets the line $A C$ again at $M$ and the circle $C A L$ meets the line $A B$ again at $N$. Prove that $L, M$ and $N$ lie on a straight line.

Exercício 81 (China Girls Math Olympiad 2011). The excircle $(O)$ of triangle $A B C$, relative of $A$, touches $B C$ at $M$. The points $D, E$ lie on the sides $A B, A C$ respectively such that $D E \| B C$. The incircle $\left(O_{1}\right)$ of triangle $A D E$ touches $D E$ at $N$. If $B O_{1} \cap D O=F$ and $C O_{1} \cap E O=G$, prove that the midpoint of $F G$ lies on $M N$.

Exercício 82 (China South East Mathematical Olympiad 2011). In triangle $A B C, A A_{0}, B B_{0}$, $C C_{0}$ are the angle bisectors, $A_{0}, B_{0}, C_{0}$ are on sides $B C, C A, A B$. Draw $A_{0} A_{1}\left\|B B_{0}, A_{0} A_{2}\right\| C C_{0}, A_{1}$ lies on $A C, A_{2}$ lies on 
$A B$. The line $A_{1} A_{2}$ intersects $B C$ at $A_{3}$. The points $B_{3}, C_{3}$ are constructed similarly. Prove that $A_{3}, B_{3}, C_{3}$ are collinear.

Exercício 83 (Chinese Mathematical Olympiad 2011). On the circumcircle of the acute triangle $A B C, D$ is the midpoint of $\widehat{B C}$. Let $X$ be a point on $\widehat{B D}, E$ the midpoint of $\widehat{A X}$, and let $S$ lie on $\widetilde{A C}$. The lines $S D$ and $B C$ have intersection $R$, and the lines $S E$ and $A X$ have intersection $T$. If $R T \| D E$, prove that the incenter of the triangle $A B C$ is on the line $R T$.

Exercício 84 (Czech-Polish-Slovak Match 2011). In convex quadrilateral $A B C D$, let $M$ and $N$ denote the midpoints of sides $A D$ and $B C$, respectively. On sides $A B$ and $C D$ are points $K$ and $L$, respectively, such that $\measuredangle M K A=\measuredangle N L C$. Prove that if lines $B D, K M$, and $L N$ are concurrent, then $\measuredangle K M N=\measuredangle B D C$ and $\measuredangle L N M=\measuredangle A B D$.

Exercício 85 (Czech-Slovak Mathematical Olympiad 2011). In acute triangle $A B C$, which is not equilateral, let $P$ denote the foot of the altitude from $C$ to side $A B$; let $H$ denote the orthocenter; let $O$ denote the circumcenter; let $D$ denote the intersection of line $C O$ with $A B$; and let $E$ denote the midpoint of $C D$. Prove that line EP passes through the midpoint of $\mathrm{OH}$.

Exercício 86 (Geometrical Olympiad in Honour of I. F. Sharygin 2011). The incircle of right-angled triangle $A B C\left(\measuredangle B=90^{\circ}\right)$ touches $A B, B C, C A$ at points $C_{1}, A_{1}, B_{1}$ respectively. Points $A_{2}, C_{2}$ are the reflections of $B_{1}$ in lines $B C, A B$ respectively. Prove that lines $A_{1} A_{2}$ and $C_{1} C_{2}$ meet on the median of triangle $A B C$.

Exercício 87 (Geometrical Olympiad in Honour of I. F. Sharygin 2011). The diagonals of trapezoid ABCD meet at point $O$. Point $M$ of lateral side $C D$ and points $P, Q$ of bases $B C$ and $A D$ are such that segments $M P$ and MQ are parallel to the diagonals of the trapezoid. Prove that line PQ passes through point $O$.

Exercício 88 (Geometrical Olympiad in Honour of I. F. Sharygin 2011). Given are triangle $A B C$ and line $\ell$. The reflections of $\ell$ in $A B$ and $A C$ meet at point $A_{1}$. Points $B_{1}, C_{1}$ are defined similarly. Prove that lines $A A_{1}$, $B B_{1}, C C_{1}$ concur.

Exercício 89 (Geometrical Olympiad in Honour of I. F. Sharygin 2011). On a circle with diameter AC, let $B$ be an arbitrary point distinct from $A$ and $C$. Points $M, N$ are the midpoints of chords $A B, B C$, and points $P, Q$ are the midpoints of smaller arcs related to these chords. Lines $A Q$ and $B C$ meet at point $K$, and lines $C P$ and $A B$ meet at point $L$. Prove that lines $M Q, N P$ and $K L$ concur.

Exercício 90 (Geometrical Olympiad in Honour of I. F. Sharygin 2011). Let CX, CY be the tangents from vertex $C$ of triangle $A B C$ to the circle passing through the midpoints of its sides. Prove that lines $X Y, A B$ and the tangent at point $C$ to the circumcircle of $A B C$ concur.

Exercício 91 (Geometrical Olympiad in Honour of I. F. Sharygin 2011). Given are triangle $A B C$ and line $\ell$ intersecting $B C, C A$ and $A B$ at points $A_{1}, B_{1}$ and $C_{1}$ respectively. Point $A^{\prime}$ is the midpoint of the segment between the projections of $A_{1}$ to $A B$ and $A C$. Points $B^{\prime}$ and $C^{\prime}$ are defined similarly.

a) Prove that $A^{\prime}, B^{\prime}$ and $C^{\prime}$ lie on some line $\ell^{\prime}$.

b) Suppose $\ell$ passes through the circumcenter of triangle ABC. Prove that in this case $\ell^{\prime}$ passes through the center of its nine-points circle. 
Exercício 92 (German Federal Mathematical Competition 2011). Given a quadrilateral ABCD. The midpoint of the diagonal $A C$ is $U$, the midpoint of the diagonal $B D$ is $V$. Let $S$ be the midpoint of the line $U V$. Prove that the lines connecting the midpoints of opposite sides of $A B C D$ intersect at $S$.

Exercício 93 (Indian National Mathematical Olympiad 2011). Let ABCD be a cyclic quadrilateral inscribed in a circle $\Gamma$. Let $E, F, G, H$ be the midpoints of arcs $\widetilde{A B}, \widetilde{B C}, \widetilde{C D}, \widetilde{A D}$ of $\Gamma$, respectively. Suppose that $A C \cdot B D=E G \cdot F H$. Show that lines $A C, B D, E G, F H$ are all concurrent.

Exercício 94 (International Mathematics Tournament of the Towns 2011). Four perpendiculars are drawn from four vertices of a convex pentagon to the opposite sides. If these four lines pass through the same point, prove that the perpendicular from the fifth vertex to the opposite side also passes through this point.

Exercício 95 (International Tuymaada Olympiad 2011). In a convex hexagon $A C^{\prime} B A^{\prime} C B^{\prime}$, every two opposite sides are equal. Let $A_{1}$ denote the point of intersection of $B C$ with the perpendicular bisector of $A A^{\prime}$. Define $B_{1}$ and $C_{1}$ similarly. Prove that $A_{1}, B_{1}$, and $C_{1}$ are collinear.

Exercício 96 (Iranian Mathematical Olympiad 2011). We have four circles in plane such that any two of them are tangent to each other. Connect the tangency point of two circles to the tangency point of two other circles. Prove that these three lines are concurrent.

Exercício 97 (Iranian Mathematical Olympiad 2011). In triangle $A B C, X$ and $Y$ are the tangency points of incircle (with center $I$ ) with sides $A B$ and $A C$, respectively. A tangent line to the circumcircle of triangle $A B C$ (with center $O$ ) at point $A$, intersects the extension of $B C$ at $D$. If $D, X$ and $Y$ are collinear then prove that $D, I$ and $O$ are also collinear.

Exercício 98 (Iranian Mathematical Olympiad 2011). Given triangle $A B C, D$ is the foot of the external angle bisector of $\angle A, I$ its incenter of $A B C$ and $I_{a}$ its excenter relative to vertex $A$. Perpendicular from $I$ to $D I_{a}$ intersects the circumcircle of triangle in $A^{\prime}$. Define $B^{\prime}$ and $C^{\prime}$ similarly. Prove that $A A^{\prime}, B B^{\prime}$ and $C C^{\prime}$ are concurrent.

Exercício 99 (Kazakhstan Mathematical Olympiad 2011). Let $w$ be the circumcircle of triangle ABC with an obtuse angle $C$ and $C^{\prime}$ symmetric point of point $C$ with respect to $A B . M$ is midpoint of $A B . C^{\prime} M$ intersects $w$ at $N\left(C^{\prime}\right.$ between $M$ and $\left.N\right)$. Let $B C^{\prime}$ second crossing point $w$ in $F$, and $A C^{\prime}$ again crosses the $w$ at point $E$. Let $K$ be the midpoint of $E F$. Prove that the lines $A B, C N$ and $K C^{\prime}$ are concurrent.

Exercício 100 (Kyrgyzstan Mathematical Olympiad 2011). For a given chord $M N$ of a circle discussed the triangle $A B C$, whose base is the diameter $A B$ of this circle, which do not intersect the $M N$, and the sides $A C$ and $B C$ pass through the ends of $M$ and $N$ of the chord $M N$. Prove that the heights of all such triangles $A B C$ drawn from the vertex $C$ to the side $A B$, intersect at one point.

Exercício 101 (Mediterranean Mathematical Olympiad 2011). Let D be the foot of the internal bisector of the angle $\angle A$ of the triangle $A B C$. The straight line which joins the incenters of the triangles $A B D$ and $A C D$ cut $A B$ and $A C$ at $M$ and $N$, respectively. Show that $B N$ and $C M$ meet on the bisector $A D$.

Exercício 102 (Mexican Mathematical Olympiad 2011). Let ABC be an acute triangle and $\Gamma$ its circumcircle. Let $\ell$ be the line tangent to $\Gamma$ at $A$. Let $D$ and $E$ be the intersections of the circumference with center $B$ and radius $A B$ with lines $\ell$ and $A C$, respectively. Prove that the orthocenter of $A B C$ lies on line $D E$. 
Exercício 103 (Montenegro National Math Olympiad 2011). In triangle $A B C$, let the incircle of center $O$, which touches the sides $A B, B C$ and $A C$ respectively in points $E, F$ and $D$. The lines $A O$ and $C O$ intersect $E F$ in points $N$ and $M$ respectively. Prove that the center of the circumcircle of triangle $O M N$, points $O$ and $D$ lie on a straight line.

Exercício 104 (Romanian Stars of Mathematics 2011). Let $A B C$ be an acute-angled triangle with $A B \neq B C$, $M$ the midpoint of $A C, N$ the point where the median $B M$ meets again the circumcircle of $A B C, H$ the orthocentre of $A B C, D$ the point on the circumcircle for which $\measuredangle B D H=90^{\circ}$, and $K$ the point that makes ANCK a parallelogram. Prove the lines $A C, K H, B D$ are concurrent.

Exercício 105 (Russian Mathematical Olympiad 2011). Given is an acute angled triangle ABC. A circle going through $B$ and the triangle's circumcenter, $O$, intersects $B C$ and $B A$ at points $P$ and $Q$ respectively. Prove that the intersection of the heights of the triangle POQ lies on line AC.

Exercício 106 (Russian Mathematical Olympiad 2011). On side $B C$ of parallelogram $A B C D$ (angle $\angle A$ is acute) lies point $T$ so that triangle ATD is an acute triangle. Let $O_{1}, O_{2}$, and $O_{3}$ be the circumcenters of triangles $A B T, D A T$, and CDT respectively. Prove that the orthocenter of triangle $\mathrm{O}_{1} \mathrm{O}_{2} \mathrm{O}_{3}$ lies on line $A D$.

Exercício 107 (Serbia National Math Olympiad 2011). Let $H$ be orthocenter and $O$ circumcenter of an acuted angled triangle $A B C . D$ and $E$ are feets of perpendiculars from $A$ and $B$ on $B C$ and $A C$ respectively. Let $O D$ and $O E$ intersect $B E$ and $A D$ in $K$ and $L$, respectively. Let $X$ be intersection of circumcircles of triangles $H K D$ and $H L E$ different than $H$, and $M$ is midpoint of $A B$. Prove that $K, L, M$ are collinear if and only if $X$ is circumcenter of triangle EOD.

Exercício 108 (Swiss Mathematical Olympiad 2011). Let $A B C$ a triangle with $\measuredangle C A B=90^{\circ}$ and $L$ a point on the segment $B C$. The circumcircle of triangle $A B L$ intersects $A C$ at $M$ and the circumcircle of triangle $C A L$ intersects $A B$ at $N$. Show that $L, M$ and $N$ are collinear.

Exercício 109 (United States of America Mathematical Olympiad 2011). In hexagon ABCDEF, which is nonconvex but not self-intersecting, no pair of opposite sides are parallel. The internal angles satisfy $\measuredangle A=$ $3 \cdot \measuredangle D, \measuredangle C=3 \cdot \measuredangle F$, and $\measuredangle E=3 \cdot \measuredangle B$. Furthermore $A B=D E, B C=E F$, and $C D=F A$. Prove that diagonals $A D, B E$, and $C F$ are concurrent.

Exercício 110 (Vietnamese Math Olympiad 2011). Let $A B$ be a diameter of a circle $(O)$ and let $P$ be any point on the tangent drawn at $B$ to $(O)$. Define $A P \cap(O)=C \neq A$, and let $D$ be the point diametrically opposite to $C$. If $D P$ meets $(O)$ second time in $E$, then, prove that $A E, B C, P O$ concur at $M$.

\section{COLETÂNEA 2010}

Exercício 111 (Asian Pacific Mathematics Olympiad 2010). Let $A B C$ be an acute angled triangle satisfying the conditions $A B>B C$ and $A C>B C$. Denote by $O$ and $H$ the circumcentre and orthocentre, respectively, of the triangle $A B C$. Suppose that the circumcircle of the triangle $A H C$ intersects the line $A B$ at $M$ different from $A$, and the circumcircle of the triangle $A H B$ intersects the line $A C$ at $N$ different from $A$. Prove that the circumcentre of the triangle $M N H$ lies on the line $O H$. 
Exercício 112 (Balkan Mathematical Olympiad 2010). Let $A B C$ be an acute triangle with orthocentre $H$, and let $M$ be the midpoint of $A C$. The point $C_{1}$ on $A B$ is such that $C C_{1}$ is an altitude of the triangle $A B C$. Let $H_{1}$ be the reflection of $H$ in $A B$. The orthogonal projections of $C_{1}$ onto the lines $A H_{1}, A C$ and $B C$ are $P, Q$ and $R$, respectively. Let $M_{1}$ be the point such that the circumcentre of triangle PQR is the midpoint of the segment $M M_{1}$. Prove that $M_{1}$ lies on the segment $B H_{1}$.

Exercício 113 (Baltic Way 2010). Let $A B C D$ be a square and let $S$ be the point of intersection of its diagonals $A C$ and $B D$. Two circles $k, k^{\prime}$ go through $A, C$ and $B, D$; respectively. Furthermore, $k$ and $k^{\prime}$ intersect in exactly two different points $P$ and $Q$. Prove that $S$ lies on $P Q$.

Exercício 114 (Benelux Mathematical Olympiad 2010). On a line $\ell$ there are three different points $A, B$ and $P$ in that order. Let a be the line through A perpendicular to $\ell$, and let $b$ be the line through $B$ perpendicular to $\ell$. A line through $P$, not coinciding with $\ell$, intersects $a$ in $Q$ and $b$ in $R$. The line through A perpendicular to $B Q$ intersects $B Q$ in $L$ and $B R$ in $T$. The line through $B$ perpendicular to AR intersects $A R$ in $K$ and $A Q$ in $S$.

a) Prove that $P, T, S$ are collinear.

b) Prove that $P, K, L$ are collinear.

Exercício 115 (Brazilian Olympic Revenge 2010). Let $A B C$ to be a triangle and $\Gamma$ its circumcircle. Also, let $D, F, G$ and $E$, in this order, on the arc $\overline{B C}$ which does not contain $A$ satisfying $\measuredangle B A D=\measuredangle C A E$ and $\measuredangle B A F=\measuredangle C A G$. Let $D^{\prime}, F^{\prime}, G^{\prime}$ and $E^{\prime}$ to be the intersections of $A D, A F, A G$ and $A E$ with $B C$, respectively. Moreover, $X$ is the intersection of $D F^{\prime}$ with $E G^{\prime}, Y$ is the intersection of $D^{\prime} F$ with $E^{\prime} G, Z$ is the intersection of $D^{\prime} G$ with $E^{\prime} F$ and $W$ is the intersection of $E F^{\prime}$ with $D G^{\prime}$. Prove that $X, Y$ and A are collinear, such as $W, Z$ and $A$. Moreover, prove that $\measuredangle B A X=\measuredangle C A Z$.

Exercício 116 (Chilean Mathematical Olympiad 2010). The sides $B C, C A$ and $A B$ of a triangle $A B C$ are tangent to a circle at points $X, Y$ and $Z$ respectively. Show that the center of this circle is on the line through the midpoints of $A X$ and $B C$.

Exercício 117 (Geometrical Olympiad in Honour of I. F. Sharygin 2010). A point $E$ lies on the altitude $B D$ of triangle $A B C$, and $\measuredangle A E C=90^{\circ}$. Points $O_{1}$ and $O_{2}$ are the circumcenters of triangles $A E B$ and CEB; points $F, L$ are the midpoints of the segments $A C$ and $\mathrm{O}_{1} \mathrm{O}_{2}$. Prove that the points $L, E, F$ are collinear.

Exercício 118 (Geometrical Olympiad in Honour of I. F. Sharygin 2010). Points $M$ and $N$ lie on the side BC of the regular triangle $A B C$ ( $M$ is between $B$ and $N$ ), and $\measuredangle M A N=30^{\circ}$. The circumcircles of triangles AMC and ANB meet at a point $K$. Prove that the line AK passes through the circumcenter of triangle AMN.

Exercício 119 (Geometrical Olympiad in Honour of I. F. Sharygin 2010). A circle touches the sides of an angle with vertex A at points B and C. A line passing through A intersects this circle in points D and E. A chord $B X$ is parallel to DE. Prove that XC passes through the midpoint of the segment DE.

Exercício 120 (Geometrical Olympiad in Honour of I. F. Sharygin 2010). A point B lies on a chord AC of circle $\omega$. Segments $A B$ and $B C$ are diameters of circles $\omega_{1}$ and $\omega_{2}$ centered at $O_{1}$ and $O_{2}$ respectively. These circles intersect $\omega$ for the second time in points $D$ and $E$ respectively. The rays $O_{1} D$ and $O_{2} E$ meet in a point $F$, and the rays $A D$ and $C E$ do in a point $G$. Prove that the line $F G$ passes through the midpoint of the segment AC. 
Exercício 121 (Geometrical Olympiad in Honour of I. F. Sharygin 2010). The incircle of an acute-angled triangle $A B C$ touches $A B, B C, C A$ at points $C_{1}, A_{1}, B_{1}$ respectively. Points $A_{2}, B_{2}$ are the midpoints of the segments $B_{1} C_{1}, A_{1} C_{1}$ respectively. Let $P$ be a common point of the incircle and the line $C O$, where $O$ is the circumcenter of triangle $A B C$. Let also $A^{\prime}$ and $B^{\prime}$ be the second common points of $P A_{2}$ and $P B_{2}$ with the incircle. Prove that a common point of $A A^{\prime}$ and $B B^{\prime}$ lies on the altitude of the triangle dropped from the vertex C.

Exercício 122 (Geometrical Olympiad in Honour of I. F. Sharygin 2010). A cyclic hexagon ABCDEF is such that $A B \cdot C F=2 \cdot B C \cdot F A, C D \cdot E B=2 \cdot D E \cdot B C$ and $E F \cdot A D=2 \cdot F A \cdot D E$. Prove that the lines $A D, B E$ and $C F$ are concurrent.

Exercício 123 (German Federal Mathematical Competition 2010). Let $A B C$ be an acute-angled triangle with $B C>C A . M$ is the midpoint of $A B$. The perpendicular bisector of segment $A B$ intersects $B C$ at $P$ and $C A$ at $Q$. If $P R \perp C A(R \in C A)$ and $Q S \perp B C(S \in B C)$, prove that $R$, $S$ and $M$ are collinear.

Exercício 124 (Iberoamerican Olympiad 2010). The circle $\Gamma$ is inscribed to the scalene triangle ABC. $\Gamma$ is tangent to the sides $B C, C A$ and $A B$ at $D, E$ and $F$ respectively. The line $E F$ intersects the line $B C$ at $G$. The circle of diameter $G D$ intersects $\Gamma$ in $R(R \neq D)$. Let $P, Q(P \neq R, Q \neq R)$ be the intersections of $\Gamma$ with $B R$ and $C R$, respectively. The lines $B Q$ and $C P$ intersects at $X$. The circumcircle of triangle $C D E$ meets $Q R$ at $M$, and the circumcircle of triangle $B D F$ meet $P R$ at $N$. Prove that $P M, Q N$ and $R X$ are concurrent.

Exercício 125 (Iberoamerican Olympiad 2010). Let $A B C D$ be a cyclic quadrilateral whose diagonals $A C$ and $B D$ are perpendicular. Let $O$ be the circumcenter of $A B C D, K$ the intersection of the diagonals, $L \neq O$ the intersection of the circles circumscribed to triangles $O A C$ and $O B D$, and $G$ the intersection of the diagonals of the quadrilateral whose vertices are the midpoints of the sides of $A B C D$. Prove that $O, K, L$ and $G$ are collinear.

Exercício 126 (Indian Regional Mathematical Olympiad 2010). Let $A B C$ be a triangle in which $\measuredangle A=60^{\circ}$. Let $B E$ and $C F$ be the bisectors of angles $\angle B$ and $\angle C$ with $E$ on $A C$ and $F$ on $A B$. Let $M$ be the reflection of $A$ in line EF. Prove that $M$ lies on BC.

Exercício 127 (Indian National Mathematical Olympiad 2010). Let $A B C$ be an acute-angled triangle with altitude AK. Let $H$ be its ortho-centre and $O$ be its circumcentre. Suppose $\mathrm{KOH}$ is an acute-angled triangle and $P$ its circumcentre. Let $Q$ be the reflection of $P$ in the line HO. Show that $Q$ lies on the line joining the midpoints of $A B$ and $A C$.

Exercício 128 (Iranian Mathematical Olympiad 2010). In a triangle $A B C, O$ is the circumcenter and $I$ is the incenter. $X$ is the reflection of $I$ to $O . A_{1}$ is foot of the perpendicular from $X$ to $B C . B_{1}$ and $C_{1}$ are defined similarly. Prove that $A A_{1}, B B_{1}$ and $C C_{1}$ are concurrent.

Exercício 129 (Iranian Mathematical Olympiad 2010). In a triangle $A B C, \measuredangle C=45^{\circ} . A D$ is the altitude of the triangle. $X$ is on $A D$ such that $\measuredangle X B C=90-\measuredangle B$ ( $X$ is in the triangle). AD and $C X$ cut the circumcircle of $A B C$ in $M$ and $N$ respectively. If tangent to circumcircle of $A B C$ at $M$ cuts $A N$ at $P$, prove that $P, B$ and $O$ are collinear.

Exercício 130 (Korean Mathematical Olympiad 2010). Let I be the incenter of triangle $A B C$. The incircle touches $B C, C A, A B$ at points $P, Q, R$. A circle passing through $B, C$ is tangent to the circle $I$ at point $X, a$ 
circle passing through $C, A$ is tangent to the circle I at point $Y$, and a circle passing through $A, B$ is tangent to the circle I at point $Z$, respectively. Prove that three lines $P X, Q Y, R Z$ are concurrent.

Exercício 131 (Korean Mathematical Olympiad 2010). Let $A B C D$ be a cyclic convex quadrilateral. Let $E$ be the intersection of lines $A B, C D . P$ is the intersection of line passing $B$ and perpendicular to $A C$, and line passing $C$ and perpendicular to $B D . Q$ is the intersection of line passing $D$ and perpendicular to $A C$, and line passing $A$ and perpendicular to BD. Prove that three points E, $P, Q$ are collinear.

Exercício 132 (Korean Mathematical Olympiad 2010). Given is a trapezoid $A B C D$ where $A B$ and $C D$ are parallel, and $A, B, C, D$ are clockwise in this order. Let $\Gamma_{1}$ be the circle with center $A$ passing through $B, \Gamma_{2}$ be the circle with center $C$ passing through $D$. The intersection of line $B D$ and $\Gamma_{1}$ is $P(P \neq B$, and $P \neq D)$. Denote by $\Gamma$ the circle with diameter $P D$, and let $\Gamma$ and $\Gamma_{1}$ meet at $X(X \neq P) . \Gamma$ and $\Gamma_{2}$ meet at $Y$. If the circumcircle of triangle $X B Y$ and $\Gamma_{2}$ meet at $Q$, prove that $B, D, Q$ are collinear.

Exercício 133 (Kürschák/Eötvös Math Competition 2010). Consider a triangle $A B C$, with the points $A_{1}, A_{2}$ on side $B C ; B_{1}, B_{2}$ on side $A C ; C_{1}$ and $C_{2}$ on side $A B$ such that $A C_{1}<A C_{2}, B A_{1}<B A_{2}, C B_{1}<C B_{2}$. Let the circles $A B_{1} C_{1}$ and $A B_{2} C_{2}$ meet at $A$ and $A^{\prime}$. Similarly, let the circles $B C_{1} A_{1}$ and $B C_{2} A_{2}$ intersect at $B^{\prime} \neq B$, let $C A_{1} B_{1}$ and $C A_{2} B_{2}$ intersect at $C^{\prime} \neq C$. Prove that the lines $A A^{\prime}, B B^{\prime}, C C^{\prime}$ are concurrent.

Exercício 134 (Mexican Mathematical Olympiad 2010). Let $\gamma_{1}$ and $\gamma_{2}$ be two circles externally tangent at a point $A$. A line tangent to $\gamma_{1}$ at $B$ intersects $\gamma_{2}$ at $C$ and $D$; then the segment $A B$ is extended to intersect $\gamma_{2}$ at a point $E$. Let $F$ be the midpoint of $\widetilde{C D}$ that does not contain $E$, and let $H$ be the intersection of $B F$ with $\gamma_{2}$. Show that $C D, A F$, and $E H$ are concurrent.

Exercício 135 (Middle European Mathematical Olympiad 2010). We are given a cyclic quadrilateral $A B C D$ with a point $E$ on the diagonal $A C$ such that $A D=A E$ and $C B=C E$. Let $M$ be the center of the circumcircle $k$ of the triangle $B D E$. The circle $k$ intersects the line $A C$ in the points $E$ and $F$. Prove that the lines $F M, A D$ and $B C$ meet at one point.

Exercício 136 (Polish Mathematical Olympiad 2010). In the convex pentagon ABCDE all interior angles have the same measure. Prove that the perpendicular bisector of segment $E A$, the perpendicular bisector of segment $B C$ and the angle bisector of $\angle C D E$ intersect in one point.

Exercício 137 (Romania District Olympiad 2010). A right that passes through the incircle I of the triangle $A B C$ intersects the side $A B$ and $C A$ in $P$ and $Q$, respectively. We denote $B C=a, A C=b, A B=c$ and $\frac{P B}{P A}=p$, $\frac{Q C}{Q A}=q$. If $a^{2}=4 b c p q$, prove that the rights $A I, B Q$ and $C P$ are concurrents.

Exercício 138 (Romanian Masters In Mathematics 2010). Let $A_{1} A_{2} A_{3} A_{4}$ be a quadrilateral with no pair of parallel sides. For each $i=1,2,3,4$, define $\omega_{1}$ to be the circle touching the quadrilateral externally, and which is tangent to the lines $A_{i-1} A_{i}, A_{i} A_{i+1}$ and $A_{i+1} A_{i+2}$ (indices are considered modulo 4 so $A_{0}=A_{4}, A_{5}=A_{1}$ and $\left.A_{6}=A_{2}\right)$. Let $T_{i}$ be the point of tangency of $\omega_{i}$ with the side $A_{i} A_{i+1}$. Prove that the lines $A_{1} A_{2}, A_{3} A_{4}$ and $T_{2} T_{4}$ are concurrent if and only if the lines $A_{2} A_{3}, A_{4} A_{1}$ and $T_{1} T_{3}$ are concurrent.

Exercício 139 (Russian Mathematical Olympiad 2010). Lines tangent to circle $O$ in points $A$ and $B$, intersect in point $P$. Point $Z$ is the center of $O$. On the minor arc $\widetilde{A B}$, point $C$ is chosen not on the midpoint of the arc. 
Lines $A C$ and $P B$ intersect at point D. Lines $B C$ and $A P$ intersect at point $E$. Prove that the circumcentres of triangles $A C E, B C D$, and $P C Z$ are collinear.

Exercício 140 (Russian Mathematical Olympiad 2010). Into triangle $A B C$ gives point $K$ lies on bisector of $\angle B A C$. Line $C K$ intersect circumcircle $\omega$ of triangle $A B C$ at $M \neq C$. Circle $\Omega$ passes through $A$, touch $C M$ at $K$ and intersect segment $A B$ at $P \neq A$ and $\omega$ at $Q \neq A$. Prove, that $P, Q, M$ lies at one line.

Exercício 141 (Russian Mathematical Olympiad 2010). Quadrilateral $A B C D$ is inscribed into circle $\omega, A C$ intersect $B D$ in point $K$. Points $M_{1}, M_{2}, M_{3}, M_{4}$ are the midpoints of arcs $\widetilde{A B}, \widetilde{B C}, \widetilde{C D}, \widetilde{D A}$ respectively. Points $I_{1}, I_{2}, I_{3}, I_{4}$ are the incenters of triangles $A B K, B C K, C D K, D A K$ respectively. Prove that lines $M_{1} I_{1}, M_{2} I_{2}$, $M_{3} I_{3}, M_{4} I_{4}$ all intersect in one point. 